\title{
Guidance for Developing Principal Design Criteria for Advanced (Non-Light Water) Reactors
}

Jim Kinsey and Mark Holbrook

December 2015

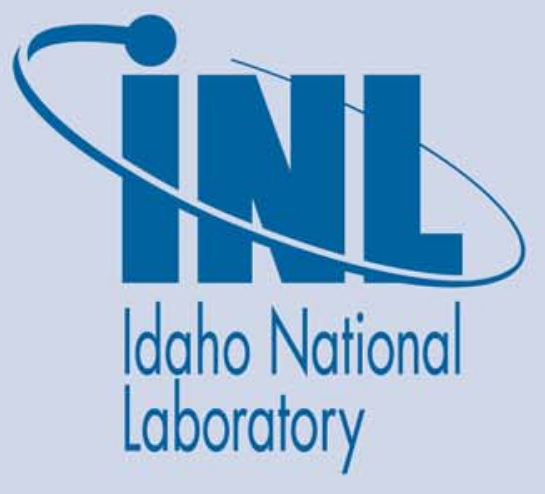

The INL is a U.S. Department of Energy National Laboratory operated by Battelle Energy Alliance 
INL/EXT-14-31179

Revision 1

\section{Guidance for Developing Principal Design Criteria for Advanced (Non-Light Water) Reactors}

Jim Kinsey and Mark Holbrook

December 2014

Idaho National Laboratory

Idaho Falls, Idaho 83415

http://www.inl.gov

Prepared for the

U.S. Department of Energy

Office of Nuclear Energy

Under DOE Idaho Operations Office

Contract DE-AC07-05ID14517 


\section{DISCLAIMER}

This information was prepared as an account of work sponsored by an agency of the U.S. Government. Neither the U.S. Government nor any agency thereof, nor any of their employees, makes any warranty, expressed or implied, or assumes any legal liability or responsibility for the accuracy, completeness, or usefulness, of any information, apparatus, product, or process disclosed, or represents that its use would not infringe privately owned rights. References herein to any specific commercial product, process, or service by trade name, trade mark, manufacturer, or otherwise, does not necessarily constitute or imply its endorsement, recommendation, or favoring by the U.S. Government or any agency thereof. The views and opinions of authors expressed herein do not necessarily state or reflect those of the U.S. Government or any agency thereof. 
INL/EXT-14-31179

Revision 1

\section{Guidance for Developing Principal Design Criteria for Advanced (Non-Light Water) Reactors}

December 2014

Idaho National Laboratory

Idaho Falls, Idaho 83415

http://www.inl.gov

Prepared for the

U.S. Department of Energy

Office of Nuclear Energy

Under DOE Idaho Operations Office

Contract DE-AC07-05ID14517 



\title{
Guidance for Developing Principal Design Criteria for Advanced (Non-Light Water) Reactors
}

\author{
INL/EXT-14-31179 \\ Revision 1 \\ December 2014
}

Approved by:
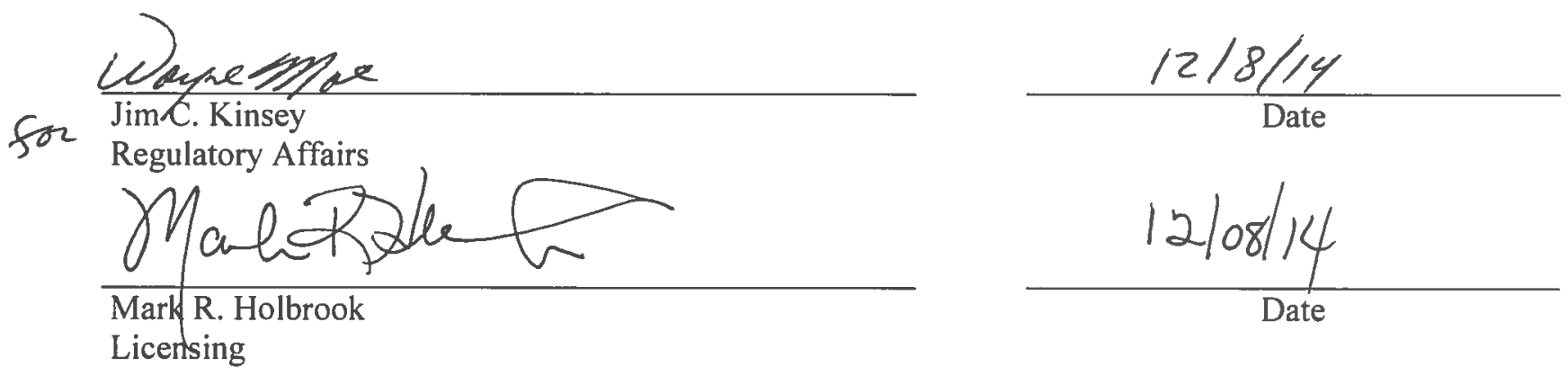



\section{SUMMARY}

In July 2013, the US Department of Energy (DOE) and US Nuclear Regulatory Commission (NRC) established a joint initiative to address a key portion of the licensing framework essential to advanced (non-light water) reactor technologies. The initiative addressed the "General Design Criteria for Nuclear Power Plants," Appendix A to10 Code of Federal Regulations (CFR) 50, which were developed primarily for light water reactors (LWRs), specific to the needs of advanced reactor design and licensing. The need for General Design Criteria (GDC) clarifications in non-LWR applications has been consistently identified as a concern by the industry and varied stakeholders and was acknowledged by the NRC staff in their 2012 Report to Congress ${ }^{1}$ as an area for enhancement.

The initiative to adapt GDC requirements for non-light water advanced reactor applications is being accomplished in two phases. Phase 1, managed by DOE, consisted of reviews, analyses and evaluations resulting in recommendations and deliverables to $\mathrm{NRC}$ as input for $\mathrm{NRC}$ staff development of regulatory guidance. Idaho National Laboratory (INL) developed this technical report using technical and reactor technology stakeholder inputs coupled with analysis and evaluations provided by a team of knowledgeable DOE national laboratory personnel with input from individual industry licensing consultants. The DOE national laboratory team reviewed six different classes of emerging commercial reactor technologies against 10 CFR 50 Appendix A GDC requirements and proposed guidance for their adapted use in non-LWR applications.

The results of the Phase 1 analysis are contained in this report. A set of draft Advanced Reactor Design Criteria (ARDC) has been proposed for consideration by the NRC in the establishment of guidance for use by non-LWR designers and NRC staff. The proposed criteria were developed to preserve the underlying safety bases expressed by the original GDC, and recognizing that advanced reactors may take advantage of various new passive and inherent safety features different from those associated with LWRs.

The DOE effort in this first phase also included development of two representative sets of technology-specific design criteria that are consistent with the proposed ARDC. These proposed criteria adaptations were generated by using the standard industry design features commonly associated with two very different advanced reactor concepts, the modular high temperature gas-cooled reactor (HTGR) and the sodium fast reactor (SFR). These sets are referred to as the modular High Temperature Gas Reactor Design Criteria (mHTGR-DC) and the Sodium Fast Reactor Design Criteria (SFR-DC). The proposed mHTGR-DC and SFR-DC also include new design criteria that are unique to these advanced designs, and do not currently exist in the Appendix A GDC.

Phase 2 of the initiative is to be managed by the NRC and would involve review of the Phase 1 work products and intended issuance of regulatory guidance resulting from the review. This process will include resolution of outstanding NRC staff technical questions and comments gathered through the public interaction process. The DOE national laboratory team and industry licensing consultants will remain available to assist during Phase 2. NRC has stated that they intend to develop and issue regulatory guidance commensurate with an official NRC staff position. The issuance of this new NRC regulatory guidance is expected to provide the following benefits:

- reduced regulatory uncertainty for advanced reactor developers,

- improved guidance for NRC staff reviewing advanced reactor license applications, and

- improved timeliness and efficiency of licensing activities for both applicants and NRC staff. 


\section{ACKNOWLEDGEMENTS}

The content of this technical report was compiled at INL, and is based on the contributions of the following national laboratories, further supplemented by a small group of industry licensing consultants.

- Argonne National Laboratory

- Idaho National Laboratory

- Oak Ridge National Laboratory 


\section{CONTENTS}

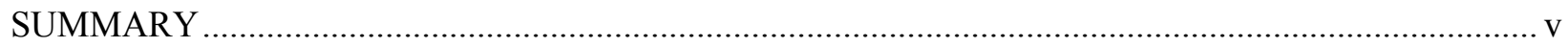

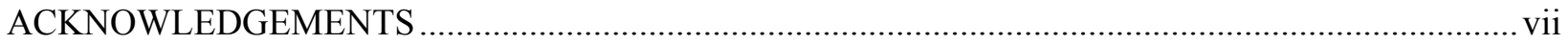

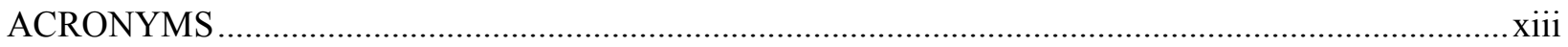

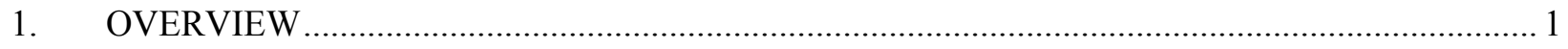

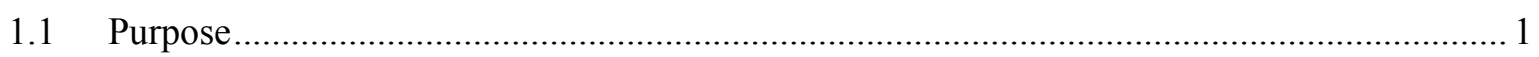

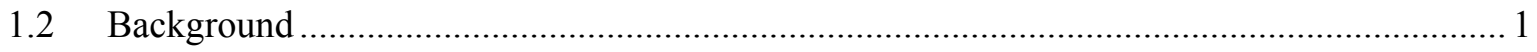

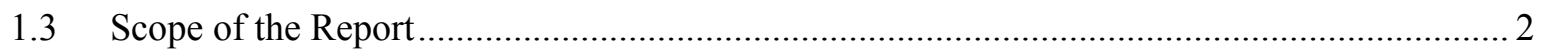

2. PROJECT ORGANIZATION AND INTERFACE …............................................................. 5

2.1 Department of Energy and Nuclear Regulatory Commission Joint Initiative......................... 5

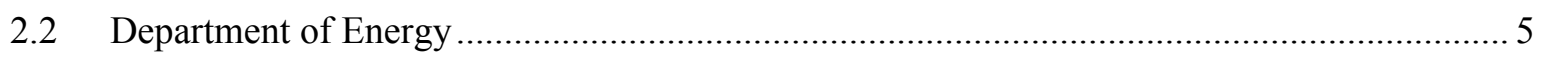

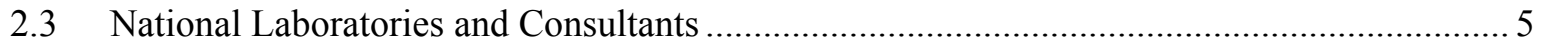

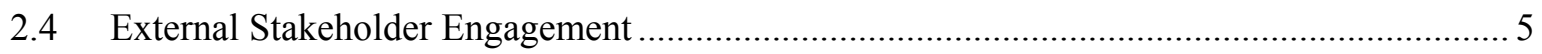

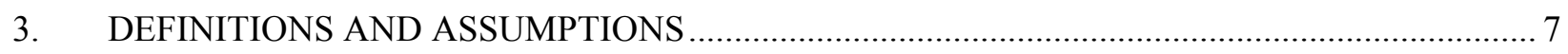

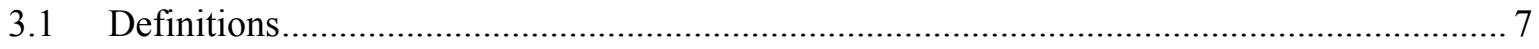

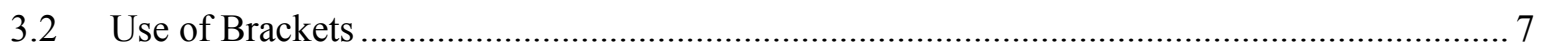

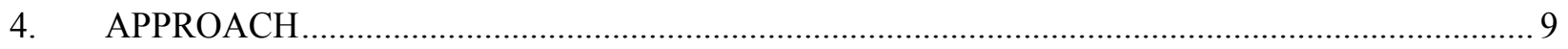

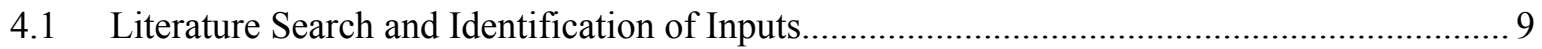

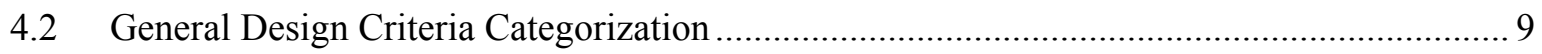

4.3 Process for Development of Proposed Advanced Reactor Design Criteria .......................... 10

5. ADVANCED (NON-LWR) REACTOR DESIGN CRITERIA.................................................. 11

5.1 Key Attributes and Design Features of the Advanced Reactor Designs Considered............. 11

5.1.1 Existing Design Criteria Associated With Coolant, Coolant Systems, Coolant Pressure ..................................................................................... 11

5.1.2 Existing Design Criteria Associated With Containment........................................ 12

5.1.3 Existing Design Criteria Associated With Onsite and Offsite Electric Power Systems ................................................................................................ 12

5.2 Proposed Advanced Reactor Design Criteria - Summary of Insights and Significant

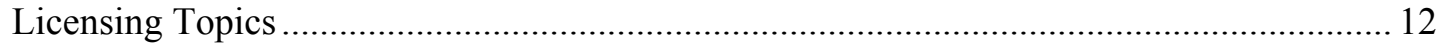

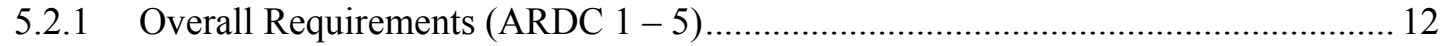

5.2.2 Protection by Multiple Fission Product Barriers (ARDC 10 - 19) ............................. 12

5.2.3 Protection and Reactivity Control Systems (ARDC 20 - 29) ................................... 13

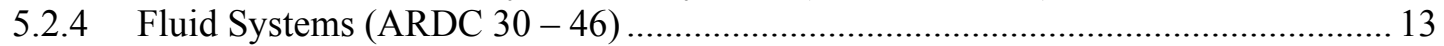

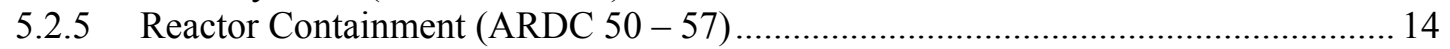

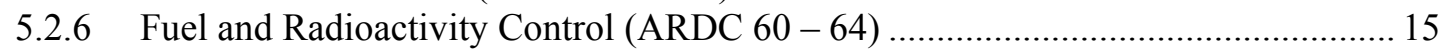

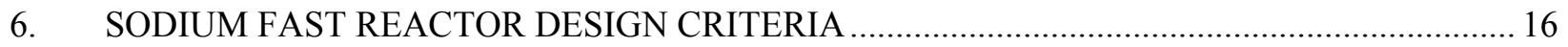

6.1 Key Attributes and Design Features of the Sodium Fast Reactor ...................................... 16

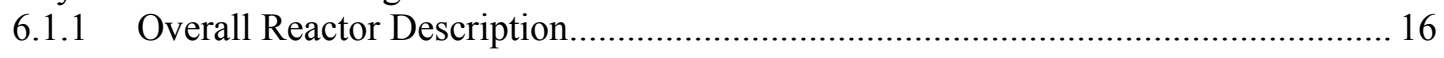




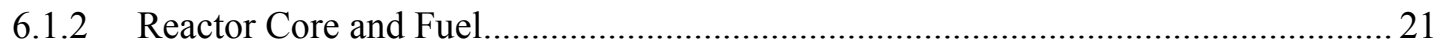

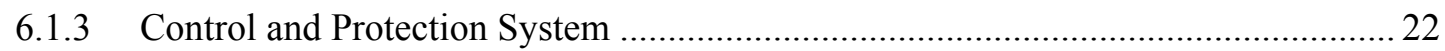

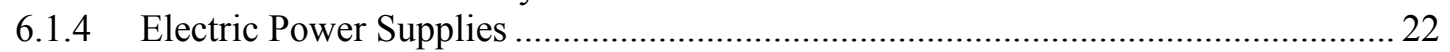

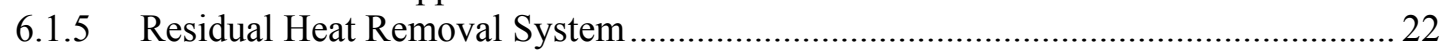

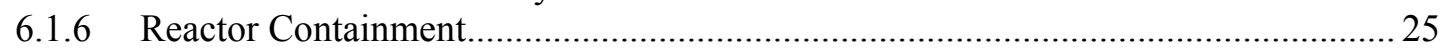

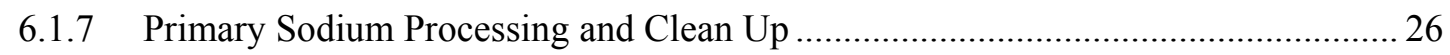

6.1.8 Sodium Piping and Equipment Heating and Insulation System ................................26

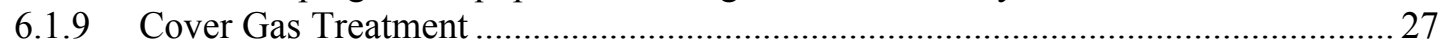

6.2 Proposed Sodium Fast Reactor Design Criteria - Summary of Insights and

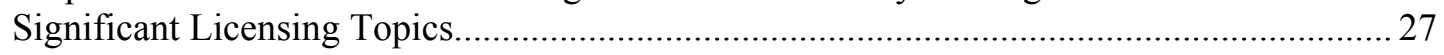

6.2.1 Overall Requirements (SFR Design Criteria 1 - 5) .......................................... 27

6.2.2 Protection by Multiple Fission Product Barriers (SFR Design Criteria 10 -

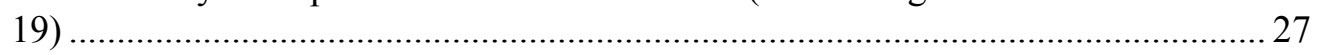

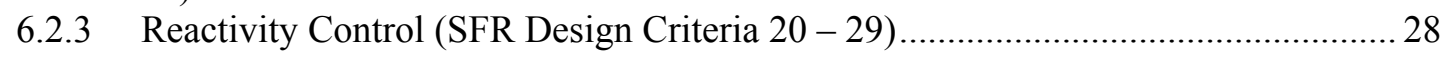

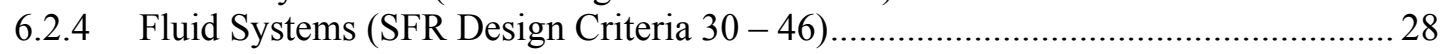

6.2.5 Reactor Containment (SFR Design Criteria 50 - 57) .......................................... 28

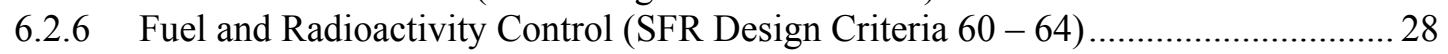

6.2.7 New Design Criteria Proposed for SFRs (SFR Design Criteria 70 - 74) .................. 29

7. MODULAR HIGH TEMPERATURE GAS-COOLED REACTOR DESIGN CRITERIA............. 30

7.1 Key Attributes and Design Features of the Modular HTGR .............................................. 30

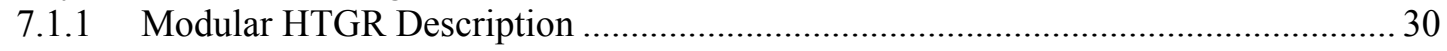

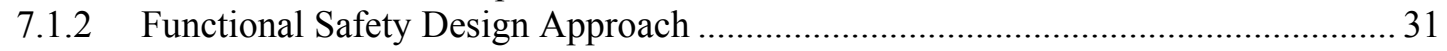

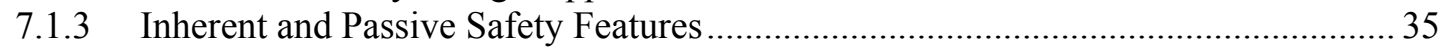

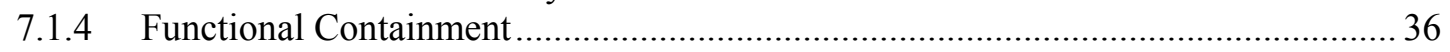

7.2 Proposed Modular HTGR Design Criteria - Summary of Insights and Significant

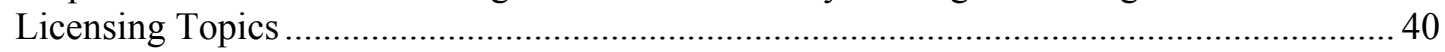

7.2.1 Overall Requirements (Modular HTGR Design Criteria 1 - 5) .............................. 40

7.2.2 Protection by Multiple Fission Product Barriers (Modular HTGR Design

Criteria $10-19)$

7.2.3 Protection and Reactivity Control Systems (Modular HTGR Design Criteria

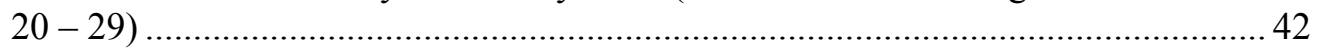

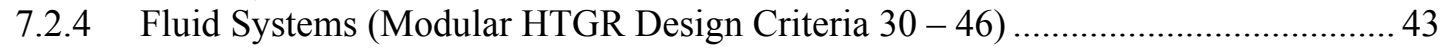

7.2.5 Reactor Containment (Modular HTGR Design Criteria 50 - 57) ............................... 43

7.2.6 Fuel and Radioactivity Control (Modular HTGR Design Criteria 60 - 64) .............. 45

7.2.7 New Design Criteria Proposed for Modular HTGRs (Modular HTGR

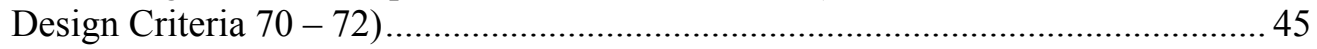

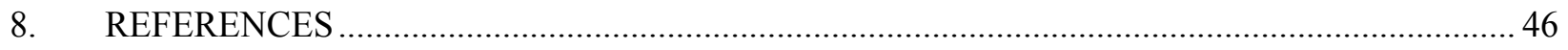

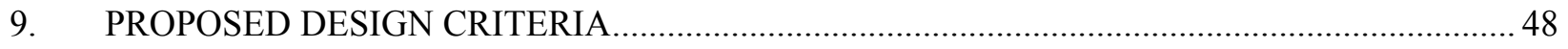

9.1 Proposed Advanced Reactor Design Criteria ................................................................ 48

9.2 Proposed Sodium Fast Reactor Design Criteria ............................................................ 73

9.3 Proposed Modular High Temperature Gas-Cooled Reactor Design Criteria ....................... 99

9.4 General Design Criteria - Advanced Reactor Design Criteria - SFR Design Criteria mHTGR Design Criteria Comparison Table. 


\section{FIGURES}

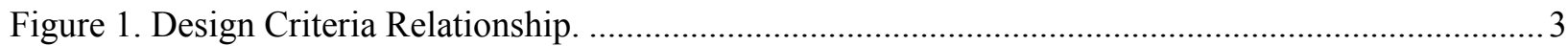

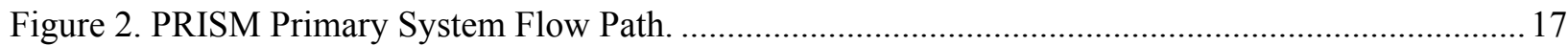

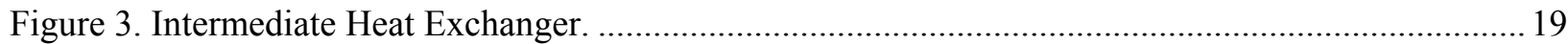

Figure 4. Intermediate Heat Transport System and Associated Power Conversion System......................20

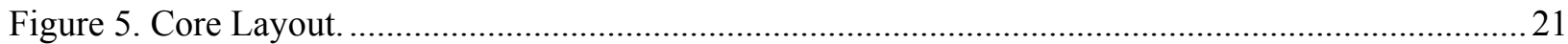

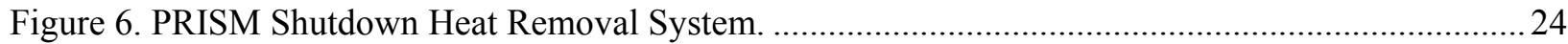

Figure 7. Direct Reactor Auxiliary Cooling System (DRACS).......................................................... 24

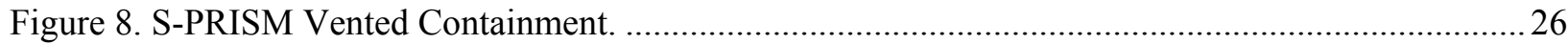

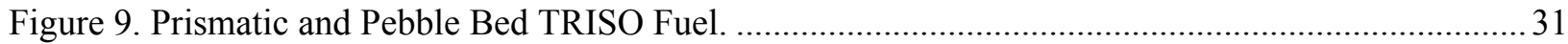

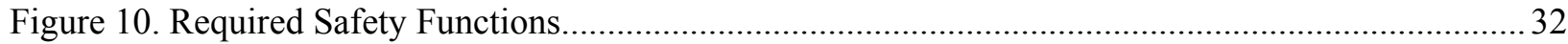

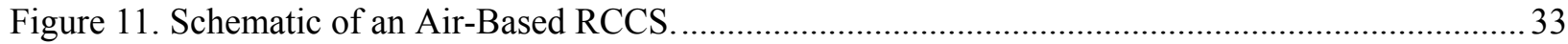

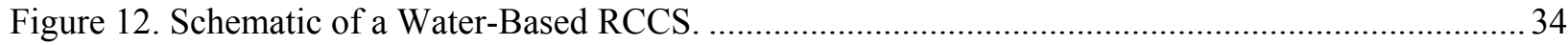

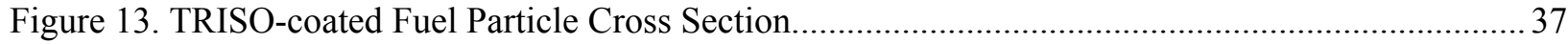

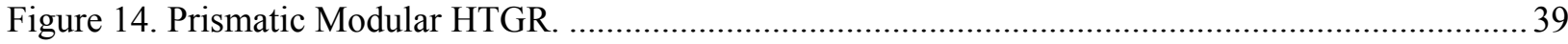

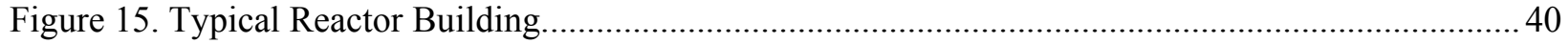

TABLES

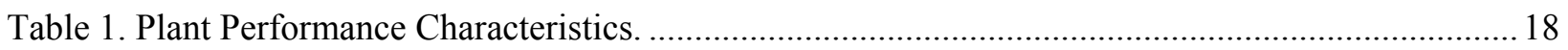

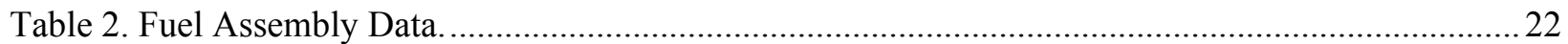




\section{ACRONYMS}

A-C alternating current

ACRS Advisory Committee on Reactor Safety

ACS Auxiliary Cooling System

$\mathrm{AE} \quad$ anticipated events

ANL Argonne National Laboratory

AOO anticipated operational occurrence

ARDC Advanced Reactor Design Criteria

AVR Arbeitsgemeinschaft Versuchsreaktor

CFR Code of Federal Regulations

DC design criteria

D-C direct current

DOE Department of Energy

DRACS Direct Reactor Auxiliary Cooling System

EAB exclusion area boundary

EM electromagnetic

EPA Environmental Protection Act

FHR Fluoride High Temperature Reactor

GA General Atomics

GDC General Design Criteria

GE General Electric

GFR gas-cooled fast reactor

HAA head access area

HPB helium pressure boundary

HPS Helium Purification System

HTGR high temperature gas-cooled reactor

HTS heat transport system

IHTS intermediate heat transport system

IHX Intermediate Heat Exchanger

INL Idaho National Laboratory

IPyC inner pyrocarbon

LBE licensing basis events

LFR lead fast reactor

LWR light water reactor 


$\begin{array}{ll}\text { MHTGR } & \text { modular high temperature gas reactor } \\ \text { MSR } & \text { molten salt reactors } \\ \text { NGNP } & \text { Next Generation Nuclear Plant } \\ \text { NRC } & \text { Nuclear Regulatory Commission } \\ \text { OPyC } & \text { outer pyrocarbon } \\ \text { ORNL } & \text { Oak Ridge National Laboratory } \\ \text { PAG } & \text { Protective Action Guide } \\ \text { PDC } & \text { principal design criteria } \\ \text { PRA } & \text { probabilistic risk assessment } \\ \text { PRISM } & \text { Power Reactor Inherently Safe Module } \\ \text { PSID } & \text { preliminary safety information document } \\ \text { RCCS } & \text { Reactor Cavity Cooling System } \\ \text { RHR } & \text { residual heat removal } \\ \text { RS } & \text { reactor system } \\ \text { RVACS } & \text { Reactor Vessel Auxiliary Cooling System } \\ \text { SAFDL } & \text { specified acceptable fuel design limits } \\ \text { SARRDL } & \text { specified acceptable core radionuclide release design limit } \\ \text { SCS } & \text { shutdown cooling system } \\ \text { SFR } & \text { sodium fast reactor } \\ \text { SFR-DC } & \text { Sodium Fast Reactor Design Criteria } \\ \text { SG } & \text { steam generator } \\ \text { SGS } & \text { steam generator system } \\ \text { SiC } & \text { silicon carbide } \\ \text { SMR } & \text { small modular reactor } \\ \text { SSC } & \text { structures, systems, and components } \\ \text { TLRC } & \text { top level regulatory criteria } \\ \text { TRISO } & \text { tristructural isotropic } \\ \text { TRP } & \text { Technical Review Panel } \\ \text { VHTR } & \text { very high temperature reactor } \\ \text { VS } & \text { Vessel System } \\ \end{array}$




\title{
Guidance for Developing Principal Design Criteria for Advanced (Non-Light Water) Reactors
}

\author{
1. OVERVIEW
}

\subsection{Purpose}

The Department of Energy (DOE) and Nuclear Regulatory Commission (NRC) established a joint initiative in July 2013 to address a key portion of the licensing framework needed for the licensing of advanced (non-light water) reactor technologies. The initiative addressed the "General Design Criteria for Nuclear Power Plants," Appendix A to10 CFR 50, which were developed primarily for light water reactors (LWRs), relative to licensing of advanced reactor designs. The overall purpose this effort is to establish clear guidance for the development of the principal design criteria (PDC) that advanced nonLWR developers will be required to include in their NRC license applications. Completion of this effort and the NRC's future issuance of the associated regulatory guidance are expected to provide the following key benefits:

- Reduced regulatory uncertainty for advanced reactor developers.

- Improved guidance for NRC staff reviewing advanced reactor license applications.

- Improved timeliness and efficiency of licensing activities for both applicants and NRC staff.

The implementation of this initiative, including NRC's issuance of regulatory guidance, aligns with the Commission's "Policy Statement on the Regulation of Advanced Reactors", ${ }^{2}$ which includes the following excerpt regarding the Commission's expectations for the establishment of regulatory requirements for advanced reactors:

To provide for more timely and effective regulation of advanced reactors, the Commission encourages the earliest possible interaction of applicants, vendors, other government agencies, and the NRC to provide for early identification of regulatory requirements for advanced reactors and to provide all interested parties, including the public, with a timely, independent assessment of the safety and security characteristics of advanced reactor designs. Such licensing interaction and guidance early in the design process will contribute towards minimizing complexity and adding stability and predictability in the licensing and regulation of advanced reactors.

\subsection{Background}

10 CFR 50 and 10 CFR 52 both require that license applicants establish PDC derived from 10 CFR 50 Appendix A, "General Design Criteria For Nuclear Power Plants." Since the General Design Criteria (GDC) in Appendix A were written with a focus on LWR technologies, this PDC development requirement is especially challenging for potential future license applicants pursuing advanced (nonLWR) technologies and designs. This challenge has been identified in various forums that include:

- The DOE-instituted Advanced Reactor Concepts Technical Review Panel (TRP) convened in 2012 to evaluate viable reactor concepts from industry, in order to identify research and development needs. The TRP members and reactor designers involved in this process noted the need for a regulatory framework for non-light water advanced reactors.

- The NRC-provided Report to Congress in $2012^{1}$ on advanced reactors reflected the need for enhancements to the existing regulatory framework to address potential policy, licensing, and 
technical issues presented by advanced reactor designs. Such enhancements would contribute to improvements in the effectiveness and efficiency of future licensing of those designs.

- $\quad$ The DOE-instituted Advanced Reactor Concepts Technical Review Panel (TRP) convened in 2014 also noted the need for regulatory framework for non-light water advanced reactors.

This report proposes stakeholder-informed guidance for the adaptation of the Appendix A GDC to advanced (non-LWR) reactor technologies. The intended outcome of the joint DOE-NRC initiative supported by this report is NRC-issued regulatory guidance related to the requirements of $10 \mathrm{CFR} 50$ and 10 CFR 52 pertaining to PDC development for advanced (non-LWR) reactor designs. The NRC's issuance of that guidance is one step in developing an overall regulatory framework for such technologies.

\subsection{Scope of the Report}

As discussed in Reference 3, the GDC establish the minimum requirements for the PDC. However, when they were written, they were specifically focused on LWR designs. The need for clarification of the applicability of the GDC to reactor types other than LWRs has been consistently identified by the nuclear industry, including various stakeholders and advanced technology developers, and acknowledged by the NRC staff. Further, the potential need to adapt the GDCs is reflected in the introductory statement contained in 10 CFR 50 Appendix A:

These General Design Criteria establish minimum requirements for the principal design criteria for water-cooled nuclear power plants similar in design and location to plants for which construction permits have been issued by the Commission. The General Design Criteria are also considered to be generally applicable to other types of nuclear power units and are intended to provide guidance in establishing the principal design criteria for such other units.

The advanced reactor design criteria (ARDC) included in Section 9.1 of this report are intended to provide specific inputs and recommendations to support the NRC staff's issuance of guidance reflecting how developers of the selected advanced reactor technology types could adapt or "bridge" the existing LWR-focused GDC contained in 10 CFR 50 Appendix A to the development of their respective principal design criteria, while retaining the underlying safety principles of the GDC. This material is intended to directly support the joint licensing initiative established by DOE and NRC. ${ }^{3}$

The material contained in Section 9 is arranged as follows; Section 9.1 contains a set of adapted criteria, designated ARDC, that are intended to be generally applicable to the following advanced reactor technology types:

- $\quad$ Sodium Fast Reactors (SFRs)

- Lead Fast Reactors (LFRs)

- Gas-Cooled Fast Reactors (GFRs)

- Modular High Temperature Gas-Cooled Reactors (mHTGRs)

- Fluoride High Temperature Reactors (FHRs)

- Molten Salt Reactors (MSRs).

Section 9.2 contains a set of criteria, further adapted and refined from the ARDC that is intended to be specifically applicable to Sodium Fast Reactor technology. These criteria are designated Sodium Fast Reactor Design Criteria (SFR-DC). 
Section 9.3 contains a set of criteria, further adapted and refined from the ARDC that is intended to be specifically applicable to modular HTGR technology. These criteria are designated modular High Temperature Gas-Cooled Reactor Design Criteria (mHTGR-DC).

The relationship among the 10 CFR 50 GDC, the ARDC (Section 9.1 of this report), the two sets of technology-specific design criteria contained in this report (Sections 9.2 and 9.3), and the PDC that a future license applicant is required to submit for a specific design is reflected in the figure below.

\section{Existing General Design Criteria from 10 CFR 50 Appendix A}

\section{Advanced Reactor Design Criteria}

(Section 9.1 of this report)

\section{Technology Specific Design Criteria}

(Sections 9.2 and 9.3 of this report)

\section{Principal Design Criteria \\ (Developed by Individual Advanced Reactor License Applicants)}

Figure 1. Design Criteria Relationship.

The scope of this report also includes the identification of new design criteria that are necessary to address specific safety design approaches and attributes of the SFR and modular HTGR technology types. These new criteria are reflected in Sections 9.2 and 9.3 of this report, identified with a numbering scheme that commences at the end of the GDC adaptations proposed for those two technology types. The new criteria were developed in keeping with the introductory text from 10 CFR 50 Appendix A, which indicates that:

The development of these General Design Criteria is not yet complete. ... some of the specific design requirements for structures, systems, and components important to safety have not as yet been suitably defined. Their omission does not relieve any applicant from considering these matters in the design of a specific facility and satisfying the necessary safety requirements.

The criteria proposed in Section 9 of this report are intended to address the associated NRC regulatory requirements, consistent with the general content and format of the existing LWR-based GDC contained in Appendix A to 10 CFR 50. These proposed GDC adaptations do not include criteria that address other areas of regulatory guidance, or associated technology design goals.

It is also noted that this DOE-NRC initiative and the content of this report do not include consideration of existing regulations and regulatory guidance regarding design requirements found outside of the scope of 10 CFR 50, Appendix A. It therefore does not include proposed advanced reactor adaptations of other key NRC design requirements, such as those reflected in: 
- $\quad 10$ CFR 50.62 - Requirements for reduction of risk from anticipated transients without scram events for light-water-cooled nuclear power plant.

- $\quad 10$ CFR 50.63 - Loss of all alternating current power.

The content of this report is intended to support the intended outcome of the DOE-NRC initiative. That outcome is NRC-issued regulatory guidance related to the requirements of 10 CFR 50 and 10 CFR 52 pertaining to the development of PDC for advanced reactor designs.

Future advanced reactor license applicants will be expected to provide the design detail and associated technical justifications necessary to support their bases for proposing to implement the GDC adaptation guidance provided by NRC. Those justifications are expected to be closely related to the "Rationale for Modification" summaries provided for each criterion in Sections 9.1, 9.2, and 9.3. 


\section{PROJECT ORGANIZATION AND INTERFACE \\ 2.1 Department of Energy and Nuclear Regulatory Commission Joint Initiative}

The joint DOE and NRC initiative, supported by development activities documented within this report, is being conducted in two phases.

Phase 1 was conducted by the DOE, and resulted in the development of this technical report. This phase established the necessary resources to implement the report development steps needed to ensure that the necessary research, analysis, evaluation, and documentation has been completed to support the GDC adaptations proposed in Section 9. To retain its independence, the NRC staff has maintained an awareness of DOE activities during this phase, but did not engage in interactions associated with the content or the rationales being developed for the proposed GDC adaptations.

Phase 2 of this initiative will involve the NRC staff's review of this technical report, including interactions with the public and engagement with DOE to address requests for further information or clarification, initiation of the associated regulatory guidance development process, and issuance of that regulatory guidance.

\subsection{Department of Energy}

This effort is being managed and coordinated within the DOE's Office of Nuclear Reactor Technologies. DOE activities to date have included:

- Arranging and confirming the overall scope of the effort with NRC,

- Directing the activities of the national laboratories and consultants supporting this work, and

- Facilitating the participation of the advanced reactor commercial sector and related industry and trade organizations.

\subsection{National Laboratories and Consultants}

The DOE was supported in the development of this technical report by a team of national laboratory staff who are very familiar with the advanced non-LWR technologies, in particular with the underlying safety bases for the SFR and mHTGR technology types. This portion of the technical report development team included representatives from:

- Argonne National Laboratory (ANL)

- Idaho National Laboratory (INL)

- Oak Ridge National Laboratory (ORNL).

This national laboratory team was then further supplemented by consultants with significant insight and previous experience in the area of advanced reactor licensing.

\subsection{External Stakeholder Engagement}

DOE facilitated and coordinated direct industry engagement and involvement with the development of the GDC adaptations proposed within this report. This engagement was intended to ensure key design concepts and information for the various advanced reactor technology types were considered, and that industry feedback was collected and addressed in the proposed GDC adaptations. Industry engagement regarding the content of this report has consisted of: 
- An online public meeting (a webinar) summarizing the initiative, including its overall purpose, schedule, and opportunities for external stakeholder involvement.

- A request from DOE to industry to provide summary descriptions and associated safety basis insights for advanced reactor technologies under development.

- Two public workshops that summarized the proposed GDC adaptations, collected stakeholder comments and feedback on those draft adaptations, and presented the resolution of those inputs as reflected in this technical report.

Industry stakeholder organizations that responded by submitting summary design information, comments, and inputs on the draft design criteria presented in the workshops included:

- American Nuclear Society

- AREVA

- Argonne National Laboratory

- Flibe Energy

- CBI Federal Services

- General Atomics

- General Electric

- Gen4 Energy, Inc.

- Hybrid Power Technologies, LLC

- Japan Atomic Energy Agency

- Korea Atomic Energy Research Institute

- TerraPower

- Toshiba

- X-energy, LLC. 


\section{DEFINITIONS AND ASSUMPTIONS}

\subsection{Definitions}

The following definitions have been established and are utilized in various portions of this technical report. They were developed to ensure a clear understanding of their use within the proposed design criteria and associated rationales. It is noted that two of these terms, Important to Safety and Postulated Accidents are currently utilized within 10 CFR 50 Appendix A. They are defined here to ensure consistent usage within the report.

Functional Containment - A barrier, or set of barriers taken together, that effectively limit the physical transport and release of radionuclides to the environment across a full range of normal operating conditions, anticipated operational occurrences, and accident conditions. Functional containment is relied upon to ensure that dose at the site boundary as a consequence of postulated accidents meets regulatory limits.

Important to Safety - Based on existing 10 CFR 50 Appendix A language, this designation refers to structures, systems, and components (SSCs) that provide reasonable assurance the facility can be operated without undue risk to the health and safety of the public. SSCs with this designation are safety related and are relied upon to remain functional during design basis accidents.

Undue risk is associated with the inability to ensure the capability to prevent or mitigate the consequences of accidents which could result in offsite radiological consequences exceeding the limits set forth in 10 CFR 50.34 (or 10 CFR 52.79).

modular HTGR - Refers to the category of HTGRs that use the inherent high temperature characteristics of tristructural isotropic (TRISO) coated fuel particles, graphite moderator, and helium coolant, as well as passive heat removal from a low power density core with a relatively large height-todiameter ratio within an uninsulated steel reactor vessel. The modular HTGR is designed in such a way to ensure during design basis events (including loss of forced cooling or loss of helium pressure conditions) that radionuclides are retained at their source in the fuel and regulatory requirements for offsite dose are met at the Exclusion Area Boundary.

Postulated Accidents - Based on existing 10 CFR 50 Appendix A language, this term refers to the design basis accidents a nuclear facility must be designed and built to withstand without loss of the systems, structures, and components relied upon to ensure public health and safety.

\subsection{Use of Brackets}

Brackets have been added around certain text to identify portions of original GDC language where advanced designs may need to provide alternative descriptions to address underlying criterion requirements. This approach is intended to address topics such as:

- Technology-specific terminology issues

- LWR-specific example lists

- Technology-specific approaches to safety design. 
The use of brackets in the proposed design criteria is not intended to alter the underlying safety basis of the criterion. Advanced reactor developers generally would be expected to address the topics within brackets by providing information specific to their designs when establishing the PDC. It should be noted this approach is similar in concept to the bracket structure utilized by LWR licensees and the NRC staff regarding the Standardized Technical Specifications. 


\section{APPROACH \\ 4.1 Literature Search and Identification of Inputs}

An extensive literature search was performed to identify and collect key historical references and other information pertinent to the development of proposed design criteria adaptations for advanced nonLWRs. Historical information that was collected and utilized in the development of the proposed ARDC included:

- Advanced reactor design descriptions, including preliminary safety information documents (PSIDs) and conceptual design studies

- Results of previous NRC licensing and pre-application reviews of advanced reactors

- NRC documents related to policy and advanced reactor licensing topics, including various NUREGs and SECY documents

- Related documents developed by industry consensus standards organizations

- Selected national laboratory research plans associated with advanced reactors.

The results of this literature search were then supplemented with additional information provided by external stakeholders, including advanced reactor developers, through a DOE request for current design summary information, as discussed in Section 2.4.

Non-proprietary documents utilized as key inputs in the development of the proposed design criteria adaptations are referenced throughout this report and identified in Section 8.

\subsection{General Design Criteria Categorization}

Following a review of the inputs collected from the above literature search, the team then assessed and categorized the applicability of the LWR-based GDC from Appendix A to the SFR and modular HTGR design types. The relative level of applicability of each criterion was characterized in one of the following four categories:

- GDC is generic and applicable to all advanced reactors - no adaptation needed.

- GDC is LWR specific, but can be adapted to advanced reactors with minor editorial guidance to address LWR terminology.

- GDC is LWR specific and significant adaptation is needed to address advanced reactors.

- GDC is not applicable to advanced reactor technology.

During this categorization and follow-on draft GDC adaptation process, the team also identified a fifth category dealing with topics specific to the advanced reactor designs that require development of new design criteria to address safety design elements not covered by the current LWR-based GDC.

The purpose of this initial categorization effort was to assist the team in prioritizing and organizing its efforts in developing the resulting criteria adaptations reflected in Section 9. 


\subsection{Process for Development of Proposed Advanced Reactor Design Criteria}

The GDC adaptations that were developed in response to reviewed design information are summarized in Sections 5, 6, and 7. Proposed adaptations were developed in a sequence that ensured comprehensive coverage of the various advance non-LWR design types, while including as much specificity and clarity as possible within each criterion.

First, two sets of "technology-specific" design criteria were developed to ascertain the nature and need of adaptation with respect to well documented non- LWRs. One set addressed SFR technology (Sections 6 and 9.2) and the other addressed the modular HTGR (Sections 7 and 9.3). Revisions were based on available design information, previous NRC pre-application reviews of the design types, and more recent industry and DOE national laboratory initiatives in these technology areas.

These two sets of technology-specific design criteria were then used as the basis for initial development of the ARDC. This approach was chosen both because of the diversity in the design basis events and how they are addressed within those two technology types and because of the availability of detailed non-proprietary design information. Those initial inputs and content were then modified to incorporate the additional insights gained from the review of the less detailed summary design descriptions available for other advanced reactor design types. These designs included LFRs, GFRs, FHRs, and MSRs.

The initial draft set of ARDC was then supplemented based on feedback and comments provided by external stakeholders. That feedback, provided through a series of interactions established and implemented by the DOE, was comprised of:

- Request for written comments provided to industry on March 28, 2014

- Industry Workshop Number 1 held on April 15-16, 2014

- Industry Workshop Number 2 held on July 16-17, 2014.

The results of this ARDC development effort are described in Sections 5 and 9.1.

To maintain consistency with the existing GDC and facilitate NRC staff review, the proposed design criteria adaptations reflected in Sections 9.1, 9.2, and 9.3 are arranged in a format that aligns with the existing structure of 10 CFR 50 Appendix A. The number and scope of the proposed adaptations were restricted to those considered necessary to improve regulatory certainty and clarity for stakeholders. 


\section{ADVANCED (NON-LWR) REACTOR DESIGN CRITERIA}

\subsection{Key Attributes and Design Features of the Advanced Reactor Designs Considered}

The Commission's "Policy Statement on the Regulation of Advanced Reactors"2 includes the following excerpts regarding its expectations associated with the development and design of advanced reactors.

Regarding advanced reactors, the Commission expects, as a minimum, at least the same degree of protection of the environment and public health and safety and the common defense and security that is required for current generation light-water reactors (LWRs). Furthermore, the Commission expects that advanced reactors will provide enhanced margins of safety and/or use simplified, inherent, passive, or other innovative means to accomplish their safety and security functions. Among the attributes that could assist in establishing the acceptability or licensability of a proposed advanced reactor design, and therefore should be considered in advanced designs, are:

- Highly reliable and less complex shutdown and decay heat removal systems. The use of inherent or passive means to accomplish this objective is encouraged (negative temperature coefficient, natural circulation, etc.).

- Longer time constants and sufficient instrumentation to allow for more diagnosis and management before reaching safety systems challenge and/or exposure of vital equipment to adverse conditions.

- Simplified safety systems that, where possible, reduce required operator actions, equipment subjected to severe environmental conditions, and components needed for maintaining safe shutdown conditions. Such simplified systems should facilitate operator comprehension, reliable system function, and more straightforward engineering analysis.

Developers of various advanced reactor concepts are addressing this policy guidance through different approaches, in accordance with the different technical aspects of the reactor designs being developed. The ARDC reflected in Section 9.1 have been developed to adapt the existing LWR-based GDC to address those approaches in a general, broadly applicable manner.

The ARDC development reflected in this report identified a relatively small number of underlying advanced reactor concepts and design attributes that affect multiple criteria. Those "cross-cutting" topics are summarized below and addressed in greater detail in Section 9.1.

\subsubsection{Existing Design Criteria Associated With Coolant, Coolant Systems, Coolant Pressure}

The original GDC contained several criteria elements associated with reactor coolant, reactor coolant pressure, reactor coolant systems, and the maintenance or restoration of reactor coolant inventory. These requirements are associated with the design characteristics of LWRs. Those designs typically rely on maintaining and circulating large volumes of water or water/steam under high pressure during normal operations to remove heat from the core.

The advanced reactor designs reviewed within this effort generally move away from this LWR-based approach as they work to achieve simpler, more passive, highly reliable, and less complex methods for providing the necessary heat removal functions. These designs are characterized by the use of different cooling mediums (sodium, helium, molten salt, etc.) some of which operate at lower pressures, and that 
tend to have differing levels of significance in providing the cooling safety function(s). Therefore, the ARDC provided in Section 9.1 propose a number of adaptations to the LWR-based criteria related to this topic. These adaptations have generally been addressed through the use of brackets, as discussed in Section 3.2.

\subsubsection{Existing Design Criteria Associated With Containment}

The existing GDC related to containment are associated with the pressure-retaining structure relied upon for radionuclide retention in LWR-based designs. Certain advanced reactor design types (primarily the modular HTGR) accomplish the radionuclide retention function by instead utilizing a multiple barrier functional containment that is focused to a greater degree on retaining radionuclides at their source (see the Functional Containment definition provided in Section 3.1 above). The ARDC have been developed to accommodate this functional containment approach, while retaining the design criteria for technologies utilizing a containment structure as the radionuclide barrier. This accommodation affects a number of criteria, including those associated with the containment's design, design basis, cooling, atmosphere control, penetrations/isolation, and inspection/testing.

\subsubsection{Existing Design Criteria Associated With Onsite and Offsite Electric Power Systems}

The content of multiple GDC are based on nuclear plant designs that rely on both offsite and onsite electrical power sources, and the capability to reliably switch between those sources, to accomplish various functions important to safety. The advanced reactor design concepts that were reviewed generally place less reliance on electrical power consistent with the expectations expressed in the NRC Advanced Policy Statement regarding use of simplified, inherent, or passive means to accomplish safety functions. In addition, each of the concepts reviewed strives to avoid reliance on offsite power to accomplish safety functions, and relies on onsite power for more limited purposes than the current large LWR designs. GDC that specified particular supply combinations of electric power were revised to allow for greater flexibility and simplification while still requiring a reliable source of electric power for essential functions.

\subsection{Proposed Advanced Reactor Design Criteria - Summary of Insights and Significant Licensing Topics}

The proposed ARDC summarized in the following sections address a broad spectrum of advanced reactor technology types identified in Section 1.3. These summaries are therefore intended to provide a high level overview of important design criteria adaptations being proposed for this group of technologies. Proposed ARDC wording, along with rationales that justify the change, can be found in Section 9.1.

\subsubsection{Overall Requirements (ARDC $1-5)$}

These criteria contain a set of broad requirements that can generally be applied as written for the advanced reactor technologies being addressed by this report. Suggested adapatation for this ARDC group are associated with the cross-cutting topics summarized in Section 5.1 above.

\subsubsection{Protection by Multiple Fission Product Barriers (ARDC $10-19$ )}

This group of criteria establishes the need for multiple barriers to the release of fission products, consistent with the defense in depth concept for providing reasonable assurance that the facility can be operated without undue risk to the health and safety of the public. Each of the advanced reactor technology types that were reviewed embrace and implement this multiple barrier concept, albeit in different ways. 
The two basic approaches described by the reactor developers include either (1) a reactor containment structure as a fission product barrier strongly relied upon for radionuclide retention, or (2) the establishment of barriers that are close to the source of the fission products as part of the overall multiple barrier concept. The concept of a functional containment is proposed in ARDC 16 to address these varying barrier approaches, and is defined in Section 3.1 above.

Because advanced reactor designs have a potential to incorporate new factors that might influence inherent reactor protection, the applicability of such influence has been broadened from "coolant systems" to include additional factors (including structures or other fluids) that may contribute to reactivity feedback. It is intended that these systems be designed to compensate for rapid reactivity increases in the reactor core.

The advanced reactor design concepts that were reviewed generally place less reliance on electrical power through their incorporation of simplified, inherent, or passive means to accomplish safety functions. However, in some cases, the design descriptions reviewed did not include specific descriptions of the planned electrical power systems configuration and functions. The proposed adaptations and use of brackets in these electric power areas intend to recognize and address these differing and developing approaches by allowing flexibility in the configuration of the required electric power systems. These adaptations maintain the underlying safety basis associated with the design criteria, including the establishment of sufficient independence, redundancy and testability to perform the safety function.

Control room design requirements have been expanded to address overall habitability, in addition to retaining the existing requirements associated with radiation protection.

Brackets have been added to address the cross-cutting topic from Section 5.1 above associated with use of the terms "coolant," "coolant systems," and "coolant pressure," and in other areas containing LWR-based text.

\subsubsection{Protection and Reactivity Control Systems (ARDC 20 - 29)}

This group of design criteria provides the requirements associated with protection system functions and reactivity control during normal plant operations, including anticipated operational occurrences (AOOs), and during postulated accidents. Proposed adaptations in this group include the allowance for utilizing more than two reactivity control systems to satisfy redundancy and capability requirements (ARDC 26). In addition, an adaptation to Criterion 27 is proposed, since the advanced designs evaluated do not utilize an emergency core cooling system for poison addition.

\subsubsection{Fluid Systems (ARDC $30-46$ )}

Significant adaptations are proposed concerning application of GDC 34 and GDC 35 to advanced reactors. In LWR applications, GDC 34 specifies residual reactor core heat must be transferred to the ultimate heat sink at rates which ensure protection of specified acceptable fuel design limits (SAFDLs) and design conditions of the reactor coolant pressure boundary. Historically, this criterion is applied to normal operational conditions that include AOOs.

LWRs are also required by GDC 35 to have an emergency core cooling capability. This requirement addresses cooling during loss of coolant accident conditions and requires core heat cooling at rates such that (1) fuel and clad damage that could interfere with continued effective core cooling is prevented, and (2) clad metal-water reaction is limited to negligible amounts. The criterion has typically been applied to safety systems largely separate and distinct from the residual core heat removal capabilities otherwise addressed by GDC 34. 
Design information gathered in conjunction with ARDC development indicated that advanced reactors employ a different core heat removal strategy than LWRs. There appears to be little or no distinction between residual core heat removal systems used during normal operations (GDC 34) and the systems for emergency core heat removal addressed by GDC 35. In general, higher levels of plant simplicity and reliability are sought by relying on a single safety-related core heat transfer system (with suitable redundancy) for all design conditions.

This observation was discussed during Stakeholder Workshops Number 1 and Number 2 and was the subject of a request for additional stakeholder information during Workshop Number 1. Results of these interactions confirmed that while advanced reactor design philosophies still require safety consideration of residual core heat removal during normal and accident conditions, a separate system analogous to the dedicated "emergency core cooling" system of LWRs is not employed.

ARDC development proceeded with the presumption that advanced (non-LWR) reactors will rely on a single robust residual core heat removal system that will operate as necessary under appropriate design conditions. ARDC 34 was revised to provide for a single effective core cooling capability with heat transfer rates adequate to maintain safety under normal operations (including anticipated operational occurrences) and accident conditions. Since some advanced designs preclude fuel damage and eliminate the possibility of clad metal-water reaction, the exact nature of what constitutes continuous effective core cooling under accident conditions remains to be defined by designers and reviewed by the NRC staff. ARDC 36 and 37 were similarly adapted to assure the requisite heat removal capability required by ARDC 34 are inspected and tested as appropriate.

The underlying safety intent behind GDC 34 and GDC 35 is fully addressed by consolidation of requirements into a single criterion. Their merging is recommended to minimize potential confusion and/or conflict that might arise when two different design criteria, originally established to address separate and distinct safety systems performing their functions under different operational scenarios, are applied to a single system. This approach is consistent with the single residual heat removal (RHR) system configuration that was assessed in NUREG-1368 "Preapplication Safety Evaluation Report for PRISM LMR."4 It should be noted, however, if an advanced reactor design employs an emergency core cooling system as a separate system from the one that transfers residual core heat during normal operations, the basis for criteria consolidation maynot apply. In that case, the PDC development process should look directly to GDC 34 through 37 for guidance.

\subsubsection{Reactor Containment (ARDC 50 - 57)}

Proposed brackets and clarifications within this section are intended to address existing LWR-specific language. In addition, a series of adpatations are proposed to clarify that this group of design requirements is generally applicable only to those advanced (non-LWR) reactor technologies and configurations that utilize a reactor containment structure as a radionuclide barrier. The proposed adaptations in this group, therefore, address one method (containment structure) for satisfying the Containment Design requirements from ARDC 16. Certain technology types may implement ARDC 16 using other methods and functional containment configurations. 


\subsubsection{Fuel and Radioactivity Control (ARDC 60 - 64)}

The existing criteria covering these topics utilize language more generally applicable to the various advanced (non-LWR) reactor technologies without the need for numerous adaptations. However, some of the designs reviewed may utilize spent fuel storage and cooling configurations different from the current LWR-based fuel pool configuration. In addition, due to the varying plant configurations utilized in establishing multiple barriers to the release of radioactivity, brackets have been inserted to address the LWR-based descriptions of areas and atmospheres associated with those releases. 


\section{SODIUM FAST REACTOR DESIGN CRITERIA}

SFR designs are distinguished from traditional LWR designs in a number of important aspects. These include: (1) the fast neutron spectrum (minimum use of moderating materials in the core) results in a more compact core design; (2) the sodium coolant has a high thermal heat conductivity allowing better heat removal from the fuel, resulting in a higher core power density; (3) the sodium coolant has a high boiling point $\left(880^{\circ} \mathrm{C}\right)$ allowing the SFR to operate at near-atmospheric pressure with about a $300^{\circ} \mathrm{C}$ margin above the peak coolant operating temperatures of $550^{\circ} \mathrm{C}$; (4) sodium has a melting point of about $98^{\circ} \mathrm{C}$ resulting in the need for freeze prevention for the reactor and piping systems; (5) exposure of sodium to neutrons in the core forms sodium-24 a short-lived (15-hour half-life) beta/gamma emitter which requires a leak-tight primary system and sodium leak detection capability; and 6) sodium is chemically reactive with air, water, and concrete, which must be taken into account in reactor design and operation.

In particular, because of the chemical reaction with sodium and water, a SFR employs an intermediate heat transfer system between the reactor coolant and the steam generator to prevent possible chemical reactions between the radioactive primary coolant and water/steam as a result of a steam generator tube leak. The heat transfer medium in this system is generally sodium.

The designs examined remove residual heat passively from the core, with no reliance on offsite A-C power to perform safety functions during postulated accidents.

The fuel form used in a SFR can either be metal rodlets or oxide pellets with stainless steel or HT-9 alloy cladding. The current SFR designs being examined in the United States are focusing on metal fuel because of its safety advantages during severe accidents.

Several sodium reactor designs were examined; however, the principal basis for information on the SFR design used to formulate the SFR-DC was the Power Reactor Inherently Safe Module (PRISM) design as developed by General Electric (GE) for the DOE. This design is described in the Preliminary System Information Document (PSID) submitted to NRC in December 1987. ${ }^{5}$ This document and in a few cases, updated information on the S-PRISM reactor supplied by $\mathrm{GE}^{6,7}$ in response to an information request issued by DOE in December 2013, served as the basis for the development of the SFR DC. The principal reason for the using the PRISM design as a reference was the design incorporates a largely passive approach similar to other reactors being considered in the US; thus, it is representative of the class of passive, metal-fueled, pool-type SFRs. In addition, the information is publicly available, the design is mature, key safety features are well established, and relevant documents from pre-licensing interactions with NRC are available for regulatory guidance.

\subsection{Key Attributes and Design Features of the Sodium Fast Reactor}

\subsubsection{Overall Reactor Description}

The PRISM power plant is described to illustrate design features typical of pool-type SFR reactors. It consists of nine reactor modules; each producing $435 \mathrm{MWt}$. The design emphasizes inherent safety characteristics and modularity. The small size of the modules allows the use of inherent shutdown and passive decay heat removal features that permit simplification of the safety-related systems in the plant. This advanced reactor design is consistent with the NRC advanced reactor policy statement ${ }^{2}$ regarding such features.

The reactor uses metal fuel and employs a pool-type design configuration for each module (all primary system components are located inside the reactor vessel). Each reactor module is below grade. 
The active core height is 47 inches with a linear heat rate of $<12 \mathrm{kWt} / \mathrm{ft}$. The core outlet temperature is $468^{\circ} \mathrm{C}$. The reactivity and power are controlled by six control assemblies, which also scram the reactor using two diverse actuators when rapid shutdown is required.

The primary heat transport system is contained within the reactor vessel. It is composed of the hot pool, the shell side of the intermediate heat exchanger (IHX), the cold pool, four submersible electromagnetic (EM) pumps, the pump discharge piping, and the core inlet plenum. The sodium exits the IHX at its base and enters the cold pool.

From the pump suction, cold pool sodium is drawn through the fixed shield assemblies to the pump inlet manifold. The four EM pumps draw in cold pool sodium and discharge it into the high pressure core inlet plenum through piping connecting each pump to the plenum. The sodium is then heated as it flows upward through the core and into the hot pool. The primary system flow path is shown in Figure 2.

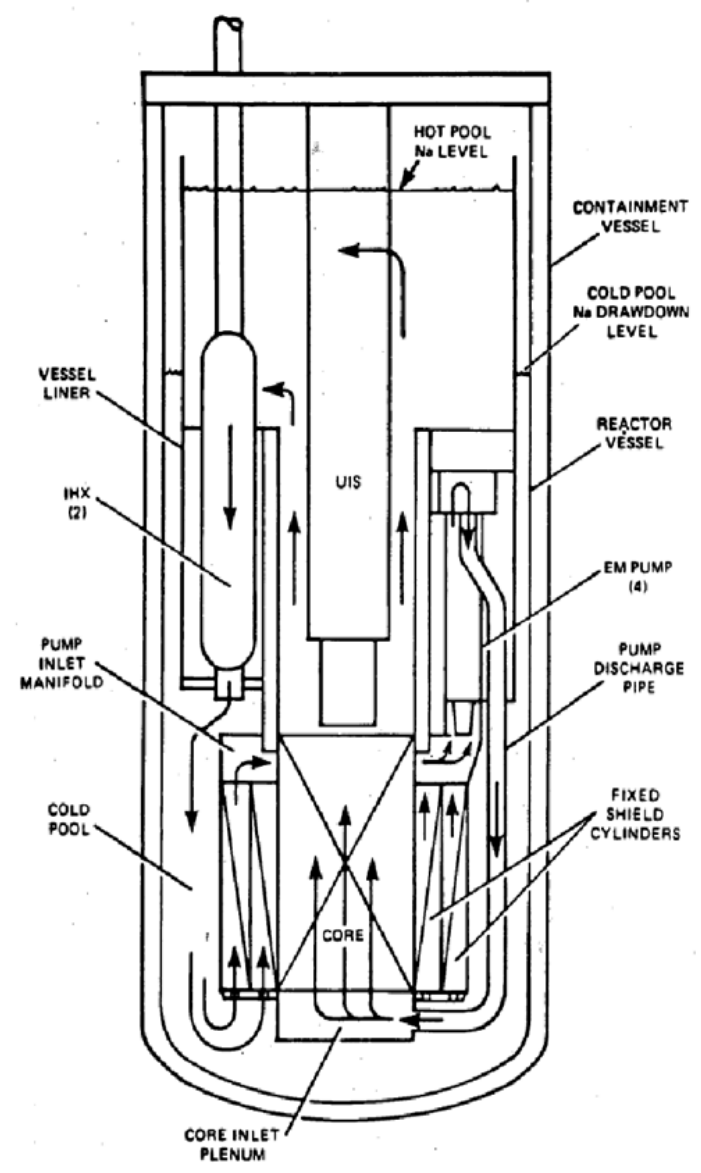

Figure 2. PRISM Primary System Flow Path.

Two IHXs are located in the reactor vessel. These are connected to one intermediate heat transport loop which contains sodium as the heat transport fluid. The heat is transported via a steam generator to a turbine which is shared by two other reactor modules to make up a power block. The PRISM plant design consists of three power blocks, each consisting of three reactor modules connected to one turbine. A summary of the PRISM plant performance characteristics is found in Table 1. 
Table 1. Plant Performance Characteristics ${ }^{5}$.

\begin{tabular}{|l|l|}
\hline Overall Plant & \\
\hline Number of Reactor Modules & Nine \\
\hline Plant Thermal Power & $3825 \mathrm{MWt}$ \\
\hline Net Electrical output & $1245 \mathrm{MWe}$ \\
\hline Net Station Efficiency & $32.4 \%$ \\
\hline Turbine Throttle Conditions & $965 \mathrm{psia} / 540^{\circ} \mathrm{F}$ \\
\hline Reactor Module & \\
\hline Thermal Power (Core) & $425 \mathrm{MWt}$ \\
\hline Primary Sodium Inlet/Outlet Temperature & $610^{\circ} \mathrm{F} / 875^{\circ} \mathrm{F}$ \\
\hline Primary Sodium Flow Rate & $40,800 \mathrm{GPM}$ \\
\hline Intermediate Sodium Inlet/Outlet Temperature & $540^{\circ} \mathrm{F} / 800^{\circ} \mathrm{F}$ \\
\hline Intermediate Sodium Flow Rate & $41,000 \mathrm{GPM}$ \\
\hline Feedwater Temperature & $420^{\circ} \mathrm{F}$ \\
\hline IHTS Hot Leg Temperature & $800^{\circ} \mathrm{F}$ \\
\hline IHTS Cold Leg Temperature & $540^{\circ} \mathrm{F}$ \\
\hline Steam Cycle & Saturated \\
\hline Turbine Type & $\begin{array}{l}1800 \mathrm{RPM} \text { Tandem Compound, Four Flow } \\
-38 \text { inch last stage bucket }\end{array}$ \\
\hline
\end{tabular}

The IHX (shown in Figure 3) consists of upper and lower tube sheets separated by straight tubes with a central downcomer and riser for incoming and outgoing intermediate sodium, respectively. Primary sodium from the hot pool enters the IHX at an elevation below the upper tube sheet. The primary sodium flows downward around the tube and shell to above the lower tube sheet, and exits into the reactor cold plenum. The cold leg intermediate sodium flows down the central downcomer, and splits into two streams just below the lower tube sheet. Each stream then flows up through the straight tubes. The intermediate sodium exits the bundle just above the upper tube sheet. This sodium leaves the IHX through the intermediate outlet nozzle for use in the intermediate heat transport system (IHTS).

Figure 4 shows how the IHTS couples the reactor modules to the steam generators and ultimately to the turbine. For each reactor module, the IHTS consists of piping and components to transport heat from the primary heat transport system to the steam generator system (SGS). The IHTS system is comprised of a piped loop thermally coupled to the primary heat transport system by the intermediate heat exchangers located in the reactor vessel and the steam generator building evaporator located in the steam generator building. Intermediate sodium is circulated by a pump located in the cold leg through the tube side of the IHX and the shell side of the steam generator.

The PRISM steam generator is a shell-and-tube counter-flow heat exchanger with water/steam on the tube side and sodium on the shell side. The tubes are straight and of double-wall construction. The PRISM steam generator is representative of many steam generator designs (hockey stick, helical coil, Utube) that are found in SFRs. A common feature of SFR steam generators is that each has water/steam on the tube side and sodium on the shell side. 
The feedwater and turbine system of an SFR are similar to those of a PWR but with different operational conditions due to the higher operating temperatures found in SFRs.

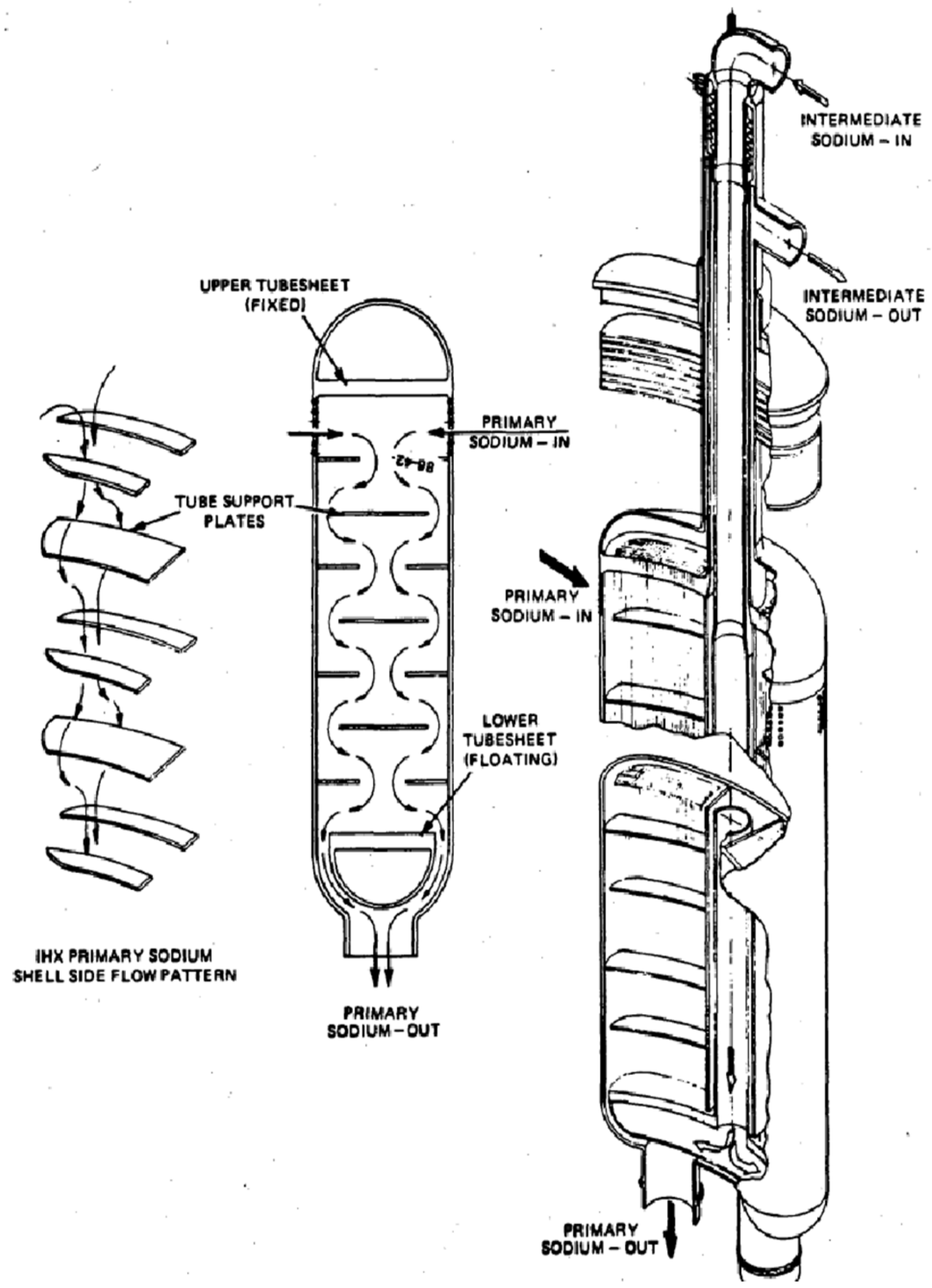

Figure 3. Intermediate Heat Exchanger. 


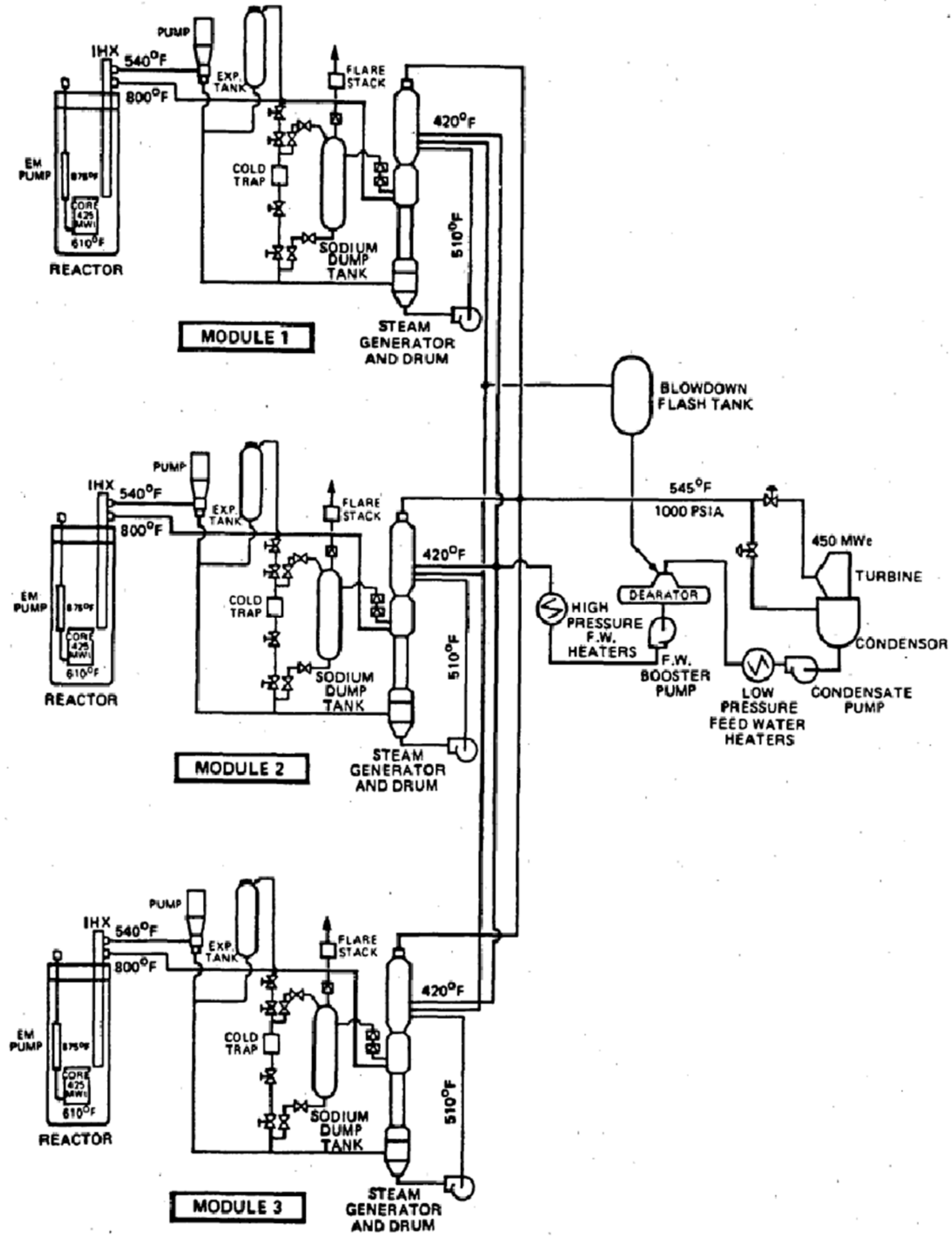

Figure 4. Intermediate Heat Transport System and Associated Power Conversion System. 


\subsubsection{Reactor Core and Fuel}

The PRISM reactor core is a heterogeneous configuration. It consists of 42 hexagonal fuel assemblies, 25 internal blanket assemblies, 36 radial blankets surrounded by 60 shield assemblies. The six control/shutdown assemblies are located in the core. A core layout is shown in Figure 5. Fuel assembly information is contained in Table 2.

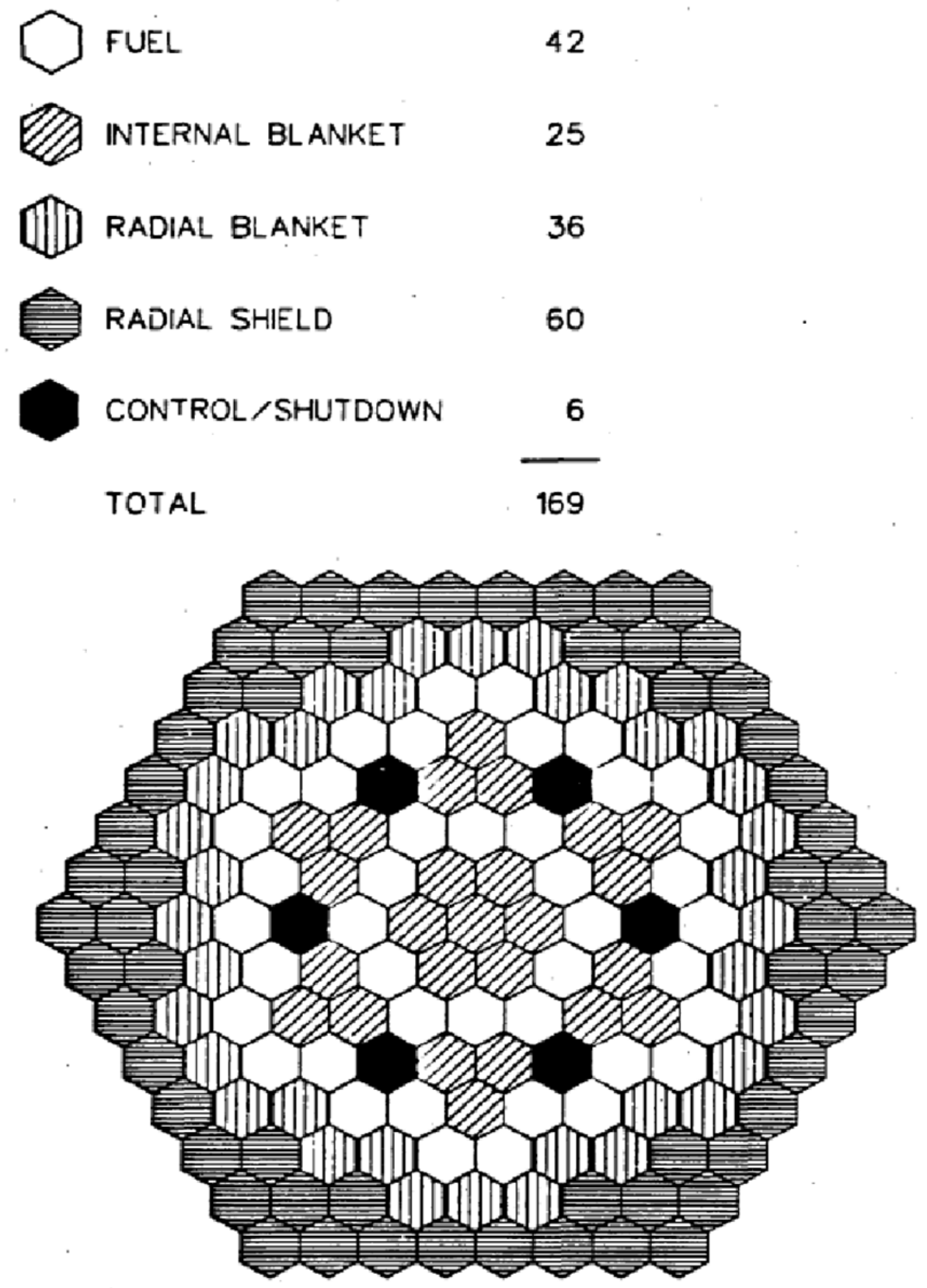

Figure 5. Core Layout. 
Table 2. Fuel Assembly Data ${ }^{5}$.

\begin{tabular}{|l|l|}
\hline \multicolumn{2}{|c|}{ REFERENCE CORE FUEL } \\
\hline \multicolumn{2}{|c|}{ ASSEMBLY DATA } \\
\hline Duct Pitch (in.) & 6.282 \\
\hline Duct Material & HT9 \\
\hline Duct Gap (in.) & 0.175 \\
\hline Duct Wall Thickness (in.) & 0.140 \\
\hline Duct Outer Flat To Flat (in.) & 6.107 \\
\hline Duct Inner Flat To Flat (in.) & 5.827 \\
\hline Overall Assembly Length (in.) & 186 \\
\hline Bundle Flow Area (in.) ${ }^{2}$ & 10.88 \\
\hline Pins Per Assembly & 271 \\
\hline Pin Spacer & Straight start wire wrap \\
\hline Pin Pitch/Diameter & 1.199 \\
\hline Fuel Height (in.) & 47 \\
\hline Upper Gas Plenum Height (in.) & 70 \\
\hline Upper Shielding (in.) & Upper gas plenum \\
\hline Lower Shielding (in.) & 40 \\
\hline \multicolumn{2}{|c|}{ PIN DATA } \\
\hline Fuel Type & U-Pu-10\%Zr \\
\hline Pin Overall Length (in.) & 158 \\
\hline Pin Outer Diameter (in.) & 0.290 \\
\hline Cladding Material & HT9 \\
\hline Cladding Thickness (in.) & 0.022 \\
\hline Fuel Diameter (in.) & 0.213 \\
\hline
\end{tabular}

\subsubsection{Control and Protection System}

Each reactor module has two diverse scram methods; a gravity-driven rod drop and a powered rod drive-in. Shutdown redundancy is provided by designing each absorber bundle, using natural boron as the absorber, such that it has sufficient worth to shut down the reactor from hot, full power condition to cold, zero power condition with the remaining five rods withdrawn to the normal full power operating position. The reactor protection system (RPS) is entirely independent from the plant control system (PCS) and is a digital system. The automated operation of nine reactor modules and three turbine-generators (three power blocks) is supervised from a centralized plant control room.

\subsubsection{Electric Power Supplies}

For each unit, the electric power system consists of a non-class $1 \mathrm{E} A-\mathrm{C}$ power system and a Class $1 \mathrm{E}$ $\mathrm{D}-\mathrm{C}$ power system. The non-Class $1 \mathrm{E}$ high voltage A-C system interfaces with four divisions of the 125 V D-C system via the rectifier/charger units, which also provides protection against A-C transients from the station auxiliary A-C system reflecting into the Class $1 \mathrm{E}$ system. The four divisions of Class $1 \mathrm{E} 125 \mathrm{~V}$ $\mathrm{D}-\mathrm{C}$ power are all battery backed. The four divisions of $\mathrm{D}-\mathrm{C}$ power also supply static inverters which provide four isolated Class $1 \mathrm{E} 120 \mathrm{~V}$ vital A-C busses.

\subsubsection{Residual Heat Removal System}

The Residual Heat Removal (RHR) system for the PRISM design ${ }^{5}$ consists of the normal heat removal pathway that transfers heat generated in the reactor core to the steam generator system where it is 
transported via the feedwater and steam system through turbine bypass valves to the turbine condenser. To remove reactor shutdown heat when the normal heat removal pathway is not available, a safety-grade reactor shutdown heat removal system, the Reactor Vessel Auxiliary Cooling System (RVACS), is provided in the PRISM. In addition to the RVACS, a safety-grade Auxiliary Cooling System (ACS) is provided in the S-PRISM design (the ACS is a non-safety-grade system in the PRISM design). Figure 6 shows the PRISM shutdown heat removal system, including the RVACS, ACS, and the normal condenser cooling system.

The RVACS operates by passively transferring heat generated in the core to the sodium coolant, which increases the temperature of the reactor vessel wall. The heat from the reactor vessel wall is radiated to the containment vessel wall across the argon gas-filled gap between the reactor vessel and the containment vessel. As the reactor vessel wall temperature increases, radiant heat transfer between the reactor vessel wall and the containment wall increases rapidly. The containment vessel wall is cooled by the circulation of outside air. This passive system is always in operation.

The ACS in both the PRISM and the S-PRISM design is a passive system that operates when the normal heat removal pathway via the steam generator feedwater system and turbine bypass system to the turbine condenser is not available. System operation does not require either the primary system pumps or the IHTS system pumps to operate. Primary system heat is passively transferred to the IHTS through the intermediate heat exchanger by natural convection. The IHTS circulates passively through the shell side of the steam generator. The steam generator is surrounded by an insulated shroud with an air intake at the bottom and an exhaust isolation damper at the top. Outside air circulates around the steam generator shell to remove decay heat. The ACS initiates when the exhaust damper is opened. Although not used in the PRISM or S-PRISM designs, some SFR designs employ a passive RHR system known as a direct reactor auxiliary cooling system (DRACS). In a DRACS, decay heat removal heat exchangers are immersed directly into the primary coolant system. Sodium or a sodium-compatible fluid flows by natural circulation in a loop between the DRACS heat exchangers and an air-cooled heat exchanger. The air cooling is also by natural circulation. The system operates passively except for dampers, which open to enable the natural air circulation and activate the system. Figure 7 provides an illustration of a DRACS. ${ }^{8}$ 


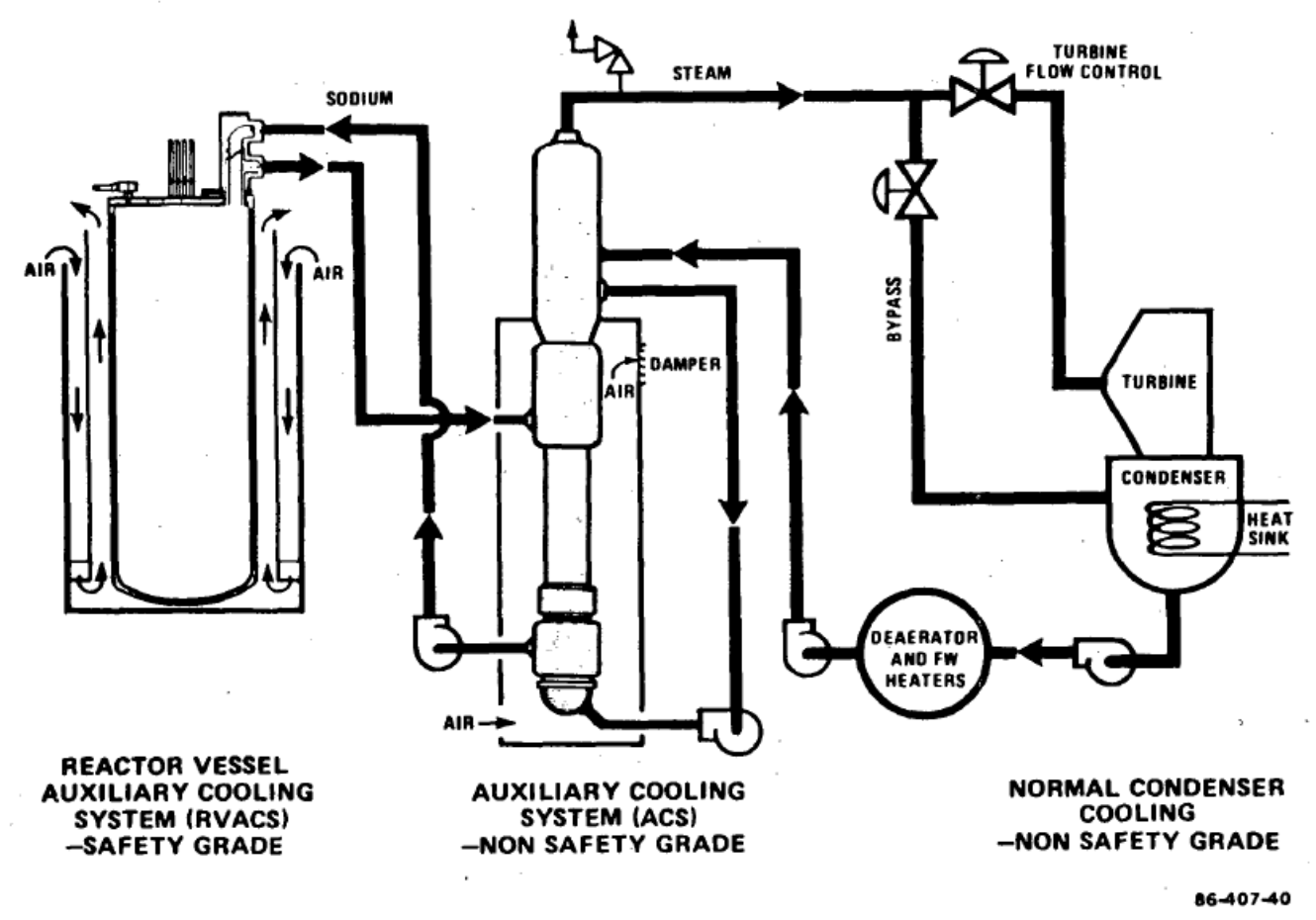

Figure 6. PRISM Shutdown Heat Removal System.

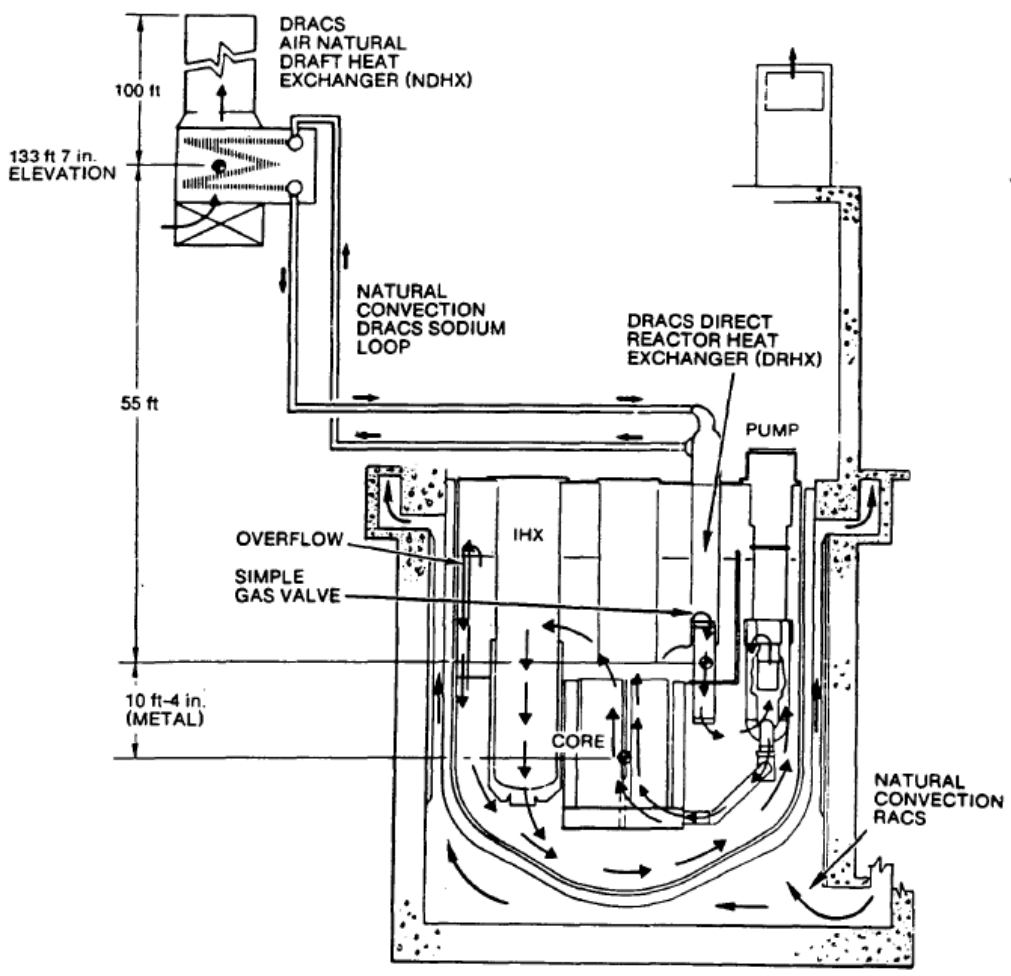

Figure 7. Direct Reactor Auxiliary Cooling System (DRACS). 


\subsubsection{Reactor Containment}

The PRISM containment system ${ }^{5}$ is not representative of the current SFR containments. A more representative containment is the S-PRISM containment as described in a document provided by GE as part of the DOE information call ${ }^{6}$ The S-PRISM containment was used as the basis for the development of the containment-related SFR-DC. The S-PRISM reactor containment design is one example of several SFR containment concepts considered by designers. It should be noted that the S-PRISM power block consists of two reactor units compared to three reactor units for the PRISM design. There are three SPRISM containment structures per plant, each containing two reactors.

The S-PRISM containment consists of two separate volumes that together surround the reactor system. The first or lower containment volume is a leak-tight steel vessel that surrounds the reactor vessel and is welded to the reactor closure. This vessel also serves as a guard vessel. The second containment region is a rectangular building located directly above the reactor closure. The above-reactor containment volume is a low-leakage pressure-retaining steel-lined concrete room that provides access to the components located on the top of the reactor vessel. The upper and lower containment arrangement is shown in Figure 8.

The steel lined upper containment structure is designed to limit leakage to less than $1 \%$ volume per day at 5 psig to mitigate postulated design basis accidents. The lower containment vessel has no penetrations and is designed to remain essentially leak tight. The 8-inch annulus between the reactor vessel and the containment vessel is sized to retain the primary sodium in the unlikely event of a reactor vessel leak such that the reactor core, the stored spent fuel, and the inlets to the intermediate heat exchangers remain covered with sodium. This ensures the internal sodium flow path will not be interrupted and shutdown heat removal via the RVACS and the IHTS (if available) will maintain safe temperatures within the core and reactor system (RS). The annulus between the two vessels is filled with argon at a higher pressure (about 12 psig) than the reactor cover gas, which is at atmospheric pressure. The argon pressure is maintained at a constant level and is continuously monitored with pressure sensors, sodium ionization detectors, and sodium liquid detectors for early warning of any leak in either vessel.

Figure 8 shows how the S-PRISM upper containment volume will automatically be expanded to include the service room that is located between the two reactor containment volumes through the action of a rupture disk if the pressure in the first containment exceeds $1 \mathrm{psig}$. If the pressure in the first containment and the service room exceeds $4 \mathrm{psig}$, the service room volume will be vented to the second containment region by the action of the second rupture disk. 


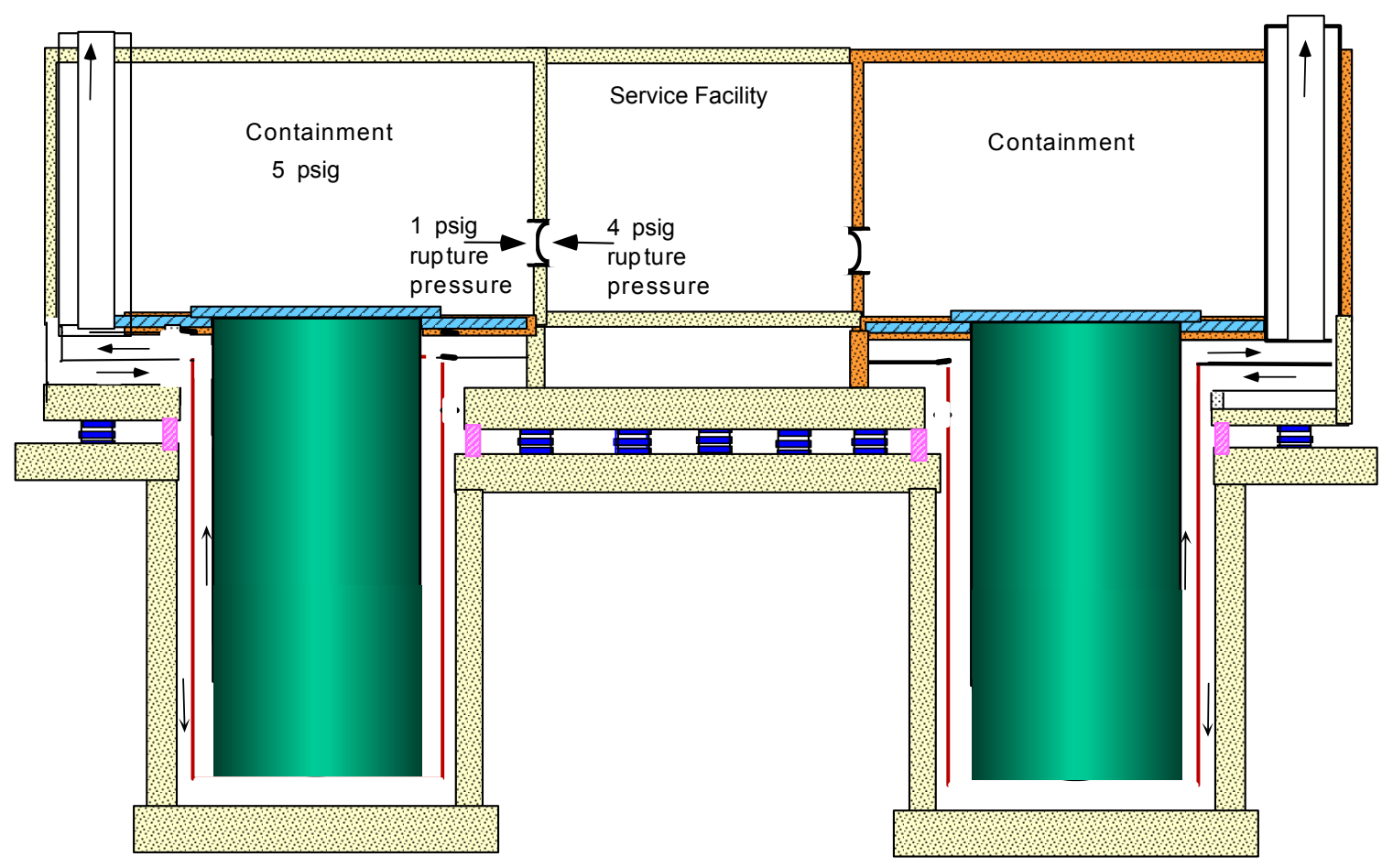

Figure 8. S-PRISM Vented Containment.

\subsubsection{Primary Sodium Processing and Clean Up}

The primary sodium processing subsystem (PSPS) ${ }^{5}$ provides purification of sodium contained in the reactor vessel. It also provides the capability to transfer and temporarily store primary sodium during periods of reactor assembly replacement. There is one system for each power block. Connecting lines are isolated such that only one reactor module can be processed at a time. Primary sodium processing occurs during reactor refueling periods. Prior to plant start-up the primary sodium processing system is used to purify the fresh sodium and "clean" the internals of the reactor vessel. Sodium is pumped through a nitrogen-cooled cold trap to purify the sodium. Double isolation valves are located inside the reactor HAA as well as next to the processing equipment to limit the consequences of postulated sodium spills.

\subsubsection{Sodium Piping and Equipment Heating and Insulation System}

The function of the sodium piping and equipment heating and insulation system is to liquefy and maintain the sodium as a liquid. The system comprises electrical trace-heating and reactor vessel preheating equipment, as well as pipe and vessel insulation. Thermocouple monitors and solid-state relays control the power to the cables, and thus, control the heat rate. There are local and global control centers for the heating system. The reactor vessel preheating system consists of two self-contained blower heater packages. The insulation for the systems consists of alumina silica sandwiched between layers of stainless steel. 


\subsubsection{Cover Gas Treatment}

The PRISM reactor is designed to operate as a hermetically-sealed system and is opened only for refueling or maintenance. Thus, there is no feed/bleed of reactor cover gas during operation. The helium cover gas is replaced before refueling with clean gas. A portable, vehicle-mounted, helium gas supply system $^{5}$ is provided to evacuate, purge, and establish the reactor cover gas pressure at refueling. The system consists of a helium supply, filter, vacuum pump, receiver tank, vapor trap, compressor, and storage/transfer tank. The reactor cover gas is evacuated from the reactor before refueling to the receiver tank through the vapor trap using the vacuum pump. From the receiver tank, the cover gas is transferred to the helium storage/transfer tank using the compressor. The cover gas is replenished with clean helium. The radioactive reactor cover gas, collected by the mobile unit, is then transferred to the gaseousradioactive- waste system for processing. The waste is kept in storage for 45 days for the radioactivity to decay to allowable levels and then reused or discharged to the atmosphere through a monitored exhaust.

\subsection{Proposed Sodium Fast Reactor Design Criteria - Summary of Insights and Significant Licensing Topics}

The ARDC developed under Section 5 of this report have been further refined by applying them to a representative SFR design concept (PRISM) and in some cases to the more recent version of the reactor (S-PRISM) that incorporates major design features of the U.S. SFR existing concepts (i.e., inherent and passive safety, pool design, metal fuel, etc.). This was done to demonstrate how proposed adaptations of 10 CFR 50 Appendix A Design Criteria for advanced reactors can be utilized to guide the development of design-specific PDC. For SFRs, additional design criteria, SFR-DC 70-74, have been introduced to address safety design implications unique to the use of sodium as a reactor coolant that may not be adequately addressed in the ARDC.

\subsubsection{Overall Requirements (SFR Design Criteria 1 - 5)}

ARDC 1-5 are applicable as written to the SFR designs with no changes. SFRs use an alkali metal coolant (sodium) which may result in a fire and generate hazardous reaction products if exposed to air or water. Additional design criteria resulting from the use of sodium are addressed in a set of SFR-specific DCs 70-74. The general fire design criterion addressed in ARDC 3 is applicable to the SFR as written.

\subsubsection{Protection by Multiple Fission Product Barriers (SFR Design Criteria 10 - 19)}

ARDC are generally applicable as written to the SFR designs with a few exceptions, typically where terminology changes have been made to reflect the SFR design characteristics more clearly. For example, the term "reactor coolant pressure boundary" was changed to "reactor primary coolant boundary" inside the bracketed phrase in ARDC 13. The word "pressure" was removed in order to clarify that sodiumcooled fast reactors operate at near atmospheric pressure and, therefore, the primary coolant boundary is not a pressure boundary in the sense of an LWR. The term "primary" was inserted to clarify that sodiumcooled fast reactors generally have two heat transfer systems, both of which typically contain sodium. The primary system has coolant in contact with the reactor core. This distinguishes it from intermediate system which transfers heat from the primary system through intermediate heat exchangers to the balance of plant. The primary coolant boundary is the safety-related boundary similar to the coolant pressure boundary in a LWR. 
All subsequent SFR design criteria which use the bracketed term "reactor coolant pressure boundary" have been changed to "reactor primary coolant boundary" to ensure the SFR DC containing this phrase are understood to apply to the primary coolant boundary and not the intermediate heat transfer system boundary. No other changes from ARDC 10-19 were deemed necessary for the SFR. It should be noted that the intermediate heat transfer system has a separate design criterion, SFR-DC 70.

\subsubsection{Reactivity Control (SFR Design Criteria 20 - 29)}

ARDC are generally applicable as written to the SFR designs reviewed. The SFR design criteria were left mostly unchanged as compared to the ARDC, with minor updates proposed to reflect specific differences in design and plant configuration. These updates were reflected as design specific adaptations within ARDC bracketed text. For example, a change was made to SFR-DC 23 to reflect the reactive sodium coolant as discussed in Section 6.2.1. In SFR-DC 28, the term "reactor coolant pressure boundary" was changed to "reactor primary coolant boundary" inside the bracketed phrase as discussed in Section 6.2.2. In addition, SFR-specific postulated reactivity accidents replaced the bracketed list of postulated reactivity accidents from ARDC 28.

\subsubsection{Fluid Systems (SFR Design Criteria 30 - 46)}

ARDC are generally applicable as written to the SFR designs, with a few exceptions, typically where the terminology changes have been added to more clearly reflect the SFR design characteristics. The term "reactor coolant pressure boundary" was changed to "reactor primary coolant boundary" inside the bracketed phrases in ARDC 30-34 as discussed in Section 6.2.2.

Potential degradation effects associated with sodium coolant on the reactor primary coolant boundary were added within a bracketed portion of ARDC 31.

\subsubsection{Reactor Containment (SFR Design Criteria 50 - 57)}

ARDC are generally applicable as written to the SFR designs reviewed, which utilize containment structures as discussed in Section 6.1.6. Therefore, these criteria were left mostly unchanged as compared to the ARDC, with minor updates made to reflect specific differences in design and plant configuration.

As discussed in Section 6.1.6, the PRISM employs a passive residual heat removal system, parts of which may penetrate the containment. Safety-grade systems must be available to respond to accident conditions. It is possible that including containment isolation valves in such systems may make the overall residual heat removal system less reliable. Therefore, language was included in SFR-DC 54 and 57 to acknowledge that a design applicant may present a safety basis to the NRC staff that containment isolation valves are not required for a residual heat removal system. The added language is not intended to imply that containment isolation valves are not required without further substantiation by the designer.

In SFR-DC 55 and 57, the term "reactor coolant pressure boundary" was changed to "reactor primary coolant boundary" inside the bracketed phrase as discussed in Section 6.2.2.

\subsubsection{Fuel and Radioactivity Control (SFR Design Criteria 60 - 64)}

ARDC are generally applicable as written to the SFR designs reviewed. Minor updates were made to reflect specific differences in design and plant configuration. These updates were reflected as design specific changes within ARDC bracketed text. 


\subsubsection{New Design Criteria Proposed for SFRs (SFR Design Criteria 70 - 74)}

Five design criteria were added to address additional considerations associated with the use of sodium as a primary coolant.

SFR-DC 70 addresses the design of the intermediate heat transfer loop. In many designs, a single barrier in the IHX (described in Section 6.1) separates the radioactive primary sodium from the nonactivated coolant in the intermediate heat transport system. For these situations the reactor should be designed to ensure that, if a leak occurs in the IHX barrier separating the two fluids, they are compatible and the primary radioactive sodium does not leak into the non-activated intermediate coolant providing a possible pathway to release of radioactive sodium from the containment. Generally, this is accomplished by maintaining a pressure differential between the two systems assuring leakage from intermediate to the primary system.

Although the intermediate heat transport system contains non-radioactive coolant, it should be monitored and inspected in areas where a sodium leak and any subsequent chemical reaction with air, concrete, or water might interfere with the safety function of equipment.

SFR-DC 71 addresses the need for maintaining purity of primary sodium coolant and cover gas. Although sodium is not a corrosive coolant, it can interact with trace impurities in heat transfer surfaces over time. Therefore, maintaining its purity is important to prevent chemical attack and to prevent buildup of reaction products which might lead to fouling or plugging of coolant channels.

SFR-DC 72 addresses the fact that sodium melts at $98^{\circ} \mathrm{C}$ and is a solid at room temperature. After startup, core residual heat is sufficient to keep sodium in the liquid state. However, heating may be required during initial filling operations, in cases of extended periods of shutdown, and to prevent sodium freezing in some sample or instrument lines. This criterion requires that a heating system be provided to assure that sodium freezing does not occur in safety related systems and components which contain or could be required to contain sodium. The criterion also requires the heating system be designed and controlled so as not to exceed safety design limits of these safety systems while in operation.

SFR-DC 73 requires sodium leak detection and mitigation of reactions between sodium and air or concrete in the event of a leak to assure that safety functions of SSCs that could be affected by the leak are maintained.

SFR-DC 74 addresses the issue of potential sodium-water reactions. In SFRs using a conventional steam turbine power conversion system, the low pressure intermediate heat transfer system will interface with a high pressure steam/water system inside the steam generator (described in Section 6.1.1). A leak in the steam generator tubes could result in an energetic chemical reaction between water/steam and sodium. This criterion requires the designer to minimize the possibility of a steam generator leak and to mitigate the effects should a leak occur to assure the function of SSCs important to safety is not compromised. 


\section{MODULAR HIGH TEMPERATURE GAS-COOLED REACTOR DESIGN CRITERIA}

There are two basic modular HTGR designs that are very similar, except for their reactor core configurations. Those two designs, the prismatic and the pebble bed types, both reflect the key attributes of modular HTGRs that are further summarized in this section.

Based on a review of the design summary material provided by external stakeholders in support of this effort, and a review of the historical information collected through the literature search described in Section 4, the principal source utilized for modular HTGR design information when developing the proposed GDC adaptations was the Modular High Temperature Gas-Cooled Reactor (MHTGR) developed by General Atomics. The principal reasons for use of this source are related to its design maturity, the publicly-available design detail developed by General Atomics ${ }^{9}$ and the availability of relevant documents from pre-licensing interactions with NRC. ${ }^{10,11,12}$

It is noted that although the General Atomics design description was utilized as a key input, the design criteria adaptations proposed in Section 9 of this report address and apply to both the prismatic and pebble bed modular HTGR design types and also apply to a range of variants on these two design types.

\subsection{Key Attributes and Design Features of the Modular HTGR}

The following subsections are based on material found in the Next Generation Nuclear Plant (NGNP) Mechanistic Source Terms White Paper ${ }^{13}$ and INL/EXT-13-30872, "Modular HTGR Safety Basis and Approach."14

\subsubsection{Modular HTGR Description}

The current designs of the modular HTGR have resulted from extensive experimental and commercial gas-cooled reactor operations, and significant design activity by gas-cooled reactor suppliers and several governments. The modular HTGR concept evolved from early air-cooled and carbon dioxide $\left(\mathrm{CO}_{2}\right)$ cooled reactors. The use of helium instead of air or $\mathrm{CO}_{2}$ as the coolant in combination with ceramic fuel and a graphite moderator offered enhanced neutronic and thermal efficiencies and several advanced safety characteristics. The combination of helium coolant and graphite moderator makes it possible to produce high temperature nuclear heat. Two reactor core configurations, a pebble bed core and a prismatic core, have been developed for the commercial HTGR designs.

Coated particle fuel has been used in HTGRs since their inception. TRISO coated particle fuel was first introduced in the Dragon reactor, and Fort St. Vrain was the first electricity producing HTGR with an all TRISO-particle core. TRISO-coated particle fuel has been the fuel of choice for all modular HTGR designs.

The fuel element for a prismatic modular HTGR consists of TRISO-coated UCO fuel particles are bonded together in a carbonaceous matrix to form cylindrical compacts approximately $12.5 \mathrm{~mm}$ in diameter and up to about $50 \mathrm{~mm}$ in length. These compacts are loaded into hexagonal-shaped blocks fabricated from high-purity, nuclear grade graphite.

The TRISO fuel particle is also used in the pebble bed reactor and is similar to that used in the prismatic reactor except the fuel kernel may consist of stoichiometric uranium dioxide $\left(\mathrm{UO}_{2}\right)$. The UO2 kernel composition was chosen based on the experience in the German High Temperature Reactor (HTR) program. Pebble bed fuel consists of a matrix graphite body pressed into a spherical shape. A fuel sphere is divided into two regions: the inner spherical region is known as the fuel region, and the outer shell 
surrounding the fuel region is known as the fuel-free region. The fuel region of each fuel sphere contains a large number of evenly distributed TRISO-coated fuel particles, while there are no particles in the fuelfree region. The prismatic and pebble bed fuel forms are depicted in Figure 9.

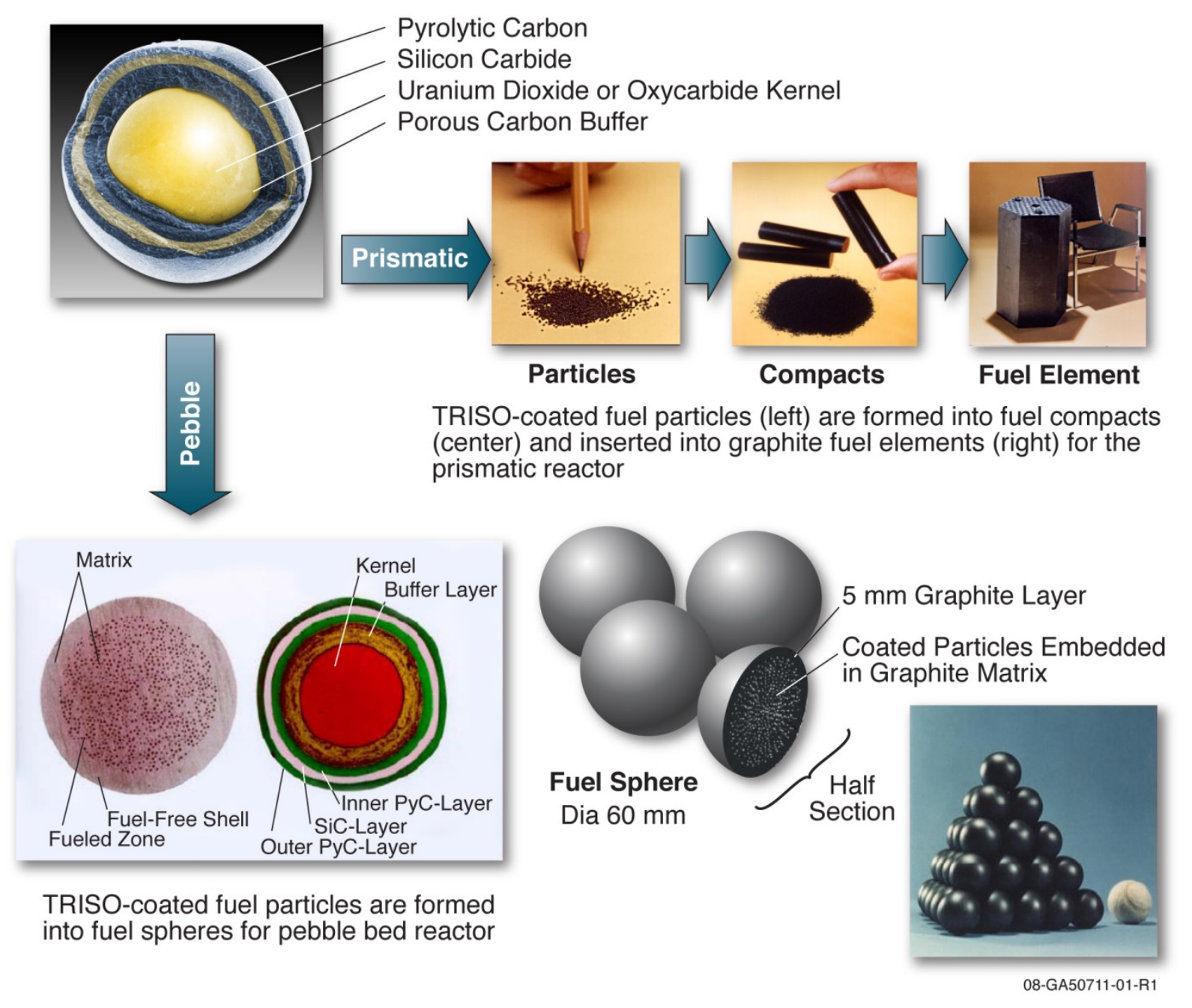

Figure 9. Prismatic and Pebble Bed TRISO Fuel.

The General Atomics MHTGR reactor plant utilized as a principal information source is described in the MHTGR PSID ${ }^{9}$ and NUREG- $1338^{10}$ and is a modular, graphite-moderated, helium cooled, high temperature, thermal-power reactor plant design with a relatively low power density. The standard MTHGR plant design consisted of four identical reactor modules, each rated at $350 \mathrm{MW}(\mathrm{t})$. The total plant electrical output rating is $540 \mathrm{MW}(\mathrm{e})$, with a power conversion efficiency of about 39 percent. Each reactor module is located in its own below-grade silo.

Key modular HTGR design approaches, design attributes, and major component descriptions are provided in the following sections.

\subsubsection{Functional Safety Design Approach}

The safety design approach for the modular HTGR is to control radionuclides primarily at their source within the coated fuel particle under accident conditions without requiring active design features or operator actions. The safety design approach is framed in terms of reactor-specific safety functions 
(Figure 10) developed from the top level safety objective of containing the radioactive material and then considering the specific functions that protect the integrity of the fuel and other radionuclide retention barriers. Other safety and special non-safety functions are included in the design to contribute to the plant capabilities for defense-in-depth or to control smaller, nonlimiting sources of radionuclides. ${ }^{15}$

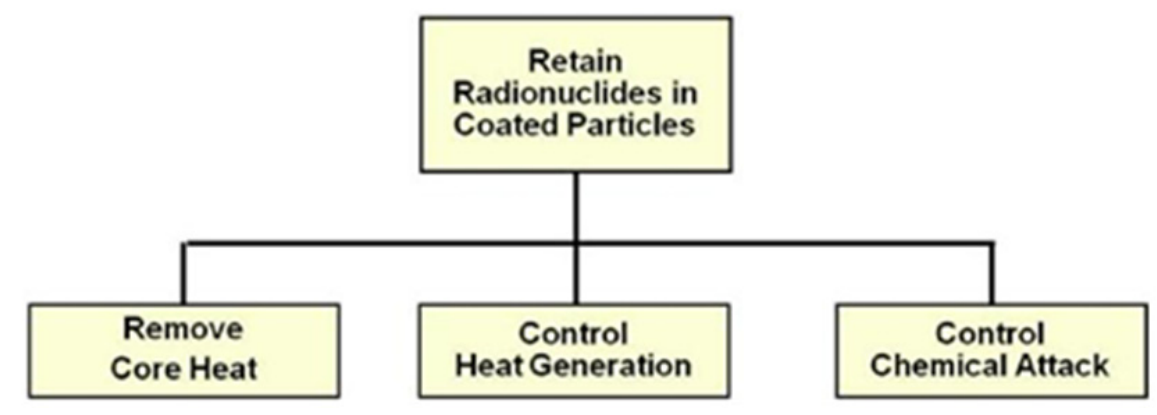

Figure 10. Required Safety Functions.

\subsubsection{Remove Core Heat}

Similar to existing LWRs, modular HTGRs have multiple methods for accomplishing core heat removal. Reactor cooling can be accomplished by the main loop cooling system, the shutdown cooling system (a non-safety related small circulator and heat exchanger located at the bottom of the reactor vessel), or by passive cooling from the core through the reactor vessel to the Reactor Cavity Cooling System (RCCS). The shutdown cooling system is designed specifically for residual heat removal in the event that main loop cooling is unavailable. The modular HTGR core is designed so that residual heat removal is not dependent on the helium coolant within the reactor being under pressure for either forced cooling or passive cooling scenarios. Even in the event that all forced cooling systems are unavailable, the core design ensures passive residual heat removal capability. The limited core diameter, limited power density, and core assembly configuration (large length-to-diameter ratio) limit core and fuel temperatures during passive cooling with the reactor system pressurized or depressurized. The RCCS, which is independent and diverse from the forced cooling systems, keeps structures, including the reactor building concrete, within allowable temperature limits.

Reactor heat is transferred through the reactor vessel walls to the RCCS cooling panels by conduction, natural convection, and radiation heat transfer; the vessel walls are uninsulated to facilitate this process. With RCCS cooling under core heat-up accident conditions, core temperatures will peak after about 2 days at temperatures below that at which significant coated fuel particle degradation can occur. Subsequently, the particles will cool within several days to below normal operation levels.

An RCCS design may be either passive or active during normal operations but is always in passive mode capable of removing residual core heat under accident conditions. Air-based systems always operate passively but water-based systems may employ an active mode during normal operation to aid in residual core heat removal.

A conceptual air-based RCCS diagram is provided in Figure 11. This system typically consists of two steel inlet/outlet structures for the inlet and outlet of atmospheric air, a set of cooling panels surrounding the full length of the reactor vessel within the reactor cavity (for receiving heat and transferring it to the air), and a set of concentric hot and cold ductwork for transporting air between cooling panels and the inlet/outlet structures. The RCCS cooling panels operate continuously in natural circulation for all modes of plant operation and maintain separation between the outside atmosphere and the reactor cavity 
atmosphere. The reactor building (which is also safety related) forms part of the ductwork system and contributes structural features that enable the RCCS to meets its requirements.

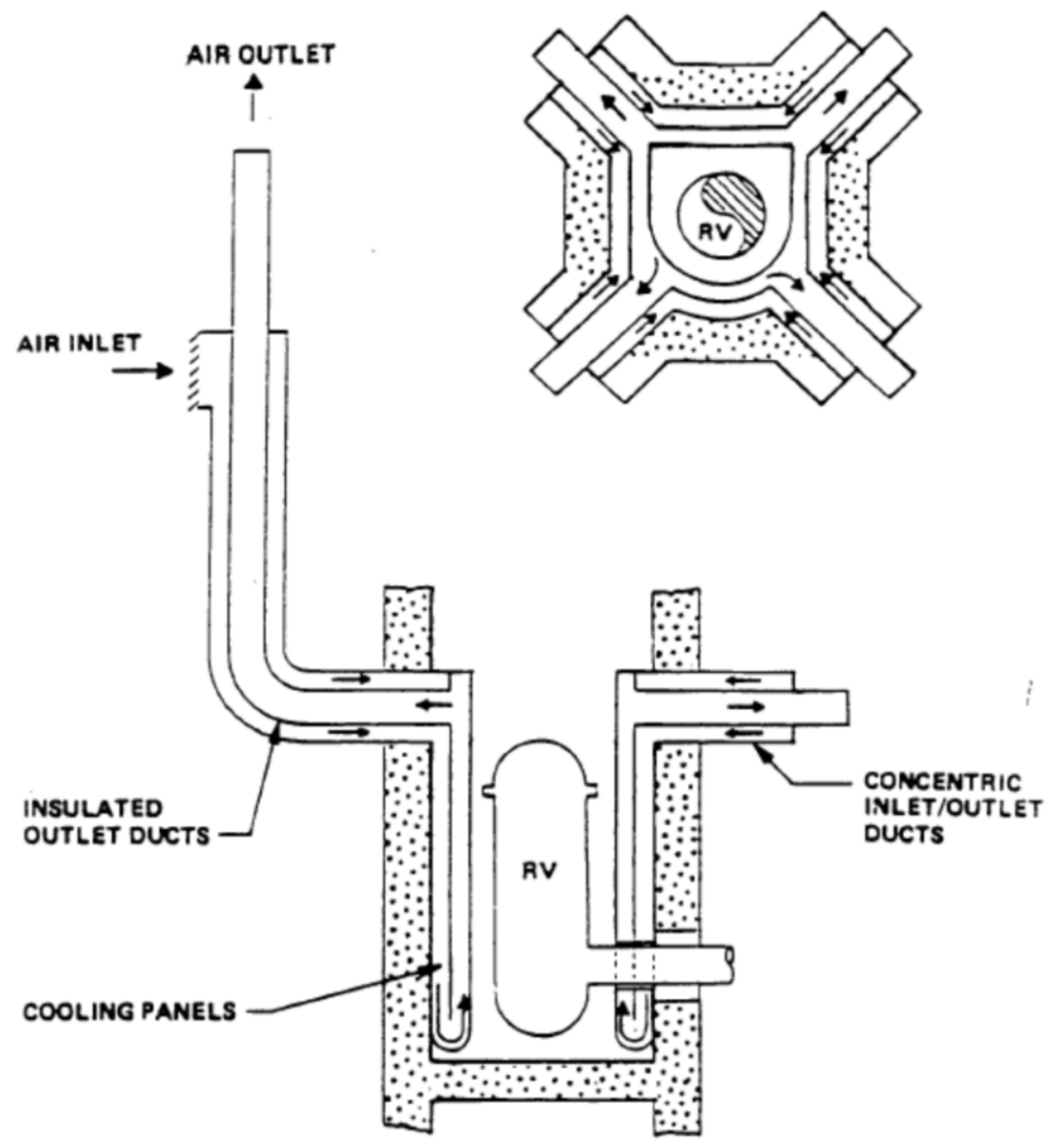

Figure 11. Schematic of an Air-Based RCCS.

The water-based RCCS nominally has reactor cavity walls lined with water panels to form an air-towater heat exchanger. As can be seen in Figure 12, heated water in these panels flows to a water storage tank, the water inventory of which is constantly replaced by cooler water. Water in the storage tank is then actively cooled by a dedicated cooling system. However, should the dedicated tank cooling system become unavailable, RCCS operation then provides passive heat rejection by vaporizing water in the holding tank. ${ }^{16}$ 


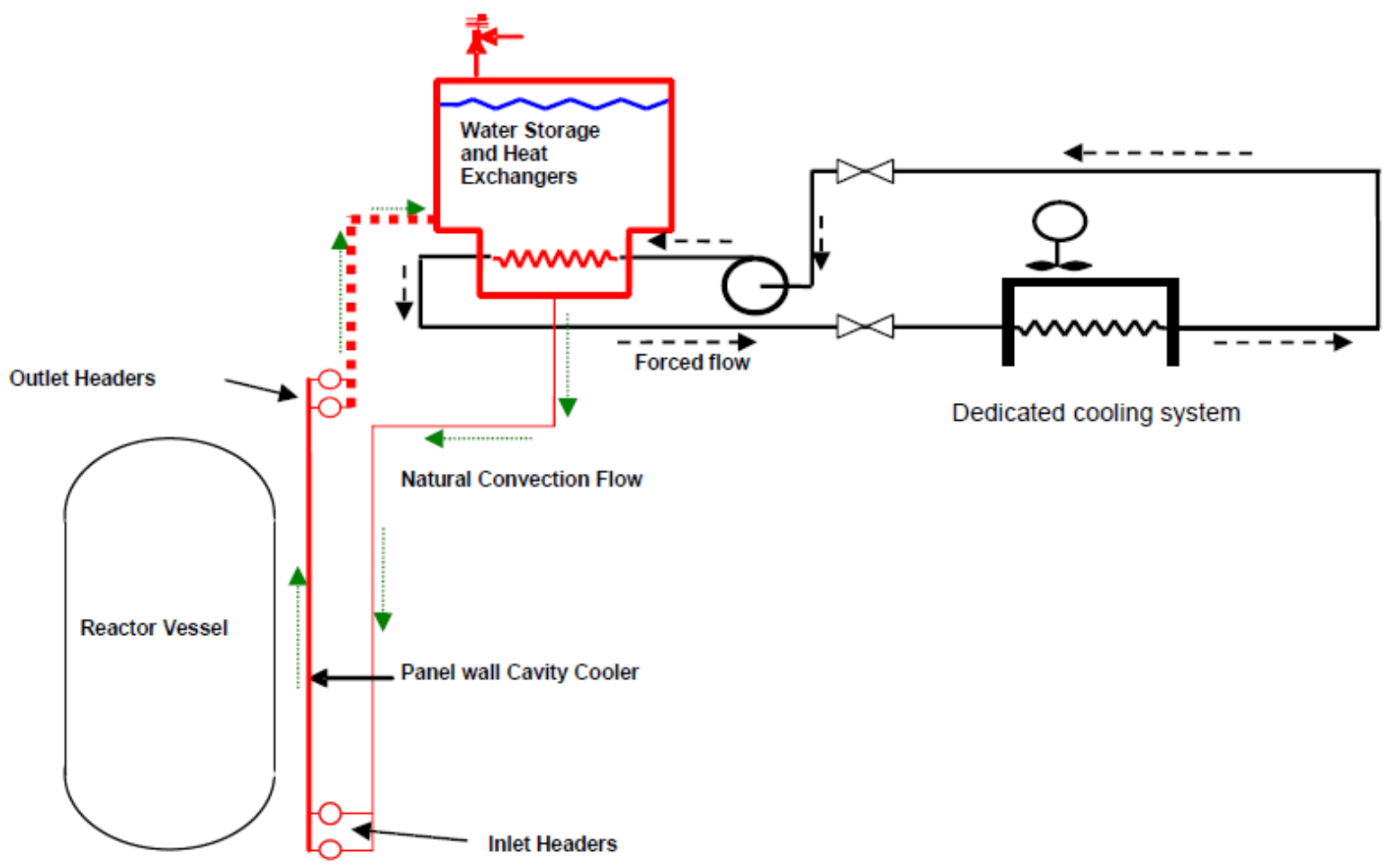

Figure 12. Schematic of a Water-Based RCCS.

The vessel system of modular HTGRs also has a unique safety function in support of core cooling systems. While containing the helium coolant is an important vessel function for modular HTGRs, "core coverage" by the helium is not required, and sufficient core cooling can be provided even if the helium coolant pressure is lost. Therefore, the safety function for the vessel system (VS) is to provide structural support for the reactor core and to maintain adequate cooling geometry for radiation and conduction during passive core cooling. Vessel pressure boundary leakage is not a concern for maintaining safety for modular HTGRs if adequate core structural support is maintained to allow passive cooling.

\subsubsection{Control Heat Generation}

Control of heat generation is accomplished by a very large core negative temperature coefficient and two independent reactivity control systems. Control rods drop by gravity into the core upon loss of electrical power. An automatic positive control action initiated in response to various accidents, including reactivity initiated accidents, can also cause the rods to drop. Power is not needed to insert the control rods. In addition, modular HTGRs have a redundant and diverse system (the reserve shutdown system) to drop borated graphite pellets by gravity into designated fuel element or reflector channels for reactivity control equivalent to rod insertion. Initiation of the latter system typically requires a positive control signal and an active protection system response. However, A-C power is not required for these functions.

\subsubsection{Control Chemical Attack}

Chemical attack on fuel particles and on the graphite core structure can result from water or air ingress into the primary system. The likelihood of water entering the primary system is limited by the absence of high pressure and high-energy sources of water in proximity to the primary system, with the exception of the SG. In the event of a tube leak in the higher pressure SG, the steam and feedwater 
systems would be isolated. A-C power is not required for this function. If steam is generated and transported to the core, the reaction of steam and graphite is slow, endothermic, and is not self-sustaining.

The likelihood of a breach of the helium pressure boundary (HPB), such that air ingress becomes a concern, is limited by the high quality associated with the pressure vessels and the limited size of penetrations. In the event of a breach, primary helium would leak out into reactor building compartments until pressures equilibrate. Most notably, the high pressure helium would act to expel the reactor building air out the vent. Then, the ingress rate of the helium-air gas mixture would be small, as the gas mixture enters the breach primarily by natural circulation and diffusion at the same time as helium, which it is displacing, exits through the same breach.

Exposure to moisture does not affect fuel particles, except for the very small fraction with defective coating layers that could lead to hydrolysis of the affected fuel kernels and a temporary increase in radionuclide releases.

Unlike coal or charcoal, man-made (artificial) graphites are engineered materials that exhibit none of the oxidation and combustion properties associated with carbonaceous fuels. Nuclear-grade graphites have even lower levels of impurities than conventional graphites. As a result, they are even more difficult to oxidize. Demonstration tests have shown negligible mass loss for nuclear-grade graphite under conditions for which charcoal and coal were completely consumed and reduced to ash. The combustion characteristics of graphite are more like that of diamond, another highly structured and highly pure form of carbon.

\subsubsection{Inherent and Passive Safety Features}

To achieve the safety objectives for the modular HTGR, the design relies on inherent and passive safety features. Modular HTGRs use the inherent high temperature characteristics of TRISO-coated fuel particles, graphite moderator, and helium, along with passive heat removal capability of a low-powerdensity core with a relatively large height-to-diameter ratio within an uninsulated steel reactor vessel to ensure sufficient core RHR under pressurized or depressurized loss-of-forced cooling conditions.

Graphite can withstand even higher temperatures than the fuel without structural damage, which complements the fuel's high temperature capability. Graphite structures in the core provide extremely large heat capacity. The high heat capacity and low power density of the core result in very slow and predictable temperature transients. In addition, the strength of graphite increases with temperature over the full range of temperatures applicable to the modular HTGR. The long mean free path of neutrons in graphite provides a neutronically stable core. The graphite also holds up certain radionuclides, further reducing potential release from the core.

Helium is chemically inert and neutronically transparent, meaning it will not aggravate an accident by contributing to any chemical or nuclear reaction. Helium will not change phase in the reactor, thereby eliminating the problem of two-phase flow within the reactor, which would affect reactivity and temperature control. The use of helium also minimizes the problems of primary system corrosion and greatly reduces the resultant buildup of radioactive byproducts associated with water-cooled reactors.

Modular HTGRs are designed to passively remove residual and decay heat from the core regardless of whether helium is present. Passive heat removal is possible due to the large thermal margins (between the highest expected accident fuel temperatures and the temperature above which fuel particle coating degradation may occur), low power density, and core configuration. The relatively large length-todiameter ratio of the core provides a large surface area for heat removal through the uninsulated steel reactor vessel. The concrete walls surrounding the reactor vessel are covered by panels that remove the 
heat radiating from the reactor vessel. These panels are an essential part of the RCCS relied upon in modular HTGR designs. The RCCS can be either air-cooled or water-cooled. In the modular HTGR, both RCCS designs have a passive cooling capability that does not rely on electric power during accident conditions.

The large negative temperature coefficient of modular HTGRs, along with their large thermal margins, provide for an inherent shutdown capability to deal with failures to scram the reactor as demonstrated by testing in the AVR reactor in Germany and HTR-10 reactor in China. Gravity-driven and diverse reactivity control systems provide further confidence of the ability to shut down the reactor.

No AC powered safety-related systems and no operator actions are required to respond to the accident scenarios that have been postulated for modular HTGRs throughout their licensing history. In addition to requiring no operator actions, the design is generally insensitive to operator errors.

\subsubsection{Functional Containment}

A functional containment, consistent with the definition provided in Section 3 above, can consist of a structure surrounding the reactor and its cooling system (as is provided for LWRs and other reactor types) or multiple barriers internal and/or external to the reactor and its cooling system. Modular HTGRs employ a functional containment that consists of an integrated set of five radionuclide retention barriers: 1) the coated fuel particle kernel, 2) the fuel particle coatings surrounding the particle kernel, 3) the carbonaceous matrix and graphite that surrounds the fuel particles, 4) the reactor helium pressure boundary, and 5) the reactor building. The modular HTGR functional containment safety design objective is to meet 10 CFR 50.34 (10 CFR 52.79) offsite dose requirements at the plant's exclusion area boundary (EAB) with margins.

The most important radionuclide retention barrier for the modular HTGR is the one closest to the source of radionuclides, the ceramic coating layers surrounding the fuel kernel. As shown in Figure 13, these coating layers include the inner pyrocarbon (IPyC), silicon carbide ( $\mathrm{SiC}$ ), and outer pyrocarbon $(\mathrm{OPyC})$, which together with the buffer layer constitute the TRISO coating. The coating system acts as a miniature pressure vessel that has been engineered to provide containment of the radionuclides and gases generated by fission of the nuclear material in the kernel. Thousands of these TRISO-coated particles are bonded in a carbonaceous material into either a cylindrical fuel compact for the prismatic HTGR or a spherical fuel element for the pebble bed HTGR. These fuel particles can withstand extremely high temperature without losing their ability to retain radionuclides under all accident conditions. This high temperature radionuclide retention capability is the key element in the design and licensing of modular HTGRs.

In the following sections, the barriers of the modular HTGR functional containment and the behavior of radionuclides in the functional containment are briefly described. Radionuclide behavior in the functional containment is modeled mechanistically to determine source terms for use in safety analyses. More detailed information can be found in the NGNP's "Mechanistic Source Terms White Paper." 13 In its review of the modular HTGR approach to functional containment and approach to determination of mechanistic source terms, conducted for the NGNP, the NRC staff found both approaches to be reasonable. ${ }^{13}$ 


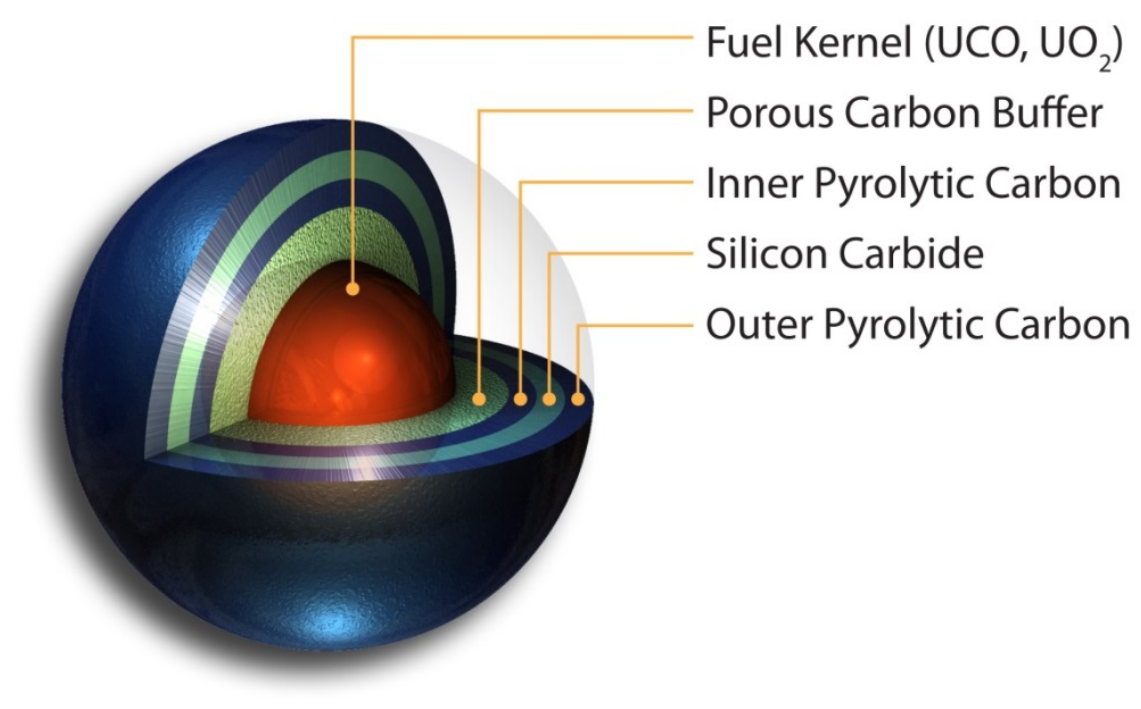

Figure 13. TRISO-coated Fuel Particle Cross Section.

\subsubsection{Fuel Particle Kernel}

The first barrier to radionuclide transport and release is the fuel kernel itself. Under normal operating conditions, the kernel retains a substantial fraction ( $>95 \%)$ of the radiologically important, short-lived fission gases such as Kr-88 and I-131. At elevated (accident) temperatures the effectiveness of the fuel kernels for retaining fission gases can be reduced to a retention fraction of $80-90 \%$ at the peak temperature locations. ${ }^{17}$

Metallic fission products such as silver, cesium, palladium, and other noble metals are diffusively released to some degree from the small percentage of fuel kernels at the upper end of the range of normal operating temperatures (typically $>1100-1200^{\circ} \mathrm{C}$ ). The other fission metals, including radiologically important Sr-90, are only released from the kernel by fission recoil at normal operating temperatures. At elevated (accident) temperature conditions, the retention in fuel kernels of long-lived, volatile fission metals such as $\mathrm{Cs}, \mathrm{Ag}$, and $\mathrm{Sr}$ is strongly dependent on temperature and burnup.

\subsubsection{Fuel Particle Coatings}

The second and most important barrier to radionuclide release from the core, particularly during accidents, is the set of $\mathrm{SiC}$ and $\mathrm{PyC}$ coatings of each fuel particle, as shown in Figure 13. Both the $\mathrm{SiC}$ and $\mathrm{PyC}$ coatings provide a barrier to the release of fission gases. The SiC coating acts as the primary barrier to the release of most metallic fission products because of the low solubilities and diffusion coefficients of fission metals in SiC. ${ }^{18}$ Results to date of fuel qualification tests ${ }^{19}$ confirm that the modular HTGR coated fuel particles will perform as expected to retain radionuclides at their source during normal operation, including anticipated operational occurrences, and during postulated accidents. 


\subsubsection{Core Graphite and Carbonaceous Materials}

For a prismatic core, the fuel compact matrix and the fuel block graphite collectively comprise the third fission product transport and release barrier. For a pebble bed core, the analog is the pebble matrix, including the unfueled outer shell of the spherical pebble fuel element.

The fuel matrix material is a relatively porous carbonaceous material that provides little holdup of the fission gases that are released from the fuel particles. The effect is generally neglected in calculations of fission gas transport in the fuel matrix as well as in the fuel block graphite. However, the fuel matrix has a high content of amorphous carbon, and this constituent of the matrix is highly sorptive of metallic fission products, especially strontium, europium, and actinides.

The graphite block of a prismatic fuel element, which is denser and has a more ordered structure than the fuel matrix material, is somewhat less sorptive of the fission metals than the matrix, but it is more effective as a diffusion barrier. The effectiveness of the graphite as a release barrier decreases as the temperature increases. Fission metals that escape the core in either a prismatic or pebble bed reactor will be sorbed into upper and lower graphite reflectors in addition to being deposited onto metallic surfaces as the primary coolant circulates through the system.

Events entailing ingress of moisture into the reactor can result in limited graphite oxidation and mobilization of fission products contained in the oxidized graphite. However, as discussed in Section 7.1.2.3, measures are taken to limit these effects.

\subsubsection{Helium Pressure Boundary}

The next transport and release barrier is the reactor HPB, which contains the primary circuit. Once the fission products have been transported from the core into the helium gas stream, they are transported throughout the primary circuit by the helium. The HPS controls chemical impurities in the helium, and efficiently removes gaseous fission products from the helium at a rate determined by the gas flow rate through the purification system. ${ }^{13}$

For the condensable fission products, the dominant removal mechanism is deposition ("plateout") on the various helium-wetted surfaces in the primary circuit. The plateout rate is determined by the mass transfer rates from the coolant to the fixed surfaces, by the sorptivities of the various materials of construction for the volatile fission products, and by the temperatures of the surfaces.

The circulating and plateout activities in the primary circuit are potential sources of release to the environment in the event of helium leaks or as a result of the venting of helium in response to over pressurization of the primary circuit due to water/steam ingress from an SG leak. A small fraction of the plateout near the leak location may be re-entrained, or "lifted off" if the rate of depressurization is sufficiently rapid.

Figure 14 shows a prismatic modular HTGR reactor, including the core, reactor internals, and vessel system. 


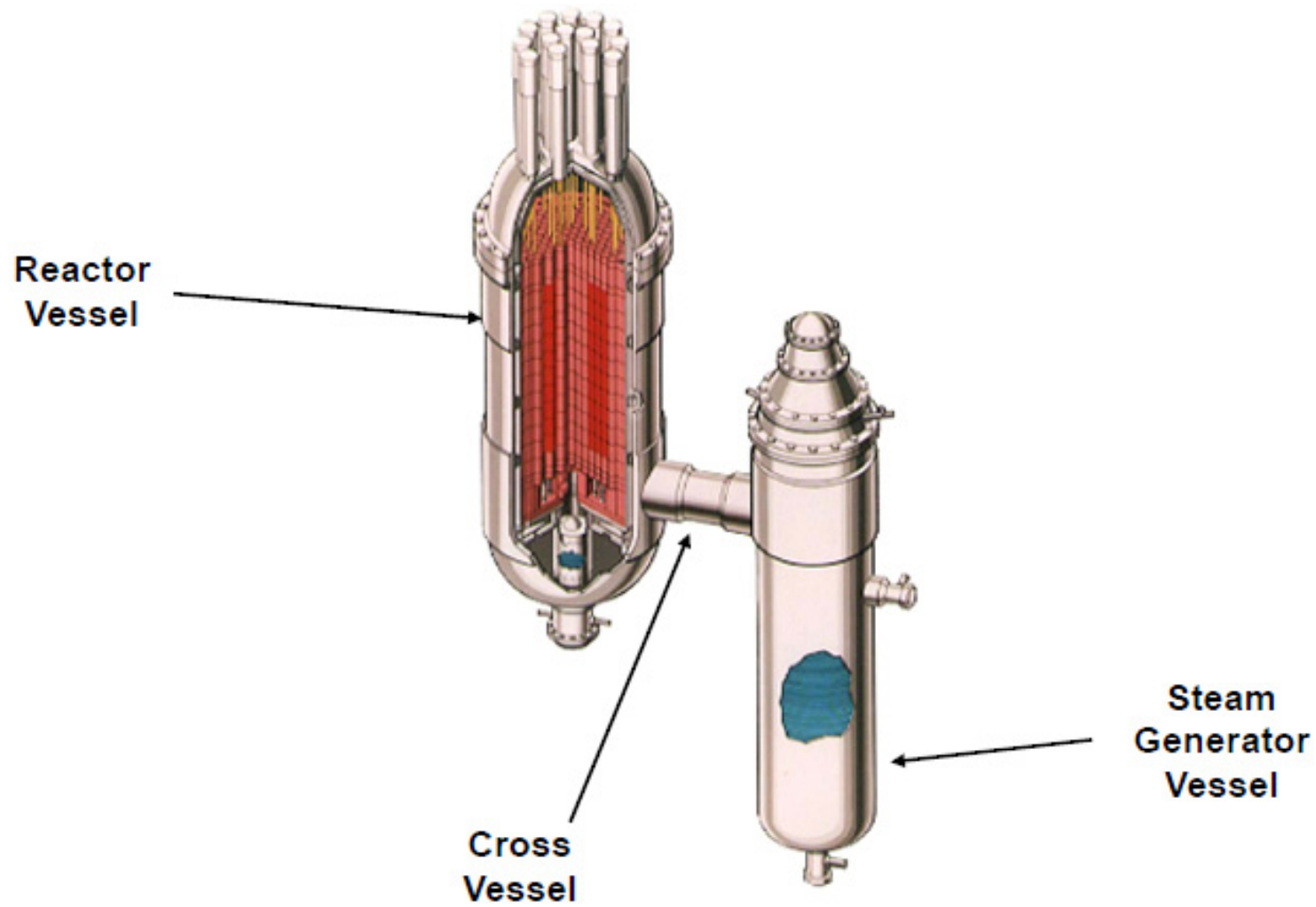

Figure 14. Prismatic Modular HTGR.

\subsubsection{Reactor Building}

The reactor building, which is below grade, is the final barrier to the transport and release of radionuclides to the environment. Its effectiveness as a release barrier is highly event specific. Typically, a vented low pressure reactor building is the baseline design for both prismatic and pebble bed modular HTGRs. Retention of radionuclides in the reactor building is influenced by several factors, including the extent to which the design of the building is compartmentalized, the action of the reactor building heating, ventilation, and air conditioning (HVAC) system, the action of the building overpressure relief system, and reactor building leakage. ${ }^{13}$

As previously noted, the functional containment safety design objective of a modular HTGR is to meet 10 CFR 50.34 (10 CFR 52.79) offsite dose requirements at the plant's exclusion area boundary $(\mathrm{EAB})$ with margins. This goal is typically achieved without taking credit for the radionuclide retention characteristics offered by the reactor building.

Figure 15 illustrates a typical reactor building. The reactor building consists of the structures shown in the figure as being below grade. 


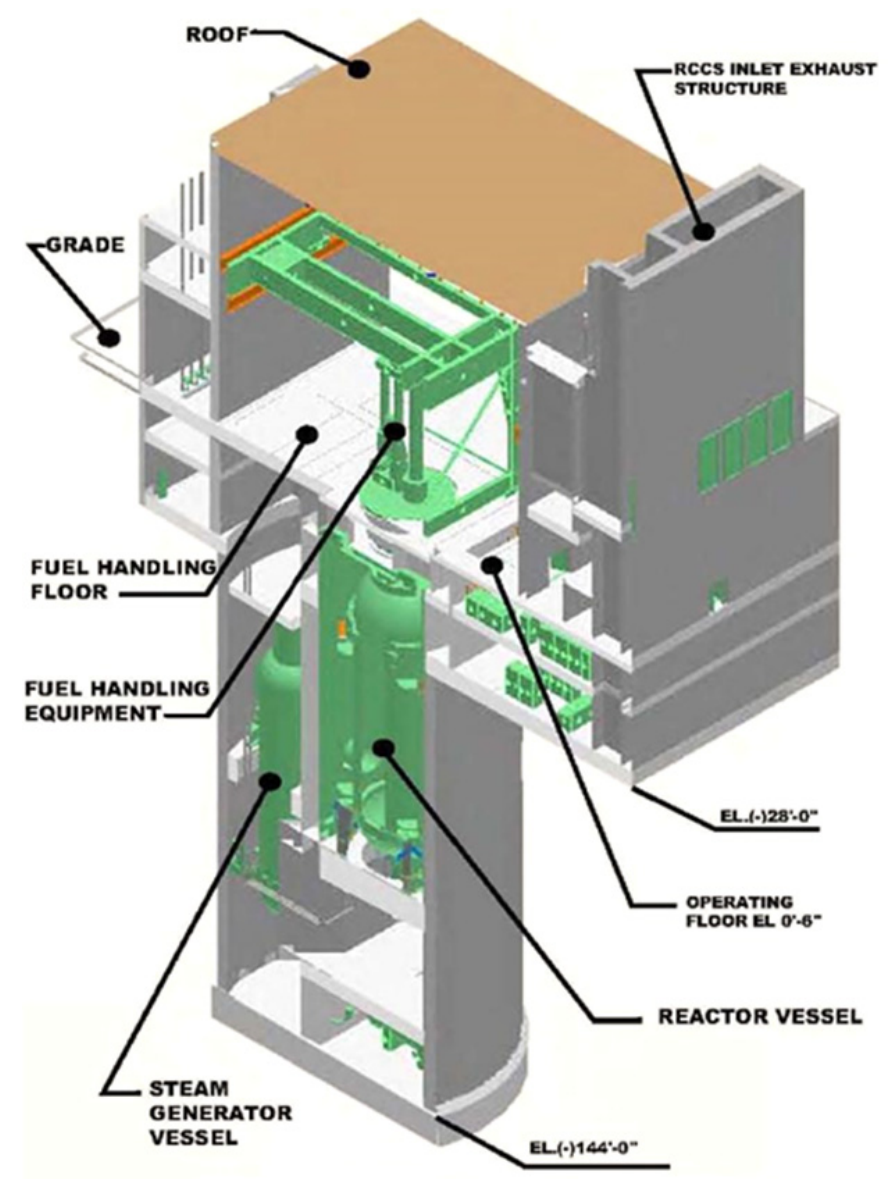

Figure 15. Typical Reactor Building.

\subsection{Proposed Modular HTGR Design Criteria - Summary of Insights and Significant Licensing Topics}

The ARDC developed under Section 5 (and as documented in Section 9.3) of this report have been further refined by adapting and applying them to a standard modular HTGR design concept. This was done to demonstrate how proposed adjustments to 10 CFR 50 Design Criteria for advanced non-LWRs can be translated into qualitative statements of design commitment as design-specific PDC.

\subsubsection{Overall Requirements (Modular HTGR Design Criteria 1 - 5)}

As noted by Section 5.3.1, this set of criteria can be generally applied as written for the advanced reactor technologies addressed by this report. For the modular HTGR, these criteria were left mostly unchanged as compared to the ARDC, with minor updates proposed to reflect specific differences in design and plant configuration.

As discussed in the "Modular HTGR Safety Basis and Approach" white paper, ${ }^{14}$ modular HTGRs are designed to passively remove residual and decay heat from the core regardless of whether the primary coolant is present. Passive heat removal is possible, in part, due to the core configuration. A relatively large length-to-diameter ratio of the core provides a large surface area for heat removal through the uninsulated steel reactor vessel. However, these desirable passive design characteristics limit the amount of output power an individual reactor module can produce. Therefore, it is expected most advanced 
HTGR designs will adopt multiple reactor modules to allow for scaling the overall plant capacity to match the specific market need.

GDC 5 establishes the functional requirements that provide assurance that SSCs can perform their safety functions independent of any other reactor units they may service. Modular HTGR-DC 5 revised the original GDC language to explicitly account for the multi-modular nature of expected advanced HTGR designs. The language was chosen to capture the importance of not sharing SSCs among modules or among module groups.

\subsubsection{Protection by Multiple Fission Product Barriers (Modular HTGR Design Criteria 10 - 19)}

GDC 10 for light water reactors (LWRs) states that, "The reactor core and associated coolant, control, and protection systems shall be designed with appropriate margin to ensure that specified acceptable fuel design limits (SAFDLs) are not exceeded during any condition of normal operation, including the effects of anticipated operation occurrences" (acronym added). Section 4.2 of the NRC Standard Review Plan for Light Water Reactors (NUREG-0800) provides information regarding how this particular criterion should be applied in LWR fuel system design. This information is LWR technology-specific and deals with fuel performance phenomena that are not found in modular HTGR fuel performance. As such, the modular HTGR design criteria that address fuel design limits must be appropriately adapted to reflect the underlying intent in preserving TRISO-coated fuel integrity during normal operations, including anticipated operational occurrences.

The need for a relevant fuel limit that can serve as a counterpart to the LWR SAFDL was noted by NRC staff during the course of assessing the prelicensing submittals made by the NGNP program. ${ }^{12}$

As discussed in Section 7.1.4 above, the modular HTGR fuel safety design approach seeks to control radionuclides primarily at the source, i.e., within the coated fuel particle, during normal operation and during accident conditions. To meet this objective, the TRISO-coated fuel is designed and manufactured to have extremely low levels of initial fabrication defects and to experience very low rates of subsequent incremental particle failure during normal and postulated accident conditions. This capability has demonstrated and continues to be confirmed through NGNP-related fuel qualification irradiation and safety tests. ${ }^{19}$

During modular HTGR operations, retention of radionuclides at their source (i.e., within the fuel particle) can be demonstrated by monitoring the level of circulating radionuclides in the helium coolant and the condensable radionuclide concentrations that plate out on surfaces within the reactor HPB. A low radionuclide inventory circulating in the helium provides an ongoing direct indication of the state of overall fuel particle integrity. The circulating and plated out radionuclide inventories can also be linked directly to the offsite dose projections for postulated accidents.

To address the need for a fuel performance limit that addresses the performance of coated particle fuel, acceptable design limits for modular HTGR fuel performance are characterized in terms of directly measurable core radionuclide release from the core to within the reactor helium pressure boundary. The term chosen to represent the modular HTGR fuel performance limit is "specified acceptable core radionuclide release design limit (SARRDL)." This new limit was incorporated into all modular HTGR design criteria in which reference is made to the LWR-based specified acceptable fuel design limit (SAFDL).

The SARRDL is a limit for modular HTGR fuel performance that is directly related to potential offsite dose consequences of postulated accidents. It is a limit on gaseous radionuclide inventory in the 
helium coolant and condensable radionuclide inventory on the surfaces within the helium pressure boundary (HPB) that is not to be exceeded during normal operation and anticipated operational occurrences. These radionuclide inventories are measured by collecting and analyzing helium coolant samples and by analyzing instruments removed from selected locations within the HPB. The values are set to ensure that calculated offsite doses do not exceed regulatory requirements at the Exclusion Area Boundary for each of the most limiting LBEs. The values are established, for LBEs involving a breach of the helium pressure boundary, taking into account the contributions to offsite dose from release of the gaseous radionuclide inventory in the helium, a fraction of the condensable radionuclide inventory within the reactor HPB, and, for LBEs also involving core heatup, a delayed release of a fraction of the radionuclide inventory in the reactor core.

The SARRDL is proposed as an alternative to the SAFDL that aligns with the modular HTGR safety basis and the role played by TRISO-coated particle fuel. The quantitative value of the SARRDL will be design specific and remains to be established by modular HTGR designers and formally endorsed by the NRC staff. The use of the SARRDL as a fuel performance limit will meet the underlying safety intent of GDC 10 regarding reactor design.

The other modular HTGR design criteria in this group, i.e., modular HTGR-DC 11 - 19, were adapted from the ARDC proposed in Section 5 to reflect the design and configuration differences specific to the modular HTGR. The general ARDC language appearing in modular HTGR-DC 11 addresses the role associated systems may play in contributing to reactivity feedback, although no other systems are expected to be applicable in this respect. Modular HTGR-DC 14 implemented changes to the corresponding ARDC language to identify the reactor HPB as an alternative description for the coolant pressure boundary. This change was also made in all modular HTGR DCs where "coolant pressure boundary" was originally used. Proposed revisions include significant changes to GDC 17 (Electric Power Systems), which reflects the understanding that a modular HTGR design will rely only on D-C power during postulated accidents rather than both A-C and D-C power sources.

\subsubsection{Protection and Reactivity Control Systems (Modular HTGR Design Criteria 20 - 29)}

As discussed in the "Modular HTGR Safety Basis and Approach" white paper, ${ }^{14}$ Page 18 , control of modular HTGR heat generation is accomplished by a very large core negative temperature coefficient and two independent reactivity control systems. Control rods drop by gravity into the core upon loss of electrical power. An automatic positive control action initiated in response to various accidents, including reactivity initiated accidents, can also cause the rods to drop, or the event itself may cut the power supply. In addition, modular HTGRs have a redundant and diverse system (the reserve shutdown system) to drop borated graphite pellets by gravity into designated fuel element or reflector channels for reactivity control equivalent to rod insertion. Initiation of the latter system typically requires a positive control signal and an active protection system response. However, A-C power is not required for these functions.

Modular HTGR-DC 26 implemented changes to the corresponding ARDC language to provide the flexibility to allow for more than two reactivity control systems and to also allow any of the available reactivity control systems to provide the capability to keep the reactor subcritical under cold conditions.

The list of reactivity accidents in Modular HTGR-DC 28 was modified to include modular HTGR phenomena, such as reactor temperature changes, that could affect reactivity, including the effects of moisture ingress. These changes were made to reflect use of helium as a working fluid. As noted in Section 7.1.3, helium does not have the same safety significance or effect on core reactivity as water does in a traditional LWR design. 


\subsubsection{Fluid Systems (Modular HTGR Design Criteria 30 - 46)}

The LWR "reactor coolant pressure boundary" terminology and other similar system descriptions have been revised to reflect the cooling-related role played by the reactor HPB of modular HTGRs. While retention of primary circuit helium coolant is an important operational function for a modular HTGR, "core coverage" by the helium to protect core integrity and inhibit subsequent radionuclide release is not a required safety function. Sufficient core cooling is provided by another cooling system separate, distinct, and independent of the core. This system is called the RCCS, and is designed to function as intended even in the event all helium coolant pressure and circulation capability is lost. (See Section 7.1 additional information concerning the heat removal path to the ultimate heat sink.) Because the required safety function of the modular HTGR VS is to provide structural support for the reactor core and maintain geometry adequate for passive heat removal via radiation and conduction, the modular HTGR design criteria dealing with fluid systems had to be modified to emphasize these design attributes.

As with an LWR, a modular HTGR utilizes multiple methods of core heat removal. During normal operations, reactor cooling can be accomplished by utilizing the main loop cooling system, the shutdown cooling system (a non-safety related small circulator and heat exchanger located at the bottom of the reactor vessel), and by passive core cooling through the reactor vessel to the safety related RCCS. In the event that all forced cooling capabilities become unavailable, the overall modular HTGR core design (which employs a large length to diameter ratio reactor vessel and low core power density) ensures passive residual heat transfer and removal capability that maintains fuel temperatures below design objectives. Passive heat removal performance is achieved regardless of whether the primary reactor circuit is pressurized or depressurized.

Design of a passive RCCS that operates independent of forced core cooling systems is addressed by modular HTGR-DC 34 and is applicable for both normal and accident conditions. Reviewed design information indicated the RCCS will also keep other safety-related structures within allowable temperature limits, and while RCCS operation may be passive or active under normal conditions (depending on specific design details), the RCCS is always in passive mode under accident conditions. Reactor residual heat is transferred through uninsulated reactor vessel walls to the RCCS by conduction, natural convection, and radiative heat transfer. Because there is no need for a separate heat removal system in modular HTGRs dedicated to an "emergency core cooling" function as required in GDC 35 for LWRs, all safety related core RHR functions are consolidated into modular HTGR-DCs 34, 36, and 37.

The ARDC set forth in Criteria $38-46$ presume that a containment structure is used to provide a needed radionuclide retention function and address topics of containment heat removal, atmosphere cleanup, and cooling. However, there is no functional equivalent to a containment structure in a modular HTGR nor is there need to provide systems similar to those assuring containment structure integrity and safety performance. Available modular HTGR design information indicates buildup of combustible gas mixtures within the reactor building are not a source of hazard. While applicants must still demonstrate this condition through appropriate engineering analysis, a provision requiring the vented reactor building to have an atmospheric cleanup system is unnecessary. For these reasons, ARDC $38-46$ have been designated "not applicable" to the modular HTGR design.

\subsubsection{Reactor Containment (Modular HTGR Design Criteria 50 - 57)}

This group of design criteria addresses design of a reactor containment structure that supports limiting the release of radionuclides to the environment. Rather than using a containment structure to meet regulatory limits for radionuclide release, the modular HTGR relies upon a multi-barrier functional containment configuration (see Section 5.3.2) to control the release of radionuclides. This functional 
containment approach is made up of a collection of design selections that, when taken together, ensure radionuclides are retained within multiple and independent attenuation barriers with an emphasis on retention at the fuel source. These barriers are described in Section 7.1.2 of this report. Taken together, the functional containment system of a modular HTGR meets applicable NRC regulatory requirements and satisfies plant design goals concerning radionuclide release.

Additional information on modular HTGR functional containment can be found in the "Modular HTGR Safety Basis and Approach" white paper, ${ }^{14}$ and in a set of NGNP slides presented during an NRC public meeting in July $2012 .^{20}$

The upper tier performance standard for the modular HTGR functional containment is to ensure the integrity of fuel particle barriers (i.e., the kernel and coatings of the TRISO-coated fuel particles). This standard is met by ensuring no LBE can lead to conditions that result in significant fuel particle failure. Compliance with that standard is confirmed by monitoring the following characteristics:

- Ensuring radionuclide retention within fuel during normal operation by confirming a relatively low radionuclide inventory release into the helium pressure boundary (HPB).

- Limiting radionuclide releases to the environs to meet the onsite and offsite radionuclide dose acceptance criteria at the exclusion area boundary $(\mathrm{EAB})$ with adequate margin for a wide spectrum of off-normal events.

- Maintaining a capability to establish controlled leakage and controlled release of delayed accident source term radionuclides.

Additional advanced reactor containment functional performance standards were identified by NRC staff in SECY-05-0006. These standards indicate the following accident prevention and mitigation safety functions should also be either directly or indirectly provided:

- Protect risk-significant SSCs from internal and external events.

- Physically support risk-significant SSCs.

- Protect onsite workers from radiation.

- Remove heat to prevent risk-significant SSCs from exceeding design or safety limits.

- Provide physical protection (i.e., security) for risk-significant SSCs.

The existing GDC 50 - 57, as well as the proposed ARDC 50-57, have no functional counterpart or operational equivalent in the modular HTGR design when satisfying the above functional performance standards. As such, they are determined to be not applicable. Rather, the functional containment performance standards above are achieved by the application of other design criteria that specifically address TRISO-coated particle fuel integrity and protecting the passive heat removal pathway from the fuel to the ultimate heat sink. These functions are accomplished by design decisions derived from the application of the following proposed modular HTGR design criteria:

- mHTGR-DC 10 - Reactor Design

- mHTGR-DC 15 - Reactor Helium Pressure Boundary

- mHTGR-DC 16 - Containment Design

- $\quad$ mHTGR-DC 34 - Passive Residual Heat Removal

- mHTGR-DC 70 - Reactor Vessel and Reactor System Structural Design Basis

- mHTGR-DC 71 - Reactor Building Design Basis. 
It should be noted that the functional containment design goal of a modular HTGR is to meet 10 CFR 50.34 (10 CFR 52.79) offsite dose requirements at the plant's EAB with margin. This goal will be achieved without taking credit for the radionuclide retention characteristics offered by the reactor building. Thus, the proposed modular HTGR DCs associated with functional containment performance and related radionuclide retention capabilities need not include the reactor building as a necessary radionuclide release barrier component. Section 7.1.4.5 of this report provides further discussion of the reactor building.

\subsubsection{Fuel and Radioactivity Control (Modular HTGR Design Criteria 60 - 64)}

The overall requirements described in this set of criteria associated with the control and monitoring of releases of radioactivity to the environment and requirements associated with fuel storage, monitoring, and handling were generally applicable to modular HTGRs, with minor updates proposed to reflect the modular HTGR design type.

ARDC 61 (Fuel Storage and Handling and Radioactivity Control) includes some modified wording (relative to the original GDC) to allow for the possibility that some advanced design fuel storage systems may use dry fuel storage. The original GDC wording specifying the need to maintain a "coolant inventory" would not apply for these designs. In this case, no further adjustments were needed to accommodate modular HTGR designs, and the ARDC language was adopted.

Brackets were used in ARDC 64 (Monitoring Reactivity Releases) to allow for some flexibility in identifying areas where monitoring for radioactivity releases is needed. The modular HTGR version of this criterion was generalized to reflect the modular HTGR's different design configuration and functional containment arrangement.

\subsubsection{New Design Criteria Proposed for Modular HTGRs (Modular HTGR Design Criteria 70 - 72)}

Modular HTGRs do not have a traditional LWR "reactor containment structure," but instead rely on a multi-barrier functional containment configuration to control the release of radionuclides. In addition to the new criteria identified in this set, other functional containment design requirements are addressed by proposed modular HTGR-DC 10 (Reactor Design), 15 (Reactor Helium Pressure Boundary Design), 16 (Functional Containment Design), and 34 (Passive Residual Heat Removal).

Modular HTGR design criterion 70 was added to address the roles of the Reactor Vessel and Reactor System in maintaining the internal geometry necessary for passive removal of residual heat and neutron absorber insertion.

Modular HTGR design criteria 71 and 72 were added to address the design basis and periodic inspection and surveillance requirements for the Reactor Building to ensure it provides its safety function of protecting and maintaining the necessary geometry for the passive removal of residual heat and providing a discharge pathway for helium depressurization events. 


\section{REFERENCES}

1. NRC Report to Congress: Advanced Reactor Licensing, August 2012, ML12153A014.

2. U.S. Nuclear Regulatory Commission's "Policy Statement on the Regulation of Advanced Reactors" (73 Fed. Reg. 60612, October 14, 2008).

3. NRC Letter to J. Kelly (DOE) - Initiative Regarding U.S. Nuclear Regulatory Commission Licensing Strategy For Advanced Reactor Technologies, July 9, 2013, ML13141A276.

4. NUREG-1368, "Preapplication Safety Evaluation Report for PRISM LMR," February 1994.

5. General Electric, "PRISM - Preliminary Safety Information Document", GEFR-00793, UC-87Ta, San Jose, CA, 1987.

6. C. Boardman, et. al., "Containment Performance of S-PRISM under Severe Beyond Design Basis Conditions" 9th International Conference on Nuclear Engineering, Paris, France, April 2001.

7. C. Boardman, et. al., GE Nuclear Energy Division, "A Description of the S-PRISM Plant," 8th International Conference on Nuclear Engineering, Baltimore, MD, April 2000.

8. U.S. Nuclear Regulatory Commission, "Preapplication Safety Evaluation Report for the Sodium Advanced Fast Reactor (SAFR) Liquid-Metal Reactor," NUREG-1369, December 1991, ML063410561.

9. DOE-HTGR-86-024, "Preliminary Safety Information Document for the Standard MHTGR," Amendment 13, August 7, 1992.

10. NUREG-1338 (draft), "Draft Preapplication Safety Evaluation Report for the Modular HighTemperature Gas-Cooled Reactor," March 1989.

11. NUREG-1338, "Preapplication Safety Evaluation Report for the Modular High-Temperature GasCooled Reactor (MHTGR)," December 1995.

12. "Next Generation Nuclear Plant - Assessment of Key Licensing Issues," U.S. Nuclear Regulatory Commission, July 17, 2014, ML14174A734 (Enclosure 1: ML14174A774) (Enclosure 2: ML14174A845).

13. "Mechanistic Source Terms White Paper," Idaho National Laboratory, INL/EXT-10-17997, Rev.0, July 2010, ML102040260.

14. "Modular HTGR Safety Basis and Approach," Idaho National Laboratory, INL/EXT-13-30872, January 2014.

15. "Next Generation Nuclear Plant Defense-in-Depth Approach," Idaho National Laboratory, INL/EXT09-17319, December 2009, ML093480191.

16. "NGNP Nuclear Heat Source System Boundaries and Interfaces," AREVA Engineering Information Record, 51-9105936-001, Section 8.5, September 30, 2008.

17. "Compilation of Fuel Performance and Fission Product Transport Models and Database for MHTGR Design," Oak Ridge National Laboratory, ORNL/NPR-91/6, October 1993.

18. “NGNP Fuel Qualification White Paper,” Idaho National Laboratory, INL/EXT-10-17686, July 2010, ML102040261. 
19. PLN-3636, 2014, "Technical Program Plan for the Very High Temperature Reactor Technology Development Office/Advanced Gas Reactor Fuel Development and Qualification Program,"

INL/MIS-10-20662, Rev. 3, Very High Temperature Reactor Technology Development Office, May 2014.

20. "NRC Public Meeting - NGNP Functional Containment," Slides presented to NRC, July 11, 2012, ML12223A151. 


\section{PROPOSED DESIGN CRITERIA}

\subsection{Proposed Advanced Reactor Design Criteria}

\begin{tabular}{|c|c|c|c|}
\hline \multicolumn{4}{|c|}{ I. Overall Requirements } \\
\hline Criterion & Current GDC Language & Proposed ARDC Language & Rationale for Modification \\
\hline 1 & $\begin{array}{l}\text { Quality standards and records. } \\
\text { Structures, systems, and components important } \\
\text { to safety shall be designed, fabricated, erected, } \\
\text { and tested to quality standards commensurate } \\
\text { with the importance of the safety functions to be } \\
\text { performed. Where generally recognized codes } \\
\text { and standards are used, they shall be identified } \\
\text { and evaluated to determine their applicability, } \\
\text { adequacy, and sufficiency and shall be } \\
\text { supplemented or modified as necessary to } \\
\text { assure a quality product in keeping with the } \\
\text { required safety function. A quality assurance } \\
\text { program shall be established and implemented in } \\
\text { order to provide adequate assurance that these } \\
\text { structures, systems, and components will } \\
\text { satisfactorily perform their safety functions. } \\
\text { Appropriate records of the design, fabrication, } \\
\text { erection, and testing of structures, systems, and } \\
\text { components important to safety shall be } \\
\text { maintained by or under the control of the nuclear } \\
\text { power unit licensee throughout the life of the unit. }\end{array}$ & Same as GDC & \\
\hline 2 & $\begin{array}{l}\text { Design bases for protection against natural } \\
\text { phenomena. } \\
\text { Structures, systems, and components important } \\
\text { to safety shall be designed to withstand the } \\
\text { effects of natural phenomena such as } \\
\text { earthquakes, tornadoes, hurricanes, floods, } \\
\text { tsunami, and seiches without loss of capability to } \\
\text { perform their safety functions. The design bases } \\
\text { for these structures, systems, and components } \\
\text { shall reflect: (1) Appropriate consideration of the } \\
\text { most severe of the natural phenomena that have } \\
\text { been historically reported for the site and } \\
\text { surrounding area, with sufficient margin for the } \\
\text { limited accuracy, quantity, and period of time in } \\
\text { which the historical data have been accumulated, } \\
\text { (2) appropriate combinations of the effects of } \\
\text { normal and accident conditions with the effects of }\end{array}$ & Same as GDC & \\
\hline
\end{tabular}


3 Fire protection

Structures, systems, and components important to safety shall be designed and located to minimize, consistent with other safety requirements, the probability and effect of fires and explosions. Noncombustible and heat resistant materials shall be used wherever practical throughout the unit, particularly in locations such as the containment and control room. Fire detection and fighting systems of appropriate capacity and capability shall be provided and designed to minimize the adverse effects of fires on structures, systems, and components important to safety. Firefighting systems shall be designed to assure that their rupture or inadvertent operation does not significantly impair the safety capability of these structures, systems, and components.

$4 \quad$ Environmental and dynamic effects design bases.

Structures, systems, and components important to safety shall be designed to accommodate the effects of and to be compatible with the environmental conditions associated with normal operation, maintenance, testing, and postulated accidents, including loss-of-coolant accidents.

These structures, systems, and components shall be appropriately protected against dynamic effects, including the effects of missiles, pipe whipping, and discharging fluids, that may result from equipment failures and from events and conditions outside the nuclear power unit. However, dynamic effects associated with postulated pipe ruptures in nuclear power units may be excluded from the design basis when analyses reviewed and approved by the Commission demonstrate that the probability of fluid system piping rupture is extremely low under conditions consistent with the design basis for the piping.

\section{Fire protection.}

Structures, systems, and components important to safety shall be designed and located to minimize, consistent with other safety requirements, the probability and effect of fires and explosions.

Noncombustible and heat resistant materials shall be used wherever practical throughout the unit[,

\section{particularly in locations such as the containment} and control room]. Fire detection and fighting systems of appropriate capacity and capability shall be provided and designed to minimize the adverse effects of fires on structures, systems, and components important to safety. Firefighting systems shall be designed to assure that their rupture or inadvertent operation does not significantly impair the safety capability of these structures, systems, and components.

\section{Environmental and dynamic effects design bases.} Structures, systems, and components important to safety shall be designed to accommodate the effects of and to be compatible with the environmental conditions associated with normal operation, maintenance,

testing, and postulated accidents, including loss of coolant accidents. These structures, systems, and components shall be appropriately protected against dynamic effects, including the effects of missiles, pipe whipping, and discharging fluids, that may result from equipment failures and from events and conditions outside the nuclear power unit. However, dynamic effects associated with postulated pipe ruptures in nuclear power units may be excluded from the design basis when analyses reviewed and approved by the Commission demonstrate that the probability of fluid system piping rupture is extremely low under conditions consistent with the design basis for the piping.

\section{Rationale for Modification}

Brackets have been added around certain text to identify portions of original GDC language where advanced designs may need to provide alternative descriptions to address underlying criterion requirements.

\section{Edit removes an LWR emphasis on LOCAs}

that may not apply to some designs. For example, helium is not needed in an HTGR to remove heat from the core during postulated accidents and does not have the same importance as water does to LWR designs to assure that fuel integrity is maintained. Therefore, a specific reference to "loss of coolant accidents" is not applicable to all designs. LOCAs may still require analysis in conjunction with postulated accidents if relevant to the design. 


\begin{tabular}{|c|l|l|l|}
\hline \multicolumn{2}{|c|}{ I. Overall Requirements } \\
\hline Criterion & Current GDC Language & Proposed ARDC Language & Rationale for Modification \\
\hline 5 & $\begin{array}{l}\text { Sharing of structures, systems, and components. } \\
\text { Structures, systems, and components important } \\
\text { to safety shall not be shared among nuclear }\end{array}$ & Same as GDC & \\
& $\begin{array}{l}\text { power units unless it can be shown that such } \\
\text { sharing will not significantly impair their ability to } \\
\text { perform their safety functions, including, in the } \\
\text { event of an accident in one unit, an orderly } \\
\text { shutdown and cooldown of the remaining units. }\end{array}$ & & \\
\hline
\end{tabular}

\begin{tabular}{|c|c|c|c|}
\hline \multicolumn{4}{|c|}{ II. Multiple Barriers } \\
\hline Criterion & Current GDC Language & Proposed ARDC Language & Rationale for Modification \\
\hline 10 & $\begin{array}{l}\text { Reactor design. } \\
\text { The reactor core and associated coolant, control, } \\
\text { and protection systems shall be designed with } \\
\text { appropriate margin to assure that specified } \\
\text { acceptable fuel design limits are not exceeded } \\
\text { during any condition of normal operation, } \\
\text { including the effects of anticipated operational } \\
\text { occurrences. }\end{array}$ & $\begin{array}{l}\text { Reactor Design. } \\
\text { The reactor core and associated [coolant], control, } \\
\text { and protection systems shall be designed with } \\
\text { appropriate margin to assure that specified acceptable } \\
\text { fuel design limits are not exceeded during any } \\
\text { condition of normal operation, including the effects of } \\
\text { anticipated operational occurrences. }\end{array}$ & $\begin{array}{l}\text { Criterion addresses design margins during } \\
\text { normal ops and AOOs. } \\
\text { Brackets have been added around "coolant" to } \\
\text { identify a portion of original GDC language } \\
\text { where advanced designs may need to provide } \\
\text { alternative descriptions to address underlying } \\
\text { criterion requirements. This consideration is } \\
\text { important to designs such as the mHTGRs. }\end{array}$ \\
\hline 11 & $\begin{array}{l}\text { Reactor inherent protection. } \\
\text { The reactor core and associated coolant systems } \\
\text { shall be designed so that in the power operating } \\
\text { range the net effect of the prompt inherent } \\
\text { nuclear feedback characteristics tends to } \\
\text { compensate for a rapid increase in reactivity. }\end{array}$ & $\begin{array}{l}\text { Reactor inherent protection. } \\
\text { The reactor core and associated coolant systems that } \\
\text { contribute to reactivity feedback shall be designed so } \\
\text { that in the power operating range the net effect of the } \\
\text { prompt inherent nuclear feedback characteristics tends } \\
\text { to compensate for a rapid increase in reactivity. }\end{array}$ & $\begin{array}{l}\text { Wording changed to broaden applicability from } \\
\text { "coolant systems" to additional factors } \\
\text { (including structures or other fluids) that may } \\
\text { contribute to reactivity feedback; these } \\
\text { systems are to be designed to compensate for } \\
\text { rapid reactivity increase. }\end{array}$ \\
\hline 12 & $\begin{array}{l}\text { Suppression of reactor power oscillations. } \\
\text { The reactor core and associated coolant, control, } \\
\text { and protection systems shall be designed to } \\
\text { assure that power oscillations which can result in } \\
\text { conditions exceeding specified acceptable fuel } \\
\text { design limits are not possible or can be reliably } \\
\text { and readily detected and suppressed. }\end{array}$ & $\begin{array}{l}\text { Suppression of reactor power oscillations. } \\
\text { The reactor core and associated [coolant], control, } \\
\text { and protection systems shall be designed to assure } \\
\text { that power oscillations which can result in conditions } \\
\text { exceeding specified acceptable fuel design limits are } \\
\text { not possible or can be reliably and readily detected and } \\
\text { suppressed. }\end{array}$ & $\begin{array}{l}\text { Brackets have been added around "coolant" to } \\
\text { identify a portion of original GDC language } \\
\text { where advanced designs may need to provide } \\
\text { alternative descriptions to address underlying } \\
\text { criterion requirements. } \\
\text { Helium lacks influence in modular HTGR } \\
\text { power oscillations but SFR reactor coolant } \\
\text { may contribute to power oscillations. Criterion } \\
\text { applies to both technologies according to the } \\
\text { respective design factors that influence power } \\
\text { oscillations. }\end{array}$ \\
\hline
\end{tabular}




\begin{tabular}{|c|c|c|c|}
\hline \multicolumn{4}{|c|}{ II. Multiple Barriers } \\
\hline Criterion & Current GDC Language & Proposed ARDC Language & Rationale for Modification \\
\hline 13 & $\begin{array}{l}\text { Instrumentation and control. } \\
\text { Instrumentation shall be provided to monitor } \\
\text { variables and systems over their anticipated } \\
\text { ranges for normal operation, for anticipated } \\
\text { operational occurrences, and for accident } \\
\text { conditions as appropriate to assure adequate } \\
\text { safety, including those variables and systems that } \\
\text { can affect the fission process, the integrity of the } \\
\text { reactor core, the reactor coolant pressure } \\
\text { boundary, and the containment and its } \\
\text { associated systems. Appropriate controls shall be } \\
\text { provided to maintain these variables and systems } \\
\text { within prescribed operating ranges }\end{array}$ & $\begin{array}{l}\text { Instrumentation and control. } \\
\text { Instrumentation shall be provided to monitor variables } \\
\text { and systems over their anticipated ranges for normal } \\
\text { operation, for anticipated operational occurrences, and } \\
\text { for accident conditions as appropriate to assure } \\
\text { adequate safety, including those variables and } \\
\text { systems that can affect the fission process, the } \\
\text { integrity of the reactor core, [the reactor coolant } \\
\text { pressure boundary, and the containment and its } \\
\text { associated systems]. Appropriate controls shall be } \\
\text { provided to maintain these variables and systems } \\
\text { within prescribed operating ranges. }\end{array}$ & $\begin{array}{l}\text { The ARDC is interpreted with a generic intent } \\
\text { for application and encompasses all } \\
\text { appropriate safety systems. } \\
\text { Brackets have been added around certain text } \\
\text { to identify portions of original GDC language } \\
\text { where advanced designs may need to provide } \\
\text { alternative descriptions to address underlying } \\
\text { criterion requirements. }\end{array}$ \\
\hline 14 & $\begin{array}{l}\text { Reactor coolant pressure boundary. } \\
\text { The reactor coolant pressure boundary shall be } \\
\text { designed, fabricated, erected, and tested so as to } \\
\text { have an extremely low probability of abnormal } \\
\text { leakage, of rapidly propagating failure, and of } \\
\text { gross rupture. }\end{array}$ & $\begin{array}{l}\text { Reactor [coolant pressure] boundary. } \\
\text { The reactor [coolant pressure] boundary shall be } \\
\text { designed, fabricated, erected, and tested so as to have } \\
\text { an extremely low probability of abnormal leakage, of } \\
\text { rapidly propagating failure, and of gross rupture. }\end{array}$ & $\begin{array}{l}\text { Brackets have been added around "coolant } \\
\text { pressure" to identify portions of original GDC } \\
\text { language where advanced designs may need } \\
\text { to provide alternative descriptions to address } \\
\text { underlying criterion requirements. }\end{array}$ \\
\hline 15 & $\begin{array}{l}\text { Reactor coolant system design. } \\
\text { The reactor coolant system and associated } \\
\text { auxiliary, control, and protection systems shall be } \\
\text { designed with sufficient margin to assure that the } \\
\text { design conditions of the reactor coolant pressure } \\
\text { boundary are not exceeded during any condition } \\
\text { of normal operation, including anticipated } \\
\text { operational occurrences. }\end{array}$ & $\begin{array}{l}\text { Reactor [coolant] system design. } \\
\text { The reactor [coolant] system and associated auxiliary, } \\
\text { control, and protection systems shall be designed with } \\
\text { sufficient margin to assure that the design conditions of } \\
\text { the reactor [coolant pressure] boundary are not } \\
\text { exceeded during any condition of normal operation, } \\
\text { including anticipated operational occurrences. }\end{array}$ & $\begin{array}{l}\text { The design of the advanced reactor equivalent } \\
\text { to the reactor coolant system boundary is } \\
\text { addressed in ARDC } 14 \text {. ARDC } 15 \text { addresses } \\
\text { protection of the advanced reactor equivalent } \\
\text { to the reactor coolant system during normal } \\
\text { ops and AOOs. } \\
\text { Brackets have been added around "coolant" } \\
\text { and "coolant pressure" to identify portions of } \\
\text { original GDC language where advanced } \\
\text { designs may need to provide alternative } \\
\text { descriptions to address underlying criterion } \\
\text { requirements. }\end{array}$ \\
\hline 16 & $\begin{array}{l}\text { Containment design. } \\
\text { Reactor containment and associated systems } \\
\text { shall be provided to establish an essentially leak- } \\
\text { tight barrier against the uncontrolled release of } \\
\text { radioactivity to the environment and to assure } \\
\text { that the containment design conditions important } \\
\text { to safety are not exceeded for as long as } \\
\text { postulated accident conditions require. }\end{array}$ & $\begin{array}{l}\text { Containment design. } \\
\text { A rReactor functional containment, and associated } \\
\text { systems consisting of a structure surrounding the } \\
\text { reactor and its cooling system or multiple barriers } \\
\text { internal and/or external to the reactor and its cooling } \\
\text { system, shall be provided to establish an essentially } \\
\text { leak-tight barrier against the uncontrolled control the } \\
\text { release of radioactivity to the environment and to } \\
\text { assure that the functional containment design } \\
\text { conditions important to safety are not exceeded for as }\end{array}$ & $\begin{array}{l}\text { To clarify criterion applicability in advanced } \\
\text { reactors without a containment structure, } \\
\text { wording is modified to adopt a "functional } \\
\text { containment" design philosophy. } \\
\text { Functional Containment is defined as: A } \\
\text { barrier, or set of barriers taken together, that } \\
\text { effectively limit the physical transport and } \\
\text { release of radionuclides to the environment } \\
\text { across a full range of normal operating }\end{array}$ \\
\hline
\end{tabular}




\begin{tabular}{|c|c|c|c|}
\hline \multicolumn{4}{|c|}{ II. Multiple Barriers } \\
\hline Criterion & Current GDC Language & Proposed ARDC Language & Rationale for Modification \\
\hline & & long as postulated accident conditions require. & $\begin{array}{l}\text { conditions, anticipated operational } \\
\text { occurrences, and accident conditions. } \\
\text { Functional containment is relied upon to } \\
\text { ensure that dose at the site boundary as a } \\
\text { consequence of postulated accidents meets } \\
\text { regulatory limits. } \\
\text { This definition advances a Commission } \\
\text { expectation that advanced reactor designs } \\
\text { consider incorporating "...defense-in-depth } \\
\text { philosophy by maintaining multiple barriers } \\
\text { against radiation release..." (NRC's Final } \\
\text { Policy Statement on Advanced Reactors, } 59 \\
\text { FR } 35461 \text { ). The NRC staff has provided } \\
\text { feedback regarding the multi-barrier functional } \\
\text { containment approach in its recent } \\
\text { assessment activities associated with NGNP } \\
\text { in: "NGNP - Assessment of Key Licensing } \\
\text { Issues", ML14174A734 (enclosure } 1 \text { - } \\
\text { ML14174A7740). } \\
\text { "...essentially leak-tight..." is replaced by } \\
\text { "...effective barrier..." to describe a flexible } \\
\text { containment function for concepts that may } \\
\text { rely on acceptable design condition leak rates. } \\
\text { This accommodates the HTGR serial } \\
\text { attenuation barriers and containment building } \\
\text { barrier approaches. }\end{array}$ \\
\hline 17 & $\begin{array}{l}\text { Electric power systems. } \\
\text { An onsite electric power system and an offsite } \\
\text { electric power system shall be provided to permit } \\
\text { functioning of structures, systems, and } \\
\text { components important to safety. The safety } \\
\text { function for each system (assuming the other } \\
\text { system is not functioning) shall be to provide } \\
\text { sufficient capacity and capability to assure that } \\
\text { (1) specified acceptable fuel design limits and } \\
\text { design conditions of the reactor coolant pressure } \\
\text { boundary are not exceeded as a result of } \\
\text { anticipated operational occurrences and (2) the } \\
\text { core is cooled and containment integrity and } \\
\text { other vital functions are maintained in the event }\end{array}$ & $\begin{array}{l}\text { Electric power systems. } \\
\text { An onsite eElectric power systems and an offsite } \\
\text { electric power system shall be provided to permit } \\
\text { functioning of structures, systems, and components } \\
\text { important to safety. The safety function for the each } \\
\text { systems (assuming the other system is not functioning) } \\
\text { shall be to provide sufficient capacity, and capability, } \\
\text { and reliability to assure that (1) specified acceptable } \\
\text { fuel design limits and design conditions of the reactor } \\
\text { [coolant pressure] boundary are not exceeded as a } \\
\text { result of anticipated operational occurrences and (2) } \\
\text { the core is cooled and the containment integrity and } \\
\text { other vital functions that rely on electric power are } \\
\text { maintained in the event of postulated accidents. }\end{array}$ & $\begin{array}{l}\text { A reliable power system is required for SSCs } \\
\text { during postulated accident conditions. The } \\
\text { emphasis of the ARDC is placed on requiring } \\
\text { reliability of power sources rather than } \\
\text { prescribing how such reliability can be } \\
\text { attained. } \\
\text { Reference to onsite vs. offsite electric power } \\
\text { systems is deleted from the first paragraph to } \\
\text { provide for those reactor designs that do not } \\
\text { depend on offsite power to provide for } \\
\text { functioning of SSCs important to safety. } \\
\text { These power systems shall be sufficient in }\end{array}$ \\
\hline
\end{tabular}


\begin{tabular}{c|c} 
Criterion & Current GDC Language
\end{tabular}

of postulated accidents.

The onsite electric power supplies, including the batteries, and the onsite electric distribution system, shall have sufficient independence, redundancy, and testability to perform their safety functions assuming a single failure.

Electric power from the transmission network to the onsite electric distribution system shall be supplied by two physically independent circuits (not necessarily on separate rights of way) designed and located so as to minimize to the extent practical the likelihood of their simultaneous failure under operating and postulated accident and environmental conditions. A switchyard common to both circuits is acceptable. Each of these circuits shall be designed to be available in sufficient time following a loss of all onsite alternating current power supplies and the other offsite electric power circuit, to assure that specified acceptable fuel design limits and design conditions of the reactor coolant pressure boundary are not exceeded. One of these circuits shall be designed to be available within a few seconds

following a loss-of-coolant accident to assure that core cooling, containment integrity, and other vital safety functions are maintained.

Provisions shall be included to minimize the probability of losing electric power from any of the remaining supplies as a result of, or coincident with, the loss of power generated by the nuclear power unit, the loss of power from the transmission network, or the loss of power from the onsite electric power supplies.

18 Inspection and testing of electric power systems. Electric power systems important to safety shall be designed to permit appropriate periodic inspection and testing of important areas and features, such as wiring, insulation, connections,

\section{Proposed ARDC Language}

The onsite electric power systemssupplies, including

the batteries, and the onsite electric distribution

system, shall have sufficient independence,

redundancy, and testability to perform their safety

functions, assuming a single failure.

Electric power from the transmission network to the ensite electric distribution system shall be supplied by two physically independent circuits (not necessarily on separate rights of way) designed and located so as to minimize to the extent practical the likelihood of their simultaneous failure under operating and postulated accident and environmental conditions. A switchyare common to both circuits is acceptable. Each of these circuits shall be designed to be available in sufficient time following a loss of all onsite alternating current power supplies and the other offsite electric power circuit, to assure that specified acceptable fuel design

limits and design conditions of the reactor coolant pressure boundary are not exceeded. One of these circuits shall be designed to be available within a few seconds following a loss-of-coolant accident to assure that core cooling, containment integrity, and other vita safety functions are maintained.

Provisions shall be included to minimize the probability of losing electric power from any of the remaining supplies as a result of, or coincident with, the loss of power generated by the nuclear power unit, the loss of power from the transmission network, or the loss of power from the onsite electric power supplies.

Inspection and testing of electric power systems. Electric power systems important to safety shall be designed to permit appropriate periodic inspection and testing of important areas and features, such as wiring, insulation, connections, and switchboards, to assess

\section{Rationale for Modification}

capacity, capability, and reliability to assure vital safety functions are maintained.

Text related to "...supplies, including batteries, and the onsite distribution system," was deleted to allow increased flexibility regarding advanced reactor designs. However, it is still expected such onsite systems must remain capable of performing assigned safety functions during accidents as a condition of requisite reliability

Brackets have been added around "coolant pressure" to identify a portion of original GDC language where advanced designs may need to provide alternative descriptions to address underlying criterion requirements.

The existing single switchyard allowance remains available under ARDC-17. If a particular advanced design requires use of GDC single switchyard allowance wording, the designer should look to GDC-17 for guidance when developing PDC.

Brackets have been added around certain text to identify portions of original GDC language where advanced designs may need to provide alternative descriptions to address underlying criterion requirements. 


\section{Criterion Current GDC Language}

and switchboards, to assess the continuity of the systems and the condition of their components.

The systems shall be designed with a capability

to test periodically (1) the operability and

functional performance of the components of the systems, such as onsite power sources, relays, switches, and buses, and (2) the operability of the systems as a whole and, under conditions as close to design as practical, the full operation sequence that brings the systems into operation, including operation of applicable portions of the protection system, and the transfer of power among the nuclear power unit, the offsite power system, and the onsite power system.

19 Control room.

A control room shall be provided from which actions can be taken to operate the nuclear power unit safely under normal conditions and to maintain it in a safe condition under accident conditions, including loss-of-coolant accidents Adequate radiation protection shall be provided to permit access and occupancy of the control room under accident conditions without personnel receiving radiation exposures in excess of $5 \mathrm{rem}$ whole body, or its equivalent to any part of the body, for the duration of the accident. Equipment at appropriate locations outside the control room shall be provided (1) with a design capability for prompt hot shutdown of the reactor, including necessary instrumentation and controls to maintain the unit in a safe condition during hot shutdown, and (2) with a potential capability for subsequent cold shutdown of the reactor through the use of suitable procedures.

Applicants for and holders of construction permits and operating licenses under this part who apply on or after January 10,1997, applicants for design approvals or certifications under part 52 of this chapter who apply on or after January 10 ,

1997, applicants for and holders of combined licenses or manufacturing licenses under part 52 the continuity of the systems and the condition of their components. The systems shall be designed with a capability to test periodically (1) the operability and functional performance of the components of the systems, such as [onsite power sources, relays, switches, and buses] and (2) the operability of the systems as a whole and, under conditions as close to design as practical, the full operation sequence that brings the systems into operation, including operation of applicable portions of the protection system- and the transfer of power among systems. the nuclear power unit, the offsite power system, and the onsite power system

\section{Control room.}

A control room shall be provided from which actions can be taken to operate the nuclear power unit safely under normal conditions and to maintain it in a safe condition under accident conditions, -including loss-ofcoolant accidents. Adequate radiation protection shall be provided to permit access and occupancy of the control room under accident conditions without personnel receiving radiation exposures in excess of 5 rem total effective dose equivalent (TEDE) whole body or its equivalent to any part of the body, for the duration of the accident

Adequate habitability measures shall be provided to permit access and occupancy of the control room during normal operations and under accident conditions.

Equipment at appropriate locations outside the control room shall be provided (1) with a design capability for prompt hot shutdown of the reactor, including

necessary instrumentation and controls to maintain the unit in a safe condition during hot shutdown, and (2) with a potential capability for subsequent cold shutdown of the reactor through the use of suitable procedures.

Applicants for and holders of construction permits and

\section{Rationale for Modification}

Wording pertaining to additional system examples have been deleted to allow increased flexibility associated with various designs.

Text related to the nuclear power unit, offsite power system, and onsite power system is deleted to be consistent with ARDC 17.

Criterion was updated to remove specific emphasis on LOCA, which may be not appropriate for advanced designs such as the mHTGR.

Adjusted obsolete reference to "whole body, or its equivalent to any part of the body" to the current TEDE standard as defined in $\S 50.2$.

Control room habitability requirement beyond that associated with radiation protection has been added to address concern that nonradionuclide accidents may also affect control room access and occupancy (new second paragraph).

Eliminated reference to legacy licensing issue - last paragraph not applicable to future applicants. 
Criterion Current GDC Language

of this chapter who do not reference a standard design approval or certification, or holders of operating licenses using an alternative source term under $\S 50.67$, shall meet the requirements of this criterion, except that with regard to control room access and occupancy, adequate radiation protection shall be provided to ensure that radiation exposures shall not exceed $0.05 \mathrm{~Sv}(5$ rem) total effective dose equivalent (TEDE) as defined in $\S 50.2$ for the duration of the accident.

\section{Proposed ARDC Language}

operating licenses under this part who apply on or after danuary 10,1997, applicants for design approvals or certifications under part 52 of this chapter who-apply on or after January 10, 1997, applicants for and holders of combined licenses or manufacturing licenses under part 52 of this chapter who do not reference a standard design approval or certification, or holders of operating licenses using an alternative source term under $\$ 50.67$, shall meet the

requirements of this criterion, except that with regard to control room access and occupancy, adequate radiation protection shall be provided to ensure that fadiation exposures shall not exceed $0.05 \mathrm{~Sv}$ (5 rem) total effective dose equivalent (TEDE) as defined in $\S$ 50.2 for the duration of the accident.

\section{Rationale for Modification}

\section{Reactivity Control}

\section{Criterion Current GDC Language}

20

The protection system shall be designed (1) to initiate automatically the operation of appropriate systems including the reactivity control systems, to assure that specified acceptable fuel design limits are not exceeded as a result of anticipated operational occurrences and (2) to sense accident conditions and to initiate the operation of systems and components important to safety.

21 Protection system reliability and testability.

The protection system shall be designed for high functional reliability and inservice testability commensurate with the safety functions to be performed. Redundancy and independence designed into the protection system shall be sufficient to assure that (1) no single failure results in loss of the protection function and (2) removal from service of any component or channel does not result in loss of the required minimum redundancy unless the acceptable reliability of operation of the protection system can be otherwise demonstrated. The protection system shall be designed to permit periodic
Proposed ARDC Language Same as GDC

Same as GDC

\section{Rationale for Modification}




\begin{tabular}{|c|c|c|c|}
\hline \multicolumn{4}{|c|}{ III. Reactivity Control } \\
\hline Criterion & Current GDC Language & Proposed ARDC Language & Rationale for Modification \\
\hline & $\begin{array}{l}\text { testing of its functioning when the reactor is in } \\
\text { operation, including a capability to test channels } \\
\text { independently to determine failures and losses of } \\
\text { redundancy that may have occurred. }\end{array}$ & & \\
\hline 22 & $\begin{array}{l}\text { Protection system independence. } \\
\text { The protection system shall be designed to } \\
\text { assure that the effects of natural phenomena, } \\
\text { and of normal operating, maintenance, testing, } \\
\text { and postulated accident conditions on redundant } \\
\text { channels do not result in loss of the protection } \\
\text { function, or shall be demonstrated to be } \\
\text { acceptable on some other defined basis. Design } \\
\text { techniques, such as functional diversity or } \\
\text { diversity in component design and principles of } \\
\text { operation, shall be used to the extent practical to } \\
\text { prevent loss of the protection function. }\end{array}$ & Same as GDC & \\
\hline 23 & $\begin{array}{l}\text { Protection system failure modes. } \\
\text { The protection system shall be designed to fail } \\
\text { into a safe state or into a state demonstrated to } \\
\text { be acceptable on some other defined basis if } \\
\text { conditions such as disconnection of the system, } \\
\text { loss of energy (e.g., electric power, instrument } \\
\text { air), or postulated adverse environments (e.g., } \\
\text { extreme heat or cold, fire, pressure, steam, } \\
\text { water, and radiation) are experienced. }\end{array}$ & $\begin{array}{l}\text { Protection system failure modes. } \\
\text { The protection system shall be designed to fail into a } \\
\text { safe state or into a state demonstrated to be } \\
\text { acceptable on some other defined basis if conditions } \\
\text { such as disconnection of the system, loss of energy } \\
\text { (e.g., [electric power, instrument air]), or postulated } \\
\text { adverse environments (e.g., [extreme heat or cold, } \\
\text { fire, pressure, steam, water, and radiation]) are } \\
\text { experienced. }\end{array}$ & $\begin{array}{l}\text { It is understood that items that follow "e.g.," do } \\
\text { not constitute an all-inclusive list. Therefore, } \\
\text { the original GDC wording is left as-is so that } \\
\text { technology-specific items could be substituted } \\
\text { in subsequent PDCs. } \\
\text { Brackets have been added around certain text } \\
\text { to identify portions of original GDC language } \\
\text { where advanced designs may need to provide } \\
\text { alternative descriptions to address underlying } \\
\text { criterion requirements. The brackets were } \\
\text { used for items in the example lists to convey } \\
\text { the understanding that some examples may be } \\
\text { design-specific and, therefore, would not } \\
\text { apply. }\end{array}$ \\
\hline 24 & $\begin{array}{l}\text { Separation of protection and control systems. } \\
\text { The protection system shall be separated from } \\
\text { control systems to the extent that failure of any } \\
\text { single control system component or channel, or } \\
\text { failure or removal from service of any single } \\
\text { protection system component or channel which is } \\
\text { common to the control and protection systems } \\
\text { leaves intact a system satisfying all reliability, } \\
\text { redundancy, and independence requirements of } \\
\text { the protection system. Interconnection of the } \\
\text { protection and control systems shall be limited so }\end{array}$ & Same as GDC & \\
\hline
\end{tabular}




\begin{tabular}{|c|c|c|c|}
\hline \multicolumn{4}{|c|}{ III. Reactivity Control } \\
\hline Criterion & Current GDC Language & Proposed ARDC Language & Rationale for Modification \\
\hline & $\begin{array}{l}\text { as to assure that safety is not significantly } \\
\text { impaired. }\end{array}$ & & \\
\hline 25 & $\begin{array}{l}\text { Protection system requirements for reactivity } \\
\text { control malfunctions. } \\
\text { The protection system shall be designed to } \\
\text { assure that specified acceptable fuel design limits } \\
\text { are not exceeded for any single malfunction of } \\
\text { the reactivity control systems, such as accidental } \\
\text { withdrawal (not ejection or dropout) of control } \\
\text { rods. }\end{array}$ & Same as GDC & \\
\hline 26 & $\begin{array}{l}\text { Reactivity control system redundancy and } \\
\text { capability. } \\
\text { Two independent reactivity control systems of } \\
\text { different design principles shall be provided. One } \\
\text { of the systems shall use control rods, preferably } \\
\text { including a positive means for inserting the rods, } \\
\text { and shall be capable of reliably controlling } \\
\text { reactivity changes to assure that under conditions } \\
\text { of normal operation, including anticipated } \\
\text { operational occurrences, and with appropriate } \\
\text { margin for malfunctions such as stuck rods, } \\
\text { specified acceptable fuel design limits are not } \\
\text { exceeded. The second reactivity control system } \\
\text { shall be capable of reliably controlling the rate of } \\
\text { reactivity changes resulting from planned, normal } \\
\text { power changes (including xenon burnout) to } \\
\text { assure acceptable fuel design limits are not } \\
\text { exceeded. One of the systems shall be capable } \\
\text { of holding the reactor core subcritical under cold } \\
\text { conditions. }\end{array}$ & $\begin{array}{l}\text { Reactivity control system redundancy and capability. } \\
\text { [Two] independent reactivity control systems of } \\
\text { different design principles shall be provided. One of the } \\
\text { systems shall use control rods, preferably including a } \\
\text { positive means for inserting the rods, and shall be } \\
\text { capable of reliably controlling reactivity changes to } \\
\text { assure that under conditions of normal operation, } \\
\text { including anticipated operational occurrences, and with } \\
\text { appropriate margin for malfunctions such as stuck } \\
\text { rods, specified acceptable fuel design limits are not } \\
\text { exceeded. The-A second reactivity control system shall } \\
\text { be capable of reliably controlling the rate of reactivity } \\
\text { changes resulting from planned, normal power } \\
\text { changes [(including xenon burnout)] to assure } \\
\text { acceptable fuel design limits are not exceeded. One of } \\
\text { the systems shall be capable of holding the reactor } \\
\text { core subcritical under cold conditions. }\end{array}$ & $\begin{array}{l}\text { Brackets have been added around certain text } \\
\text { to identify portions of original GDC language } \\
\text { where advanced designs may need to provide } \\
\text { alternative descriptions to address underlying } \\
\text { criterion requirements. The specification for } \\
\text { two systems was placed in brackets to provide } \\
\text { flexibility to account for a range of design } \\
\text { options to meet the GDC safety goal } \\
\text { potentially using more than two independent } \\
\text { reactivity control systems. The sentence } \\
\text { structure precludes using just one system due } \\
\text { to the requirement for independence and the } \\
\text { plurality of the word system. The word "the' is } \\
\text { replaced at the start of the third sentence by } \\
\text { the word "a" to soften the specificity for just two } \\
\text { systems in the original GDC. } \\
\text { The parenthetical phrase "including xenon } \\
\text { burnout" is placed in brackets because this } \\
\text { phenomenon does not apply to fast reactor } \\
\text { designs. Therefore, the requirement to include } \\
\text { provisions for xenon burnout can be struck } \\
\text { from fast-reactor design-specific criterion. }\end{array}$ \\
\hline 27 & $\begin{array}{l}\text { Combined reactivity control systems capability. } \\
\text { The reactivity control systems shall be designed } \\
\text { to have a combined capability, in conjunction with } \\
\text { poison addition by the emergency core cooling } \\
\text { system, of reliably controlling reactivity changes } \\
\text { to assure that under postulated accident } \\
\text { conditions and with appropriate margin for stuck } \\
\text { rods the capability to cool the core is maintained. }\end{array}$ & $\begin{array}{l}\text { Combined reactivity control systems capability. } \\
\text { The reactivity control systems shall be designed to } \\
\text { have a combined capability, in conjunction with poison } \\
\text { addition by the emergency core cooling system, of } \\
\text { reliably controlling reactivity changes to assure that } \\
\text { under postulated accident conditions and with } \\
\text { appropriate margin for stuck rods the capability to cool } \\
\text { the core is maintained. }\end{array}$ & $\begin{array}{l}\text { None of the advanced non-LWR designs } \\
\text { evaluated in the review utilized poison addition } \\
\text { via an ECCS. } \\
\text { In addition, ARDC 34, Residual heat removal, } \\
\text { combines the ECCS requirements in GDC } 35 \\
\text { into ARDC } 34 \text {, because none of the advanced } \\
\text { non-LWR designs evaluated utilized an ECCS. } \\
\text { Advanced non-LWR designs that do use }\end{array}$ \\
\hline
\end{tabular}




\begin{tabular}{|c|c|c|c|}
\hline \multicolumn{4}{|c|}{ III. Reactivity Control } \\
\hline Criterion & Current GDC Language & Proposed ARDC Language & Rationale for Modification \\
\hline & & & $\begin{array}{l}\text { poison addition or an ECCS will have to look to } \\
\text { GDC } 27 \text { and GDC } 35 \text { for guidance. }\end{array}$ \\
\hline 28 & $\begin{array}{l}\text { Reactivity limits. } \\
\text { The reactivity control systems shall be designed } \\
\text { with appropriate limits on the potential amount } \\
\text { and rate of reactivity increase to assure that the } \\
\text { effects of postulated reactivity accidents can } \\
\text { neither (1) result in damage to the reactor coolant } \\
\text { pressure boundary greater than limited local } \\
\text { yielding nor (2) sufficiently disturb the core, its } \\
\text { support structures or other reactor pressure } \\
\text { vessel internals to impair significantly the } \\
\text { capability to cool the core. These postulated } \\
\text { reactivity accidents shall include consideration of } \\
\text { rod ejection (unless prevented by positive } \\
\text { means), rod dropout, steam line rupture, changes } \\
\text { in reactor coolant temperature and pressure, and } \\
\text { cold water addition. }\end{array}$ & $\begin{array}{l}\text { Reactivity limits. } \\
\text { The reactivity control systems shall be designed with } \\
\text { appropriate limits on the potential amount and rate of } \\
\text { reactivity increase to assure that the effects of } \\
\text { postulated reactivity accidents can neither (1) result in } \\
\text { damage to the reactor [coolant pressure] boundary } \\
\text { greater than limited local yielding nor (2) sufficiently } \\
\text { disturb the core, its support structures or other reactor } \\
\text { pressure vessel internals to impair significantly the } \\
\text { capability to cool the core. These postulated reactivity } \\
\text { accidents shall include consideration of [rod ejection } \\
\text { (unless prevented by positive means), rod dropout, } \\
\text { steam line rupture, changes in reactor coolant } \\
\text { temperature and pressure, and cold water } \\
\text { addition]. }\end{array}$ & $\begin{array}{l}\text { Brackets have been added around "coolant } \\
\text { pressure" to identify portions of original GDC } \\
\text { language where advanced designs may need } \\
\text { to provide design-specific descriptive } \\
\text { terminology to address underlying criterion } \\
\text { requirements. } \\
\text { The phrase "reactor pressure vessel" is } \\
\text { truncated to "reactor vessel" to acknowledge } \\
\text { that some advanced reactor designs (SFRs for } \\
\text { example) operate at low or atmospheric } \\
\text { pressure and the traditional concept of a } \\
\text { reactor pressure vessel is misleading. } \\
\text { Therefore, the word "pressure" is removed for } \\
\text { technical clarity without impacting the ARDC } \\
\text { safety basis. }\end{array}$ \\
\hline & & & $\begin{array}{l}\text { The list of "postulated reactivity accidents" } \\
\text { include consideration of initiating events that } \\
\text { are inappropriate for the many advanced non- } \\
\text { LWR reactor designs. For example: Advanced } \\
\text { reactor designs operating at low pressure and } \\
\text { low flow are not likely to be subject to rod } \\
\text { ejection initiating events. Advanced reactor } \\
\text { designs typically utilize rods inserted from the } \\
\text { top of the reactor, so rod drop out would not be } \\
\text { a reactivity insertion event. Advanced reactor } \\
\text { designs utilizing an intermediate loop may not } \\
\text { be sensitive to steam line ruptures and } \\
\text { advanced designs using a Brayton cycle would } \\
\text { not use steam at all. Therefore, the example } \\
\text { list is placed in brackets and it is appropriate } \\
\text { and expected that design-specific initiating } \\
\text { events will be provided. }\end{array}$ \\
\hline 29 & $\begin{array}{l}\text { Protection against anticipated operational } \\
\text { occurrences. } \\
\text { The protection and reactivity control systems } \\
\text { shall be designed to assure an extremely high } \\
\text { probability of accomplishing their safety functions } \\
\text { in the event of anticipated operational occurrences. }\end{array}$ & Same as GDC & \\
\hline
\end{tabular}




\begin{tabular}{|c|c|c|c|}
\hline \multicolumn{4}{|c|}{ IV. Fluid Systems } \\
\hline Criterion & Current GDC Language & Proposed ARDC Language & Rationale for Modification \\
\hline 30 & $\begin{array}{l}\text { Quality of reactor coolant pressure boundary. } \\
\text { Components which are part of the reactor coolant } \\
\text { pressure boundary shall be designed, fabricated, } \\
\text { erected, and tested to the highest quality } \\
\text { standards practical. Means shall be provided for } \\
\text { detecting and, to the extent practical, identifying } \\
\text { the location of the source of reactor coolant } \\
\text { leakage. }\end{array}$ & $\begin{array}{l}\text { Quality of reactor [coolant pressure] boundary. } \\
\text { Components which are part of the reactor [coolant } \\
\text { pressure] boundary shall be designed, fabricated, } \\
\text { erected, and tested to the highest quality standards } \\
\text { practical. Means shall be provided for detecting and, to } \\
\text { the extent practical, identifying the location of the } \\
\text { source of reactor [coolant] leakage. }\end{array}$ & $\begin{array}{l}\text { Brackets have been added around "coolant } \\
\text { pressure" and "coolant" to identify portions of } \\
\text { original GDC language where advanced } \\
\text { designs may need to provide alternative } \\
\text { descriptions to address underlying criterion } \\
\text { requirements. }\end{array}$ \\
\hline 31 & $\begin{array}{l}\text { Fracture prevention of reactor coolant pressure } \\
\text { boundary. } \\
\text { The reactor coolant pressure boundary shall be } \\
\text { designed with sufficient margin to assure that } \\
\text { when stressed under operating, maintenance, } \\
\text { testing, and postulated accident conditions (1) the } \\
\text { boundary behaves in a nonbrittle manner and (2) } \\
\text { the probability of rapidly propagating fracture is } \\
\text { minimized. The design shall reflect consideration } \\
\text { of service temperatures and other conditions of } \\
\text { the boundary material under operating, } \\
\text { maintenance, testing, and postulated accident } \\
\text { conditions and the uncertainties in determining } \\
\text { (1) material properties, (2) the effects of } \\
\text { irradiation on material properties, (3) residual, } \\
\text { steady state and transient stresses, and (4) size } \\
\text { of flaws. }\end{array}$ & $\begin{array}{l}\text { Fracture prevention of reactor [coolant pressure] } \\
\text { boundary. } \\
\text { The reactor [coolant pressure] boundary shall be } \\
\text { designed with sufficient margin to assure that when } \\
\text { stressed under operating, maintenance, testing, and } \\
\text { postulated accident conditions (1) the boundary } \\
\text { behaves in a nonbrittle manner and (2) the probability } \\
\text { of rapidly propagating fracture is minimized. The } \\
\text { design shall reflect consideration of service } \\
\text { temperatures [and other conditions] of the boundary } \\
\text { material under operating, maintenance, testing, and } \\
\text { postulated accident conditions and the uncertainties in } \\
\text { determining (1) material properties, (2) the effects of } \\
\text { irradiation on material properties, (3) residual, steady } \\
\text { state and transient stresses, and (4) size of flaws. }\end{array}$ & $\begin{array}{l}\text { Brackets have been added around "coolant } \\
\text { pressure" and "and other conditions" to identify } \\
\text { portions of original GDC language where } \\
\text { advanced designs may need to provide } \\
\text { alternative descriptions to address underlying } \\
\text { criterion requirements. }\end{array}$ \\
\hline 32 & $\begin{array}{l}\text { Inspection of reactor coolant pressure boundary. } \\
\text { Components which are part of the reactor coolant } \\
\text { pressure boundary shall be designed to permit } \\
\text { (1) periodic inspection and testing of important } \\
\text { areas and features to assess their structural and } \\
\text { leaktight integrity, and (2) an appropriate material } \\
\text { surveillance program for the reactor pressure } \\
\text { vessel. }\end{array}$ & $\begin{array}{l}\text { Inspection of reactor [coolant pressure] boundary. } \\
\text { Components which are part of the reactor [coolant } \\
\text { pressure] boundary shall be designed to permit (1) } \\
\text { periodic inspection and testing of important areas and } \\
\text { features to assess their structural and leaktight } \\
\text { integrity, and (2) an appropriate material surveillance } \\
\text { program for the reactor pressure vessel. }\end{array}$ & $\begin{array}{l}\text { Brackets have been added around "coolant } \\
\text { pressure" to identify portions of original GDC } \\
\text { language where advanced designs may need } \\
\text { to provide alternative descriptions to address } \\
\text { underlying criterion requirements. } \\
\text { The term "pressure" is deleted as the reactor } \\
\text { vessel may not necessarily be a "pressure } \\
\text { vessel". }\end{array}$ \\
\hline 33 & $\begin{array}{l}\text { Reactor coolant makeup. } \\
\text { A system to supply reactor coolant makeup for } \\
\text { protection against small breaks in the reactor } \\
\text { coolant pressure boundary shall be provided. The } \\
\text { system safety function shall be to assure that } \\
\text { specified acceptable fuel design limits are not }\end{array}$ & $\begin{array}{l}\text { Reactor [coolant] makeupinventory maintenance. } \\
\text { A system to supply maintain reactor [coolant] } \\
\text { inventory makeup for protection against small breaks in } \\
\text { the reactor [coolant pressure] boundary shall be } \\
\text { provided as necessary to. The system safety function } \\
\text { shall be to assure that specified acceptable fuel design }\end{array}$ & $\begin{array}{l}\text { Retitled with "inventory maintenance" to } \\
\text { provide more flexibility regarding advanced } \\
\text { reactor designs. } \\
\\
\text { Typically, for low pressure advanced reactor } \\
\text { primary systems, small breaks are not credible }\end{array}$ \\
\hline
\end{tabular}




\begin{tabular}{|c|c|c|c|}
\hline Criterion & Current GDC Language & Proposed ARDC Language & Rationale for Modification \\
\hline & $\begin{array}{l}\text { exceeded as a result of reactor coolant loss due } \\
\text { to leakage from the reactor coolant pressure } \\
\text { boundary and rupture of small piping or other } \\
\text { small components which are part of the } \\
\text { boundary. The system shall be designed to } \\
\text { assure that for onsite electric power system } \\
\text { operation (assuming offsite power is not } \\
\text { available) and for offsite electric power system } \\
\text { operation (assuming onsite power is not } \\
\text { available) the system safety function can be } \\
\text { accomplished using the piping, pumps, and } \\
\text { valves used to maintain coolant inventory during } \\
\text { normal reactor operation. }\end{array}$ & $\begin{array}{l}\text { limits are not exceeded as a result of reactor [coolant] } \\
\text { inventory loss due to leakage from the reactor [coolant } \\
\text { pressure] boundary and rupture of small piping or } \\
\text { other small components which are part of the } \\
\text { boundary. The system shall be designed to assure that } \\
\text { for onsite electric power system operation (assuming } \\
\text { offsite power is not available) and for offsite electric } \\
\text { power system operation (assuming onsite power is not } \\
\text { available) the system safety function can be } \\
\text { accomplished using the piping, pumps, and valves } \\
\text { used to maintain coolant inventory during normal } \\
\text { reactor operation. }\end{array}$ & $\begin{array}{l}\text { sources of significant coolant inventory loss in } \\
\text { a short time; therefore, they may not require a } \\
\text { safety makeup system. However, they must } \\
\text { maintain inventory to support core heat } \\
\text { removal. The mHTGR design does not require } \\
\text { coolant makeup during postulated accidents. } \\
\text { The term "maintain" inventory can encompass } \\
\text { "supply." } \\
\text { Brackets have been added around "coolant" } \\
\text { and "coolant pressure" to identify portions of } \\
\text { original GDC language where advanced } \\
\text { designs may need to provide alternative } \\
\text { descriptions to address underlying criterion } \\
\text { requirements. } \\
\text { The term "...shall be provided as necessary to } \\
\text { assure..." is modified to recognize the } \\
\text { inventory control system may be unnecessary } \\
\text { for some designs to maintain safety functions } \\
\text { that assure fuel design limits are not } \\
\text { exceeded. } \\
\text { The second half of the GDC paragraph } \\
\text { addresses system operability given potential } \\
\text { power supply problems. ARDC } 17 \text { requires } \\
\text { reliable power systems for SSCs performing } \\
\text { vital safety functions and must be of adequate } \\
\text { capacity and capability to operate during } \\
\text { postulated accidents. There may be various } \\
\text { combinations of power supply employed to } \\
\text { address power reliability. The ARDC } 33 \\
\text { discussion of power systems is amended to } \\
\text { clarify that necessary system safety functions } \\
\text { are to be accomplished implicitly requiring } \\
\text { electric power as necessary regardless of } \\
\text { power source and deletes reference to specific } \\
\text { onsite/offsite power supply combinations to be } \\
\text { consistent with ARDC } 17 .\end{array}$ \\
\hline 34 & $\begin{array}{l}\text { Residual heat removal. } \\
\text { A system to remove residual heat shall be } \\
\text { provided. The system safety function shall be to }\end{array}$ & $\begin{array}{l}\text { Residual heat removal. } \\
\text { A system to remove residual heat shall be provided. } \\
\text { The system safety function shall be to transfer fission }\end{array}$ & $\begin{array}{l}\text { ARDC } 34 \text { incorporates the postulated accident } \\
\text { residual heat removal requirements contained } \\
\text { in GDC } 35 \text {. }\end{array}$ \\
\hline
\end{tabular}


\begin{tabular}{l|l}
\hline Criterion & Current GDC Language \\
\hline & transfer fission product decay heat and other
\end{tabular} residual heat from the reactor core at a rate such that specified acceptable fuel design limits and the design conditions of the reactor coolant pressure boundary are not exceeded.

Suitable redundancy in components and features, and suitable interconnections, leak detection, and isolation capabilities shall be provided to assure that for onsite electric power system operation (assuming offsite power is not available) and for offsite electric power system operation (assuming onsite power is not available) the system safety function can be accomplished, assuming a single failure.

A system to provide abundant emergency core cooling shall be provided. The system safety function shall be to transfer heat from the reactor core following any loss of reactor coolant at a rate such that (1) fuel and clad damage that could interfere with continued effective core cooling is prevented and (2) clad metal-water reaction is product decay heat and other residual heat from the reactor core to an ultimate heat sink at a rate such that specified acceptable fuel design limits and the design conditions of the reactor [coolant pressure] boundary are not exceeded under all plant shutdown conditions following normal operation, including anticipated operational occurrences, and to provide continuous effective core cooling during postulated accidents.

Suitable redundancy in components and features, and suitable interconnections, leak detection, and isolation capabilities shall be provided to assure that for onsite electric power system operation (assuming offsite power is not available) and for offsite electric power system operation (assuming onsite power is not available) the system safety function can be accomplished, assuming a single failure.

\section{Rationale for Modification}

"Ultimate heat sink" is added to clarify that if ARDC 44 is deemed not applicable to the design, the RHR system is then required to provide the heat removal path to the ultimate heat sink.

Brackets have been added around "coolant pressure" to identify portions of original GDC language where advanced designs may need to provide alternative descriptions to address underlying criterion requirements.

Text of first ARDC paragraph is amended to clarify requirements that are applicable following normal operation including AOOs, and during postulated accidents following the precedent of NUREG-1368, "Preapplication SER for PRISM LMR."

Second paragraph addresses RHR system redundancy. ARDC 17 requires reliable power systems for SSCs performing vital safety functions and must be of adequate capacity and capability to operate during postulated accidents. There may be various combinations of power supply employed to address power reliability. The ARDC 34 discussion of power systems is amended to clarify that system safety functions are to be accomplished implicitly requiring electric power as necessary regardless of power source and deletes reference to specific onsite/offsite power supply combinations, consistent with ARDC 17

Advanced Reactor Design Criterion for core cooling under accident conditions is contained in ARDC-34.

\section{ARDC 35 disposition notation clarifies that} GDC 35 requirements for adequate cooling under accident conditions are now contained in ARDC 34. For the advanced reactor design information reviewed, the requirements set forth in GDC 34 and 35 were accomplished through a single system consistent with the precedent of NUREG-1368, "Preapplication 


\begin{tabular}{|c|c|c|c|}
\hline \\
\hline Criterion & Current GDC Language & Proposed ARDC Language & Rationale for Modification \\
\hline & $\begin{array}{l}\text { limited to negligible amounts. } \\
\text { Suitable redundancy in components and features, } \\
\text { and suitable interconnections, leak detection, } \\
\text { isolation, and containment capabilities shall be } \\
\text { provided to assure that for onsite electric power } \\
\text { system operation (assuming offsite power is not } \\
\text { available) and for offsite electric power system } \\
\text { operation (assuming onsite power is not } \\
\text { available) the system safety function can be } \\
\text { accomplished, assuming a single failure. }\end{array}$ & & $\begin{array}{l}\text { SER for PRISM LMR." } \\
\text { If a separate ECCS system is required for an } \\
\text { advanced reactor, the PDC process for that } \\
\text { reactor must look directly to GDC } 35 \text { for } \\
\text { guidance. }\end{array}$ \\
\hline 36 & $\begin{array}{l}\text { Inspection of emergency core cooling system. } \\
\text { The emergency core cooling system shall be } \\
\text { designed to permit appropriate periodic } \\
\text { inspection of important components, such as } \\
\text { spray rings in the reactor pressure vessel, water } \\
\text { injection nozzles, and piping, to assure the } \\
\text { integrity and capability of the system. }\end{array}$ & $\begin{array}{l}\text { Inspection of emergency core coolingresidual heat } \\
\text { removal system. } \\
\text { The emergency core cooling systemresidual heat } \\
\text { removal system shall be designed to permit } \\
\text { appropriate periodic inspection of important } \\
\text { components, such as [spray rings in the reactor } \\
\text { pressure vessel, water injection nozzles, and } \\
\text { piping], to assure the integrity and capability of the } \\
\text { system. }\end{array}$ & $\begin{array}{l}\text { GDC } 36 \text { system is renamed and revised to } \\
\text { provide for inspection of the residual heat } \\
\text { removal systems as required for ARDC } 34 \text {. } \\
\text { Brackets have been added around certain text } \\
\text { to identify portions of original GDC language } \\
\text { where advanced designs may need to provide } \\
\text { alternative descriptions to address underlying } \\
\text { criterion requirements. }\end{array}$ \\
\hline 37 & $\begin{array}{l}\text { Testing of emergency core cooling system. } \\
\text { The emergency core cooling system shall be } \\
\text { designed to permit appropriate periodic pressure } \\
\text { and functional testing to assure (1) the structural } \\
\text { and leaktight integrity of its components, (2) the } \\
\text { operability and performance of the active } \\
\text { components of the system, and (3) the operability } \\
\text { of the system as a whole and, under conditions } \\
\text { as close to design as practical, the performance } \\
\text { of the full operational sequence that brings the } \\
\text { system into operation, including operation of } \\
\text { applicable portions of the protection system, the } \\
\text { transfer between normal and emergency power } \\
\text { sources, and the operation of the associated } \\
\text { cooling water system. }\end{array}$ & $\begin{array}{l}\text { Testing of residual heat removalemergency core } \\
\text { cooling system. } \\
\text { The residual heat removal emergency core cooling } \\
\text { system shall be designed to permit appropriate } \\
\text { periodic pressure and-functional testing to assure (1) } \\
\text { the structural and leaktightintegrity of its components, } \\
\text { (2) the operability and performance of the activesystem } \\
\text { components-of the system, and (3) the operability of } \\
\text { the system as a whole and, under conditions as close } \\
\text { to design as practical, the performance of the full } \\
\text { operational sequence that brings the system into } \\
\text { operation, including operation of associated systems } \\
\text { and interfaces with an ultimate heat sink. -including } \\
\text { eperation of applicable portions of the protection } \\
\text { system, the transfer between normal and emergency } \\
\text { power sources, and the operation of the associated } \\
\text { cooling water system }\end{array}$ & $\begin{array}{l}\text { GDC } 37 \text { system is renamed and revised to } \\
\text { provide for testing of the residual heat remova } \\
\text { system of ARDC } 34 \text {. } \\
\text { A specific requirement for a pressure test is } \\
\text { removed from text yet remains a potential } \\
\text { requirement should that type of test be } \\
\text { necessary to demonstrate system } \\
\text { performance. None of the advanced reactor } \\
\text { RHR system designs examined in this study } \\
\text { have proposed a pressurized RHR system. } \\
\text { If required, "leaktight" integrity would be } \\
\text { demonstrated in the functional testing of } \\
\text { component and system performance and } \\
\text { operability. } \\
\text { "Active" is deleted in item (2) as appropriate } \\
\text { operability and performance system } \\
\text { component testing is required regardless of } \\
\text { active or passive nature. }\end{array}$ \\
\hline
\end{tabular}




\begin{tabular}{|c|c|c|c|}
\hline \multicolumn{4}{|c|}{ IV. Fluid Systems } \\
\hline Criterion & Current GDC Language & Proposed ARDC Language & Rationale for Modification \\
\hline & & & $\begin{array}{l}\text { Reference to operation of applicable portions } \\
\text { of the protection system, cooling water system, } \\
\text { and power transfers is considered part of the } \\
\text { more general "associated systems." Together } \\
\text { with the ultimate heat sink, they are part of the } \\
\text { operability testing of the system as a whole. }\end{array}$ \\
\hline 38 & $\begin{array}{l}\text { Containment heat removal. } \\
\text { A system to remove heat from the reactor } \\
\text { containment shall be provided. The system safety } \\
\text { function shall be to reduce rapidly, consistent with } \\
\text { the functioning of other associated systems, the } \\
\text { containment pressure and temperature following } \\
\text { any loss-of-coolant accident and maintain them at } \\
\text { acceptably low levels. } \\
\text { Suitable redundancy in components and features, } \\
\text { and suitable interconnections, leak detection, } \\
\text { isolation, and containment capabilities shall be } \\
\text { provided to assure that for onsite electric power } \\
\text { system operation (assuming offsite power is not } \\
\text { available) and for offsite electric power system } \\
\text { operation (assuming onsite power is not } \\
\text { available) the system safety function can be } \\
\text { accomplished, assuming a single failure. }\end{array}$ & $\begin{array}{l}\text { Containment heat removal. } \\
\text { A system to remove heat from the reactor containment } \\
\text { shall be provided as necessary. The system safety } \\
\text { function shall be to maintain reduce rapidly, consistent } \\
\text { with the functioning of other associated systems, the } \\
\text { containment pressure and temperature within } \\
\text { acceptable limits following following any loss-of-coolant } \\
\text { postulated accidents-and maintain them at acceptably } \\
\text { low levels. } \\
\text { Suitable redundancy in components and features, and } \\
\text { suitable interconnections, leak detection, isolation, and } \\
\text { containment capabilities shall be provided to assure } \\
\text { that for onsite electric power system operation } \\
\text { (assuming offsite power is not available) and for offsite } \\
\text { electric power system operation (assuming onsite } \\
\text { power is not available)the system safety function can } \\
\text { be accomplished, assuming a single failure. }\end{array}$ & $\begin{array}{l}\text { “...as necessary...” is meant to condition } \\
\text { ARDC } 38 \text { application to designs requiring heat } \\
\text { removal for conventional containments which } \\
\text { are found to require heat removal measures. } \\
\text { Remove LOCA reference to provide for any } \\
\text { postulated accident that might affect the } \\
\text { containment structure. } \\
\text { Containment structure safety system } \\
\text { redundancy is addressed in second paragraph. } \\
\text { ARDC } 17 \text { requires reliable power systems } \\
\text { supporting SSCs that perform vital safety } \\
\text { functions shall be of adequate capacity and } \\
\text { capability to operate during postulated } \\
\text { accidents; there may be various combinations } \\
\text { of power supply employed to address power } \\
\text { system reliability. } \\
\text { ARDC } 38 \text { states that the necessary system } \\
\text { safety function shall be accomplished implicitly } \\
\text { requiring electric power as necessary } \\
\text { regardless of power source and deletes } \\
\text { reference to specific onsite/offsite power } \\
\text { supply combinations, consistent with ARDC } 17 .\end{array}$ \\
\hline 39 & $\begin{array}{l}\text { Inspection of containment heat removal system. } \\
\text { The containment heat removal system shall be } \\
\text { designed to permit appropriate periodic } \\
\text { inspection of important components, such as the } \\
\text { torus, sumps, spray nozzles, and piping to assure } \\
\text { the integrity and capability of the system. }\end{array}$ & $\begin{array}{l}\text { Inspection of containment heat removal system. } \\
\text { The containment heat removal system shall be } \\
\text { designed to permit appropriate periodic inspection of } \\
\text { important components, such as [the torus, sumps, } \\
\text { spray nozzles, and piping] to assure the integrity and } \\
\text { capability of the system. }\end{array}$ & $\begin{array}{l}\text { ARDC } 39 \text { application is presumed conditioned } \\
\text { to designs as is required for support of } \\
\text { conventional containment heat removal under } \\
\text { ARDC } 38 \text {. } \\
\text { Brackets have been added around certain } \\
\text { systems to draw attention to that portion of } \\
\text { original GDC language where advanced } \\
\text { designs may substitute alternative system } \\
\text { descriptions to meet criterion requirements. }\end{array}$ \\
\hline
\end{tabular}


40 Testing of containment heat removal system. The containment heat removal system shall be designed to permit appropriate periodic pressure and functional testing to assure (1) the structural and leaktight integrity of its components, (2) the operability and performance of the active components of the system, and (3) the operability of the system as a whole, and under conditions as close to the design as practical the performance of the full operational sequence that brings the system into operation, including operation of applicable portions of the protection system, the transfer between normal and emergency power sources, and the operation of the associated cooling water system.

$41 \quad$ Containment atmosphere cleanup.

Systems to control fission products, hydrogen, oxygen, and other substances which may be released into the reactor containment shall be provided as necessary to reduce, consistent with the functioning of other associated systems, the concentration and quality of fission products released to the environment following postulated accidents, and to control the concentration of hydrogen or oxygen and other substances in the containment atmosphere following postulated accidents to assure that containment integrity is maintained.

Each system shall have suitable redundancy in components and features, and suitable interconnections, leak detection, isolation, and containment capabilities to assure that for onsite electric power system operation (assuming offsite power is not available) and for offsite electric power system operation (assuming onsite power
Proposed ARDC Language

Testing of containment heat removal system.

The containment heat removal system shall be designed to permit appropriate periodic pressure and functional testing to assure (1) the structural and leaktight-integrity of its components, (2) the operability and performance of the active-system components-of the system, and (3) the operability of the system as a whole, and under conditions as close to the design as practical, the performance of the full operational sequence that brings the system into operation including operation of applicable portions of the protection system, the transfer between normal and emergency power sources, and the operation of the associated cooling water system, including operation of associated systems.

Containment atmosphere cleanup.

Systems to control fission products, [hydrogen, oxygen,] and other substances which may be released into the reactor containment shall be provided as necessary to reduce, consistent with the functioning of other associated systems, the concentration and quality of fission products released to the environment following postulated accidents, and to control the concentration of [hydrogen or oxygen] and other substances in the containment atmosphere following postulated accidents to assure that containment integrity is maintained.

Each system shall have suitable redundancy in components and features, and suitable interconnections, leak detection, isolation, and containment capabilities to assure that for onsite electric power system operation (assuming offsite power is not available) and for offsite electric power system operation (assuming onsite power is not available) its safety function can be accomplished,
Rationale for Modification

ARDC 40 application is presumed conditioned to designs as is required for support of conventional containment heat removal under ARDC 38.

Specific mention of "pressure" testing is removed yet remains a potential requirement should it be necessary as a component of "... appropriate periodic functional testing..." of containment heat removal.

"Leaktight" integrity would be demonstrated as required in "...functional testing to assure... (2) the operability and performance of the system components..."

Reference to operation of applicable portions of the protection system, cooling water systems, and power transfers is considered part of the more general "associated systems" for operability testing of the system as a whole. Advanced reactors offer potential for reaction product generation different from associated with clad metal-water interactions. Therefore, the reference to hydrogen and oxygen is bracketed to draw attention to the possible need for exception.

ARDC 17 requires reliable power systems that support SSCs performing vital safety functions shall be of adequate capacity and capability to operate during postulated accidents. There may be various combinations of power supply employed to address power system reliability.

ARDC 41 states that system safety function is to be accomplished implicitly requiring electric power if needed regardless of source and deletes reference to specific onsite/offsite power supply combinations, consistent with ARDC 17. 


\begin{tabular}{|c|c|c|c|}
\hline \multicolumn{4}{|c|}{ IV. Fluid Systems } \\
\hline Criterion & Current GDC Language & Proposed ARDC Language & Rationale for Modification \\
\hline & $\begin{array}{l}\text { is not available) its safety function can be } \\
\text { accomplished, assuming a single failure. }\end{array}$ & assuming a single failure. & \\
\hline 42 & $\begin{array}{l}\text { Inspection of containment atmosphere cleanup } \\
\text { systems. } \\
\text { The containment atmosphere cleanup systems } \\
\text { shall be designed to permit appropriate periodic } \\
\text { inspection of important components, such as filter } \\
\text { frames, ducts, and piping to assure the integrity } \\
\text { and capability of the systems. }\end{array}$ & Same as GDC & \\
\hline 43 & $\begin{array}{l}\text { Testing of containment atmosphere cleanup } \\
\text { systems. } \\
\text { The containment atmosphere cleanup systems } \\
\text { shall be designed to permit appropriate periodic } \\
\text { pressure and functional testing to assure (1) the } \\
\text { structural and leaktight integrity of its } \\
\text { components, (2) the operability and performance } \\
\text { of the active components of the systems such as } \\
\text { fans, filters, dampers, pumps, and valves and (3) } \\
\text { the operability of the systems as a whole and, } \\
\text { under conditions as close to design as practical, } \\
\text { the performance of the full operational sequence } \\
\text { that brings the systems into operation, including } \\
\text { operation of applicable portions of the protection } \\
\text { system, the transfer between normal and } \\
\text { emergency power sources, and the operation of } \\
\text { associated systems. }\end{array}$ & $\begin{array}{l}\text { Testing of containment atmosphere cleanup systems. } \\
\text { The containment atmosphere cleanup systems shall be } \\
\text { designed to permit appropriate periodic pressure and } \\
\text { functional testing to assure (1) the structural and } \\
\text { leaktight integrity of its components, (2) the operability } \\
\text { and performance of the active-system components, of } \\
\text { the systems such as fans, filters, dampers, pumps, and } \\
\text { valves-and ( } 3 \text { ) the operability of the systems as a } \\
\text { whole and, under conditions as close to design as } \\
\text { practical, the performance of the full operational } \\
\text { sequence that brings the systems into operation, } \\
\text { including operation of applicable portions of the } \\
\text { protection system, the transfer between normal and } \\
\text { emergency power sources, and-the operation of } \\
\text { associated systems. }\end{array}$ & $\begin{array}{l}\text { ARDC } 43 \text { application is presumed conditioned } \\
\text { to designs as required for support of } \\
\text { conventional containment atmosphere cleanup } \\
\text { under ARDC } 41 . \\
\text { A specific requirement for a pressure test is } \\
\text { removed from text yet remains a potential } \\
\text { requirement should that type of test be } \\
\text { necessary as a component of “....appropriate } \\
\text { periodic functional testing..." of containment } \\
\text { cleanup systems. } \\
\text { "“...leaktight integrity..." would be demonstrated } \\
\text { as a function of functional testing and system } \\
\text { performance and operability of item (2). } \\
\text { "Active" is deleted in item (2) as appropriate } \\
\text { operability and performance testing of system } \\
\text { components is required regardless of active or } \\
\text { passive nature, as are cited examples of active } \\
\text { system components. } \\
\text { Examples of active systems under item (2) } \\
\text { have been deleted both to conform to similar } \\
\text { wording in ARDC } 37 \text { and } 40 \text { and ensure } \\
\text { passive as well as active system components } \\
\text { are considered. } \\
\text { Reference to operation of applicable portions } \\
\text { of the protection system and power transfers is } \\
\text { considered part of the more general } \\
\text { "associated systems" for operability testing of } \\
\text { the system as a whole. }\end{array}$ \\
\hline
\end{tabular}




\section{Cooling water.}

A system to transfer heat from structures,

systems, and components important to safety, to an ultimate heat sink shall be provided. The system safety function shall be to transfer the combined heat load of these structures, systems, and components under normal operating and accident conditions.

Suitable redundancy in components and features, and suitable interconnections, leak detection, and isolation capabilities shall be provided to assure that for onsite electric power system operation (assuming offsite power is not available) and for offsite electric power system operation (assuming onsite power is not available) the system safety function can be accomplished, assuming a single failure.

Inspection of cooling water system.

The cooling water system shall be designed to permit appropriate periodic inspection of important components, such as heat exchangers and piping, to assure the integrity and capability of the system.

\section{$46 \quad$ Testing of cooling water system.}

The cooling water system shall be designed to permit appropriate periodic pressure and functional testing to assure (1) the structural and leaktight integrity of its components, (2) the operability and the performance of the active components of the system, and (3) the operability of the system as a whole and, under conditions as close to design as practical, the performance of the full operational sequence that brings the system into operation for reactor shutdown and for loss-of-coolant accidents, including operation of applicable portions of the protection system and the transfer between normal and emergency power sources.
Structural and equipment coolingGooling water. In addition to the heat rejection capability of the residual heat removal system, Asystems to transfer heat from structures, systems, and components important to safety, to an ultimate heat sink shall be provided, as necessary. The system safety function shall be to transfer the combined heat load of these structures, systems, and components under normal operating and accident conditions.

Suitable redundancy in components and features, and suitable interconnections, leak detection, and isolation capabilities shall be provided to assure that for onsite electric power system operation (assuming offsite power is not available) and for offsite electric power system operation (assuming onsite power is not available) the-each system safety function can be accomplished, assuming a single failure.

\section{Inspection of structural and equipment cooling water} systems.

The cooling waterstructural and equipment cooling systems shall be designed to permit appropriate periodic inspection of important components, such as heat exchangers and piping, to assure the integrity and capability of the systems.

Testing of structural and equipment cooling water systems.

The structural and equipment cooling water systems shall be designed to permit appropriate periodic pressure and functional testing to assure (1) the structural and leaktight-integrity of their its-components, (2) the operability and the performance of the active system components-of the system, and (3) the operability of the systems as a whole and, under conditions as close to design as practical, the performance of the full operational sequences that brings the systems into operation for reactor shutdown and postulated accidents, including operation of associated systems-and for loss-of-coolant accidents, including operation of applicable portions of the

\section{Rationale for Modification}

This renamed ARDC accounts for advanced reactor design system differences to include safety-related cooling requirements for SSCs, if applicable; this ARDC does not address the residual heat removal system required under ARDC 34.

ARDC 17 requires reliable power systems that support SSCs performing vital safety functions shall be of adequate capacity and capability to operate during postulated accidents. There may be various combinations of power supply employed to address power system reliability.

ARDC 44 states that necessary system safety function will be accomplished implicitly requiring electric power as needed regardless of source and deletes reference to specific onsite/offsite power supply combinations, consistent with ARDC 17

This renamed ARDC accounts for advanced reactor system design differences to include possible safety-related cooling required for SFR SSCs.

This renamed ARDC accounts for advanced reactor system design differences to include possible safety-related cooling required for SFR SSCs.

Specific mention of "pressure" testing is removed yet remains a potential requirement should it be necessary as a component of "...appropriate periodic functional testing..." of cooling systems.

"Leaktight" integrity would be demonstrated through appropriate functional testing of system performance and operability. 


\begin{tabular}{|c|c|c|c|}
\hline \multicolumn{4}{|c|}{$\begin{array}{l}\text { IV. Fluid Systems } \\
\end{array}$} \\
\hline Criterion & Current GDC Language & Proposed ARDC Language & Rationale for Modification \\
\hline & & $\begin{array}{l}\text { protection system and the transfer between normal and } \\
\text { emergency power sources. }\end{array}$ & $\begin{array}{l}\text { "Active" is deleted in item (2) as appropriate } \\
\text { operability and performance system } \\
\text { component testing is required regardless of } \\
\text { active or passive nature. } \\
\text { Removed LOCA reference to provide for any } \\
\text { postulated accident that might affect subject } \\
\text { SSCs. } \\
\text { Reference to operation of applicable portions } \\
\text { of the protection system and power transfers is } \\
\text { considered part of the more general } \\
\text { "associated systems" for operability testing of } \\
\text { the system as a whole. }\end{array}$ \\
\hline \multicolumn{4}{|c|}{ V. Reactor Containment } \\
\hline Criterion & Current GDC Language & Proposed ARDC Language & Rationale for Modification \\
\hline 50 & $\begin{array}{l}\text { Containment design basis. } \\
\text { The reactor containment structure, including } \\
\text { access openings, penetrations, and the } \\
\text { containment heat removal system shall be } \\
\text { designed so that the containment structure and } \\
\text { its internal compartments can accommodate, } \\
\text { without exceeding the design leakage rate and } \\
\text { with sufficient margin, the calculated pressure } \\
\text { and temperature conditions resulting from any } \\
\text { loss-of-coolant accident. This margin shall reflect } \\
\text { consideration of (1) the effects of potential energy } \\
\text { sources which have not been included in the } \\
\text { determination of the peak conditions, such as } \\
\text { energy in steam generators and as required by } \S \\
50.44 \text { energy from metal-water and other } \\
\text { chemical reactions that may result from } \\
\text { degradation but not total failure of emergency } \\
\text { core cooling functioning, (2) the limited } \\
\text { experience and experimental data available for } \\
\text { defining accident phenomena and containment } \\
\text { responses, and (3) the conservatism of the } \\
\text { calculational model and input parameters. }\end{array}$ & $\begin{array}{l}\text { Containment design basis. } \\
\text { The reactor containment structure, including access } \\
\text { openings, penetrations, and the containment heat } \\
\text { removal system shall be designed so that the } \\
\text { containment structure and its internal compartments } \\
\text { can accommodate, without exceeding the design } \\
\text { leakage rate and with sufficient margin, the calculated } \\
\text { pressure and temperature conditions resulting from } \\
\text { postulated accidentsany loss-of-coolant accident. This } \\
\text { margin shall reflect consideration of (1) the effects of } \\
\text { potential energy sources which have not been included } \\
\text { in the determination of the peak conditions, such as } \\
\text { [energy in steam generators and as required by § } \\
\mathbf{5 0 . 4 4} \text { energy from metal-water and other chemical } \\
\text { reactions that may result from degradation but not } \\
\text { total failure of emergency core cooling } \\
\text { functioning], (2) the limited experience and } \\
\text { experimental data available for defining accident } \\
\text { phenomena and containment responses, and (3) the } \\
\text { conservatism of the calculational model and input } \\
\text { parameters. }\end{array}$ & $\begin{array}{l}\text { All advanced reactor designs must meet } \\
\text { functional containment requirements as } \\
\text { specified in ARDC } 16 \text { and the proposed } \\
\text { definition for a functional containment. } \\
\text { However, GDC-50 specifically addresses a } \\
\text { containment structure in the opening sentence } \\
\text { and GDCs } 51-57 \text { support the containment } \\
\text { structure's design basis. Therefore, ARDC } 51 \\
-57 \text { are modified by adding the word } \\
\text { "structure" to highlight the containment } \\
\text { structure-specific criteria. } \\
\text { The phrase "loss of coolant accident" is LWR- } \\
\text { specific because this is understood to be the } \\
\text { limiting containment structure accident for an } \\
\text { LWR design. The LOCA phrase is replaced by } \\
\text { the phrase "postulated accident" to allow for } \\
\text { consideration of the design-specific } \\
\text { containment structure limiting accident for } \\
\text { advanced non-LWR reactor designs. } \\
\text { The example at the end of subpart } 1 \text { of the } \\
\text { GDC is LWR-specific. }\end{array}$ \\
\hline
\end{tabular}




\begin{tabular}{|c|c|c|c|}
\hline \multicolumn{4}{|c|}{ V. Reactor Containment } \\
\hline Criterion & Current GDC Language & Proposed ARDC Language & Rationale for Modification \\
\hline 51 & $\begin{array}{l}\text { Fracture prevention of containment pressure } \\
\text { boundary. } \\
\text { The reactor containment boundary shall be } \\
\text { designed with sufficient margin to assure that } \\
\text { under operating, maintenance, testing, and } \\
\text { postulated accident conditions (1) its ferritic } \\
\text { materials behave in a nonbrittle manner and (2) } \\
\text { the probability of rapidly propagating fracture is } \\
\text { minimized. The design shall reflect consideration } \\
\text { of service temperatures and other conditions of } \\
\text { the containment boundary material during } \\
\text { operation, maintenance, testing, and postulated } \\
\text { accident conditions, and the uncertainties in } \\
\text { determining (1) material properties, (2) residual, } \\
\text { steady state, and transient stresses, and (3) size } \\
\text { of flaws. }\end{array}$ & $\begin{array}{l}\text { Fracture prevention of containment pressure boundary. } \\
\text { The reactor containment boundary of the reactor } \\
\text { containment structure shall be designed with sufficient } \\
\text { margin to assure that under operating, maintenance, } \\
\text { testing, and postulated accident conditions (1) its } \\
\text { ferritic materials behave in a nonbrittle manner and (2) } \\
\text { the probability of rapidly propagating fracture is } \\
\text { minimized. The design shall reflect consideration of } \\
\text { service temperatures and other conditions of the } \\
\text { containment boundary materials during operation, } \\
\text { maintenance, testing, and postulated accident } \\
\text { conditions, and the uncertainties in determining (1) } \\
\text { material properties, (2) residual, steady state, and } \\
\text { transient stresses, and (3) size of flaws. }\end{array}$ & $\begin{array}{l}\text { ARDCs 51-57 support ARDC-50, which } \\
\text { specifically applies to advanced non-LWR } \\
\text { designs that utilize a fixed containment } \\
\text { structure. Therefore, the word "structure" is } \\
\text { added to each of these ARDCs to clearly } \\
\text { convey the understanding that some advanced } \\
\text { non-LWR designs may not utilize a fixed } \\
\text { containment structure and provide an } \\
\text { alternative to the ARDC. In some cases, the } \\
\text { word "the" was also added to make the phrase } \\
\text { grammatically correct. } \\
\text { Containment pressure boundary fracture } \\
\text { prevention for the scope of non-LWR } \\
\text { advanced reactors should not be limited to } \\
\text { ferritic materials. Therefore, "ferritic" is } \\
\text { eliminated. }\end{array}$ \\
\hline 52 & $\begin{array}{l}\text { Capability for containment leakage rate testing. } \\
\text { The reactor containment and other equipment } \\
\text { which may be subjected to containment test } \\
\text { conditions shall be designed so that periodic } \\
\text { integrated leakage rate testing can be conducted } \\
\text { at containment design pressure. }\end{array}$ & $\begin{array}{l}\text { Capability for containment leakage rate testing. } \\
\text { The reactor containment structure and other equipment } \\
\text { which may be subjected to containment test conditions } \\
\text { shall be designed so that periodic integrated leakage } \\
\text { rate testing can be conducted at containment design } \\
\text { pressure. }\end{array}$ & $\begin{array}{l}\text { ARDCs 51-57 support ARDC 50, which } \\
\text { specifically applies to advanced non-LWR } \\
\text { designs that utilize a fixed containment } \\
\text { structure. Therefore, the word "structure" is } \\
\text { added to each of these ARDCs to clearly } \\
\text { convey the understanding that this ARDC only } \\
\text { applies to designs employing containment } \\
\text { structures. In some cases, the word "the" was } \\
\text { also added to make the phrase grammatically } \\
\text { correct. }\end{array}$ \\
\hline 53 & $\begin{array}{l}\text { Provisions for containment testing and inspection. } \\
\text { The reactor containment shall be designed to } \\
\text { permit (1) appropriate periodic inspection of all } \\
\text { important areas, such as penetrations, (2) an } \\
\text { appropriate surveillance program, and (3) } \\
\text { periodic testing at containment design pressure } \\
\text { of the leaktightness of penetrations which have } \\
\text { resilient seals and expansion bellows. }\end{array}$ & $\begin{array}{l}\text { Provisions for containment testing and inspection. } \\
\text { The reactor containment structure shall be designed to } \\
\text { permit (1) appropriate periodic inspection of all } \\
\text { important areas, such as penetrations, (2) an } \\
\text { appropriate surveillance program, and (3) periodic } \\
\text { testing at containment design pressure of the } \\
\text { leaktightness of penetrations which have resilient seals } \\
\text { and expansion bellows. }\end{array}$ & $\begin{array}{l}\text { ARDCs 51-57 support ARDC 50, which } \\
\text { specifically applies to advanced non-LWR } \\
\text { designs that utilize a fixed containment } \\
\text { structure. Therefore, the word "structure" is } \\
\text { added to each of these ARDCs to clearly } \\
\text { convey the understanding that this ARDC only } \\
\text { applies to designs employing containment } \\
\text { structures. In some cases, the word "the" was } \\
\text { also added to make the phrase grammatically } \\
\text { correct. }\end{array}$ \\
\hline 54 & $\begin{array}{l}\text { Piping systems penetrating containment. } \\
\text { Piping systems penetrating primary reactor } \\
\text { containment shall be provided with leak } \\
\text { detection, isolation, and containment capabilities } \\
\text { having redundancy, reliability, and performance }\end{array}$ & $\begin{array}{l}\text { Piping systems penetrating containment. } \\
\text { Piping systems penetrating the primary reactor } \\
\text { containment structure shall be provided with leak } \\
\text { detection, isolation, and containment capabilities } \\
\text { having redundancy, reliability, and performance }\end{array}$ & $\begin{array}{l}\text { ARDCs 51-57 support ARDC 50, which } \\
\text { specifically applies to advanced non-LWR } \\
\text { designs that utilize a fixed containment } \\
\text { structure. Therefore, the word "structure" is } \\
\text { added to each of these ARDCs to clearly }\end{array}$ \\
\hline
\end{tabular}


Criterion Current GDC Language

capabilities which reflect the importance to safety of isolating these piping systems. Such piping systems shall be designed with a capability to test periodically the operability of the isolation valves and associated apparatus and to determine if valve leakage is within acceptable limits.

55 Reactor coolant pressure boundary penetrating containment.

Each line that is part of the reactor coolant pressure boundary and that penetrates primary reactor containment shall be provided with containment isolation valves as follows, unless it can be demonstrated that the containment isolation provisions for a specific class of lines, such as instrument lines, are acceptable on some other defined basis:

(1) One locked closed isolation valve inside and one locked closed isolation valve outside containment; or

(2) One automatic isolation valve inside and one locked closed isolation valve outside containment; or

(3) One locked closed isolation valve inside and one automatic isolation valve outside containment. A simple check valve may not be used as the automatic isolation valve outside containment; or

(4) One automatic isolation valve inside and one automatic isolation valve outside containment. A simple check valve may not be used as the automatic isolation valve outside containment.

Isolation valves outside containment shall be located as close to containment as practical and upon loss of actuating power, automatic isolation valves shall be designed to take the position that provides greater safety.

Other appropriate requirements to minimize the probability or consequences of an accidental rupture of these lines or of lines connected to
Proposed ARDC Language

capabilities which reflect the importance to safety of isolating these piping systems. Such piping systems shall be designed with a capability to test periodically the operability of the isolation valves and associated apparatus and to determine if valve leakage is within acceptable limits.

\section{Reactor [coolant pressure] boundary penetrating} containment.

Each line that is part of the reactor [coolant pressure] boundary and that penetrates the primary reactor containment structure shall be provided with containment isolation valves as follows, unless it can be demonstrated that the containment isolation provisions for a specific class of lines, such as instrument lines, are acceptable on some other defined basis:

(1) One locked closed isolation valve inside and one locked closed isolation valve outside containment; or (2) One automatic isolation valve inside and one locked closed isolation valve outside containment; or

(3) One locked closed isolation valve inside and one automatic isolation valve outside containment. A simple check valve may not be used as the automatic isolation valve outside containment; or

(4) One automatic isolation valve inside and one automatic isolation valve outside containment. $A$ simple check valve may not be used as the automatic isolation valve outside containment.

Isolation valves outside containment shall be located as close to containment as practical and upon loss of actuating power, automatic isolation valves shall be designed to take the position that provides greater safety.

Other appropriate requirements to minimize the probability or consequences of an accidental rupture of these lines or of lines connected to them shall be provided as necessary to assure adequate safety. Determination of the appropriateness of these requirements, such as higher quality in design,

\section{Rationale for Modification}

convey the understanding that this ARDC only applies to designs employing containment structures. In some cases, the word "the" was also added to make the phrase grammatically correct.

ARDCs 51-57 support ARDC 50, which specifically applies to advanced non-LWR designs that utilize a fixed containment structure. Therefore, the word "structure" is added to each of these ARDCs to clearly convey the understanding that this ARDC only applies to designs employing containment structures. In some cases, the word "the" was also added to make the phrase grammatically correct.

The phrase "coolant pressure" is placed in brackets to provide advanced non-LWR vendors the opportunity to provide designspecific descriptive terminology. 


\begin{tabular}{|l|l|}
\hline Criterion & Current GDC Language \\
\hline & them shall be provided as necessary to assure
\end{tabular}
adequate safety. Determination of the appropriateness of these requirements, such as higher quality in design, fabrication, and testing, additional provisions for inservice inspection, protection against more severe natural phenomena, and additional isolation valves and containment, shall include consideration of the population density, use characteristics, and physical characteristics of the site environs.

56 Primary containment isolation.

Each line that connects directly to the

containment atmosphere and penetrates primary reactor containment shall be provided with containment isolation valves as follows, unless it can be demonstrated that the containment isolation provisions for a specific class of lines, such as instrument lines, are acceptable on some other defined basis:

(1) One locked closed isolation valve inside and one locked closed isolation valve outside containment; or

(2) One automatic isolation valve inside and one locked closed isolation valve outside containment; or

(3) One locked closed isolation valve inside and one automatic isolation valve outside containment. A simple check valve may not be used as the automatic isolation valve outside containment; or

(4) One automatic isolation valve inside and one automatic isolation valve outside containment. A simple check valve may not be used as the automatic isolation valve outside containment.

Isolation valves outside containment shall be located as close to the containment as practical and upon loss of actuating power, automatic isolation valves shall be designed to take the position that provides greater safety.

Proposed ARDC Lanquage

fabrication, and testing, additional provisions for

inservice inspection, protection against more severe natural phenomena, and additional isolation valves and containment, shall include consideration of the population density, use characteristics, and physical characteristics of the site environs.

Primary containment isolation.

Each line that connects directly to the containment atmosphere and penetrates the primary reactor containment structure shall be provided with

containment isolation valves as follows, unless it can be demonstrated that the containment isolation provisions for a specific class of lines, such as instrument lines, are acceptable on some other defined basis:

(1) One locked closed isolation valve inside and one locked closed isolation valve outside containment; or

(2) One automatic isolation valve inside and one locked closed isolation valve outside containment; or (3) One locked closed isolation valve inside and one automatic isolation valve outside containment. A simple check valve may not be used as the automatic isolation valve outside containment; or

(4) One automatic isolation valve inside and one automatic isolation valve outside containment. A simple check valve may not be used as the automatic isolation valve outside containment.

Isolation valves outside containment shall be located as close to the containment as practical and upon loss of actuating power, automatic isolation valves shall be designed to take the position that provides greater safety.

\section{Rationale for Modification}

\section{ARDCs 51-57 support ARDC 50, which} specifically applies to advanced non-LWR designs that utilize a fixed containment structure. Therefore, the word "structure" is added to each of these ARDCs to clearly convey the understanding that this ARDC only applies to designs employing containment structures. In some cases, the word "the" was also added to make the phrase grammatically correct. 


\begin{tabular}{|c|c|c|c|}
\hline \multicolumn{4}{|c|}{ V. Reactor Containment } \\
\hline Criterion & Current GDC Language & Proposed ARDC Language & Rationale for Modification \\
\hline 57 & $\begin{array}{l}\text { Closed system isolation valves. } \\
\text { Each line that penetrates primary reactor } \\
\text { containment and is neither part of the reactor } \\
\text { coolant pressure boundary nor connected directly } \\
\text { to the containment atmosphere shall have at } \\
\text { least one containment isolation valve which shall } \\
\text { be either automatic, or locked closed, or capable } \\
\text { of remote manual operation. This valve shall be } \\
\text { outside containment and located as close to the } \\
\text { containment as practical. A simple check valve } \\
\text { may not be used as the automatic isolation valve. }\end{array}$ & $\begin{array}{l}\text { Closed system isolation valves. } \\
\text { Each line that penetrates the primary reactor } \\
\text { containment structure and is neither part of the reactor } \\
\text { [coolant pressure] boundary nor connected directly to } \\
\text { the containment atmosphere shall have at least one } \\
\text { containment isolation valve which shall be either } \\
\text { automatic, or locked closed, or capable of remote } \\
\text { manual operation. This valve shall be outside } \\
\text { containment and located as close to the containment } \\
\text { as practical. A simple check valve may not be used as } \\
\text { the automatic isolation valve. }\end{array}$ & $\begin{array}{l}\text { ARDCs 51-57 support ARDC-50, which } \\
\text { specifically applies to advanced non-LWR } \\
\text { designs that utilize a fixed containment } \\
\text { structure. Therefore, the word "structure" is } \\
\text { added to each of these ARDCs to clearly } \\
\text { convey the understanding that this ARDC only } \\
\text { applies to designs employing containment } \\
\text { structures. In some cases, the word "the" was } \\
\text { also added to make the phrase grammatically } \\
\text { correct. } \\
\text { The phrase "coolant pressure" is placed in } \\
\text { brackets to provide advanced non-LWR } \\
\text { vendors the opportunity to provide design- } \\
\text { specific descriptive terminology. }\end{array}$ \\
\hline
\end{tabular}

\begin{tabular}{|c|c|c|c|}
\hline \multicolumn{4}{|c|}{ VI. Fuel and Radioactivity Control } \\
\hline Criterion & Current GDC Language & Proposed ARDC Language & Rationale for Modification \\
\hline 60 & $\begin{array}{l}\text { Control of releases of radioactive materials to the } \\
\text { environment. } \\
\text { The nuclear power unit design shall include } \\
\text { means to control suitably the release of } \\
\text { radioactive materials in gaseous and liquid } \\
\text { effluents and to handle radioactive solid wastes } \\
\text { produced during normal reactor operation, } \\
\text { including anticipated operational occurrences. } \\
\text { Sufficient holdup capacity shall be provided for } \\
\text { retention of gaseous and liquid effluents } \\
\text { containing radioactive materials, particularly } \\
\text { where unfavorable site environmental conditions } \\
\text { can be expected to impose unusual operational } \\
\text { limitations upon the release of such effluents to } \\
\text { the environment. }\end{array}$ & Same as GDC & \\
\hline 61 & $\begin{array}{l}\text { Fuel storage and handling and radioactivity } \\
\text { control. } \\
\text { The fuel storage and handling, radioactive waste, } \\
\text { and other systems which may contain } \\
\text { radioactivity shall be designed to assure } \\
\text { adequate safety under normal and postulated } \\
\text { accident conditions. These systems shall be } \\
\text { designed (1) with a capability to permit }\end{array}$ & $\begin{array}{l}\text { Fuel storage and handling and radioactivity control. } \\
\text { The fuel storage and handling, radioactive waste, and } \\
\text { other systems which may contain radioactivity shall be } \\
\text { designed to assure adequate safety under normal and } \\
\text { postulated accident conditions. These systems shall be } \\
\text { designed (1) with a capability to permit appropriate } \\
\text { periodic inspection and testing of components } \\
\text { important to safety, (2) with suitable shielding for }\end{array}$ & $\begin{array}{l}\text { The underlying concept of establishing } \\
\text { functional requirements for radioactivity control } \\
\text { in fuel storage and fuel handling systems is } \\
\text { independent of the design of non-LWR } \\
\text { advanced reactors. However, some advanced } \\
\text { designs may use dry fuel storage that } \\
\text { incorporates cooling jackets that can be liquid- } \\
\text { cooled or air-cooled to remove heat. This }\end{array}$ \\
\hline
\end{tabular}




\begin{tabular}{|c|c|c|c|}
\hline Criterion & Current GDC Lanquaqe & Proposed $t$ & Rationale for Modification \\
\hline & $\begin{array}{l}\text { appropriate periodic inspection and testing of } \\
\text { components important to safety, (2) with suitable } \\
\text { shielding for radiation protection, (3) with } \\
\text { appropriate containment, confinement, and } \\
\text { filtering systems, (4) with a residual heat removal } \\
\text { capability having reliability and testability that } \\
\text { reflects the importance to safety of decay heat } \\
\text { and other residual heat removal, and (5) to } \\
\text { prevent significant reduction in fuel storage } \\
\text { coolant inventory under accident conditions. }\end{array}$ & $\begin{array}{l}\text { radiation protection, (3) with appropriate containment, } \\
\text { confinement, and filtering systems, (4) with a residual } \\
\text { heat removal capability having reliability and testability } \\
\text { that reflects the importance to safety of decay heat and } \\
\text { other residual heat removal, and (5) to prevent } \\
\text { significant reduction in fuel storage coolant inventory } \\
\text { cooling under accident conditions. }\end{array}$ & $\begin{array}{l}\text { modification to this GDC allows for both liquid } \\
\text { and air-cooling of the dry fuel storage } \\
\text { containers. }\end{array}$ \\
\hline 62 & $\begin{array}{l}\text { Prevention of criticality in fuel storage and } \\
\text { handling. } \\
\text { Criticality in the fuel storage and handling system } \\
\text { shall be prevented by physical systems or } \\
\text { processes, preferably by use of geometrically } \\
\text { safe configurations. }\end{array}$ & Same as GDC & \\
\hline 63 & $\begin{array}{l}\text { Monitoring fuel and waste storage. } \\
\text { Appropriate systems shall be provided in fuel } \\
\text { storage and radioactive waste systems and } \\
\text { associated handling areas (1) to detect conditions } \\
\text { that may result in loss of residual heat removal } \\
\text { capability and excessive radiation levels and (2) } \\
\text { to initiate appropriate safety actions. }\end{array}$ & Same as GDC & \\
\hline 64 & $\begin{array}{l}\text { Monitoring radioactivity releases. } \\
\text { Means shall be provided for monitoring the } \\
\text { reactor containment atmosphere, spaces } \\
\text { containing components for recirculation of loss- } \\
\text { of-coolant accident fluids, effluent discharge } \\
\text { paths, and the plant environs for radioactivity that } \\
\text { may be released from normal operations, } \\
\text { including anticipated operational occurrences, } \\
\text { and from postulated accidents. }\end{array}$ & $\begin{array}{l}\text { Monitoring radioactivity releases. } \\
\text { Means shall be provided for monitoring the [reactor } \\
\text { containment] atmosphere, [spaces containing } \\
\text { components for recirculation of loss-of-coolant } \\
\text { accident fluids,] effluent discharge paths, and the } \\
\text { plant environs for radioactivity that may be released } \\
\text { from normal operations, including anticipated } \\
\text { operational occurrences, and from postulated } \\
\text { accidents. }\end{array}$ & $\begin{array}{l}\text { Brackets are added around "reactor } \\
\text { containment" to allow for plant designs that do } \\
\text { not incorporate an LWR-style pressure- } \\
\text { retaining containment structure. } \\
\text { Brackets are added around "spaces containing } \\
\text { components for recirculation of loss of coolant } \\
\text { accident fluids" to allow for plant designs that } \\
\text { do not have loss-of-coolant accident fluids, but } \\
\text { may have other similar equipment that exist in } \\
\text { spaces where radioactivity should be } \\
\text { monitored. }\end{array}$ \\
\hline
\end{tabular}




\subsection{Proposed Sodium Fast Reactor Design Criteria}

\begin{tabular}{|c|c|c|c|}
\hline \multicolumn{4}{|c|}{ I. Overall Requirements } \\
\hline Criterion & Proposed ARDC Language & Proposed SFR-DC Language & Rationale for Modification \\
\hline 1 & $\begin{array}{l}\text { Quality standards and records. } \\
\text { Structures, systems, and components important } \\
\text { to safety shall be designed, fabricated, erected, } \\
\text { and tested to quality standards commensurate } \\
\text { with the importance of the safety functions to be } \\
\text { performed. Where generally recognized codes } \\
\text { and standards are used, they shall be identified } \\
\text { and evaluated to determine their applicability, } \\
\text { adequacy, and sufficiency and shall be } \\
\text { supplemented or modified as necessary to } \\
\text { assure a quality product in keeping with the } \\
\text { required safety function. A quality assurance } \\
\text { program shall be established and implemented in } \\
\text { order to provide adequate assurance that these } \\
\text { structures, systems, and components will } \\
\text { satisfactorily perform their safety functions. } \\
\text { Appropriate records of the design, fabrication, } \\
\text { erection, and testing of structures, systems, and } \\
\text { components important to safety shall be } \\
\text { maintained by or under the control of the nuclear } \\
\text { power unit licensee throughout the life of the unit. }\end{array}$ & $\begin{array}{l}\text { ARDC with no further SFR-specific clarification } \\
\text { provided. }\end{array}$ & \\
\hline 2 & $\begin{array}{l}\text { Design bases for protection against natural } \\
\text { phenomena. } \\
\text { Structures, systems, and components important } \\
\text { to safety shall be designed to withstand the } \\
\text { effects of natural phenomena such as } \\
\text { earthquakes, tornadoes, hurricanes, floods, } \\
\text { tsunami, and seiches without loss of capability to } \\
\text { perform their safety functions. The design bases } \\
\text { for these structures, systems, and components } \\
\text { shall reflect: (1) Appropriate consideration of the } \\
\text { most severe of the natural phenomena that have } \\
\text { been historically reported for the site and } \\
\text { surrounding area, with sufficient margin for the } \\
\text { limited accuracy, quantity, and period of time in } \\
\text { which the historical data have been accumulated, } \\
\text { (2) appropriate combinations of the effects of } \\
\text { normal and accident conditions with the effects of } \\
\text { the natural phenomena and (3) the importance of } \\
\text { the safety functions to be performed. }\end{array}$ & $\begin{array}{l}\text { ARDC with no further SFR-specific clarification } \\
\text { provided. }\end{array}$ & \\
\hline
\end{tabular}




\begin{tabular}{|c|c|c|c|}
\hline \multicolumn{4}{|c|}{ I. Overall Requirements } \\
\hline Criterion & Proposed ARDC Language & Proposed SFR-DC Language & Rationale for Modification \\
\hline 3 & $\begin{array}{l}\text { Fire protection. } \\
\text { Structures, systems, and components important } \\
\text { to safety shall be designed and located to } \\
\text { minimize, consistent with other safety } \\
\text { requirements, the probability and effect of fires } \\
\text { and explosions. Noncombustible and heat } \\
\text { resistant materials shall be used wherever } \\
\text { practical throughout the unit[, particularly in } \\
\text { locations such as the containment and } \\
\text { control room]. Fire detection and fighting } \\
\text { systems of appropriate capacity and capability } \\
\text { shall be provided and designed to minimize the } \\
\text { adverse effects of fires on structures, systems, } \\
\text { and components important to safety. Firefighting } \\
\text { systems shall be designed to assure that their } \\
\text { rupture or inadvertent operation does not } \\
\text { significantly impair the safety capability of these } \\
\text { structures, systems, and components. }\end{array}$ & $\begin{array}{l}\text { ARDC with no further SFR-specific clarification } \\
\text { provided. }\end{array}$ & \\
\hline 4 & $\begin{array}{l}\text { Environmental and dynamic effects design } \\
\text { bases. } \\
\text { Structures, systems, and components important } \\
\text { to safety shall be designed to accommodate the } \\
\text { effects of and to be compatible with the } \\
\text { environmental conditions associated with normal } \\
\text { operation, maintenance, testing, and postulated } \\
\text { accidents. These structures, systems, and } \\
\text { components shall be appropriately protected } \\
\text { against dynamic effects, including the effects of } \\
\text { missiles, pipe whipping, and discharging fluids, } \\
\text { that may result from equipment failures and from } \\
\text { events and conditions outside the nuclear power } \\
\text { unit. However, dynamic effects associated with } \\
\text { postulated pipe ruptures in nuclear power units } \\
\text { may be excluded from the design basis when } \\
\text { analyses reviewed and approved by the } \\
\text { Commission demonstrate that the probability of } \\
\text { fluid system piping rupture is extremely low under } \\
\text { conditions consistent with the design basis for } \\
\text { the piping. }\end{array}$ & $\begin{array}{l}\text { ARDC with no further SFR-specific clarification } \\
\text { provided. }\end{array}$ & \\
\hline
\end{tabular}




\begin{tabular}{|c|c|c|c|}
\hline \multicolumn{4}{|c|}{ I. Overall Requirements } \\
\hline Criterion & Proposed ARDC Language & Proposed SFR-DC Language & Rationale for Modification \\
\hline 5 & $\begin{array}{l}\text { Sharing of structures, systems, and components. } \\
\text { Structures, systems, and components important } \\
\text { to safety shall not be shared among nuclear } \\
\text { power units unless it can be shown that such } \\
\text { sharing will not significantly impair their ability to } \\
\text { perform their safety functions, including, in the } \\
\text { event of an accident in one unit, an orderly } \\
\text { shutdown and cooldown of the remaining units. }\end{array}$ & $\begin{array}{l}\text { ARDC with no further SFR-specific clarification } \\
\text { provided. }\end{array}$ & \\
\hline
\end{tabular}

\begin{tabular}{|c|c|c|c|}
\hline \multicolumn{4}{|c|}{ II. Multiple Barriers } \\
\hline Criterion & Proposed ARDC Language & Proposed SFR-DC Language & Rationale for Modification \\
\hline 10 & $\begin{array}{l}\text { Reactor Design. } \\
\text { The reactor core and associated [coolant], } \\
\text { control, and protection systems shall be designed } \\
\text { with appropriate margin to assure that specified } \\
\text { acceptable fuel design limits are not exceeded } \\
\text { during any condition of normal operation, } \\
\text { including the effects of anticipated operational } \\
\text { occurrences. }\end{array}$ & $\begin{array}{l}\text { ARDC with no further SFR-specific clarification } \\
\text { provided. }\end{array}$ & \\
\hline 11 & $\begin{array}{l}\text { Reactor inherent protection. } \\
\text { The reactor core and associated systems that } \\
\text { contribute to reactivity feedback shall be } \\
\text { designed so that in the power operating range the } \\
\text { net effect of the prompt inherent nuclear } \\
\text { feedback characteristics tends to compensate for } \\
\text { a rapid increase in reactivity. }\end{array}$ & $\begin{array}{l}\text { ARDC with no further SFR-specific clarification } \\
\text { provided. }\end{array}$ & \\
\hline 12 & $\begin{array}{l}\text { Suppression of reactor power oscillations. } \\
\text { The reactor core and associated [coolant], } \\
\text { control, and protection systems shall be designed } \\
\text { to assure that power oscillations which can result } \\
\text { in conditions exceeding specified acceptable fuel } \\
\text { design limits are not possible or can be reliably } \\
\text { and readily detected and suppressed. }\end{array}$ & $\begin{array}{l}\text { ARDC with no further SFR-specific clarification } \\
\text { provided. }\end{array}$ & \\
\hline 13 & $\begin{array}{l}\text { Instrumentation and control. } \\
\text { Instrumentation shall be provided to monitor } \\
\text { variables and systems over their anticipated } \\
\text { ranges for normal operation, for anticipated } \\
\text { operational occurrences, and for accident } \\
\text { conditions as appropriate to assure adequate } \\
\text { safety, including those variables and systems that } \\
\text { can affect the fission process, the integrity of the }\end{array}$ & $\begin{array}{l}\text { ARDC with additional SFR-specific clarification } \\
\text { provided: } \\
\text { Instrumentation and control. } \\
\text { Instrumentation shall be provided to monitor variables } \\
\text { and systems over their anticipated ranges for normal } \\
\text { operation, for anticipated operational occurrences, and } \\
\text { for accident conditions as appropriate to assure }\end{array}$ & $\begin{array}{l}\text { "Reactor coolant pressure boundary" is } \\
\text { relabeled within the brackets as "reactor } \\
\text { primary coolant boundary" to reflect that the } \\
\text { SFR reactor primary system operates at low- } \\
\text { pressure. Thus, the coolant boundary design } \\
\text { requirements differ from the traditional LWR } \\
\text { coolant pressure boundary requirements. The } \\
\text { effects of low pressure design are }\end{array}$ \\
\hline
\end{tabular}




\begin{tabular}{|c|c|c|c|}
\hline \multicolumn{4}{|c|}{ II. Multiple Barriers } \\
\hline Criterion & Proposed ARDC Language & Proposed SFR-DC Language & Rationale for Modification \\
\hline & $\begin{array}{l}\text { reactor core, [the reactor coolant pressure } \\
\text { boundary, and the containment and its } \\
\text { associated systems]. Appropriate controls shall } \\
\text { be provided to maintain these variables and } \\
\text { systems within prescribed operating ranges. }\end{array}$ & $\begin{array}{l}\text { adequate safety, including those variables and } \\
\text { systems that can affect the fission process, the } \\
\text { integrity of the reactor core, [the reactor primary } \\
\text { coolant pressure boundary, and the containment } \\
\text { and its associated systems]. Appropriate controls } \\
\text { shall be provided to maintain these variables and } \\
\text { systems within prescribed operating ranges. }\end{array}$ & $\begin{array}{l}\text { acknowledged in NUREG-1368 (page 3-28) } \\
\text { (ML063410561) under discussion of GDC } 4 \\
\text { and on (page 3-30) under GDC 14. The use of } \\
\text { the term "primary" implies the GDC is } \\
\text { applicable to the primary cooling system, not } \\
\text { the intermediate cooling system. (See Section } \\
6.3 .1 \text { of this report for a description of the SFR } \\
\text { cooling systems.) } \\
\text { Section 3.2.4.5 of NUREG-1368, (page 3-57) } \\
\text { discussed the need for an additional GDC } \\
\text { focused on the intermediate cooling system } \\
\text { design requirements. The design requirements } \\
\text { related to the intermediate loop are addressed } \\
\text { in new SFR-DC } 70 \text {. }\end{array}$ \\
\hline 14 & $\begin{array}{l}\text { Reactor [coolant pressure] boundary. } \\
\text { The reactor [coolant pressure] boundary shall } \\
\text { be designed, fabricated, erected, and tested so } \\
\text { as to have an extremely low probability of } \\
\text { abnormal leakage, of rapidly propagating failure, } \\
\text { and of gross rupture. }\end{array}$ & $\begin{array}{l}\text { ARDC with additional SFR-specific clarification } \\
\text { provided: } \\
\text { Reactor [primary coolant-pressure] boundary. } \\
\text { The reactor [primary coolant-pressure] boundary } \\
\text { shall be designed, fabricated, erected, and tested so } \\
\text { as to have an extremely low probability of abnormal } \\
\text { leakage, of rapidly propagating failure, and of gross } \\
\text { rupture. }\end{array}$ & $\begin{array}{l}\text { "Reactor coolant pressure boundary" is } \\
\text { relabeled within the brackets as "reactor } \\
\text { primary coolant boundary" to reflect that the } \\
\text { SFR reactor primary system operates at low- } \\
\text { pressure. Thus, the coolant boundary design } \\
\text { requirements differ from the traditional LWR } \\
\text { coolant pressure boundary requirements. The } \\
\text { effects of low pressure design are } \\
\text { acknowledged in NUREG-1368 (page 3-28) } \\
\text { (ML063410561) under discussion of GDC } 4 \\
\text { and on (page 3-30) under GDC 14. The use of } \\
\text { the term "primary" implies the GDC is } \\
\text { applicable to the primary cooling system, not } \\
\text { the intermediate cooling system. (See Section } \\
6.3 .1 \text { of this report for a description of the SFR } \\
\text { cooling systems.) } \\
\text { Section 3.2.4.5 of NUREG-1368, (page 3-57) } \\
\text { discussed the need for an additional GDC } \\
\text { focused on the intermediate cooling system } \\
\text { design requirements. The design requirements } \\
\text { related to the intermediate loop are addressed } \\
\text { in new SFR-DC 70. } \\
\text { The cover gas boundary is included as part of the } \\
\text { reactor primary coolant boundary (referred to as } \\
\text { RCPB by PRISM) per NUREG-1368 (page 3-38). }\end{array}$ \\
\hline
\end{tabular}




\begin{tabular}{|c|c|c|c|}
\hline \multicolumn{4}{|c|}{ II. Multiple Barriers } \\
\hline Criterion & Proposed ARDC Language & Proposed SFR-DC Language & Rationale for Modification \\
\hline 15 & $\begin{array}{l}\text { Reactor [coolant] system design. } \\
\text { The reactor [coolant] system and associated } \\
\text { auxiliary, control, and protection systems shall be } \\
\text { designed with sufficient margin to assure that the } \\
\text { design conditions of the reactor [coolant } \\
\text { pressure] boundary are not exceeded during any } \\
\text { condition of normal operation, including } \\
\text { anticipated operational occurrences. }\end{array}$ & $\begin{array}{l}\text { ARDC with additional SFR-specific clarification } \\
\text { provided: } \\
\text { Reactor [primary coolant] system design. } \\
\text { The reactor [primary coolant] system and associated } \\
\text { auxiliary, control, and protection systems shall be } \\
\text { designed with sufficient margin to assure that the } \\
\text { design conditions of the reactor [primary } \\
\text { coolantpressure] boundary are not exceeded during } \\
\text { any condition of normal operation, including anticipated } \\
\text { operational occurrences. }\end{array}$ & $\begin{array}{l}\text { "Reactor coolant pressure boundary" is } \\
\text { relabeled within the brackets as "reactor } \\
\text { primary coolant boundary" to reflect that the } \\
\text { SFR reactor primary system operates at low- } \\
\text { pressure. Thus, the coolant boundary design } \\
\text { requirements differ from the traditional LWR } \\
\text { coolant pressure boundary requirements. The } \\
\text { effects of low pressure design are } \\
\text { acknowledged in NUREG-1368 (page 3-28) } \\
\text { (ML063410561) under discussion of GDC } 4 \\
\text { and on (page 3-30) under GDC 14. The use of } \\
\text { the term "primary" implies the GDC is } \\
\text { applicable to the primary cooling system, not } \\
\text { the intermediate cooling system. (See Section } \\
6.3 .1 \text { of this report for a description of the SFR } \\
\text { cooling systems.) } \\
\text { Section 3.2.4.5 of NUREG-1368, (page 3-57) } \\
\text { discussed the need for an additional GDC } \\
\text { focused on the intermediate cooling system } \\
\text { design requirements. The design requirements } \\
\text { related to the intermediate loop are addressed } \\
\text { in new SFR-DC } 70 \text {. } \\
\text { NUREG-1368, Table } 3.3 \text { (page 3-21) } \\
\text { recommended adding the sodium heating } \\
\text { system to the GDC. The sodium heating } \\
\text { system is addressed in new SFR-DC } 72 \text {. }\end{array}$ \\
\hline 16 & $\begin{array}{l}\text { Containment design. } \\
\text { A reactor functional containment, consisting of a } \\
\text { structure surrounding the reactor and its cooling } \\
\text { system or multiple barriers internal and/or } \\
\text { external to the reactor and its cooling system, } \\
\text { shall be provided to effectively control the release } \\
\text { of radioactivity to the environment and to assure } \\
\text { that the functional containment design conditions } \\
\text { important to safety are not exceeded for as long } \\
\text { as postulated accident conditions require. }\end{array}$ & $\begin{array}{l}\text { ARDC with no further SFR-specific clarification } \\
\text { provided. }\end{array}$ & \\
\hline 17 & $\begin{array}{l}\text { Electric power systems. } \\
\text { Electric power systems shall be provided to } \\
\text { permit functioning of structures, systems, and } \\
\text { components important to safety. The safety }\end{array}$ & $\begin{array}{l}\text { ARDC with additional SFR-specific clarification } \\
\text { provided: } \\
\text { Electric power systems. }\end{array}$ & $\begin{array}{l}\text { "Reactor coolant pressure boundary" is } \\
\text { relabeled within the brackets as "reactor } \\
\text { primary coolant boundary" to reflect that the } \\
\text { SFR reactor primary system operates at low- }\end{array}$ \\
\hline
\end{tabular}




\section{Criterion Proposed ARDC Language}

function for the systems shall be to provide sufficient capacity, capability, and reliability to assure that (1) specified acceptable fuel design limits and design conditions of the reactor [coolant pressure] boundary are not exceeded as a result of anticipated operational occurrences and (2) vital functions that rely on electric power are maintained in the event of postulated accidents.

The onsite electric power systems shall have sufficient independence, redundancy, and testability to perform their safety functions, assuming a single failure.

Inspection and testing of electric power systems. Electric power systems important to safety shall be designed to permit appropriate periodic inspection and testing of important areas and features, such as wiring, insulation, connections, and switchboards, to assess the continuity of the systems and the condition of their components.

The systems shall be designed with a capability to test periodically (1) the operability and functional performance of the components of the systems, such as [onsite power sources, relays, switches, and buses] and (2) the operability of the systems as a whole and, under conditions as close to design as practical, the full operation sequence that brings the systems into operation, including operation of applicable portions of the protection system and the transfer of power among systems.

19 Control room.

A control room shall be provided from which actions can be taken to operate the nuclear power unit safely under normal conditions and to maintain it in a safe condition under accident

\section{Proposed SFR-DC Language}

Electric power systems shall be provided to permit functioning of structures, systems, and components important to safety. The safety function for the systems shall be to provide sufficient capacity, capability, and reliability to assure that (1) specified acceptable fuel design limits and design conditions of the reactor [primary coolant-pressure] boundary are not exceeded as a result of anticipated operational occurrences and (2) vital functions that rely on electric power are maintained in the event of postulated accidents.

The onsite electric power systems shall have sufficient independence, redundancy, and testability to perform their safety functions, assuming a single failure.

\section{ARDC with no further SFR-specific clarification} provided.

\section{Rationale for Modification}

pressure. Thus, the coolant boundary design requirements differ from the traditional LWR coolant pressure boundary requirements. The effects of low pressure design are acknowledged in NUREG-1368 (page 3-28) (ML063410561) under discussion of GDC 4 and on (page 3-30) under GDC 14. The use of the term "primary" implies the GDC is applicable to the primary cooling system, not the intermediate cooling system. (See Section 6.3.1 of this report for a description of the SFR cooling systems.)

Section 3.2.4.5 of NUREG-1368, (page 3-57) discussed the need for an additional GDC focused on the intermediate cooling system design requirements. The design requirements related to the intermediate loop are addressed in new SFR-DC 70.
ARDC with no further SFR-specific clarification provided. 

provided to permit access and occupancy of the control room under accident conditions without personnel receiving radiation exposures in excess of 5 rem total effective dose equivalent (TEDE), for the duration of the accident.

Adequate habitability measures shall be provided to permit access and occupancy of the control room during normal operations and under accident conditions.

Equipment at appropriate locations outside the control room shall be provided (1) with a design capability for prompt hot shutdown of the reactor, including necessary instrumentation and controls to maintain the unit in a safe condition during hot shutdown, and (2) with a potential capability for subsequent cold shutdown of the reactor through the use of suitable procedures.

\begin{tabular}{|c|l|l|l|}
\hline \multicolumn{2}{|l|}{ III. Reactivity Control } \\
\hline Criterion & Proposed ARDC Language & Proposed SFR-DC Language & Rationale for Modification \\
\hline 20 & $\begin{array}{l}\text { Protection system functions. } \\
\text { The protection system shall be designed (1) to } \\
\text { initiate automatically the operation of appropriate } \\
\text { systems including the reactivity control systems, } \\
\text { to assure that specified acceptable fuel design } \\
\text { limits are not exceeded as a result of anticipated } \\
\text { operational occurrences and (2) to sense } \\
\text { accident conditions and to initiate the operation of } \\
\text { systems and components important to safety. }\end{array}$ & $\begin{array}{l}\text { ARDC with no further SFR-specific clarification } \\
\text { provided. }\end{array}$ \\
\hline 21 & $\begin{array}{l}\text { Protection system reliability and testability. } \\
\text { The protection system shall be designed for high } \\
\text { functional reliability and inservice testability } \\
\text { commensurate with the safety functions to be } \\
\text { performed. Redundancy and independence } \\
\text { designed into the protection system shall be } \\
\text { sufficient to assure that (1) no single failure } \\
\text { results in loss of the protection function and (2) } \\
\text { removal from service of any component or }\end{array}$ & $\begin{array}{l}\text { ARDC with no further SFR-specific clarification } \\
\text { provided. }\end{array}$ & \\
\hline
\end{tabular}




\begin{tabular}{|c|c|c|c|}
\hline \multicolumn{4}{|c|}{ III. Reactivity Control } \\
\hline Criterion & Proposed ARDC Language & Proposed SFR-DC Language & Rationale for Modification \\
\hline & $\begin{array}{l}\text { channel does not result in loss of the required } \\
\text { minimum redundancy unless the acceptable } \\
\text { reliability of operation of the protection system } \\
\text { can be otherwise demonstrated. The protection } \\
\text { system shall be designed to permit periodic } \\
\text { testing of its functioning when the reactor is in } \\
\text { operation, including a capability to test channels } \\
\text { independently to determine failures and losses of } \\
\text { redundancy that may have occurred. }\end{array}$ & & \\
\hline 22 & $\begin{array}{l}\text { Protection system independence. } \\
\text { The protection system shall be designed to } \\
\text { assure that the effects of natural phenomena, } \\
\text { and of normal operating, maintenance, testing, } \\
\text { and postulated accident conditions on redundant } \\
\text { channels do not result in loss of the protection } \\
\text { function, or shall be demonstrated to be } \\
\text { acceptable on some other defined basis. Design } \\
\text { techniques, such as functional diversity or } \\
\text { diversity in component design and principles of } \\
\text { operation, shall be used to the extent practical to } \\
\text { prevent loss of the protection function. }\end{array}$ & $\begin{array}{l}\text { ARDC with no further SFR-specific clarification } \\
\text { provided. }\end{array}$ & \\
\hline 23 & $\begin{array}{l}\text { Protection system failure modes. } \\
\text { The protection system shall be designed to fail } \\
\text { into a safe state or into a state demonstrated to } \\
\text { be acceptable on some other defined basis if } \\
\text { conditions such as disconnection of the system, } \\
\text { loss of energy (e.g., [electric power, instrument } \\
\text { air]), or postulated adverse environments (e.g., } \\
\text { [extreme heat or cold, fire, pressure, steam, } \\
\text { water, and radiation]) are experienced. }\end{array}$ & $\begin{array}{l}\text { ARDC with additional SFR-specific clarification } \\
\text { provided: } \\
\text { Protection system failure modes. } \\
\text { The protection system shall be designed to fail into a } \\
\text { safe state or into a state demonstrated to be } \\
\text { acceptable on some other defined basis if conditions } \\
\text { such as disconnection of the system, loss of energy } \\
\text { (e.g., [electric power, instrument air]), or postulated } \\
\text { adverse environments (e.g., [extreme heat or cold, } \\
\text { fire, sodium and sodium reaction products, } \\
\text { pressure, steam, water, and radiation]) are } \\
\text { experienced. }\end{array}$ & $\begin{array}{l}\text { The first bracketed phrase from the ARDC, } \\
\text { "electric power, instrument air" is retained } \\
\text { for the example application of SFR-DC } 23 \text {, } \\
\text { because these examples are generic. } \\
\text { In NUREG-1368, Table } 3.3 \text { (page 3-21), } \\
\text { (ML063410561) NRC staff recommended } \\
\text { adding the phrase "sodium and sodium } \\
\text { reaction products" to the list of postulated } \\
\text { adverse environments in the GDC. Therefore, } \\
\text { "sodium and sodium reaction products" are } \\
\text { added to the second bracketed list of } \\
\text { examples in ARDC } 23 \text { and "pressure, steam, } \\
\text { and water" are removed in the SFR-DC } 23 \\
\text { example application of the ARDC } 23 \text { guidance } \\
\text { because, based on available design } \\
\text { documentation, the latter items are not } \\
\text { applicable to SFR design protection system } \\
\text { failure modes. }\end{array}$ \\
\hline
\end{tabular}




\begin{tabular}{|c|c|c|c|}
\hline \multicolumn{4}{|c|}{ III. Reactivity Control } \\
\hline Criterion & Proposed ARDC Language & Proposed SFR-DC Language & Rationale for Modification \\
\hline 24 & $\begin{array}{l}\text { Separation of protection and control systems. } \\
\text { The protection system shall be separated from } \\
\text { control systems to the extent that failure of any } \\
\text { single control system component or channel, or } \\
\text { failure or removal from service of any single } \\
\text { protection system component or channel which is } \\
\text { common to the control and protection systems } \\
\text { leaves intact a system satisfying all reliability, } \\
\text { redundancy, and independence requirements of } \\
\text { the protection system. Interconnection of the } \\
\text { protection and control systems shall be limited so } \\
\text { as to assure that safety is not significantly } \\
\text { impaired. }\end{array}$ & $\begin{array}{l}\text { ARDC with no further SFR-specific clarification } \\
\text { provided. }\end{array}$ & \\
\hline 25 & $\begin{array}{l}\text { Protection system requirements for reactivity } \\
\text { control malfunctions. } \\
\text { The protection system shall be designed to } \\
\text { assure that specified acceptable fuel design limits } \\
\text { are not exceeded for any single malfunction of } \\
\text { the reactivity control systems, such as accidental } \\
\text { withdrawal (not ejection or dropout) of control rods. }\end{array}$ & $\begin{array}{l}\text { ARDC with no further SFR-specific clarification } \\
\text { provided. }\end{array}$ & \\
\hline 26 & $\begin{array}{l}\text { Reactivity control system redundancy and } \\
\text { capability. } \\
\text { [Two] independent reactivity control systems of } \\
\text { different design principles shall be provided. One } \\
\text { of the systems shall use control rods, preferably } \\
\text { including a positive means for inserting the rods, } \\
\text { and shall be capable of reliably controlling } \\
\text { reactivity changes to assure that under conditions } \\
\text { of normal operation, including anticipated } \\
\text { operational occurrences, and with appropriate } \\
\text { margin for malfunctions such as stuck rods, } \\
\text { specified acceptable fuel design limits are not } \\
\text { exceeded. A second reactivity control system } \\
\text { shall be capable of reliably controlling the rate of } \\
\text { reactivity changes resulting from planned, normal } \\
\text { power changes [(including xenon burnout)] to } \\
\text { assure acceptable fuel design limits are not } \\
\text { exceeded. One of the systems shall be capable } \\
\text { of holding the reactor core subcritical under cold } \\
\text { conditions. }\end{array}$ & $\begin{array}{l}\text { ARDC with additional SFR-specific clarification } \\
\text { provided: } \\
\text { Reactivity control system redundancy and capability. } \\
\text { [Two] independent reactivity control systems of } \\
\text { different design principles shall be provided. One of the } \\
\text { systems shall use control rods, preferably including a } \\
\text { positive means for inserting the rods, and shall be } \\
\text { capable of reliably controlling reactivity changes to } \\
\text { assure that under conditions of normal operation, } \\
\text { including anticipated operational occurrences, and with } \\
\text { appropriate margin for malfunctions such as stuck } \\
\text { rods, specified acceptable fuel design limits are not } \\
\text { exceeded. A second reactivity control system shall be } \\
\text { capable of reliably controlling the rate of reactivity } \\
\text { changes resulting from planned, normal power } \\
\text { changes [(including xenon burnout)] to assure } \\
\text { acceptable fuel design limits are not exceeded. One of } \\
\text { the systems shall be capable of holding the reactor } \\
\text { core subcritical under cold conditions. }\end{array}$ & $\begin{array}{l}\text { Xenon burnout is not an issue of concern for a } \\
\text { fast reactor; therefore, this bracketed phrase is } \\
\text { removed from SFR-DC } 26 \text { per NUREG-1368, } \\
\text { Table 3.3 (page 3-22) (ML063410561). } \\
\text { Also, "cold conditions" is a relative term for all } \\
\text { non-LWR advanced reactor designs. This term } \\
\text { will have to be defined by the applicant within } \\
\text { the PDC. }\end{array}$ \\
\hline
\end{tabular}


27 Combined reactivity control systems capability. The reactivity control systems shall be designed to have a combined capability of reliably controlling reactivity changes to assure that under postulated accident conditions and with appropriate margin for stuck rods the capability to cool the core is maintained.

28 Reactivity limits.

The reactivity control systems shall be designed with appropriate limits on the potential amount and rate of reactivity increase to assure that the effects of postulated reactivity accidents can neither (1) result in damage to the reactor [coolant pressure] boundary greater than limited local yielding nor (2) sufficiently disturb the core, its support structures or other reactor vessel internals to impair significantly the capability to cool the core. These postulated reactivity accidents shall include consideration of [rod ejection (unless prevented by positive means), rod dropout, steam line rupture, changes in reactor coolant temperature and pressure, and cold water addition]

Proposed SFR-DC Language

ARDC with no further SFR-specific clarification provided.

\section{r}

\section{ARDC with additional SFR-specific clarification} provided:

\section{Reactivity limits.}

The reactivity control systems shall be designed with appropriate limits on the potential amount and rate of reactivity increase to assure that the effects of postulated reactivity accidents can neither (1) result in damage to the reactor [primary coolant-pressure] boundary greater than limited local yielding nor (2) sufficiently disturb the core, its support structures or other reactor vessel internals to impair significantly the capability to cool the core. These postulated reactivity accidents shall include consideration of [rod ejection (unless prevented by positive means), rod dropout, steam line rupture, changes in reactor coolant temperature and pressure, and cold water additionchanges in power/flow rates].

\section{Rationale for Modification}

"Reactor coolant pressure boundary" is relabeled within the brackets as "reactor primary coolant boundary" to reflect that the SFR reactor primary system operates at lowpressure. Thus, the coolant boundary design requirements differ from the traditional LWR coolant pressure boundary requirements. The effects of low pressure design are acknowledged in NUREG-1368 (page 3-28) (ML063410561) under discussion of GDC 4 and on (page 3-30) under GDC 14. The use of the term "primary" implies the GDC is applicable to the primary cooling system, not the intermediate cooling system. (See Section 6.3.1 of this report for a description of the SFR cooling systems.)

Section 3.2.4.5 of NUREG-1368, (page 3-57) discussed the need for an additional GDC focused on the intermediate cooling system design requirements. The design requirements related to the intermediate loop are addressed in new SFR-DC 70.

NUREG-1368 (page 3-37) noted that some of the postulated reactivity accidents that must be considered per part 2 of the GDC are LWR specific. Specifically, rod ejection is a potential accident in a reactor with a pressurized coolant system (e.g. PWR) and rod dropout is associated with BWR designs. In PRISM, rod ejection is prevented by a mechanical control driveline and mechanism, and by having the rod bundle weight greater than the uplift force of the core flow. Steam line rupture and cold 


\begin{tabular}{|c|c|c|c|}
\hline \multicolumn{4}{|c|}{ III. Reactivity Control } \\
\hline Criterion & Proposed ARDC Language & Proposed SFR-DC Language & Rationale for Modification \\
\hline & & & $\begin{array}{l}\text { water addition were noted by the PRISM } \\
\text { applicant in NUREG-1368 to be specific to } \\
\text { LWRs because the secondary steam cycle in } \\
\text { an SFR is separated from the primary sodium } \\
\text { loop by an intermediate loop. NRC staff agreed } \\
\text { with this position. The last sentence should } \\
\text { reflect changes in primary coolant temperature } \\
\text { and changes in power/flow rates as the } \\
\text { postulated reactivity accidents considered for } \\
\text { SFRs. Therefore, the text in the second } \\
\text { bracket in ARDC } 28 \text { is adjusted to reflect these } \\
\text { SFR design-specific details as outlined in } \\
\text { NUREG-1368 for the example application of } \\
\text { ARDC } 28 \text { to SFR-DC } 28 \text {. } \\
\text { NUREG-1368 (page 3-37) recommended } \\
\text { replacing "rod ejection" with" accidental rod } \\
\text { withdrawal," but this is explicitly addressed in } \\
\text { ARDC } 25 \text {. }\end{array}$ \\
\hline 29 & $\begin{array}{l}\text { Protection against anticipated operational } \\
\text { occurrences. } \\
\text { The protection and reactivity control systems } \\
\text { shall be designed to assure an extremely high } \\
\text { probability of accomplishing their safety functions } \\
\text { in the event of anticipated operational } \\
\text { occurrences. }\end{array}$ & $\begin{array}{l}\text { ARDC with no further SFR-specific clarification } \\
\text { provided. }\end{array}$ & \\
\hline
\end{tabular}

\begin{tabular}{|c|c|c|c|}
\hline \multicolumn{4}{|c|}{ IV. Fluid Systems } \\
\hline Criterion & Proposed ARDC Language & Proposed SFR-DC Language & Rationale for Modification \\
\hline 30 & $\begin{array}{l}\text { Quality of reactor [coolant pressure] boundary. } \\
\text { Components which are part of the reactor } \\
\text { [coolant pressure] boundary shall be designed, } \\
\text { fabricated, erected, and tested to the highest } \\
\text { quality standards practical. Means shall be } \\
\text { provided for detecting and, to the extent practical, } \\
\text { identifying the location of the source of reactor } \\
\text { [coolant] leakage. }\end{array}$ & $\begin{array}{l}\text { ARDC with additional SFR-specific clarification } \\
\text { provided: } \\
\text { Quality of reactor [primary coolant-pressure] } \\
\text { boundary. } \\
\text { Components which are part of the reactor [primary } \\
\text { coolant-pressure] boundary shall be designed, } \\
\text { fabricated, erected, and tested to the highest quality } \\
\text { standards practical. Means shall be provided for } \\
\text { detecting and, to the extent practical, identifying the } \\
\text { location of the source of reactor [coolant] leakage. }\end{array}$ & $\begin{array}{l}\text { "Reactor coolant pressure boundary" is } \\
\text { relabeled within the brackets as "reactor } \\
\text { primary coolant boundary" to reflect that the } \\
\text { SFR reactor primary system operates at low- } \\
\text { pressure. Thus, the coolant boundary design } \\
\text { requirements differ from the traditional LWR } \\
\text { coolant pressure boundary requirements. The } \\
\text { effects of low pressure design are } \\
\text { acknowledged in NUREG-1368 (page 3-28) } \\
\text { (ML063410561) under discussion of GDC } 4 \\
\text { and on (page 3-30) under GDC } 14 \text {. The use of } \\
\text { the term "primary" implies the GDC is }\end{array}$ \\
\hline
\end{tabular}




\begin{tabular}{|c|c|c|c|}
\hline \multicolumn{4}{|c|}{ IV. Fluid Systems } \\
\hline Criterion & Proposed ARDC Language & Proposed SFR-DC Language & Rationale for Modification \\
\hline & & & $\begin{array}{l}\text { applicable to the primary cooling system, not } \\
\text { the intermediate cooling system. (See Section } \\
6.3 .1 \text { of this report for a description of the SFR } \\
\text { cooling systems.) } \\
\text { Section 3.2.4.5 of NUREG-1368, (page 3-57) } \\
\text { discussed the need for an additional GDC } \\
\text { focused on the intermediate cooling system } \\
\text { design requirements. The design requirements } \\
\text { related to the intermediate loop are addressed } \\
\text { in new SFR-DC } 70 \text {. } \\
\text { The cover gas boundary is included as part of } \\
\text { the reactor primary coolant boundary (referred } \\
\text { to as RCPB by PRISM) per NUREG-1368 } \\
\text { (page 3-38). }\end{array}$ \\
\hline 31 & $\begin{array}{l}\text { Fracture prevention of reactor [coolant } \\
\text { pressure] boundary. } \\
\text { The reactor [coolant pressure] boundary shall } \\
\text { be designed with sufficient margin to assure that } \\
\text { when stressed under operating, maintenance, } \\
\text { testing, and postulated accident conditions (1) the } \\
\text { boundary behaves in a nonbrittle manner and (2) } \\
\text { the probability of rapidly propagating fracture is } \\
\text { minimized. The design shall reflect consideration } \\
\text { of service temperatures [and other conditions] } \\
\text { of the boundary material under operating, } \\
\text { maintenance, testing, and postulated accident } \\
\text { conditions and the uncertainties in determining } \\
\text { (1) material properties, (2) the effects of } \\
\text { irradiation on material properties, (3) residual, } \\
\text { steady state and transient stresses, and (4) size } \\
\text { of flaws. }\end{array}$ & $\begin{array}{l}\text { ARDC with additional SFR-specific clarification } \\
\text { provided: } \\
\text { Fracture prevention of reactor [primary coolant } \\
\text { pressure] boundary. } \\
\text { The reactor [primary coolant-pressure] boundary } \\
\text { shall be designed with sufficient margin to assure that } \\
\text { when stressed under operating, maintenance, testing, } \\
\text { and postulated accident conditions (1) the boundary } \\
\text { behaves in a nonbrittle manner and (2) the probability } \\
\text { of rapidly propagating fracture is minimized. The } \\
\text { design shall reflect consideration of service } \\
\text { temperatures [, service degradation of material } \\
\text { properties, creep, fatigue, stress rupture, and other } \\
\text { conditions] of the boundary material under operating, } \\
\text { maintenance, testing, and postulated accident } \\
\text { conditions and the uncertainties in determining (1) } \\
\text { material properties, (2) the effects of irradiation on } \\
\text { material properties, (3) residual, steady state and } \\
\text { transient stresses, and (4) size of flaws. }\end{array}$ & $\begin{array}{l}\text { "Reactor coolant pressure boundary" is } \\
\text { relabeled within the brackets as "reactor } \\
\text { primary coolant boundary" to reflect that the } \\
\text { SFR reactor primary system operates at low- } \\
\text { pressure. Thus, the coolant boundary design } \\
\text { requirements differ from the traditional LWR } \\
\text { coolant pressure boundary requirements. The } \\
\text { effects of low pressure design are } \\
\text { acknowledged in NUREG-1368 (page 3-28) } \\
\text { (ML063410561) under discussion of GDC } 4 \\
\text { and on (page 3-30) under GDC 14. The use of } \\
\text { the term "primary" implies the GDC is } \\
\text { applicable to the primary cooling system, not } \\
\text { the intermediate cooling system. (See Section } \\
6.3 .1 \text { of this report for a description of the SFR } \\
\text { cooling systems.) } \\
\text { Section 3.2.4.5 of NUREG-1368, (page 3-57) } \\
\text { discussed the need for an additional GDC } \\
\text { focused on the intermediate cooling system } \\
\text { design requirements. The design requirements } \\
\text { related to the intermediate loop are addressed } \\
\text { in new SFR-DC } 70 \text {. } \\
\text { The words "service degradation of material } \\
\text { properties, creep, fatigue, stress rupture" were }\end{array}$ \\
\hline
\end{tabular}




\begin{tabular}{|c|c|c|c|}
\hline \multicolumn{4}{|c|}{$\begin{array}{l}\text { IV. Fluid Systems } \\
\end{array}$} \\
\hline Criterion & Proposed ARDC Language & Proposed SFR-DC Language & Rationale for Modification \\
\hline & & & $\begin{array}{l}\text { added to the bracketed list based on NUREG- } \\
1368 \text {, Table } 3.3 \text { (page 3-22) recommendation. } \\
\text { The "effects of coolant chemistry" noted in } \\
\text { NUREG-1368, Table } 3.3 \text { (page 3-22) are } \\
\text { considered to be covered by the revised SFR- } \\
\text { DC. Service degradation, creep, fatigue, and } \\
\text { stress rupture can be a particular concern for } \\
\text { sodium reactors and fast neutron fluence. }\end{array}$ \\
\hline 32 & $\begin{array}{l}\text { Inspection of reactor [coolant pressure] } \\
\text { boundary. } \\
\text { Components which are part of the reactor } \\
\text { [coolant pressure] boundary shall be designed } \\
\text { to permit (1) periodic inspection and testing of } \\
\text { important areas and features to assess their } \\
\text { structural and leaktight integrity, and (2) an } \\
\text { appropriate material surveillance program for the } \\
\text { reactor vessel. }\end{array}$ & $\begin{array}{l}\text { ARDC with additional SFR-specific clarification } \\
\text { provided: } \\
\text { Inspection of reactor [primary coolant-pressure] } \\
\text { boundary. } \\
\text { Components which are part of the reactor [primary } \\
\text { coolant-pressure] boundary shall be designed to } \\
\text { permit (1) periodic inspection and testing of important } \\
\text { areas and features to assess their structural and } \\
\text { leaktight integrity, and (2) an appropriate material } \\
\text { surveillance program for the reactor vessel. }\end{array}$ & $\begin{array}{l}\text { "Reactor coolant pressure boundary" is } \\
\text { relabeled within the brackets as "reactor } \\
\text { primary coolant boundary" to reflect that the } \\
\text { SFR reactor primary system operates at low- } \\
\text { pressure. Thus, the coolant boundary design } \\
\text { requirements differ from the traditional LWR } \\
\text { coolant pressure boundary requirements. The } \\
\text { effects of low pressure design are } \\
\text { acknowledged in NUREG-1368 (page 3-28) } \\
\text { (ML063410561) under discussion of GDC } 4 \\
\text { and on (page 3-30) under GDC 14. The use of } \\
\text { the term "primary" implies the GDC is } \\
\text { applicable to the primary cooling system, not } \\
\text { the intermediate cooling system. (See Section } \\
6.3 .1 \text { of this report for a description of the SFR } \\
\text { cooling systems.) } \\
\text { Section 3.2.4.5 of NUREG-1368, (page 3-57) } \\
\text { discussed the need for an additional GDC } \\
\text { focused on the intermediate cooling system } \\
\text { design requirements. The design requirements } \\
\text { related to the intermediate loop are addressed } \\
\text { in new SFR-DC } 70 \text {. }\end{array}$ \\
\hline 33 & $\begin{array}{l}\text { Reactor [coolant] inventory maintenance. } \\
\text { A system to maintain reactor [coolant] inventory } \\
\text { for protection against small breaks in the reactor } \\
\text { [coolant pressure] boundary shall be provided } \\
\text { as necessary to assure that specified acceptable } \\
\text { fuel design limits are not exceeded as a result of } \\
\text { reactor [coolant] inventory loss due to leakage } \\
\text { from the reactor [coolant pressure] boundary } \\
\text { and rupture of small piping or other small } \\
\text { components which are part of the boundary. }\end{array}$ & $\begin{array}{l}\text { ARDC with additional SFR-specific clarification } \\
\text { provided: } \\
\text { Reactor [primary coolant] inventory maintenance. } \\
\text { A system to maintain reactor [coolant] inventory for } \\
\text { protection against small breaks in the reactor [primary } \\
\text { coolant pressure] boundary shall be provided as } \\
\text { necessary to assure that specified acceptable fuel } \\
\text { design limits are not exceeded as a result of reactor } \\
\text { [primary coolant] inventory loss due to leakage from } \\
\text { the reactor [primary coolant pressure] boundary and }\end{array}$ & $\begin{array}{l}\text { "Reactor coolant pressure boundary" is } \\
\text { relabeled within the brackets as "reactor } \\
\text { primary coolant boundary" to reflect that the } \\
\text { SFR reactor primary system operates at low- } \\
\text { pressure. Thus, the coolant boundary design } \\
\text { requirements differ from the traditional LWR } \\
\text { coolant pressure boundary requirements. The } \\
\text { effects of low pressure design are } \\
\text { acknowledged in NUREG-1368 (page 3-28) } \\
\text { (ML063410561) under discussion of GDC } 4 \\
\text { and on (page 3-30) under GDC 14. The use of }\end{array}$ \\
\hline
\end{tabular}




\begin{tabular}{|c|c|c|c|}
\hline \multicolumn{4}{|c|}{ IV. Fluid Systems } \\
\hline Criterion & Proposed ARDC Language & Proposed SFR-DC Language & Rationale for Modification \\
\hline & & $\begin{array}{l}\text { rupture of small piping or other small components } \\
\text { which are part of the boundary. }\end{array}$ & $\begin{array}{l}\text { the term "primary" implies the GDC is } \\
\text { applicable to the primary cooling system, not } \\
\text { the intermediate cooling system. (See Section } \\
6.3 .1 \text { of this report for a description of the SFR } \\
\text { cooling systems.) } \\
\text { Section 3.2.4.5 of NUREG-1368, (page 3-57) } \\
\text { discussed the need for an additional GDC } \\
\text { focused on the intermediate cooling system } \\
\text { design requirements. The design requirements } \\
\text { related to the intermediate loop are addressed } \\
\text { in new SFR-DC } 70 \text {. } \\
\text { Both pool- and loop-type SFR designs limit } \\
\text { loss of primary coolant so that an inventory } \\
\text { adequate to perform the safety function of the } \\
\text { residual heat removal system is maintained } \\
\text { under operating, maintenance, testing, and } \\
\text { postulated accident conditions. }\end{array}$ \\
\hline 34 & $\begin{array}{l}\text { Residual heat removal. } \\
\text { A system to remove residual heat shall be } \\
\text { provided. The system safety function shall be to } \\
\text { transfer fission product decay heat and other } \\
\text { residual heat from the reactor core to an ultimate } \\
\text { heat sink at a rate such that specified acceptable } \\
\text { fuel design limits and the design conditions of the } \\
\text { reactor [coolant pressure] boundary are not } \\
\text { exceeded under all plant shutdown conditions } \\
\text { following normal operation, including anticipated } \\
\text { operational occurrences, and to provide } \\
\text { continuous effective core cooling during } \\
\text { postulated accidents. } \\
\text { Suitable redundancy in components and features, } \\
\text { and suitable interconnections, leak detection, and } \\
\text { isolation capabilities shall be provided to assure } \\
\text { that the system safety function can be } \\
\text { accomplished, assuming a single failure. }\end{array}$ & $\begin{array}{l}\text { ARDC with additional SFR-specific clarification } \\
\text { provided: } \\
\text { Residual heat removal. } \\
\text { A system to remove residual heat shall be provided. } \\
\text { The system safety function shall be to transfer fission } \\
\text { product decay heat and other residual heat from the } \\
\text { reactor core to an ultimate heat sink at a rate such that } \\
\text { specified acceptable fuel design limits and the design } \\
\text { conditions of the reactor [primary coolant pressure] } \\
\text { boundary are not exceeded under all plant shutdown } \\
\text { conditions following normal operation, including } \\
\text { anticipated operational occurrences, and to provide } \\
\text { continuous effective core cooling during postulated } \\
\text { accidents. } \\
\text { Suitable redundancy in components and features, and } \\
\text { suitable interconnections, leak detection, and isolation } \\
\text { capabilities shall be provided to assure that the system } \\
\text { safety function can be accomplished, assuming a } \\
\text { single failure. }\end{array}$ & $\begin{array}{l}\text { "Reactor coolant pressure boundary" is } \\
\text { relabeled within the brackets as "reactor } \\
\text { primary coolant boundary" to reflect that the } \\
\text { SFR reactor primary system operates at low- } \\
\text { pressure. Thus, the coolant boundary design } \\
\text { requirements differ from the traditional LWR } \\
\text { coolant pressure boundary requirements. The } \\
\text { effects of low pressure design are } \\
\text { acknowledged in NUREG-1368 (page 3-28) } \\
\text { (ML063410561) under discussion of GDC } 4 \\
\text { and on (page 3-30) under GDC 14. The use of } \\
\text { the term "primary" implies the GDC is } \\
\text { applicable to the primary cooling system, not } \\
\text { the intermediate cooling system. (See Section } \\
6.3 .1 \text { of this report for a description of the SFR } \\
\text { cooling systems.) } \\
\text { Section 3.2.4.5 of NUREG-1368, (page 3-57) } \\
\text { discussed the need for an additional GDC } \\
\text { focused on the intermediate cooling system } \\
\text { design requirements. The design requirements } \\
\text { related to the intermediate loop are addressed } \\
\text { in new SFR-DC } 70 \text {. }\end{array}$ \\
\hline
\end{tabular}




\begin{tabular}{|c|c|c|c|}
\hline \multicolumn{4}{|c|}{ IV. Fluid Systems } \\
\hline Criterion & Proposed ARDC Language & Proposed SFR-DC Language & Rationale for Modification \\
\hline & & & $\begin{array}{l}\text { The SFR designs reviewed satisfied NRC staff } \\
\text { concerns in NUREG-1368 (page } 3-41 \text { ) } \\
\text { regarding residual heat removal system heat } \\
\text { transfer fluid compatibility and pressure } \\
\text { differential with the primary coolant for designs } \\
\text { where they are separated by a single passive } \\
\text { barrier. }\end{array}$ \\
\hline 35 & $\begin{array}{l}\text { Advanced Reactor Design Criterion for core } \\
\text { cooling under accident conditions is contained in } \\
\text { ARDC-34. }\end{array}$ & $\begin{array}{l}\text { ARDC with no further SFR-specific clarification } \\
\text { provided. }\end{array}$ & \\
\hline 36 & $\begin{array}{l}\text { Inspection of residual heat removal system. } \\
\text { The residual heat removal system shall be } \\
\text { designed to permit appropriate periodic } \\
\text { inspection of important components, such as } \\
\text { [spray rings in the reactor pressure vessel, } \\
\text { water injection nozzles, and piping], to assure } \\
\text { the integrity and capability of the system. }\end{array}$ & $\begin{array}{l}\text { ARDC with additional SFR-specific clarification } \\
\text { provided: } \\
\text { Inspection of residual heat removal system. } \\
\text { The residual heat removal system shall be designed to } \\
\text { permit appropriate periodic inspection of important } \\
\text { components, such as [spray rings in the reactor } \\
\text { pressure vessel, water injection nozzles, heat } \\
\text { exchangers and piping], to assure the integrity and } \\
\text { capability of the system. }\end{array}$ & $\begin{array}{l}\text { The examples are LWR specific and are } \\
\text { replaced with more design-specific examples }\end{array}$ \\
\hline 37 & $\begin{array}{l}\text { Testing of residual heat removal system. } \\
\text { The residual heat removal system shall be } \\
\text { designed to permit appropriate periodic functional } \\
\text { testing to assure (1) the structural integrity of its } \\
\text { components, (2) the operability and performance } \\
\text { of the system components, and ( } 3 \text { ) the operability } \\
\text { of the system as a whole and, under conditions } \\
\text { as close to design as practical, the performance } \\
\text { of the full operational sequence that brings the } \\
\text { system into operation, including operation of } \\
\text { associated systems and interfaces with an } \\
\text { ultimate heat sink. }\end{array}$ & $\begin{array}{l}\text { ARDC with no further SFR-specific clarification } \\
\text { provided. }\end{array}$ & \\
\hline 38 & $\begin{array}{l}\text { Containment heat removal. } \\
\text { A system to remove heat from the reactor } \\
\text { containment shall be provided as necessary to } \\
\text { maintain the containment pressure and } \\
\text { temperature within acceptable limits following } \\
\text { postulated accidents. } \\
\text { Suitable redundancy in components and features, } \\
\text { and suitable interconnections, leak detection, }\end{array}$ & $\begin{array}{l}\text { ARDC with no further SFR-specific clarification } \\
\text { provided. }\end{array}$ & \\
\hline
\end{tabular}




\begin{tabular}{|c|c|c|c|}
\hline \multicolumn{4}{|c|}{ IV. Fluid Systems } \\
\hline Criterion & Proposed ARDC Language & Proposed SFR-DC Language & Rationale for Modification \\
\hline & $\begin{array}{l}\text { isolation, and containment capabilities shall be } \\
\text { provided to assure that the system safety function } \\
\text { can be accomplished, assuming a single failure. }\end{array}$ & & \\
\hline 39 & $\begin{array}{l}\text { Inspection of containment heat removal system. } \\
\text { The containment heat removal system shall be } \\
\text { designed to permit appropriate periodic } \\
\text { inspection of important components, such as [the } \\
\text { torus, sumps, spray nozzles, and piping] to } \\
\text { assure the integrity and capability of the system. }\end{array}$ & $\begin{array}{l}\text { ARDC with additional SFR-specific clarification } \\
\text { provided: } \\
\text { Inspection of containment heat removal system. } \\
\text { The containment heat removal system shall be } \\
\text { designed to permit appropriate periodic inspection of } \\
\text { important components, such as [the torus, sumps, } \\
\text { spray nozzles, and-piping] to assure the integrity and } \\
\text { capability of the system. }\end{array}$ & The LWR-specific examples are removed. \\
\hline 40 & $\begin{array}{l}\text { Testing of containment heat removal system. } \\
\text { The containment heat removal system shall be } \\
\text { designed to permit appropriate periodic functional } \\
\text { testing to assure (1) the structural integrity of its } \\
\text { components, (2) the operability and performance } \\
\text { of the system components, and (3) the operability } \\
\text { of the system as a whole, and under conditions } \\
\text { as close to the design as practical, the } \\
\text { performance of the full operational sequence that } \\
\text { brings the system into operation, including } \\
\text { operation of associated systems. }\end{array}$ & $\begin{array}{l}\text { ARDC with no further SFR-specific clarification } \\
\text { provided. }\end{array}$ & \\
\hline 41 & $\begin{array}{l}\text { Containment atmosphere cleanup. } \\
\text { Systems to control fission products, [hydrogen, } \\
\text { oxygen,] and other substances which may be } \\
\text { released into the reactor containment shall be } \\
\text { provided as necessary to reduce, consistent with } \\
\text { the functioning of other associated systems, the } \\
\text { concentration and quality of fission products } \\
\text { released to the environment following postulated } \\
\text { accidents, and to control the concentration of } \\
\text { [hydrogen or oxygen] and other substances in } \\
\text { the containment atmosphere following postulated } \\
\text { accidents to assure that containment integrity is } \\
\text { maintained. } \\
\text { Each system shall have suitable redundancy in } \\
\text { components and features, and suitable } \\
\text { interconnections, leak detection, isolation, and } \\
\text { containment capabilities to assure that its safety } \\
\text { function can be accomplished, assuming a single }\end{array}$ & $\begin{array}{l}\text { ARDC with additional SFR-specific clarification } \\
\text { provided: } \\
\text { Containment atmosphere cleanup. } \\
\text { Systems to control fission products, [hydrogen, } \\
\text { oxygenreaction products,] and other substances } \\
\text { which may be released into the reactor containment } \\
\text { shall be provided as necessary to reduce, consistent } \\
\text { with the functioning of other associated systems, the } \\
\text { concentration and quality of fission products released } \\
\text { to the environment following postulated accidents, and } \\
\text { to control the concentration of [hydrogen or } \\
\text { oxygenreaction products] and other substances in } \\
\text { the containment atmosphere following postulated } \\
\text { accidents to assure that containment integrity is } \\
\text { maintained. } \\
\text { Each system shall have suitable redundancy in } \\
\text { components and features, and suitable }\end{array}$ & $\begin{array}{l}\text { The examples are LWR specific and are } \\
\text { replaced with more design-specific examples. } \\
\text { Means to detect sodium leakage and to limit } \\
\text { and control the extent of sodium reactions are } \\
\text { addressed in new SFR-DC } 73\end{array}$ \\
\hline
\end{tabular}




\begin{tabular}{|c|c|c|c|}
\hline \multicolumn{4}{|c|}{ IV. Fluid Systems } \\
\hline Criterion & Proposed ARDC Language & Proposed SFR-DC Language & Rationale for Modification \\
\hline & failure. & $\begin{array}{l}\text { interconnections, leak detection, isolation, and } \\
\text { containment capabilities to assure that its safety } \\
\text { function can be accomplished, assuming a single } \\
\text { failure. }\end{array}$ & \\
\hline 42 & $\begin{array}{l}\text { Inspection of containment atmosphere cleanup } \\
\text { systems. } \\
\text { The containment atmosphere cleanup systems } \\
\text { shall be designed to permit appropriate periodic } \\
\text { inspection of important components, such as filter } \\
\text { frames, ducts, and piping to assure the integrity } \\
\text { and capability of the systems. }\end{array}$ & $\begin{array}{l}\text { ARDC with no further SFR-specific clarification } \\
\text { provided. }\end{array}$ & \\
\hline 43 & $\begin{array}{l}\text { Testing of containment atmosphere cleanup } \\
\text { systems. } \\
\text { The containment atmosphere cleanup systems } \\
\text { shall be designed to permit appropriate periodic } \\
\text { functional testing to assure (1) the structural } \\
\text { integrity of its components, (2) the operability and } \\
\text { performance of the system components, and (3) } \\
\text { the operability of the systems as a whole and, } \\
\text { under conditions as close to design as practical, } \\
\text { the performance of the full operational sequence } \\
\text { that brings the systems into operation, including } \\
\text { the operation of associated systems. }\end{array}$ & $\begin{array}{l}\text { ARDC with no further SFR-specific clarification } \\
\text { provided. }\end{array}$ & \\
\hline 44 & $\begin{array}{l}\text { Structural and equipment cooling. } \\
\text { In addition to the heat rejection capability of the } \\
\text { residual heat removal system, systems to transfer } \\
\text { heat from structures, systems, and components } \\
\text { important to safety, to an ultimate heat sink shall } \\
\text { be provided, as necessary to transfer the } \\
\text { combined heat load of these structures, systems, } \\
\text { and components under normal operating and } \\
\text { accident conditions. } \\
\text { Suitable redundancy in components and features, } \\
\text { and suitable interconnections, leak detection, and } \\
\text { isolation capabilities shall be provided to assure } \\
\text { that each system safety function can be } \\
\text { accomplished, assuming a single failure. }\end{array}$ & $\begin{array}{l}\text { ARDC with no further SFR-specific clarification } \\
\text { provided. }\end{array}$ & \\
\hline 45 & $\begin{array}{l}\text { Inspection of structural and equipment cooling } \\
\text { systems. } \\
\text { The structural and equipment cooling systems } \\
\text { shall be designed to permit appropriate periodic }\end{array}$ & $\begin{array}{l}\text { ARDC with no further SFR-specific clarification } \\
\text { provided. }\end{array}$ & \\
\hline
\end{tabular}



exchangers and piping, to assure the integrity and capability of the systems.

$46 \quad$ Testing of structural and equipment cooling systems.

The structural and equipment cooling systems shall be designed to permit appropriate periodic functional testing to assure (1) the structural integrity of their components, (2) the operability and the performance of the system components, and (3) the operability of the systems as a whole and, under conditions as close to design as practical, the performance of the full operational sequences that bring the systems into operation for reactor shutdown and postulated accidents, including operation of associated systems.

Proposed SFR-DC Language

ationale for Modification

ARDC with no further SFR-specific clarification

provided.

Rationale for Modification

\begin{tabular}{|c|c|c|c|}
\hline \multicolumn{4}{|c|}{ V. Reactor Containment } \\
\hline Criterion & Proposed ARDC Language & Proposed SFR-DC Language & Rationale for Modification \\
\hline 50 & $\begin{array}{l}\text { Containment design basis. } \\
\text { The reactor containment structure, including } \\
\text { access openings, penetrations, and the } \\
\text { containment heat removal system shall be } \\
\text { designed so that the containment structure and } \\
\text { its internal compartments can accommodate, } \\
\text { without exceeding the design leakage rate and } \\
\text { with sufficient margin, the calculated pressure } \\
\text { and temperature conditions resulting from } \\
\text { postulated accidents. This margin shall reflect } \\
\text { consideration of (1) the effects of potential energy } \\
\text { sources which have not been included in the } \\
\text { determination of the peak conditions, such as } \\
\text { [energy in steam generators and as required } \\
\text { by } \$ 50.44 \text { energy from metal-water and other } \\
\text { chemical reactions that may result from } \\
\text { degradation but not total failure of emergency } \\
\text { core cooling functioning], (2) the limited } \\
\text { experience and experimental data available for } \\
\text { defining accident phenomena and containment } \\
\text { responses, and (3) the conservatism of the } \\
\text { calculational model and input parameters. }\end{array}$ & $\begin{array}{l}\text { ARDC with additional SFR-specific clarification } \\
\text { provided: } \\
\text { Containment design basis. } \\
\text { The reactor containment structure, including access } \\
\text { openings, penetrations, and the containment heat } \\
\text { removal system shall be designed so that the } \\
\text { containment structure and its internal compartments } \\
\text { can accommodate, without exceeding the design } \\
\text { leakage rate and with sufficient margin, the calculated } \\
\text { pressure and temperature conditions resulting from } \\
\text { postulated accidents. This margin shall reflect } \\
\text { consideration of (1) the effects of potential energy } \\
\text { sources which have not been included in the } \\
\text { determination of the peak conditions, such as [fission } \\
\text { products, potential spray or aerosol formation, and } \\
\text { potential exothermic chemical reactionenergy in } \\
\text { steam-generators-and-as required by } \$ 50.44 \\
\text { energy from metal-water and-other chemical } \\
\text { reactions that may result from-degradation-but not } \\
\text { total failure of emergency core cooling } \\
\text { functioning], (2) the limited experience and }\end{array}$ & $\begin{array}{l}\text { All SFR designs that were reviewed employed } \\
\text { a containment structure. } \\
\text { In NUREG-1368, Table } 3.3 \text { (page 3-24) } \\
\text { (ML063410561), NRC staff recommended } \\
\text { replacing reference to LOCA with "postulated } \\
\text { accident." NRC staff further recommended } \\
\text { (NUREG-1368, page 3-50) removing the } \\
\text { reference to } 10 \text { CFR 50.44 regarding } \\
\text { containment combustible gas control in BWRs } \\
\text { and PWRs. These changes are proposed as } \\
\text { part of ARDC- 50. In NUREG-1368 (page 3- } \\
50 \text { ), the NRC staff also recommended } \\
\text { replacing metal-water and other chemical } \\
\text { reactions from a degraded ECCS with "fission } \\
\text { products, potential spray or aerosol formation, } \\
\text { and potential exothermic chemical reactions" } \\
\text { at the end of Item } 1 \text { of GDC } 50 \text {. Therefore, the } \\
\text { contents of the brackets in ARDC } 50 \text { were } \\
\text { replaced. }\end{array}$ \\
\hline
\end{tabular}




\begin{tabular}{|c|c|c|c|}
\hline \multicolumn{4}{|c|}{ V. Reactor Containment } \\
\hline Criterion & Proposed ARDC Language & Proposed SFR-DC Language & Rationale for Modification \\
\hline & & $\begin{array}{l}\text { experimental data available for defining accident } \\
\text { phenomena and containment responses, and ( } 3) \text { the } \\
\text { conservatism of the calculational model and input } \\
\text { parameters. }\end{array}$ & \\
\hline 51 & $\begin{array}{l}\text { Fracture prevention of containment pressure } \\
\text { boundary. } \\
\text { The boundary of the reactor containment } \\
\text { structure shall be designed with sufficient margin } \\
\text { to assure that under operating, maintenance, } \\
\text { testing, and postulated accident conditions (1) its } \\
\text { materials behave in a nonbrittle manner and (2) } \\
\text { the probability of rapidly propagating fracture is } \\
\text { minimized. The design shall reflect consideration } \\
\text { of service temperatures and other conditions of } \\
\text { the containment boundary materials during } \\
\text { operation, maintenance, testing, and postulated } \\
\text { accident conditions, and the uncertainties in } \\
\text { determining (1) material properties, (2) residual, } \\
\text { steady state, and transient stresses, and (3) size } \\
\text { of flaws. }\end{array}$ & $\begin{array}{l}\text { ARDC with additional SFR-specific clarification } \\
\text { provided: } \\
\text { Fracture prevention of containment pressure-boundary. } \\
\text { The boundary of the reactor containment structure } \\
\text { shall be designed with sufficient margin to assure that } \\
\text { under operating, maintenance, testing, and postulated } \\
\text { accident conditions (1) its materials behave in a } \\
\text { nonbrittle manner and (2) the probability of rapidly } \\
\text { propagating fracture is minimized. The design shall } \\
\text { reflect consideration of service temperatures and other } \\
\text { conditions of the containment boundary materials } \\
\text { during operation, maintenance, testing, and postulated } \\
\text { accident conditions, and the uncertainties in } \\
\text { determining (1) material properties, (2) residual, steady } \\
\text { state, and transient stresses, and (3) size of flaws. }\end{array}$ & $\begin{array}{l}\text { SFR containment is a boundary/barrier to } \\
\text { release of radioactivity and not a pressure } \\
\text { boundary. Deleting the word "pressure" in the } \\
\text { SFR-DC title provides clarity as applied to the } \\
\text { SFR designs reviewed. }\end{array}$ \\
\hline 52 & $\begin{array}{l}\text { Capability for containment leakage rate testing. } \\
\text { The reactor containment structure and other } \\
\text { equipment which may be subjected to } \\
\text { containment test conditions shall be designed so } \\
\text { that periodic integrated leakage rate testing can } \\
\text { be conducted at containment design pressure. }\end{array}$ & $\begin{array}{l}\text { ARDC with no further SFR-specific clarification } \\
\text { provided. }\end{array}$ & \\
\hline 53 & $\begin{array}{l}\text { Provisions for containment testing and inspection. } \\
\text { The reactor containment structure shall be } \\
\text { designed to permit (1) appropriate periodic } \\
\text { inspection of all important areas, such as } \\
\text { penetrations, (2) an appropriate surveillance } \\
\text { program, and (3) periodic testing at containment } \\
\text { design pressure of the leaktightness of } \\
\text { penetrations which have resilient seals and } \\
\text { expansion bellows. }\end{array}$ & $\begin{array}{l}\text { ARDC with no further SFR-specific clarification } \\
\text { provided. }\end{array}$ & \\
\hline 54 & $\begin{array}{l}\text { Piping systems penetrating containment. } \\
\text { Piping systems penetrating the primary reactor } \\
\text { containment structure shall be provided with leak } \\
\text { detection, isolation, and containment capabilities } \\
\text { having redundancy, reliability, and performance } \\
\text { capabilities which reflect the importance to safety } \\
\text { of isolating these piping systems. Such piping }\end{array}$ & $\begin{array}{l}\text { ARDC with additional SFR-specific clarification } \\
\text { provided: } \\
\text { Piping systems penetrating containment. } \\
\text { Piping systems penetrating the primary reactor } \\
\text { containment structure shall be provided with leak } \\
\text { detection, isolation, and containment capabilities }\end{array}$ & $\begin{array}{l}\text { Not all penetrations will provide a release path } \\
\text { to the atmosphere. Piping that may be of } \\
\text { interest in the case of an SFR design is for the } \\
\text { intermediate heat transport system (IHTS) and } \\
\text { the passive residual heat removal system. } \\
\text { Based on stakeholder input, a designer may } \\
\text { be able to satisfactorily demonstrate that }\end{array}$ \\
\hline
\end{tabular}




\begin{tabular}{|c|c|c|c|}
\hline \multicolumn{4}{|c|}{ V. Reactor Containment } \\
\hline Criterion & Proposed ARDC Language & Proposed SFR-DC Language & Rationale for Modification \\
\hline & $\begin{array}{l}\text { systems shall be designed with a capability to } \\
\text { test periodically the operability of the isolation } \\
\text { valves and associated apparatus and to } \\
\text { determine if valve leakage is within acceptable } \\
\text { limits. }\end{array}$ & $\begin{array}{l}\text { having redundancy, reliability, and performance } \\
\text { capabilities necessary to perform the containment } \\
\text { safety function and which reflect the importance to } \\
\text { safety of preventing radioactivity releases from } \\
\text { containment through isolating these piping systems. } \\
\text { When isolation valves are required, Such piping } \\
\text { systems shall be designed with a capability to test } \\
\text { periodically the operability of the isolation valves and } \\
\text { associated apparatus and to determine if valve leakage } \\
\text { is within acceptable limits. }\end{array}$ & $\begin{array}{l}\text { containment isolation valves are not required } \\
\text { for an SFR design. This rewording for the } \\
\text { SFR-DC provides a designer the opportunity to } \\
\text { present the safety case without containment } \\
\text { isolation valves and associated need for } \\
\text { testing. Otherwise, NUREG-1368 } \\
\text { (ML063410561) (page 3-51) indicated that } \\
\text { GDC } 54 \text { was applicable as written. } \\
\text { ANSI/ANS-54.1-1989 recommended revising } \\
\text { the phrase "...containment capabilities having } \\
\text { redundancy, reliability, and performance } \\
\text { capabilities which reflect the importance to } \\
\text { safety of isolating these piping systems." to } \\
\text { “...containment capabilities as required to } \\
\text { perform the containment safety function." }\end{array}$ \\
\hline 55 & $\begin{array}{l}\text { Reactor [coolant pressure] boundary } \\
\text { penetrating containment. } \\
\text { Each line that is part of the reactor [coolant } \\
\text { pressure] boundary and that penetrates the } \\
\text { primary reactor containment structure shall be } \\
\text { provided with containment isolation valves as } \\
\text { follows, unless it can be demonstrated that the } \\
\text { containment isolation provisions for a specific } \\
\text { class of lines, such as instrument lines, are } \\
\text { acceptable on some other defined basis: } \\
\text { (1) One locked closed isolation valve inside and } \\
\text { one locked closed isolation valve outside } \\
\text { containment; or } \\
\text { (2) One automatic isolation valve inside and one } \\
\text { locked closed isolation valve outside } \\
\text { containment; or } \\
\text { (3) One locked closed isolation valve inside and } \\
\text { one automatic isolation valve outside } \\
\text { containment. A simple check valve may not be } \\
\text { used as the automatic isolation valve outside } \\
\text { containment; or } \\
\text { (4) One automatic isolation valve inside and one } \\
\text { automatic isolation valve outside containment. A } \\
\text { simple check valve may not be used as the } \\
\text { automatic isolation valve outside containment. }\end{array}$ & $\begin{array}{l}\text { ARDC with additional SFR-specific clarification } \\
\text { provided: } \\
\text { Reactor [primary coolant pressure] boundary } \\
\text { penetrating containment. } \\
\text { Each line that is part of the reactor [primary coolant } \\
\text { pressure] boundary and that penetrates the primary } \\
\text { reactor containment structure shall be provided with } \\
\text { containment isolation valves as follows, unless it can } \\
\text { be demonstrated that the containment isolation } \\
\text { provisions for a specific class of lines, such as } \\
\text { instrument lines, are acceptable on some other defined } \\
\text { basis: } \\
\text { (1) One locked closed isolation valve inside and one } \\
\text { locked closed isolation valve outside containment; or } \\
\text { (2) One automatic isolation valve inside and one } \\
\text { locked closed isolation valve outside containment; or } \\
\text { (3) One locked closed isolation valve inside and one } \\
\text { automatic isolation valve outside containment. A } \\
\text { simple check valve may not be used as the automatic } \\
\text { isolation valve outside containment; or } \\
\text { (4) One automatic isolation valve inside and one } \\
\text { automatic isolation valve outside containment. A } \\
\text { simple check valve may not be used as the automatic } \\
\text { isolation valve outside containment. }\end{array}$ & $\begin{array}{l}\text { "Reactor coolant pressure boundary" is } \\
\text { relabeled within the brackets as "reactor } \\
\text { primary coolant boundary" to reflect that the } \\
\text { SFR reactor primary system operates at low- } \\
\text { pressure. Thus, the coolant boundary design } \\
\text { requirements differ from the traditional LWR } \\
\text { coolant pressure boundary requirements. The } \\
\text { effects of low pressure design are } \\
\text { acknowledged in NUREG-1368 (page 3-28) } \\
\text { (ML063410561) under discussion of GDC } 4 \\
\text { and on (page 3-30) under GDC 14. The use of } \\
\text { the term "primary" implies the GDC is } \\
\text { applicable to the primary cooling system, not } \\
\text { the intermediate cooling system. (See Section } \\
6.3 .1 \text { of this report for a description of the SFR } \\
\text { cooling systems.) } \\
\text { Section 3.2.4.5 of NUREG-1368, (page 3-57) } \\
\text { discussed the need for an additional GDC } \\
\text { focused on the intermediate cooling system } \\
\text { design requirements. The design requirements } \\
\text { related to the intermediate loop are addressed } \\
\text { in new SFR-DC 70. } \\
\text { The cover gas boundary is included as part of } \\
\text { the reactor primary coolant boundary (referred }\end{array}$ \\
\hline
\end{tabular}




\begin{tabular}{|c|c|c|c|}
\hline \multicolumn{4}{|c|}{ V. Reactor Containment } \\
\hline Criterion & Proposed ARDC Language & Proposed SFR-DC Language & Rationale for Modification \\
\hline & $\begin{array}{l}\text { Isolation valves outside containment shall be } \\
\text { located as close to containment as practical and } \\
\text { upon loss of actuating power, automatic isolation } \\
\text { valves shall be designed to take the position that } \\
\text { provides greater safety. } \\
\\
\text { Other appropriate requirements to minimize the } \\
\text { probability or consequences of an accidental } \\
\text { rupture of these lines or of lines connected to } \\
\text { them shall be provided as necessary to assure } \\
\text { adequate safety. Determination of the } \\
\text { appropriateness of these requirements, such as } \\
\text { higher quality in design, fabrication, and testing, } \\
\text { additional provisions for inservice inspection, } \\
\text { protection against more severe natural } \\
\text { phenomena, and additional isolation valves and } \\
\text { containment, shall include consideration of the } \\
\text { population density, use characteristics, and } \\
\text { physical characteristics of the site environs. }\end{array}$ & $\begin{array}{l}\text { Isolation valves outside containment shall be located } \\
\text { as close to containment as practical and upon loss of } \\
\text { actuating power, automatic isolation valves shall be } \\
\text { designed to take the position that provides greater } \\
\text { safety. } \\
\text { Other appropriate requirements to minimize the } \\
\text { probability or consequences of an accidental rupture of } \\
\text { these lines or of lines connected to them shall be } \\
\text { provided as necessary to assure adequate safety. } \\
\text { Determination of the appropriateness of these } \\
\text { requirements, such as higher quality in design, } \\
\text { fabrication, and testing, additional provisions for } \\
\text { inservice inspection, protection against more severe } \\
\text { natural phenomena, and additional isolation valves and } \\
\text { containment, shall include consideration of the } \\
\text { population density, use characteristics, and physical } \\
\text { characteristics of the site environs. }\end{array}$ & $\begin{array}{l}\text { to as RCPB by PRISM) per NUREG-1368 } \\
\text { (page 3-38). }\end{array}$ \\
\hline 56 & $\begin{array}{l}\text { Primary containment isolation. } \\
\text { Each line that connects directly to the } \\
\text { containment atmosphere and penetrates the } \\
\text { primary reactor containment structure shall be } \\
\text { provided with containment isolation valves as } \\
\text { follows, unless it can be demonstrated that the } \\
\text { containment isolation provisions for a specific } \\
\text { class of lines, such as instrument lines, are } \\
\text { acceptable on some other defined basis: } \\
\text { (1) One locked closed isolation valve inside and } \\
\text { one locked closed isolation valve outside } \\
\text { containment; or } \\
\text { (2) One automatic isolation valve inside and one } \\
\text { locked closed isolation valve outside } \\
\text { containment; or } \\
\text { (3) One locked closed isolation valve inside and } \\
\text { one automatic isolation valve outside } \\
\text { containment. A simple check valve may not be } \\
\text { used as the automatic isolation valve outside } \\
\text { containment; or } \\
\text { (4) One automatic isolation valve inside and one } \\
\text { automatic isolation valve outside containment. A } \\
\text { simple check valve may not be used as the }\end{array}$ & $\begin{array}{l}\text { ARDC with no further SFR-specific clarification } \\
\text { provided. }\end{array}$ & \\
\hline
\end{tabular}




\begin{tabular}{|c|c|c|c|}
\hline \multicolumn{4}{|c|}{ V. Reactor Containment } \\
\hline Criterion & Proposed ARDC Language & Proposed SFR-DC Language & Rationale for Modification \\
\hline & $\begin{array}{l}\text { automatic isolation valve outside containment. } \\
\text { Isolation valves outside containment shall be } \\
\text { located as close to the containment as practical } \\
\text { and upon loss of actuating power, automatic } \\
\text { isolation valves shall be designed to take the } \\
\text { position that provides greater safety. }\end{array}$ & & \\
\hline 57 & $\begin{array}{l}\text { Closed system isolation valves. } \\
\text { Each line that penetrates the primary reactor } \\
\text { containment structure and is neither part of the } \\
\text { reactor [coolant pressure] boundary nor } \\
\text { connected directly to the containment } \\
\text { atmosphere shall have at least one containment } \\
\text { isolation valve which shall be either automatic, or } \\
\text { locked closed, or capable of remote manual } \\
\text { operation. This valve shall be outside } \\
\text { containment and located as close to the } \\
\text { containment as practical. A simple check valve } \\
\text { may not be used as the automatic isolation valve. }\end{array}$ & $\begin{array}{l}\text { ARDC with additional SFR-specific clarification } \\
\text { provided: } \\
\text { Closed system isolation valves. } \\
\text { Each line that penetrates the primary reactor } \\
\text { containment structure and is neither part of the reactor } \\
\text { [primary coolant pressure] boundary nor connected } \\
\text { directly to the containment atmosphere shall have at } \\
\text { least one containment isolation valve unless it can be } \\
\text { demonstrated that the containment safety function can } \\
\text { be met without an isolation valve and assuming failure } \\
\text { of a single active component. The isolation valve, if } \\
\text { which shallrequired, shall be either automatic, or } \\
\text { locked closed, or capable of remote manual operation. } \\
\text { This valve shall be outside containment and located as } \\
\text { close to the containment as practical. A simple check } \\
\text { valve may not be used as the automatic isolation valve. }\end{array}$ & $\begin{array}{l}\text { "Reactor coolant pressure boundary" is } \\
\text { relabeled within the brackets as "reactor } \\
\text { primary coolant boundary" to reflect that the } \\
\text { SFR reactor primary system operates at low- } \\
\text { pressure. Thus, the coolant boundary design } \\
\text { requirements differ from the traditional LWR } \\
\text { coolant pressure boundary requirements. The } \\
\text { effects of low pressure design are } \\
\text { acknowledged in NUREG-1368 (page 3-28) } \\
\text { (ML063410561) under discussion of GDC } 4 \\
\text { and on (page 3-30) under GDC 14. The use of } \\
\text { the term "primary" implies the GDC is } \\
\text { applicable to the primary cooling system, not } \\
\text { the intermediate cooling system. (See Section } \\
6.3 .1 \text { of this report for a description of the SFR } \\
\text { cooling systems.) } \\
\text { Section } 3.2 .4 .5 \text { of NUREG-1368, (page } 3-57 \text { ) } \\
\text { discussed the need for an additional GDC } \\
\text { focused on the intermediate cooling system } \\
\text { design requirements. The design requirements } \\
\text { related to the intermediate loop are addressed } \\
\text { in new SFR-DC } 70 \text {. } \\
\text { Not all penetrations will provide a release path } \\
\text { to the atmosphere. Piping that may be of } \\
\text { interest in the case of an SFR design is for the } \\
\text { intermediate heat transport system (IHTS) and } \\
\text { the residual heat removal system. A designer } \\
\text { may be able to satisfactorily demonstrate that } \\
\text { containment isolation valves are not required } \\
\text { for an SFR design. This rewording for the } \\
\text { SFR-DC provides a designer the opportunity to } \\
\text { present the safety case without containment } \\
\text { isolation valves. }\end{array}$ \\
\hline
\end{tabular}




\begin{tabular}{|l|l|l|l|}
\hline \multicolumn{2}{|c|}{ V. Reactor Containment } \\
\hline Criterion & Proposed ARDC Language & Proposed SFR-DC Language & Rationale for Modification \\
\hline & & & $\begin{array}{l}\text { The cover gas boundary is included as part of } \\
\text { the reactor primary coolant boundary (referred } \\
\text { to as RCPB by PRISM) per NUREG-1368 } \\
\text { (page 3-38). }\end{array}$ \\
\hline
\end{tabular}

\begin{tabular}{|c|c|c|c|}
\hline \multicolumn{4}{|c|}{ VI. Fuel and Radioactivity Control } \\
\hline Criterion & Proposed ARDC Language & Proposed SFR-DC Language & Rationale for Modification \\
\hline 60 & $\begin{array}{l}\text { Control of releases of radioactive materials to the } \\
\text { environment. } \\
\text { The nuclear power unit design shall include } \\
\text { means to control suitably the release of } \\
\text { radioactive materials in gaseous and liquid } \\
\text { effluents and to handle radioactive solid wastes } \\
\text { produced during normal reactor operation, } \\
\text { including anticipated operational occurrences. } \\
\text { Sufficient holdup capacity shall be provided for } \\
\text { retention of gaseous and liquid effluents } \\
\text { containing radioactive materials, particularly } \\
\text { where unfavorable site environmental conditions } \\
\text { can be expected to impose unusual operational } \\
\text { limitations upon the release of such effluents to } \\
\text { the environment. }\end{array}$ & $\begin{array}{l}\text { ARDC with no further SFR-specific clarification } \\
\text { provided. }\end{array}$ & \\
\hline 61 & $\begin{array}{l}\text { Fuel storage and handling and radioactivity } \\
\text { control. } \\
\text { The fuel storage and handling, radioactive waste, } \\
\text { and other systems which may contain } \\
\text { radioactivity shall be designed to assure } \\
\text { adequate safety under normal and postulated } \\
\text { accident conditions. These systems shall be } \\
\text { designed (1) with a capability to permit } \\
\text { appropriate periodic inspection and testing of } \\
\text { components important to safety, (2) with suitable } \\
\text { shielding for radiation protection, (3) with } \\
\text { appropriate containment, confinement, and } \\
\text { filtering systems, (4) with a residual heat removal } \\
\text { capability having reliability and testability that } \\
\text { reflects the importance to safety of decay heat } \\
\text { and other residual heat removal, and (5) to } \\
\text { prevent significant reduction in fuel storage } \\
\text { cooling under accident conditions. }\end{array}$ & $\begin{array}{l}\text { ARDC with no further SFR-specific clarification } \\
\text { provided. }\end{array}$ & \\
\hline
\end{tabular}


62 Prevention of criticality in fuel storage and handling.

Criticality in the fuel storage and handling system shall be prevented by physical systems or processes, preferably by use of geometrically safe configurations.

63 Monitoring fuel and waste storage.

Appropriate systems shall be provided in fuel storage and radioactive waste systems and associated handling areas (1) to detect conditions that may result in loss of residual heat removal capability and excessive radiation levels and (2) to initiate appropriate safety actions.

64 Monitoring radioactivity releases.

Means shall be provided for monitoring the

[reactor containment] atmosphere, [spaces containing components for recirculation of loss-of-coolant accident fluids,] effluent discharge paths, and the plant environs for radioactivity that may be released from normal operations, including anticipated operational occurrences, and from postulated accidents.
Proposed SFR-DC Language

ARDC with no further SFR-specific clarification provided.

ARDC with no further SFR-specific clarification provided.

ARDC with additional SFR-specific clarification provided:

Monitoring radioactivity releases.

Means shall be provided for monitoring the [reactor containment] atmosphere, [spaces containing components for-recirculation-of loss-of-coolant accident fluids primary system sodium and cover gas cleanup and processing,] effluent discharge paths, and the plant environs for radioactivity that may be released from normal operations, including anticipated operational occurrences, and from postulated accidents.
Rationale for Modification

The phrase "reactor containment" in the first set of brackets in ARDC 64 is retained.

In NUREG-1368, Table 3.3 (page 3-25) (ML063410561) NRC staff recommended deleting the GDC-64 phrase "spaces containing components for recirculation of loss-of-coolant accident fluids." Otherwise, the NRC staff noted that criterion requirements are independent of the design of SFRs (page 355).

However, rather than delete the second bracketed phrase from ARDC 64, "spaces containing components for recirculation of loss-of-coolant accident fluids," the bracketed text was modified to identify other SFR plant areas that should also be included to maintain consideration of all potential discharge paths and areas subject to monitoring. Therefore, primary system sodium and cover gas cleanup systems that may be outside containment and effluent processing systems are considered in place of the current text in the second set of brackets in ARDC 64. 


\begin{tabular}{|c|c|c|c|}
\hline \multicolumn{4}{|c|}{ VII. Additional SFR-DC } \\
\hline Criterion & Proposed ARDC Language & Proposed SFR-DC Language & Rationale for Modification \\
\hline 70 & N/A & $\begin{array}{l}\text { Intermediate coolant systems. } \\
\text { If an intermediate coolant system is provided, the } \\
\text { intermediate coolant shall be compatible with sodium if } \\
\text { it is separated from the reactor primary coolant by a } \\
\text { single passive barrier. Where a single barrier } \\
\text { separates the reactor primary coolant from the } \\
\text { intermediate coolant, a pressure differential shall be } \\
\text { maintained such that any leakage would flow from the } \\
\text { intermediate coolant system to the reactor primary } \\
\text { coolant system unless other provisions can be shown } \\
\text { to be acceptable. The intermediate coolant boundary } \\
\text { shall be designed to permit inspection and surveillance } \\
\text { in areas where leakage can affect the safety functions } \\
\text { of systems, structures and components. }\end{array}$ & $\begin{array}{l}\text { NUREG-1368 (page 3-57) (ML063410561) } \\
\text { Section 3.2.4.5 suggested the need for a } \\
\text { separate criterion for the intermediate coolant } \\
\text { system. Also separate criteria were included in } \\
\text { NUREG-0968 (ML082381008) (Criterion 31- } \\
\text { Design of Intermediate Cooling System and } \\
\text { Criterion 33-Inspection of Intermediate } \\
\text { Cooling System). }\end{array}$ \\
\hline 71 & $\mathrm{~N} / \mathrm{A}$ & $\begin{array}{l}\text { Reactor coolant \& cover gas purity control. } \\
\text { Systems shall be provided as necessary to maintain } \\
\text { primary coolant purity and cover gas purity within } \\
\text { specified design limits. These limits shall be based on } \\
\text { consideration of (1) chemical attack, }(2) \text { fouling and } \\
\text { plugging of passages, and (3) radioisotope } \\
\text { concentrations. }\end{array}$ & $\begin{array}{l}\text { NUREG-1368 (page 3-57) (ML063410561) } \\
\text { Section 3.2.4.6 suggested the need for a } \\
\text { separate criterion for sodium and cover gas } \\
\text { purity control. Also a separate criterion was } \\
\text { included in NUREG-0968 (ML082381008) } \\
\text { (Criterion 34-Reactor and intermediate coolant } \\
\text { and cover gas purity control). }\end{array}$ \\
\hline 72 & $\mathrm{~N} / \mathrm{A}$ & $\begin{array}{l}\text { Sodium heating systems. } \\
\text { Heating systems shall be provided as necessary for } \\
\text { systems and components important to safety, which } \\
\text { contain or could be required to contain sodium. These } \\
\text { heating systems and their controls shall be } \\
\text { appropriately designed to assure that the temperature } \\
\text { distribution and rate of change of temperature in } \\
\text { systems and components containing sodium are } \\
\text { maintained within design limits assuming a single } \\
\text { failure. }\end{array}$ & $\begin{array}{l}\text { NUREG-1368 (page 3-56) (ML063410561) } \\
\text { Section 3.2.4.2 suggested the need for a } \\
\text { separate criterion for sodium heating system. } \\
\text { Also, a separate criterion was included in } \\
\text { NUREG-0968 (ML082381008) (Criterion-7 } \\
\text { Sodium Heating Systems). }\end{array}$ \\
\hline 73 & $\mathrm{~N} / \mathrm{A}$ & $\begin{array}{l}\text { Sodium leakage detection and reaction prevention and } \\
\text { mitigation. } \\
\text { Means to detect sodium leakage and to limit and } \\
\text { control the extent of sodium-air and sodium-concrete } \\
\text { reactions shall be provided as necessary to assure that } \\
\text { the safety functions of structures, systems and } \\
\text { components important to safety are maintained. } \\
\text { Special features such as inerted enclosures or guard } \\
\text { vessels shall be provided as appropriate for systems } \\
\text { containing reactor primary sodium coolant. }\end{array}$ & $\begin{array}{l}\text { NUREG-1368 (page 3-56) (ML063410561) } \\
\text { Section 3.2.4.1 suggested the need for a } \\
\text { separate criterion for protection against sodium } \\
\text { reactions. Also, a separate criterion was } \\
\text { included in NUREG-0968 (ML082381008) } \\
\text { (Criterion-4 Protection against Sodium and } \\
\text { NaK reactions). }\end{array}$ \\
\hline
\end{tabular}




\begin{tabular}{|c|c|c|c|}
\hline \multicolumn{4}{|c|}{ VII. Additional SFR-DC } \\
\hline Criterion & Proposed ARDC Language & Proposed SFR-DC Language & Rationale for Modification \\
\hline 74 & N/A & $\begin{array}{l}\text { Sodium/water reaction prevention/mitigation. } \\
\text { Structures, systems, and components important to } \\
\text { safety containing sodium shall be designed and } \\
\text { located to limit the consequences of chemical reactions } \\
\text { between sodium and water on the safety functions of } \\
\text { any systems, structures, and components. Means } \\
\text { shall be provided as appropriate to limit possible } \\
\text { contacts between sodium and water. } \\
\text { If necessary to prevent loss of any plant safety } \\
\text { function, the sodium-steam generator system shall be } \\
\text { designed to detect and contain sodium-water reactions } \\
\text { and limit the effects of the energy and reaction } \\
\text { products released by such reactions. }\end{array}$ & $\begin{array}{l}\text { NUREG-1368 (page 3-56) (ML063410561) } \\
\text { Section 3.2.4.1 suggested the need for a } \\
\text { separate criterion for protection against sodium } \\
\text { reactions. Also, a separate criterion was } \\
\text { included in NUREG-0968 (ML082381008) } \\
\text { (Criterion-4 Protection against Sodium and } \\
\text { NaK reactions). }\end{array}$ \\
\hline
\end{tabular}




\subsection{Proposed Modular High Temperature Gas-Cooled Reactor Design Criteria}

\begin{tabular}{|c|c|c|c|}
\hline \multicolumn{4}{|c|}{ I. Overall Requirements } \\
\hline Criterion & Proposed ARDC Language & Proposed Modular HTGR-DC Language & Rationale for Modification \\
\hline 1 & $\begin{array}{l}\text { Quality standards and records. } \\
\text { Structures, systems, and components important } \\
\text { to safety shall be designed, fabricated, erected, } \\
\text { and tested to quality standards commensurate } \\
\text { with the importance of the safety functions to be } \\
\text { performed. Where generally recognized codes } \\
\text { and standards are used, they shall be identified } \\
\text { and evaluated to determine their applicability, } \\
\text { adequacy, and sufficiency and shall be } \\
\text { supplemented or modified as necessary to } \\
\text { assure a quality product in keeping with the } \\
\text { required safety function. A quality assurance } \\
\text { program shall be established and implemented } \\
\text { in order to provide adequate assurance that } \\
\text { these structures, systems, and components will } \\
\text { satisfactorily perform their safety functions. } \\
\text { Appropriate records of the design, fabrication, } \\
\text { erection, and testing of structures, systems, and } \\
\text { components important to safety shall be } \\
\text { maintained by or under the control of the } \\
\text { nuclear power unit licensee throughout the life } \\
\text { of the unit. }\end{array}$ & $\begin{array}{l}\text { ARDC with no further modular HTGR-specific } \\
\text { clarification provided. }\end{array}$ & \\
\hline 2 & $\begin{array}{l}\text { Design bases for protection against natural } \\
\text { phenomena. } \\
\text { Structures, systems, and components important } \\
\text { to safety shall be designed to withstand the } \\
\text { effects of natural phenomena such as } \\
\text { earthquakes, tornadoes, hurricanes, floods, } \\
\text { tsunami, and seiches without loss of capability } \\
\text { to perform their safety functions. The design } \\
\text { bases for these structures, systems, and } \\
\text { components shall reflect: (1) Appropriate } \\
\text { consideration of the most severe of the natural } \\
\text { phenomena that have been historically reported } \\
\text { for the site and surrounding area, with sufficient } \\
\text { margin for the limited accuracy, quantity, and } \\
\text { period of time in which the historical data have } \\
\text { been accumulated, (2) appropriate combinations } \\
\text { of the effects of normal and accident conditions } \\
\text { with the effects of the natural phenomena and }\end{array}$ & $\begin{array}{l}\text { ARDC with no further modular HTGR-specific } \\
\text { clarification provided. }\end{array}$ & \\
\hline
\end{tabular}




\begin{tabular}{|c|c|c|c|}
\hline \multicolumn{4}{|c|}{ I. Overall Requirements } \\
\hline Criterion & Proposed ARDC Language & Proposed Modular HTGR-DC Language & Rationale for Modification \\
\hline & $\begin{array}{l}\text { (3) the importance of the safety functions to be } \\
\text { performed. }\end{array}$ & & \\
\hline 3 & $\begin{array}{l}\text { Fire protection. } \\
\text { Structures, systems, and components important } \\
\text { to safety shall be designed and located to } \\
\text { minimize, consistent with other safety } \\
\text { requirements, the probability and effect of fires } \\
\text { and explosions. Noncombustible and heat } \\
\text { resistant materials shall be used wherever } \\
\text { practical throughout the unit[, particularly in } \\
\text { locations such as the containment and } \\
\text { control room]. Fire detection and fighting } \\
\text { systems of appropriate capacity and capability } \\
\text { shall be provided and designed to minimize the } \\
\text { adverse effects of fires on structures, systems, } \\
\text { and components important to safety. Firefighting } \\
\text { systems shall be designed to assure that their } \\
\text { rupture or inadvertent operation does not } \\
\text { significantly impair the safety capability of these } \\
\text { structures, systems, and components. }\end{array}$ & $\begin{array}{l}\text { ARDC with additional modular HTGR-specific } \\
\text { clarification provided: } \\
\text { Fire protection. } \\
\text { Structures, systems, and components important to } \\
\text { safety shall be designed and located to minimize, } \\
\text { consistent with other safety requirements, the } \\
\text { probability and effect of fires and explosions. } \\
\text { Noncombustible and heat resistant materials shall be } \\
\text { used wherever practical throughout the unit, } \\
\text { [particularly in locations such as the } \\
\text { containmentwith safety related equipment and the } \\
\text { control room]. Fire detection and fighting systems of } \\
\text { appropriate capacity and capability shall be provided } \\
\text { and designed to minimize the adverse effects of fires } \\
\text { on structures, systems, and components important to } \\
\text { safety. Firefighting systems shall be designed to } \\
\text { assure that their rupture or inadvertent operation does } \\
\text { not significantly impair the safety capability of these } \\
\text { structures, systems, and components. }\end{array}$ & $\begin{array}{l}\text { This criterion establishes functional requirements } \\
\text { that provide assurance that SSCs important to } \\
\text { safety can perform their safety functions during } \\
\text { fire events. It can be applied to modular HTGRs } \\
\text { with minor modification. } \\
\text { Revisions address the reference to containment. } \\
\text { The reactor building utilized by the modular } \\
\text { HTGR design does not have the same functions } \\
\text { as an LWR containment structure. In place of } \\
\text { reference to the containment, reference is made } \\
\text { instead to locations with safety related } \\
\text { equipment. }\end{array}$ \\
\hline 4 & $\begin{array}{l}\text { Environmental and dynamic effects design } \\
\text { bases. } \\
\text { Structures, systems, and components important } \\
\text { to safety shall be designed to accommodate the } \\
\text { effects of and to be compatible with the } \\
\text { environmental conditions associated with } \\
\text { normal operation, maintenance, testing, and } \\
\text { postulated accidents. These structures, } \\
\text { systems, and components shall be appropriately } \\
\text { protected against dynamic effects, including the } \\
\text { effects of missiles, pipe whipping, and } \\
\text { discharging fluids, that may result from } \\
\text { equipment failures and from events and } \\
\text { conditions outside the nuclear power unit. } \\
\text { However, dynamic effects associated with } \\
\text { postulated pipe ruptures in nuclear power units } \\
\text { may be excluded from the design basis when } \\
\text { analyses reviewed and approved by the } \\
\text { Commission demonstrate that the probability of } \\
\text { fluid system piping rupture is extremely low }\end{array}$ & $\begin{array}{l}\text { ARDC with no further modular HTGR-specific } \\
\text { clarification provided. }\end{array}$ & \\
\hline
\end{tabular}




\begin{tabular}{|c|c|c|c|}
\hline \multicolumn{4}{|c|}{ I. Overall Requirements } \\
\hline Criterion & Proposed ARDC Language & Proposed Modular HTGR-DC Language & Rationale for Modification \\
\hline & $\begin{array}{l}\text { under conditions consistent with the design } \\
\text { basis for the piping. }\end{array}$ & & \\
\hline 5 & $\begin{array}{l}\text { Sharing of structures, systems, and } \\
\text { components. } \\
\text { Structures, systems, and components important } \\
\text { to safety shall not be shared among nuclear } \\
\text { power units unless it can be shown that such } \\
\text { sharing will not significantly impair their ability to } \\
\text { perform their safety functions, including, in the } \\
\text { event of an accident in one unit, an orderly } \\
\text { shutdown and cooldown of the remaining units. }\end{array}$ & $\begin{array}{l}\text { ARDC with additional modular HTGR-specific } \\
\text { clarification provided: } \\
\text { Sharing of structures, systems, and components. } \\
\text { Structures, systems, and components important to } \\
\text { safety shall not be shared among reactor modules or } \\
\text { reactor module groups nuclear power units-unless it } \\
\text { can be shown that such sharing will not significantly } \\
\text { impair their ability to perform their safety functions, } \\
\text { including, in the event of an accident in one reactor } \\
\text { module or reactor module groupunit, an orderly } \\
\text { shutdown and cooldown of the remaining reactor } \\
\text { modules or reactor module groupsunits. }\end{array}$ & $\begin{array}{l}\text { This criterion establishes functional requirements } \\
\text { that provide assurance that SSCs can perform } \\
\text { their safety functions independent of any other } \\
\text { nuclear power units they may service. } \\
\\
\text { It is expected that modular HTGR designs will } \\
\text { include multi-module plant configurations that will } \\
\text { need to consider these requirements. The } \\
\text { criterion can be applied to modular HTGRs with } \\
\text { minor modification. The language used is } \\
\text { specific to the modular HTGR design to capture } \\
\text { the importance of not sharing SSCs among } \\
\text { modules or among module groups if the sharing } \\
\text { could lead to a loss of safety function at one of } \\
\text { the other shared modules/groups. }\end{array}$ \\
\hline \multicolumn{4}{|c|}{ II. Multiple Barriers } \\
\hline Criterion & Proposed ARDC Language & Proposed Modular HTGR-DC Language & Rationale for Modification \\
\hline 10 & $\begin{array}{l}\text { Reactor design. } \\
\text { The reactor core and associated [coolant], } \\
\text { control, and protection systems shall be } \\
\text { designed with appropriate margin to assure that } \\
\text { specified acceptable fuel design limits are not } \\
\text { exceeded during any condition of normal } \\
\text { operation, including the effects of anticipated } \\
\text { operational occurrences. }\end{array}$ & $\begin{array}{l}\text { ARDC with additional modular HTGR-specific } \\
\text { clarification provided: } \\
\text { Reactor design. } \\
\text { The reactor core-system and associated [coolantheat } \\
\text { removal], control, and protection systems shall be } \\
\text { designed with appropriate margin to assure that } \\
\text { specified acceptable fuelcore radionuclide release } \\
\text { design limits are not exceeded during any condition of } \\
\text { normal operation, including the effects of anticipated } \\
\text { operational occurrences. }\end{array}$ & $\begin{array}{l}\text { It is the entire reactor system, which includes the } \\
\text { core and other components, and the other } \\
\text { systems listed that assure that limits are not } \\
\text { exceeded. } \\
\text { The revised criterion recognizes that the role of } \\
\text { the helium in modular HTGR safety is different } \\
\text { from that of a traditional "reactor core coolant" } \\
\text { and that residual heat removal is not dependent } \\
\text { on forced helium circulation. The core design } \\
\text { ensures a passive residual heat removal } \\
\text { capability (INL/EXT-11-22708, "Modular HTGR } \\
\text { Safety Basis and Approach", Aug. 2011, } \\
\text { ML11251A169, pg. 17). } \\
\text { NGNP determined that an alternative to the } \\
\text { LWR-based SAFDL is needed which aligns with } \\
\text { the modular HTGR safety basis and the role of } \\
\text { coated particle fuel (see Section } 7.2 .2 \text { ); NRC } \\
\text { staff noted this issue before the ACRS on }\end{array}$ \\
\hline
\end{tabular}




\begin{tabular}{|c|c|c|c|}
\hline \multicolumn{4}{|c|}{\begin{tabular}{|l} 
II. Multiple Barriers \\
\end{tabular}} \\
\hline Criterion & Proposed ARDC Language & Proposed Modular HTGR-DC Language & Rationale for Modification \\
\hline & & & $\begin{array}{l}\text { 4/9/2013 (ML13119A447). "Specified acceptable } \\
\text { core radionuclide release design limits" } \\
\text { designates the modular HTGR-specific } \\
\text { regulatory limit. The quantitative value of the } \\
\text { SARRDL will be design specific. }\end{array}$ \\
\hline 11 & $\begin{array}{l}\text { Reactor inherent protection. } \\
\text { The reactor core and associated systems that } \\
\text { contribute to reactivity feedback shall be } \\
\text { designed so that in the power operating range } \\
\text { the net effect of the prompt inherent nuclear } \\
\text { feedback characteristics tends to compensate } \\
\text { for a rapid increase in reactivity. }\end{array}$ & $\begin{array}{l}\text { ARDC with no further modular HTGR-specific } \\
\text { clarification provided. }\end{array}$ & \\
\hline 12 & $\begin{array}{l}\text { Suppression of reactor power oscillations. } \\
\text { The reactor core and associated [coolant], } \\
\text { control, and protection systems shall be } \\
\text { designed to assure that power oscillations which } \\
\text { can result in conditions exceeding specified } \\
\text { acceptable fuel design limits are not possible or } \\
\text { can be reliably and readily detected and } \\
\text { suppressed. }\end{array}$ & $\begin{array}{l}\text { ARDC with additional modular HTGR-specific } \\
\text { clarification provided: } \\
\text { Suppression of reactor power oscillations. } \\
\text { The reactor core and associated [coolant], control, } \\
\text { and protection systems shall be designed to assure } \\
\text { that power oscillations which can result in conditions } \\
\text { exceeding specified acceptable fuel-core radionuclide } \\
\text { release design limits are not possible or can be reliably } \\
\text { and readily detected and suppressed. }\end{array}$ & $\begin{array}{l}\text { This criterion is applicable to the modular HTGR } \\
\text { core and associated systems but the primary } \\
\text { circuit uses helium, which does not influence } \\
\text { power oscillations due to its neutronic } \\
\text { transparency (INL/EXT-11-22708, "Modular } \\
\text { HTGR Safety Basis and Approach", Aug. 2011, } \\
\text { ML11251A169, pg. 8). Reference to "coolant" is } \\
\text { not germane to this modular HTGR criterion. } \\
\text { NGNP determined that an alternative to the } \\
\text { LWR-based SAFDL is needed which aligns with } \\
\text { the modular HTGR safety basis and the role of } \\
\text { coated particle fuel (see Section } 7.2 .2 \text { ); NRC } \\
\text { staff noted this issue before the ACRS on } \\
\text { 4/9/2013 (ML13119A447). "Specified acceptable } \\
\text { core radionuclide release design limits" } \\
\text { designates the modular HTGR-specific } \\
\text { regulatory limit. The quantitative value of the } \\
\text { SARRDL will be design specific. }\end{array}$ \\
\hline 13 & $\begin{array}{l}\text { Instrumentation and control. } \\
\text { Instrumentation shall be provided to monitor } \\
\text { variables and systems over their anticipated } \\
\text { ranges for normal operation, for anticipated } \\
\text { operational occurrences, and for accident } \\
\text { conditions as appropriate to assure adequate } \\
\text { safety, including those variables and systems } \\
\text { that can affect the fission process, the integrity } \\
\text { of the reactor core, [the reactor coolant } \\
\text { pressure boundary, and the containment and } \\
\text { its associated systems]. Appropriate controls } \\
\end{array}$ & $\begin{array}{l}\text { ARDC with additional modular HTGR-specific } \\
\text { clarification provided: } \\
\text { Instrumentation and control. } \\
\text { Instrumentation shall be provided to monitor variables } \\
\text { and systems over their anticipated ranges for normal } \\
\text { operation, for anticipated operational occurrences, and } \\
\text { for accident conditions as appropriate to assure } \\
\text { adequate safety, including those variables and } \\
\text { systems that can affect the fission process and; the } \\
\text { integrity of the reactor core, [the reactor coolant }\end{array}$ & $\begin{array}{l}\text { Modified the criterion to reflect use of the } \\
\text { modular HTGR functional containment, which is } \\
\text { summarized in a set of slides presented to NRC } \\
\text { in a July } 2012 \text { public meeting (ML12223A146) } \\
\text { with associated NRC meeting summary } \\
\text { (ML12219A205). NRC staff feedback on } \\
\text { functional containment is documented in "NGNP } \\
\text { - Assessment of Key Licensing Issues", } \\
\text { ML14174A734 (enclosure 1- ML14174A774, } \\
\text { section 3, and enclosure } 2 \text { - ML14174A845, } \\
\text { section 3.11). }\end{array}$ \\
\hline
\end{tabular}




\begin{tabular}{|c|c|c|c|}
\hline \multicolumn{4}{|c|}{ II. Multiple Barriers } \\
\hline Criterion & Proposed ARDC Language & Proposed Modular HTGR-DC Language & Rationale for Modification \\
\hline & $\begin{array}{l}\text { shall be provided to maintain these variables } \\
\text { and systems within prescribed operating ranges. }\end{array}$ & $\begin{array}{l}\text { Pressure boundary, and the containment and its } \\
\text { associated-systems]functional containment. } \\
\text { Appropriate controls shall be provided to maintain } \\
\text { these variables and systems within prescribed } \\
\text { operating ranges. }\end{array}$ & \\
\hline 14 & $\begin{array}{l}\text { Reactor [coolant pressure] boundary. } \\
\text { The reactor [coolant pressure] boundary shall } \\
\text { be designed, fabricated, erected, and tested so } \\
\text { as to have an extremely low probability of } \\
\text { abnormal leakage, of rapidly propagating failure, } \\
\text { and of gross rupture. }\end{array}$ & $\begin{array}{l}\text { ARDC with additional modular HTGR-specific } \\
\text { clarification provided: } \\
\text { Reactor [coolanthelium pressure] boundary. } \\
\text { The reactor [coolanthelium pressure] boundary shall } \\
\text { be designed, fabricated, erected, and tested so as to } \\
\text { have an extremely low probability of abnormal leakage, } \\
\text { of rapidly propagating failure,-and of gross rupture, and } \\
\text { of unacceptable ingress of air, secondary coolant, or } \\
\text { other fluids. }\end{array}$ & $\begin{array}{l}\text { The reactor HPB role and function are described } \\
\text { in Sec } 5.4 \text { of INL/EXT-11-22708, "Modular } \\
\text { HTGR Safety Basis and Approach", Aug. } 2011 \text {, } \\
\text { ML11251A169. The reactor helium pressure } \\
\text { boundary is one of the multiple functional } \\
\text { containment radionuclide release barriers in a } \\
\text { configuration summarized in a set of slides } \\
\text { presented to NRC in a July } 2012 \text { public meeting } \\
\text { (ML12223A146) with associated NRC meeting } \\
\text { summary (ML12219A205). According to working } \\
\text { definitions developed by NGNP, the reactor HPB } \\
\text { contains (but is not synonymous with) the } \\
\text { primary circuit and should not be defined purely } \\
\text { in terms of "helium wetted surfaces." } \\
\text { Criterion } 14 \text { focuses on reactor HPB design } \\
\text { against substantial failure while Criterion } 15 \\
\text { emphasizes not exceeding reactor HPB design } \\
\text { margins during normal operation, including } \\
\text { AOOs. Criterion 14 was revised to recognize that } \\
\text { the reactor HPB must be constructed to resist } \\
\text { rupture, which would trigger associated } \\
\text { radionuclide release mechanisms, and to inhibit } \\
\text { ingress of air, secondary coolant, and other } \\
\text { contaminant fluids, which could in turn, oxidize } \\
\text { the graphite core (INL/EXT-10-17997, "NGNP } \\
\text { Mechanistic Source Terms White Paper, July } \\
2010, \text { ML102040260). }\end{array}$ \\
\hline 15 & $\begin{array}{l}\text { Reactor [coolant] system design. } \\
\text { The reactor [coolant] system and associated } \\
\text { auxiliary, control, and protection systems shall } \\
\text { be designed with sufficient margin to assure that } \\
\text { the design conditions of the reactor [coolant } \\
\text { pressure] boundary are not exceeded during } \\
\text { any condition of normal operation, including } \\
\text { anticipated operational occurrences. }\end{array}$ & $\begin{array}{l}\text { ARDC with additional modular HTGR-specific } \\
\text { clarification provided: } \\
\text { Reactor [coolanthelium pressure boundary] system } \\
\text { design. } \\
\text { The reactor [coolant] system, vessel system, heat } \\
\text { removal systems, and associated auxiliary, control, } \\
\text { and protection systems shall be designed with } \\
\text { sufficient margin to assure that the design conditions of }\end{array}$ & $\begin{array}{l}\text { The reactor HPB role and function are described } \\
\text { in Sec } 5.4 \text { of INL/EXT-11-22708, "Modular } \\
\text { HTGR Safety Basis and Approach", Aug. } 2011 \text {, } \\
\text { ML11251A169. The reactor helium pressure } \\
\text { boundary is one of the multiple functional } \\
\text { containment radionuclide release barriers in a } \\
\text { configuration summarized in a set of slides } \\
\text { presented to NRC in a July } 2012 \text { public meeting } \\
\text { (ML12223A146) with associated NRC meeting }\end{array}$ \\
\hline
\end{tabular}




\begin{tabular}{|c|c|c|c|}
\hline \multicolumn{4}{|c|}{ II. Multiple Barriers } \\
\hline Criterion & Proposed ARDC Language & Proposed Modular HTGR-DC Language & Rationale for Modification \\
\hline & & $\begin{array}{l}\text { the reactor [coolanthelium pressure] boundary are } \\
\text { not exceeded during any condition of normal operation, } \\
\text { including anticipated operational occurrences. }\end{array}$ & $\begin{array}{l}\text { summary (ML12219A205). NRC staff } \\
\text { acknowledged the role played by the HPB in } \\
\text { functional containment decisions in } \\
\text { ML14174A845, Section } 3.12 .4 \text {. According to } \\
\text { working definitions developed by NGNP, the } \\
\text { reactor HPB contains (but is not synonymous } \\
\text { with) the primary circuit and should not be } \\
\text { defined purely in terms such as of "helium wetted } \\
\text { surfaces." } \\
\text { Criterion } 15 \text { focuses on not exceeding reactor } \\
\text { HPB design margins during normal operations, } \\
\text { including AOOs. Criterion } 15 \text { was modified to } \\
\text { note that the reactor system, vessel system, and } \\
\text { heat removal systems are the systems that are } \\
\text { designed with margins to ensure that the reactor } \\
\text { HPB integrity is maintained rather than the } \\
\text { "reactor coolant system". }\end{array}$ \\
\hline 16 & $\begin{array}{l}\text { Containment design. } \\
\text { A reactor functional containment, consisting of a } \\
\text { structure surrounding the reactor and its cooling } \\
\text { system or multiple barriers internal and/or } \\
\text { external to the reactor and its cooling system, } \\
\text { shall be provided to effectively control the } \\
\text { release of radioactivity to the environment and to } \\
\text { assure that the functional containment design } \\
\text { conditions important to safety are not exceeded } \\
\text { for as long as postulated accident conditions } \\
\text { require. }\end{array}$ & $\begin{array}{l}\text { ARDC with no further modular HTGR-specific } \\
\text { clarification provided. }\end{array}$ & \\
\hline 17 & $\begin{array}{l}\text { Electric power systems. } \\
\text { Electric power systems shall be provided to } \\
\text { permit functioning of structures, systems, and } \\
\text { components important to safety. The safety } \\
\text { function for the systems shall be to provide } \\
\text { sufficient capacity, capability, and reliability to } \\
\text { assure that (1) specified acceptable fuel design } \\
\text { limits and design conditions of the reactor } \\
\text { [coolant pressure] boundary are not exceeded } \\
\text { as a result of anticipated operational } \\
\text { occurrences and (2) vital functions that rely on } \\
\text { electric power are maintained in the event of } \\
\text { postulated accidents. }\end{array}$ & $\begin{array}{l}\text { ARDC with additional modular HTGR-specific } \\
\text { clarification provided: } \\
\text { Electric power systems. } \\
\text { Electric-Onsite electric power systems shall be } \\
\text { provided to permit functioning of structures, systems, } \\
\text { and components important to safety. The safety } \\
\text { function for the systems shall be to provide sufficient } \\
\text { capacity, capability, and reliability to assure that (1) } \\
\text { specified acceptable fuel core radionuclide release } \\
\text { design limits and design conditions of the reactor } \\
\text { [coolant helium pressure] boundary are not } \\
\text { exceeded as a result of anticipated operational }\end{array}$ & $\begin{array}{l}\text { The criterion was revised to align electric power } \\
\text { systems with the modular HTGR safety design } \\
\text { approach. Inputs considered in this change } \\
\text { include; } \\
\text { a) The passive safety design of modular HTGRs } \\
\text { does not rely on offsite or onsite AC power for } \\
\text { any safety-related function during any postulated } \\
\text { accident scenario (INL/EXT-11-22708, "Modular } \\
\text { HTGR Safety Basis and Approach", Aug. 2011, } \\
\text { ML11251A169, pg. 9). DC power is required for } \\
\text { some systems and is provided by safety related } \\
\text { onsite equipment. }\end{array}$ \\
\hline
\end{tabular}




\begin{tabular}{|c|c|c|c|}
\hline \multicolumn{4}{|c|}{ II. Multiple Barriers } \\
\hline Criterion & Proposed ARDC Language & Proposed Modular HTGR-DC Language & Rationale for Modification \\
\hline & $\begin{array}{l}\text { The onsite electric power systems shall have } \\
\text { sufficient independence, redundancy, and } \\
\text { testability to perform their safety functions, } \\
\text { assuming a single failure. }\end{array}$ & $\begin{array}{l}\text { occurrences and (2) vital functions that rely on electric } \\
\text { power are maintained in the event of postulated } \\
\text { accidents. } \\
\text { The onsite electric power systems shall have sufficient } \\
\text { independence, redundancy, and testability to perform } \\
\text { their safety functions, assuming a single failure as } \\
\text { required during postulated accidents. }\end{array}$ & $\begin{array}{l}\text { b) Reference to application of the single failure } \\
\text { criterion was updated to reflect the NRC staff's } \\
\text { assessment of NGNP proposals in this area, as } \\
\text { noted on July 17, } 2014 \text { in "NGNP - Assessment } \\
\text { of Key Licensing Issues", ML14174A734 } \\
\text { (enclosure 1- ML14174A774, section 1). } \\
\text { NGNP also determined that an alternative to the } \\
\text { LWR-based SAFDL is needed which aligns with } \\
\text { the modular HTGR safety basis and the role of } \\
\text { coated particle fuel; NRC staff noted this issue } \\
\text { before the ACRS on 4/9/2013 (ML13119A447). } \\
\text { "Specified acceptable core radionuclide release } \\
\text { design limits" designates the modular HTGR- } \\
\text { specific regulatory limit. The quantitative value of } \\
\text { the SARRDL will be design specific. }\end{array}$ \\
\hline 18 & $\begin{array}{l}\text { Inspection and testing of electric power systems. } \\
\text { Electric power systems important to safety shall } \\
\text { be designed to permit appropriate periodic } \\
\text { inspection and testing of important areas and } \\
\text { features, such as wiring, insulation, connections, } \\
\text { and switchboards, to assess the continuity of the } \\
\text { systems and the condition of their components. } \\
\text { The systems shall be designed with a capability } \\
\text { to test periodically (1) the operability and } \\
\text { functional performance of the components of the } \\
\text { systems, such as [onsite power sources, } \\
\text { relays, switches, and buses] and (2) the } \\
\text { operability of the systems as a whole and, under } \\
\text { conditions as close to design as practical, the } \\
\text { full operation sequence that brings the systems } \\
\text { into operation, including operation of applicable } \\
\text { portions of the protection system and the } \\
\text { transfer of power among systems. }\end{array}$ & $\begin{array}{l}\text { ARDC with no further modular HTGR-specific } \\
\text { clarification provided. }\end{array}$ & \\
\hline 19 & $\begin{array}{l}\text { Control room. } \\
\text { A control room shall be provided from which } \\
\text { actions can be taken to operate the nuclear } \\
\text { power unit safely under normal conditions and to } \\
\text { maintain it in a safe condition under accident } \\
\text { conditions. Adequate radiation protection shall } \\
\text { be provided to permit access and occupancy of }\end{array}$ & $\begin{array}{l}\text { ARDC with no further modular HTGR-specific } \\
\text { clarification provided. }\end{array}$ & \\
\hline
\end{tabular}




\begin{tabular}{|l|l|l|l|}
\hline Criterion & Proposed ARDC Language & Proposed Modular HTGR-DC Language & Rationale for Modification \\
\hline $\begin{array}{l}\text { the control room under accident conditions } \\
\text { without personnel receiving radiation exposures } \\
\text { in excess of } 5 \text { rem total effective dose equivalent } \\
\text { (TEDE), for the duration of the accident. }\end{array}$ & \\
$\begin{array}{l}\text { Adequate habitability measures shall be } \\
\text { provided to permit access and occupancy of the } \\
\text { control room during normal operations and } \\
\text { under accident conditions. }\end{array}$ & \\
$\begin{array}{l}\text { Equipment at appropriate locations outside the } \\
\text { control room shall be provided (1) with a design } \\
\text { capability for prompt hot shutdown of the } \\
\text { reactor, including necessary instrumentation and } \\
\text { controls to maintain the unit in a safe condition } \\
\text { during hot shutdown, and (2) with a potential } \\
\text { capability for subsequent cold shutdown of the } \\
\text { reactor through the use of suitable procedures. }\end{array}$ & \\
\hline
\end{tabular}

\begin{tabular}{|c|c|c|c|}
\hline \multicolumn{4}{|c|}{ III. Reactivity Control } \\
\hline Criterion & Proposed ARDC Language & Proposed Modular HTGR-DC Language & Rationale for Modification \\
\hline 20 & $\begin{array}{l}\text { Protection system functions. } \\
\text { The protection system shall be designed (1) to } \\
\text { initiate automatically the operation of } \\
\text { appropriate systems including the reactivity } \\
\text { control systems, to assure that specified } \\
\text { acceptable fuel design limits are not exceeded } \\
\text { as a result of anticipated operational } \\
\text { occurrences and (2) to sense accident } \\
\text { conditions and to initiate the operation of } \\
\text { systems and components important to safety. }\end{array}$ & $\begin{array}{l}\text { ARDC with additional modular HTGR-specific } \\
\text { clarification provided: } \\
\text { Protection system functions. } \\
\text { The protection system shall be designed (1) to initiate } \\
\text { automatically the operation of appropriate systems } \\
\text { including the reactivity control systems, to assure that } \\
\text { specified acceptable fuet-core radionuclide release } \\
\text { design limits are not exceeded as a result of anticipated } \\
\text { operational occurrences and (2) to sense accident } \\
\text { conditions and to initiate the operation of systems and } \\
\text { components important to safety. }\end{array}$ & $\begin{array}{l}\text { NGNP determined an alternative to LWR-based } \\
\text { SAFDL is needed which aligns with the modular } \\
\text { HTGR safety basis and the role of coated } \\
\text { particle fuel (see Section } 7.2 .2 \text { ); NRC staff noted } \\
\text { this issue before the ACRS on } 4 / 9 / 2013 \\
\text { (ML13119A447). "Specified acceptable core } \\
\text { radionuclide release design limits" designates } \\
\text { the modular HTGR-specific regulatory limit. The } \\
\text { quantitative value of the SARRDL will be design } \\
\text { specific. }\end{array}$ \\
\hline 21 & $\begin{array}{l}\text { Protection system reliability and testability. } \\
\text { The protection system shall be designed for } \\
\text { high functional reliability and inservice } \\
\text { testability commensurate with the safety } \\
\text { functions to be performed. Redundancy and } \\
\text { independence designed into the protection } \\
\text { system shall be sufficient to assure that (1) no } \\
\text { single failure results in loss of the protection }\end{array}$ & $\begin{array}{l}\text { ARDC with no further modular HTGR-specific } \\
\text { clarification provided. }\end{array}$ & \\
\hline
\end{tabular}




\begin{tabular}{|c|c|c|c|}
\hline \multicolumn{4}{|c|}{ III. Reactivity Control } \\
\hline Criterion & Proposed ARDC Language & Proposed Modular HTGR-DC Language & Rationale for Modification \\
\hline & $\begin{array}{l}\text { function and (2) removal from service of any } \\
\text { component or channel does not result in loss of } \\
\text { the required minimum redundancy unless the } \\
\text { acceptable reliability of operation of the } \\
\text { protection system can be otherwise } \\
\text { demonstrated. The protection system shall be } \\
\text { designed to permit periodic testing of its } \\
\text { functioning when the reactor is in operation, } \\
\text { including a capability to test channels } \\
\text { independently to determine failures and losses } \\
\text { of redundancy that may have occurred. }\end{array}$ & & \\
\hline 22 & $\begin{array}{l}\text { Protection system independence. } \\
\text { The protection system shall be designed to } \\
\text { assure that the effects of natural phenomena, } \\
\text { and of normal operating, maintenance, testing, } \\
\text { and postulated accident conditions on } \\
\text { redundant channels do not result in loss of the } \\
\text { protection function, or shall be demonstrated to } \\
\text { be acceptable on some other defined basis. } \\
\text { Design techniques, such as functional diversity } \\
\text { or diversity in component design and principles } \\
\text { of operation, shall be used to the extent } \\
\text { practical to prevent loss of the protection } \\
\text { function. }\end{array}$ & $\begin{array}{l}\text { ARDC with no further modular HTGR-specific } \\
\text { clarification provided. }\end{array}$ & \\
\hline 23 & $\begin{array}{l}\text { Protection system failure modes. } \\
\text { The protection system shall be designed to fail } \\
\text { into a safe state or into a state demonstrated to } \\
\text { be acceptable on some other defined basis if } \\
\text { conditions such as disconnection of the system, } \\
\text { loss of energy (e.g., [electric power, } \\
\text { instrument air]), or postulated adverse } \\
\text { environments (e.g., [extreme heat or cold, } \\
\text { fire, pressure, steam, water, and radiation]) } \\
\text { are experienced. }\end{array}$ & $\begin{array}{l}\text { ARDC with no further modular HTGR-specific } \\
\text { clarification provided. }\end{array}$ & \\
\hline 24 & $\begin{array}{l}\text { Separation of protection and control systems. } \\
\text { The protection system shall be separated from } \\
\text { control systems to the extent that failure of any } \\
\text { single control system component or channel, or } \\
\text { failure or removal from service of any single } \\
\text { protection system component or channel which } \\
\text { is common to the control and protection } \\
\text { systems leaves intact a system satisfying all }\end{array}$ & $\begin{array}{l}\text { ARDC with no further modular HTGR-specific } \\
\text { clarification provided. }\end{array}$ & \\
\hline
\end{tabular}




\begin{tabular}{|c|c|c|c|}
\hline \multicolumn{4}{|c|}{ III. Reactivity Control } \\
\hline Criterion & Proposed ARDC Language & Proposed Modular HTGR-DC Language & Rationale for Modification \\
\hline & $\begin{array}{l}\text { reliability, redundancy, and independence } \\
\text { requirements of the protection system. } \\
\text { Interconnection of the protection and control } \\
\text { systems shall be limited so as to assure that } \\
\text { safety is not significantly impaired. }\end{array}$ & & \\
\hline 25 & $\begin{array}{l}\text { Protection system requirements for reactivity } \\
\text { control malfunctions. } \\
\text { The protection system shall be designed to } \\
\text { assure that specified acceptable fuel design } \\
\text { limits are not exceeded for any single } \\
\text { malfunction of the reactivity control systems, } \\
\text { such as accidental withdrawal (not ejection or } \\
\text { dropout) of control rods. }\end{array}$ & $\begin{array}{l}\text { ARDC with additional modular HTGR-specific } \\
\text { clarification provided: } \\
\text { Protection system requirements for reactivity control } \\
\text { malfunctions. } \\
\text { The protection system shall be designed to assure that } \\
\text { specified acceptable fuelcore radionuclide release } \\
\text { design limits are not exceeded for any single } \\
\text { malfunction of the reactivity control systems, such as } \\
\text { accidental withdrawal (not ejection-or dropout) of control } \\
\text { rods. }\end{array}$ & $\begin{array}{l}\text { NGNP determined an alternative to LWR-based } \\
\text { SAFDL is needed which aligns with the modular } \\
\text { HTGR safety basis and the role of particle fuel } \\
\text { (see Section } 7.2 .2 \text { ); NRC staff noted this issue } \\
\text { before the ACRS on } 4 / 9 / 2013 \text { (ML13119A447). } \\
\text { "Specified acceptable core radionuclide release } \\
\text { design limits" designates the modular HTGR- } \\
\text { specific regulatory limit. The quantitative value of } \\
\text { the SARRDL will be design specific. } \\
\text { The reference to rod dropout is boiling water } \\
\text { reactor-specific; it does not apply to modular } \\
\text { HTGR designs, all of which are designed for top } \\
\text { down insertion of control rods. }\end{array}$ \\
\hline 26 & $\begin{array}{l}\text { Reactivity control system redundancy and } \\
\text { capability. } \\
\text { [Two] independent reactivity control systems of } \\
\text { different design principles shall be provided. } \\
\text { One of the systems shall use control rods, } \\
\text { preferably including a positive means for } \\
\text { inserting the rods, and shall be capable of } \\
\text { reliably controlling reactivity changes to assure } \\
\text { that under conditions of normal operation, } \\
\text { including anticipated operational occurrences, } \\
\text { and with appropriate margin for malfunctions } \\
\text { such as stuck rods, specified acceptable fuel } \\
\text { design limits are not exceeded. A second } \\
\text { reactivity control system shall be capable of } \\
\text { reliably controlling the rate of reactivity changes } \\
\text { resulting from planned, normal power changes } \\
\text { [(including xenon burnout)] to assure } \\
\text { acceptable fuel design limits are not exceeded. } \\
\text { One of the systems shall be capable of holding } \\
\text { the reactor core subcritical under cold } \\
\text { conditions. }\end{array}$ & $\begin{array}{l}\text { ARDC with additional modular HTGR-specific } \\
\text { clarification provided: } \\
\text { Reactivity control system redundancy and capability. } \\
\text { [Two] ilndependent reactivity control systems of } \\
\text { different design principles shall be provided. One of the } \\
\text { systems shall use control rods, preferably including a } \\
\text { positive means for inserting the rods, and shall be } \\
\text { capable of reliably controlling reactivity changes to } \\
\text { assure that under conditions of normal operation, } \\
\text { including anticipated operational occurrences, and with } \\
\text { appropriate margin for malfunctions such as stuck rods, } \\
\text { specified acceptable fuelcore radionuclide release } \\
\text { design limits are not exceeded. A second reactivity } \\
\text { control system shall be capable of reliably controlling } \\
\text { the rate of reactivity changes resulting from planned, } \\
\text { normal power changes [(including xenon burnout)] to } \\
\text { assure acceptable fuelcore radionuclide release design } \\
\text { limits are not exceeded. One of the systems shall be } \\
\text { capable of holding the reactor core subcritical under } \\
\text { cold conditions. }\end{array}$ & $\begin{array}{l}\text { Wording adjustments were made to provide } \\
\text { flexibility to account for a range of design options } \\
\text { to meet the criterion safety goal, potentially using } \\
\text { more than two independent reactivity control } \\
\text { systems (see MHTGR PSID, Section 4.2). } \\
\text { NGNP determined an alternative to LWR-based } \\
\text { SAFDL is needed which aligns with the modular } \\
\text { HTGR safety basis and the role of coated } \\
\text { particle fuel (see Section } 7.2 .2 \text { ); NRC staff noted } \\
\text { this issue before the ACRS on 4/9/2013 } \\
\text { (ML13119A447). "Specified acceptable core } \\
\text { radionuclide release design limits" designates } \\
\text { the modular HTGR-specific regulatory limit. The } \\
\text { quantitative value of the SARRDL will be design } \\
\text { specific. }\end{array}$ \\
\hline
\end{tabular}




\begin{tabular}{|c|c|c|c|}
\hline \multicolumn{4}{|c|}{ III. Reactivity Control } \\
\hline Criterion & Proposed ARDC Language & Proposed Modular HTGR-DC Language & Rationale for Modification \\
\hline 27 & $\begin{array}{l}\text { Combined reactivity control systems capability. } \\
\text { The reactivity control systems shall be } \\
\text { designed to have a combined capability of } \\
\text { reliably controlling reactivity changes to assure } \\
\text { that under postulated accident conditions and } \\
\text { with appropriate margin for stuck rods the } \\
\text { capability to cool the core is maintained. }\end{array}$ & $\begin{array}{l}\text { ARDC with no further modular HTGR-specific } \\
\text { clarification provided. }\end{array}$ & \\
\hline 28 & $\begin{array}{l}\text { Reactivity limits. } \\
\text { The reactivity control systems shall be } \\
\text { designed with appropriate limits on the potential } \\
\text { amount and rate of reactivity increase to assure } \\
\text { that the effects of postulated reactivity } \\
\text { accidents can neither (1) result in damage to } \\
\text { the reactor [coolant pressure] boundary } \\
\text { greater than limited local yielding nor (2) } \\
\text { sufficiently disturb the core, its support } \\
\text { structures or other reactor vessel internals to } \\
\text { impair significantly the capability to cool the } \\
\text { core. These postulated reactivity accidents } \\
\text { shall include consideration of [rod ejection } \\
\text { (unless prevented by positive means), rod } \\
\text { dropout, steam line rupture, changes in } \\
\text { reactor coolant temperature and pressure, } \\
\text { and cold water addition]. }\end{array}$ & $\begin{array}{l}\text { ARDC with additional modular HTGR-specific } \\
\text { clarification provided: } \\
\text { Reactivity limits. } \\
\text { The reactivity control systems shall be designed with } \\
\text { appropriate limits on the potential amount and rate of } \\
\text { reactivity increase to assure that the effects of } \\
\text { postulated reactivity accidents can neither (1) result in } \\
\text { damage to the reactor [coolanthelium pressure] } \\
\text { boundary greater than limited local yielding nor (2) } \\
\text { sufficiently disturb the core, its support structures or } \\
\text { other reactor vessel internals to impair significantly the } \\
\text { capability to cool the core. These postulated reactivity } \\
\text { accidents shall include consideration of [rod ejection } \\
\text { (unless prevented by positive means), rod dropout, } \\
\text { steam line rupture, changes in reactor coolant } \\
\text { temperature-and pressure, and cold-water } \\
\text { additionmoisture ingress]. }\end{array}$ & $\begin{array}{l}\text { The concept of limiting the potential rate and } \\
\text { amount of reactivity increases applies to modular } \\
\text { HTGRs, but minor revisions were made to } \\
\text { address the reactor helium pressure boundary } \\
\text { and the inapplicability of rod dropout for modular } \\
\text { HTGRs. } \\
\text { The list of reactivity accidents was modified to } \\
\text { address reactor temperature changes resulting } \\
\text { from a number of possible initiating events that } \\
\text { could affect reactivity, including moisture ingress } \\
\text { (see Sections } 15.7-15.10 \text { of MHTGR PSID). } \\
\text { Cold-water addition does not apply to the } \\
\text { modular HTGR. }\end{array}$ \\
\hline 29 & $\begin{array}{l}\text { Protection against anticipated operational } \\
\text { occurrences. } \\
\text { The protection and reactivity control systems } \\
\text { shall be designed to assure an extremely high } \\
\text { probability of accomplishing their safety } \\
\text { functions in the event of anticipated operational } \\
\text { occurrences. }\end{array}$ & $\begin{array}{l}\text { ARDC with no further modular HTGR-specific } \\
\text { clarification provided. }\end{array}$ & \\
\hline
\end{tabular}

\begin{tabular}{|c|l|l|l|}
\hline \multicolumn{2}{|l|}{ IV. Fluid Systems } \\
\hline Criterion & Proposed ARDC Language & Proposed Modular HTGR-DC Language & Rationale for Modification \\
\hline 30 & $\begin{array}{l}\text { Quality of reactor [coolant pressure] } \\
\text { boundary. }\end{array}$ & $\begin{array}{l}\text { ARDC with additional modular HTGR-specific } \\
\text { clarification provided: }\end{array}$ & $\begin{array}{l}\text { The reactor HPB is the one of multiple modular } \\
\text { HTGR fission product release barriers; the } \\
\text { release barrier configuration is summarized in } \\
\text { slides presented to NRC during a July 2012 } \\
\text { public meeting (ML12223A146) with associated } \\
\text { designed, fabricated, erected, and tested to the }\end{array}$ \\
\hline
\end{tabular}




\begin{tabular}{|c|c|c|c|}
\hline \multicolumn{4}{|c|}{ IV. Fluid Systems } \\
\hline Criterion & Proposed ARDC Language & Proposed Modular HTGR-DC Language & Rationale for Modification \\
\hline & $\begin{array}{l}\text { highest quality standards practical. Means shall } \\
\text { be provided for detecting and, to the extent } \\
\text { practical, identifying the location of the source } \\
\text { of reactor [coolant] leakage. }\end{array}$ & $\begin{array}{l}\text { [coolanthelium pressure] boundary shall be designed, } \\
\text { fabricated, erected, and tested to the highest quality } \\
\text { standards practical. Means shall be provided for } \\
\text { detecting and, to the extent practical, identifying the } \\
\text { location of the source of reactor [coolanthelium] } \\
\text { leakage. }\end{array}$ & $\begin{array}{l}\text { NRC meeting summary (ML12219A205). } \\
\text { System factors discussed in section } 2.3 .3 \text { of } \\
\text { INL/EXT-10-17997, "NGNP Mechanistic Source } \\
\text { Terms White Paper, July 2010, ML102040260, } \\
\text { note the HPB integrity is relevant to this criterion } \\
\text { due to its role in functional containment and its } \\
\text { contribution in controlling graphite chemical } \\
\text { attack via contaminant ingress. The adapted } \\
\text { criterion addresses the need for high quality HPB } \\
\text { component fabrication. }\end{array}$ \\
\hline 31 & $\begin{array}{l}\text { Fracture prevention of reactor [coolant } \\
\text { pressure] boundary. } \\
\text { The reactor [coolant pressure] boundary shall } \\
\text { be designed with sufficient margin to assure } \\
\text { that when stressed under operating, } \\
\text { maintenance, testing, and postulated accident } \\
\text { conditions (1) the boundary behaves in a } \\
\text { nonbrittle manner and (2) the probability of } \\
\text { rapidly propagating fracture is minimized. The } \\
\text { design shall reflect consideration of service } \\
\text { temperatures [and other conditions] of the } \\
\text { boundary material under operating, } \\
\text { maintenance, testing, and postulated accident } \\
\text { conditions and the uncertainties in determining } \\
\text { (1) material properties, (2) the effects of } \\
\text { irradiation on material properties, (3) residual, } \\
\text { steady state and transient stresses, and (4) } \\
\text { size of flaws. }\end{array}$ & $\begin{array}{l}\text { ARDC with additional modular HTGR-specific } \\
\text { clarification provided: } \\
\text { Fracture prevention of reactor [coolanthelium } \\
\text { pressure] boundary. } \\
\text { The reactor [coolanthelium pressure] boundary shall } \\
\text { be designed with sufficient margin to assure that when } \\
\text { stressed under operating, maintenance, testing, and } \\
\text { postulated accident conditions (1) the boundary } \\
\text { behaves in a nonbrittle manner and (2) the probability of } \\
\text { rapidly propagating fracture is minimized. The design } \\
\text { shall reflect consideration of service temperatures [and } \\
\text { other conditions] of the boundary material under } \\
\text { operating, maintenance, testing, and postulated } \\
\text { accident conditions and the uncertainties in determining } \\
\text { (1) material properties, (2) the effects of irradiation on } \\
\text { material properties, (3) residual, steady state and } \\
\text { transient stresses, and (4) size of flaws. }\end{array}$ & $\begin{array}{l}\text { The reactor HPB has a different function as } \\
\text { compared to the LWR reactor coolant pressure } \\
\text { boundary. The reactor HPB role in the functional } \\
\text { containment and in the control of core chemical } \\
\text { attack from contaminant ingress is noted in the } \\
\text { Criterion } 30 \text { rationale; radionuclide release } \\
\text { mechanisms in event of reactor HPB failure are } \\
\text { discussed in Section } 5.4 \text { of INL/EXT-11-22708, } \\
\text { "Modular HTGR Safety Basis and Approach", } \\
\text { Aug } 2011, \text { ML11251A169. } \\
\text { This criterion contributes to assuring that } \\
\text { modular HTGR functional containment will meet } \\
\text { 10CFR50.34 (10 CFR } 52.79 \text { ) requirements at the } \\
\text { plant's exclusion area boundary (EAB) with } \\
\text { margin without consideration of retention by } \\
\text { reactor building. This key functional containment } \\
\text { performance attribute was presented to the } \\
\text { ACRS by NGNP on } 1 / 17 / 13 \text { (ML13044A656), } \\
\text { and acknowledged by NRC staff on July } 17, \\
2014 \text { in "NGNP - Assessment of Key Licensing } \\
\text { Issues", ML14174A734 (enclosure 1- } \\
\text { ML14174A774, section } 3 \text {, and enclosure } 2 \text { - } \\
\text { ML14174A845, section } 3.11 \text { ). Criterion was } \\
\text { modified to reference the reactor HPB. }\end{array}$ \\
\hline 32 & $\begin{array}{l}\text { Inspection of reactor [coolant pressure] } \\
\text { boundary. } \\
\text { Components which are part of the reactor } \\
\text { [coolant pressure] boundary shall be } \\
\text { designed to permit (1) periodic inspection and } \\
\text { testing of important areas and features to }\end{array}$ & $\begin{array}{l}\text { ARDC with additional modular HTGR-specific } \\
\text { clarification provided: } \\
\text { Inspection of reactor [coolanthelium pressure] } \\
\text { boundary. } \\
\text { Components which are part of the reactor }\end{array}$ & $\begin{array}{l}\text { Criterion was modified to recognize that modular } \\
\text { HTGRs have a reactor HPB rather than RCPB. } \\
\text { The reactor HPB contributes to functional } \\
\text { containment as summarized in slides presented } \\
\text { to NRC in a July } 2012 \text { public meeting } \\
\text { (ML12223A146) with associated NRC meeting }\end{array}$ \\
\hline
\end{tabular}




\begin{tabular}{|c|c|c|c|}
\hline \multicolumn{4}{|c|}{$\begin{array}{l}\text { IV. Fluid Systems } \\
\end{array}$} \\
\hline Criterion & Proposed ARDC Language & Proposed Modular HTGR-DC Language & Rationale for Modification \\
\hline & $\begin{array}{l}\text { assess their structural and leaktight integrity, } \\
\text { and (2) an appropriate material surveillance } \\
\text { program for the reactor vessel. }\end{array}$ & $\begin{array}{l}\text { [coolanthelium pressure] boundary shall be designed } \\
\text { to permit (1) periodic inspection and testing of important } \\
\text { areas and features to assess their structural and } \\
\text { leaktightintegrity, and (2) an appropriate material } \\
\text { surveillance program for the reactor vessel. }\end{array}$ & $\begin{array}{l}\text { summary (ML12219A205). } \\
\text { Section 5.4 of INL/EXT-11-22708, "Modular } \\
\text { HTGR Safety Basis and Approach", Aug 2011, } \\
\text { ML11251A169, summarizes the radionuclide } \\
\text { release mechanisms in the event of reactor HPB } \\
\text { failure. } \\
\text { This criterion contributes to assuring that the } \\
\text { modular HTGR functional containment will meet } \\
\text { 10CFR50.34 (10 CFR } 52.79 \text { ) requirements at the } \\
\text { plant's exclusion area boundary (EAB) with } \\
\text { margin for postulated accidents without } \\
\text { consideration of retention by reactor building. } \\
\text { This key functional containment performance } \\
\text { attribute was presented to the ACRS by NGNP } \\
\text { on 1/17/13 (ML13044A656), and was } \\
\text { acknowledged by the NRC staff on July 17, 2014 } \\
\text { in "NGNP - Assessment of Key Licensing } \\
\text { Issues", ML14174A734 (enclosure 1- } \\
\text { ML14174A774, section } 3 \text { and enclosure } 2 \text { - } \\
\text { ML14174A845, section 3.11). } \\
\text { The reactor HPB requires appropriate inspection } \\
\text { and surveillance but may not require "leaktight" } \\
\text { integrity; issues related to verifying the reactor } \\
\text { HPB leakage are presumed addressed by } \\
\text { assessing "structural integrity." }\end{array}$ \\
\hline 33 & $\begin{array}{l}\text { Reactor [coolant] inventory maintenance. } \\
\text { A system to maintain reactor [coolant] } \\
\text { inventory for protection against small breaks in } \\
\text { the reactor [coolant pressure] boundary shall } \\
\text { be provided as necessary to assure that } \\
\text { specified acceptable fuel design limits are not } \\
\text { exceeded as a result of reactor [coolant] } \\
\text { inventory loss due to leakage from the reactor } \\
\text { [coolant pressure] boundary and rupture of } \\
\text { small piping or other small components which } \\
\text { are part of the boundary. }\end{array}$ & Not applicable to modular HTGR. & $\begin{array}{l}\text { Although modular HTGRs have helium makeup } \\
\text { and cleanup systems, they are not relied upon } \\
\text { during postulated accidents. Coolant makeup for } \\
\text { protection against small LWR leaks has no } \\
\text { modular HTGR counterpart (See Section } 6.1 \text {, } \\
\text { INL/EXT-11-22708, "Modular HTGR Safety } \\
\text { Basis and Approach", Aug 2011, } \\
\text { ML11251A169). } \\
\text { Modular HTGR specified acceptable core } \\
\text { radionuclide release design limits are not } \\
\text { assured by the system addressed by this ARDC; } \\
\text { adequate core cooling is maintained even with a } \\
\text { depressurized primary circuit. Criterion does not }\end{array}$ \\
\hline
\end{tabular}




\begin{tabular}{|c|c|c|c|}
\hline \multicolumn{4}{|c|}{$\begin{array}{l}\text { IV. Fluid Systems } \\
\end{array}$} \\
\hline Criterion & Proposed ARDC Language & Proposed Modular HTGR-DC Language & Rationale for Modification \\
\hline & & & apply to modular HTGRs. \\
\hline 34 & $\begin{array}{l}\text { Residual heat removal. } \\
\text { A system to remove residual heat shall be } \\
\text { provided. The system safety function shall be to } \\
\text { transfer fission product decay heat and other } \\
\text { residual heat from the reactor core to an } \\
\text { ultimate heat sink at a rate such that specified } \\
\text { acceptable fuel design limits and the design } \\
\text { conditions of the reactor [coolant pressure] } \\
\text { boundary are not exceeded under all plant } \\
\text { shutdown conditions following normal } \\
\text { operation, including anticipated operational } \\
\text { occurrences, and to provide continuous } \\
\text { effective core cooling during postulated } \\
\text { accidents. } \\
\text { Suitable redundancy in components and } \\
\text { features, and suitable interconnections, leak } \\
\text { detection, and isolation capabilities shall be } \\
\text { provided to assure that the system safety } \\
\text { function can be accomplished, assuming a } \\
\text { single failure. }\end{array}$ & $\begin{array}{l}\text { ARDC with additional modular HTGR-specific } \\
\text { clarification provided: } \\
\text { Residual-Passive residual heat removal. } \\
\text { A passive system to remove residual heat shall be } \\
\text { provided. The system safety function shall be to transfer } \\
\text { fission product decay heat and other residual heat from } \\
\text { the reactor core to an ultimate heat sink at a rate such } \\
\text { that specified acceptable fuel-core radionuclide release } \\
\text { design limits and the design conditions of the reactor } \\
\text { [coolant pressure] boundary-are not exceeded under } \\
\text { all plant shutdown conditions following normal } \\
\text { operation, including-during anticipated operational } \\
\text { occurrences, and to provide continuous effective sore } \\
\text { cooling during postulated accidents. } \\
\text { Suitable redundancy in components and features, and } \\
\text { suitable interconnections, leak detection, and isolation } \\
\text { capabilities shall be provided to assure that the system } \\
\text { safety function can be accomplished, assuming a single } \\
\text { failure. }\end{array}$ & $\begin{array}{l}\text { This criterion was revised to show that safety } \\
\text { residual heat removal in modular HTGRs relies } \\
\text { on a passive reactor cavity cooling system } \\
\text { (RCCS) as the conduit to ultimate heat sink (See } \\
\text { Section } 2.3 .4 \text { of INL/EXT-10-17997, "NGNP } \\
\text { Mechanistic Source Terms White Paper, July } \\
2010, \text { ML102040260, and page R 5-4-2 of } \\
\text { "Preliminary Safety Information Document for the } \\
\text { Standard MHTGR", HTGR-86-024, Sep 9, 1992, } \\
\text { Amendment 13). "Passive" is added to clarify } \\
\text { and emphasize its key role in the overall modular } \\
\text { HTGR design and configuration. } \\
\text { NGNP determined an alternative to LWR-based } \\
\text { SAFDL is needed which aligns with the modular } \\
\text { HTGR safety basis and the role of coated } \\
\text { particle fuel (see Section } 7.2 .2 \text { ); NRC staff noted } \\
\text { this issue before the ACRS on 4/9/2013 } \\
\text { (ML13119A447). "Specified acceptable core } \\
\text { radionuclide release design limits" designates } \\
\text { the modular HTGR-specific regulatory limit. The } \\
\text { quantitative value of the SARRDL will be design } \\
\text { specific. } \\
\text { The modular HTGR RCCS protects the integrity } \\
\text { of the reactor vessel when needed under } \\
\text { postulated accident conditions. It is also relied } \\
\text { upon for heat removal during some AOOs during } \\
\text { which the SARRDL is not to be exceeded. Text } \\
\text { of first paragraph was modified to communicate } \\
\text { RCCS function. } \\
\text { Reference to application of the single failure } \\
\text { criteria was updated to reflect the NRC staff's } \\
\text { assessment of NGNP proposals in this area, as } \\
\text { noted on July 17, } 2014 \text { in "NGNP - Assessment } \\
\text { of Key Licensing Issues", ML14174A734 } \\
\text { (enclosure 1- ML14174A774, section 1). It is } \\
\text { expected that the single failure design criterion } \\
\text { will be replaced with a probabilistic (reliability) } \\
\text { criterion in modular HTGRs. }\end{array}$ \\
\hline
\end{tabular}


sed ARDC Language

Advanced Reactor Design Criterion for core cooling under accident conditions is contained in ARDC-34.

36 Inspection of residual heat removal system. The residual heat removal system shall be designed to permit appropriate periodic inspection of important components, such as [spray rings in the reactor pressure vessel, water injection nozzles, and piping], to assure the integrity and capability of the system.

37 Testing of residual heat removal system. The residual heat removal system shall be designed to permit appropriate periodic functional testing to assure (1) the structural integrity of its components, (2) the operability and performance of the system components, and (3) the operability of the system as a whole and, under conditions as close to design as practical, the performance of the full operational sequence that brings the system into operation,
Proposed Modular HTGR-DC Language

clarification provided.

ARDC with additional modular HTGR-specific

clarification provided:

Inspection of passive residual heat removal system.

The passive residual heat removal system shall be designed to permit appropriate periodic inspection of important components, such as [spray rings in the reactor pressure vessel, water injection nozzles, and pipingdesign-specific equipment], to assure the integrity and capability of the system.

ARDC with additional modular HTGR-specific clarification provided:

Testing of passive residual heat removal system.

The passive residual heat removal system shall be designed to permit appropriate periodic functional testing to assure (1) the structural integrity of its components, (2) the operability and performance of the system components, and (3) the operability of the system as a whole and, if applicable, under conditions
Rationale for Modification

Criterion 36 is renamed and revised for inspection of the passive residual heat removal system required by Criterion 34

Modular HTGRs do not have an emergency forced cooling system but use a passive reactor cavity cooling system (RCCS) (subject to Criterion 34) for residual heat removal to keep structures, systems and components within allowable limits. The Criterion 34 RCCS (active or passive mode under normal conditions, always passive under accident conditions) is subject to inspection under Criterion 36 .

Section 2.3.4 of INL/EXT-10-17997, "NGNP Mechanistic Source Terms White Paper, July 2010, ML102040260, identifies the RCCS contribution to the modular HTGR safety basis Pg. R 5-7-1 of "Preliminary Safety Information Document for the Standard MHTGR", HTGR-86024, Sep 9, 1992, Amendment 13, states provisions for visual inspection will be required to assure RCCS integrity and structural support.

LWR-specific equipment (spray rings, water injection nozzles, and piping) inside the brackets will be replaced (later) with RCCS designspecific equipment, depending on which RCCS working fluid (air or water) is used in the design. Criterion 37 is renamed and revised for testing of the passive residual heat removal system required by modular HTGR-DC 34 .

Section 2.3.4 of INL/EXT-10-17997, "NGNP Mechanistic Source Terms White Paper, July 2010, ML102040260, notes the passive RCCS (using either air or water as heat transfer fluid) contributes to the modular HTGR safety basis and is subject to component integrity testing. 


\begin{tabular}{|c|c|c|c|}
\hline \multicolumn{4}{|c|}{$\begin{array}{l}\text { IV. Fluid Systems } \\
\end{array}$} \\
\hline Criterion & Proposed ARDC Language & Proposed Modular HTGR-DC Language & Rationale for Modification \\
\hline & $\begin{array}{l}\text { including operation of associated systems and } \\
\text { interfaces with an ultimate heat sink. }\end{array}$ & $\begin{array}{l}\text { as close to design as practical, the performance of the } \\
\text { full operational sequence that brings the system into } \\
\text { operation, including operation of associated systems } \\
\text { and interfaces with an ultimate heat sink and the } \\
\text { transition from the active normal operation mode to the } \\
\text { passive operation mode relied upon during postulated } \\
\text { accidents. }\end{array}$ & $\begin{array}{l}\text { However, Section } 6.1 \text { of INL/EXT-11-22708, } \\
\text { "Modular HTGR Safety Basis and Approach", } \\
\text { Aug 2011, ML11251A169, indicates that RCCS } \\
\text { performance does not require "leaktight" } \\
\text { conditions. } \\
\text { Some modular HTGR reactor cavity cooling } \\
\text { system (RCCS) designs will provide continuous } \\
\text { passive operation without need for a requirement } \\
\text { to test the operation sequence that brings the } \\
\text { system into operation; "if applicable" is included } \\
\text { to recognize this contingency. } \\
\text { Criterion was modified to reflect the passive } \\
\text { nature of the modular HTGR RCCS and the } \\
\text { need to verify ability to transition the RCCS from } \\
\text { active mode (if present) to passive mode during } \\
\text { postulated accidents. }\end{array}$ \\
\hline 38 & $\begin{array}{l}\text { Containment heat removal. } \\
\text { A system to remove heat from the reactor } \\
\text { containment shall be provided as necessary to } \\
\text { maintain the containment pressure and } \\
\text { temperature within acceptable limits following } \\
\text { postulated accidents. } \\
\text { Suitable redundancy in components and } \\
\text { features, and suitable interconnections, leak } \\
\text { detection, isolation, and containment } \\
\text { capabilities shall be provided to assure that the } \\
\text { system safety function can be accomplished, } \\
\text { assuming a single failure. }\end{array}$ & Not applicable to modular HTGR. & $\begin{array}{l}\text { Modular HTGRs do not employ a containment } \\
\text { structure. Modular HTGRs use multiple } \\
\text { functional containment barriers that are } \\
\text { summarized in a set of slides presented to NRC } \\
\text { in a July } 2012 \text { public meeting (ML12223A146) } \\
\text { with associated NRC meeting summary } \\
\text { (ML12219A205). } \\
\text { For the purpose of modular HTGR functional } \\
\text { containment protection, heat removal is assured } \\
\text { by Criterion } 10 \text { (Reactor design) and Criterion } 15 \\
\text { (Reactor HPB design). } \\
\text { Containment heat removal under Criterion } 38 \text { is } \\
\text { not applicable to modular HTGRs. }\end{array}$ \\
\hline 39 & $\begin{array}{l}\text { Inspection of containment heat removal } \\
\text { system. } \\
\text { The containment heat removal system shall be } \\
\text { designed to permit appropriate periodic } \\
\text { inspection of important components, such as } \\
\text { [the torus, sumps, spray nozzles, and } \\
\text { piping] to assure the integrity and capability of } \\
\text { the system. }\end{array}$ & Not applicable to modular HTGR. & $\begin{array}{l}\text { Containment heat removal under Criterion } 38 \text { is } \\
\text { not applicable to modular HTGRs, so Criterion } \\
39 \text { is also not applicable. }\end{array}$ \\
\hline
\end{tabular}




\begin{tabular}{|c|c|c|c|}
\hline \multicolumn{4}{|c|}{$\begin{array}{l}\text { IV. Fluid Systems } \\
\end{array}$} \\
\hline Criterion & Proposed ARDC Language & Proposed Modular HTGR-DC Language & Rationale for Modification \\
\hline 40 & $\begin{array}{l}\text { Testing of containment heat removal system. } \\
\text { The containment heat removal system shall be } \\
\text { designed to permit appropriate periodic } \\
\text { functional testing to assure (1) the structural } \\
\text { integrity of its components, (2) the operability } \\
\text { and performance of the system components, } \\
\text { and ( } 3 \text { ) the operability of the system as a } \\
\text { whole, and under conditions as close to the } \\
\text { design as practical, the performance of the full } \\
\text { operational sequence that brings the system } \\
\text { into operation, including operation of } \\
\text { associated systems. }\end{array}$ & Not applicable to modular HTGR. & $\begin{array}{l}\text { Containment heat removal under Criterion } 38 \text { is } \\
\text { not applicable to modular HTGRs, so Criterion } \\
40 \text { is also not applicable. }\end{array}$ \\
\hline 41 & $\begin{array}{l}\text { Containment atmosphere cleanup. } \\
\text { Systems to control fission products, } \\
\text { [hydrogen, oxygen,] and other substances } \\
\text { which may be released into the reactor } \\
\text { containment shall be provided as necessary to } \\
\text { reduce, consistent with the functioning of other } \\
\text { associated systems, the concentration and } \\
\text { quality of fission products released to the } \\
\text { environment following postulated accidents, } \\
\text { and to control the concentration of [hydrogen } \\
\text { or oxygen] and other substances in the } \\
\text { containment atmosphere following postulated } \\
\text { accidents to assure that containment integrity is } \\
\text { maintained. } \\
\text { Each system shall have suitable redundancy in } \\
\text { components and features, and suitable } \\
\text { interconnections, leak detection, isolation, and } \\
\text { containment capabilities to assure that its } \\
\text { safety function can be accomplished, assuming } \\
\text { a single failure. }\end{array}$ & Not applicable to modular HTGR. & $\begin{array}{l}\text { Modular HTGRs rely on all but one of their } \\
\text { multiple functional containment barriers to meet } \\
\text { 10CFR50.34 (10 CFR 52.79) dose criteria. The } \\
\text { exception is the reactor building. The modular } \\
\text { HTGR reactor building is vented and may not } \\
\text { have exhaust filtration provisions. Explosive gas } \\
\text { mixtures are not a source of hazard in the } \\
\text { modular HTGR reactor building (see PSID for } \\
\text { the Standard MHTGR, HTGR-86-024, pg R15-2- } \\
\text { 1). There is no corollary modular HTGR system } \\
\text { for containment atmosphere cleanup. } \\
\text { Criterion } 41 \text { is not applicable to modular HTGRs. }\end{array}$ \\
\hline 42 & $\begin{array}{l}\text { Inspection of containment atmosphere cleanup } \\
\text { systems. } \\
\text { The containment atmosphere cleanup systems } \\
\text { shall be designed to permit appropriate periodic } \\
\text { inspection of important components, such as } \\
\text { filter frames, ducts, and piping to assure the } \\
\text { integrity and capability of the systems. }\end{array}$ & Not applicable to modular HTGR. & $\begin{array}{l}\text { Containment atmosphere cleanup under } \\
\text { Criterion } 41 \text { is not applicable to modular HTGRs, } \\
\text { so Criterion } 42 \text { is also not applicable. }\end{array}$ \\
\hline
\end{tabular}




\begin{tabular}{|c|c|c|c|}
\hline \multicolumn{4}{|c|}{$\begin{array}{l}\text { IV. Fluid Systems } \\
\end{array}$} \\
\hline Criterion & Proposed ARDC Language & Proposed Modular HTGR-DC Language & Rationale for Modification \\
\hline 43 & $\begin{array}{l}\text { Testing of containment atmosphere cleanup } \\
\text { systems. } \\
\text { The containment atmosphere cleanup systems } \\
\text { shall be designed to permit appropriate periodic } \\
\text { functional testing to assure (1) the structural } \\
\text { integrity of its components, (2) the operability } \\
\text { and performance of the system components, } \\
\text { and ( } 3 \text { ) the operability of the systems as a } \\
\text { whole and, under conditions as close to design } \\
\text { as practical, the performance of the full } \\
\text { operational sequence that brings the systems } \\
\text { into operation, including the operation of } \\
\text { associated systems. }\end{array}$ & Not applicable to modular HTGR. & $\begin{array}{l}\text { Containment atmosphere cleanup under } \\
\text { Criterion } 41 \text { is not applicable to modular HTGRs, } \\
\text { so Criterion } 43 \text { is also not applicable. }\end{array}$ \\
\hline 44 & $\begin{array}{l}\text { Structural and equipment cooling. } \\
\text { In addition to the heat rejection capability of the } \\
\text { residual heat removal system, systems to } \\
\text { transfer heat from structures, systems, and } \\
\text { components important to safety, to an ultimate } \\
\text { heat sink shall be provided, as necessary to } \\
\text { transfer the combined heat load of these } \\
\text { structures, systems, and components under } \\
\text { normal operating and accident conditions. } \\
\text { Suitable redundancy in components and } \\
\text { features, and suitable interconnections, leak } \\
\text { detection, and isolation capabilities shall be } \\
\text { provided to assure that each system safety } \\
\text { function can be accomplished, assuming a } \\
\text { single failure. }\end{array}$ & Not applicable to modular HTGR. & $\begin{array}{l}\text { The only safety related modular HTGR heat } \\
\text { transfer system is the RCCS, which is addressed } \\
\text { by Criterion } 34 \text {. There is no modular HTGR } \\
\text { system analogous to that addressed in Criterion } \\
44 \text { (See Section } 6 \text { of INL/EXT-11-22708, } \\
\text { "Modular HTGR Safety Basis and Approach", } \\
\text { Aug 2011, ML11251A169). } \\
\text { Criterion } 44 \text { is not applicable to modular HTGRs. }\end{array}$ \\
\hline 45 & $\begin{array}{l}\text { Inspection of structural and equipment cooling } \\
\text { systems. } \\
\text { The structural and equipment cooling systems } \\
\text { shall be designed to permit appropriate periodic } \\
\text { inspection of important components, such as } \\
\text { heat exchangers and piping, to assure the } \\
\text { integrity and capability of the systems. }\end{array}$ & Not applicable to modular HTGR. & $\begin{array}{l}\text { Cooling water under Criterion } 44 \text { is not } \\
\text { applicable to modular HTGRs, so Criterion } 45 \text { is } \\
\text { also not applicable. }\end{array}$ \\
\hline 46 & $\begin{array}{l}\text { Testing of structural and equipment cooling } \\
\text { systems. } \\
\text { The structural and equipment cooling systems } \\
\text { shall be designed to permit appropriate periodic } \\
\text { functional testing to assure (1) the structural } \\
\text { integrity of their components, (2) the operability }\end{array}$ & Not applicable to modular HTGR. & $\begin{array}{l}\text { Cooling water under Criterion } 44 \text { is not } \\
\text { applicable to modular HTGRs, so Criterion } 46 \text { is } \\
\text { also not applicable. }\end{array}$ \\
\hline
\end{tabular}




\begin{tabular}{|l|l|l|l|}
\hline Criterion & Proposed ARDC Language & Proposed Modular HTGR-DC Language & Rationale for Modification \\
\hline & $\begin{array}{l}\text { and the performance of the system } \\
\text { components, and (3) the operability of the } \\
\text { systems as a whole and, under conditions as } \\
\text { close to design as practical, the performance of } \\
\text { the full operational sequences that bring the } \\
\text { systems into operation for reactor shutdown } \\
\text { and postulated accidents, including operation of } \\
\text { associated systems. }\end{array}$ & & \\
\hline
\end{tabular}

\begin{tabular}{|c|c|c|c|}
\hline \multicolumn{4}{|c|}{ V. Reactor Containment } \\
\hline Criterion & Proposed ARDC Language & Proposed Modular HTGR-DC Language & Rationale for Modification \\
\hline 50 & $\begin{array}{l}\text { Containment design basis. } \\
\text { The reactor containment structure, including } \\
\text { access openings, penetrations, and the } \\
\text { containment heat removal system shall be } \\
\text { designed so that the containment structure and } \\
\text { its internal compartments can accommodate, } \\
\text { without exceeding the design leakage rate and } \\
\text { with sufficient margin, the calculated pressure } \\
\text { and temperature conditions resulting from } \\
\text { postulated accidents. This margin shall reflect } \\
\text { consideration of (1) the effects of potential } \\
\text { energy sources which have not been included } \\
\text { in the determination of the peak conditions, } \\
\text { such as [energy in steam generators and as } \\
\text { required by } § 50.44 \text { energy from metal-water } \\
\text { and other chemical reactions that may } \\
\text { result from degradation but not total failure } \\
\text { of emergency core cooling functioning], (2) } \\
\text { the limited experience and experimental data } \\
\text { available for defining accident phenomena and } \\
\text { containment responses, and ( } 3 \text { ) the } \\
\text { conservatism of the calculational model and } \\
\text { input parameters. }\end{array}$ & Not applicable to modular HTGR. & $\begin{array}{l}\text { Modular HTGRs do not have a "reactor } \\
\text { containment structure", but instead rely on a } \\
\text { multi-barrier functional containment configuration } \\
\text { to control the release of radionuclides. That } \\
\text { configuration is summarized in a set of slides } \\
\text { presented to NRC in a July } 2012 \text { public meeting } \\
\text { (ML12223A146) with associated NRC meeting } \\
\text { summary (ML12219A205). } \\
\text { Design requirements for the individual } \\
\text { constituents of the modular HTGR functional } \\
\text { containment are addressed by proposed } \\
\text { modular HTGR Design Criteria } 10 \text { (Reactor } \\
\text { Design), } 15 \text { (Reactor Helium Pressure Boundary } \\
\text { Design), } 16 \text { (Containment Design), 34 (Passive } \\
\text { Residual Heat Removal), } 70 \text { (Reactor Vessel } \\
\text { and Reactor System Structural Design Basis), } \\
\text { and } 71 \text { (Reactor Building Design Basis). } \\
\text { Performance standards for the functional } \\
\text { containment have been proposed by NGNP and } \\
\text { were reviewed by the NRC staff as summarized } \\
\text { in their July 17, 2014 report "NGNP - } \\
\text { Assessment of Key Licensing Issues", } \\
\text { ML14174A734 (enclosure 1- ML14174A774, } \\
\text { section 3). } \\
\text { It is further noted that the modular HTGR } \\
\text { functional containment will meet 10CFR50.34 } \\
\text { (10 CFR 52 79) reguirements at the plant's }\end{array}$ \\
\hline
\end{tabular}




\begin{tabular}{|c|c|c|c|}
\hline \multicolumn{4}{|c|}{ V. Reactor Containment } \\
\hline Criterion & Proposed ARDC Language & Proposed Modular HTGR-DC Language & Rationale for Modification \\
\hline & & & $\begin{array}{l}\text { exclusion area boundary (EAB) with margin } \\
\text { without consideration of reactor building } \\
\text { retention. This key functional containment } \\
\text { performance attribute was presented to the } \\
\text { ACRS by NGNP on } 1 / 17 / 13 \text { (ML13044A656), } \\
\text { and was discussed by NRC staff as a part of the } \\
\text { functional containment performance standard } \\
\text { (Assessment Report ML14174A734 with } \\
\text { enclosure } 1-\text { ML14174A774, section 3, and } \\
\text { enclosure } 2-\text { ML14174A845, section 3.3). }\end{array}$ \\
\hline 51 & $\begin{array}{l}\text { Fracture prevention of containment pressure } \\
\text { boundary. } \\
\text { The boundary of the reactor containment } \\
\text { structure shall be designed with sufficient } \\
\text { margin to assure that under operating, } \\
\text { maintenance, testing, and postulated accident } \\
\text { conditions (1) its materials behave in a } \\
\text { nonbrittle manner and (2) the probability of } \\
\text { rapidly propagating fracture is minimized. The } \\
\text { design shall reflect consideration of service } \\
\text { temperatures and other conditions of the } \\
\text { containment boundary materials during } \\
\text { operation, maintenance, testing, and postulated } \\
\text { accident conditions, and the uncertainties in } \\
\text { determining (1) material properties, (2) residual, } \\
\text { steady state, and transient stresses, and (3) } \\
\text { size of flaws. }\end{array}$ & Not applicable to modular HTGR. & $\begin{array}{l}\text { This criterion is associated with rapid fracture } \\
\text { propagation of the LWR-based containment } \\
\text { pressure boundary. The modular HTGR Reactor } \\
\text { Building does not provide a corresponding } \\
\text { pressure retention function, so this criterion does } \\
\text { not apply. Requirements regarding the } \\
\text { performance of the modular HTGR Reactor } \\
\text { Building are addressed by new Criterion } 71 \\
\text { (design basis) and Criterion } 72 \text { (provisions for } \\
\text { testing and inspection). }\end{array}$ \\
\hline 52 & $\begin{array}{l}\text { Capability for containment leakage rate testing. } \\
\text { The reactor containment structure and other } \\
\text { equipment which may be subjected to } \\
\text { containment test conditions shall be designed } \\
\text { so that periodic integrated leakage rate testing } \\
\text { can be conducted at containment design } \\
\text { pressure. }\end{array}$ & Not applicable to modular HTGR. & $\begin{array}{l}\text { The modular HTGR Reactor Building does not } \\
\text { provide a pressure retention function, and it is } \\
\text { not relied upon to meet the offsite dose } \\
\text { requirements of } 10 \text { CFR } 50.34 \text { (10 CFR 52.79). } \\
\text { Therefore, this criterion does not apply. } \\
\text { Requirements regarding the performance of the } \\
\text { modular HTGR Reactor Building are addressed } \\
\text { by new Criterion } 71 \text { (design basis) and Criterion } \\
72 \text { (provisions for testing and inspection). }\end{array}$ \\
\hline 53 & $\begin{array}{l}\text { Provisions for containment testing and } \\
\text { inspection. } \\
\text { The reactor containment structure shall be } \\
\text { designed to permit (1) appropriate periodic } \\
\text { inspection of all important areas, such as } \\
\text { penetrations, (2) an appropriate surveillance }\end{array}$ & Not applicable to modular HTGR. & $\begin{array}{l}\text { Reactor Building testing and inspection is } \\
\text { addressed by new Criterion } 72 .\end{array}$ \\
\hline
\end{tabular}




\begin{tabular}{|c|c|c|c|}
\hline \multicolumn{4}{|c|}{ V. Reactor Containment } \\
\hline Criterion & Proposed ARDC Language & Proposed Modular HTGR-DC Language & Rationale for Modification \\
\hline & $\begin{array}{l}\text { program, and (3) periodic testing at } \\
\text { containment design pressure of the } \\
\text { leaktightness of penetrations which have } \\
\text { resilient seals and expansion bellows. }\end{array}$ & & \\
\hline 54 & $\begin{array}{l}\text { Piping systems penetrating containment. } \\
\text { Piping systems penetrating the primary reactor } \\
\text { containment structure shall be provided with } \\
\text { leak detection, isolation, and containment } \\
\text { capabilities having redundancy, reliability, and } \\
\text { performance capabilities which reflect the } \\
\text { importance to safety of isolating these piping } \\
\text { systems. Such piping systems shall be } \\
\text { designed with a capability to test periodically } \\
\text { the operability of the isolation valves and } \\
\text { associated apparatus and to determine if valve } \\
\text { leakage is within acceptable limits. }\end{array}$ & Not applicable to modular HTGR. & $\begin{array}{l}\text { The modular HTGR Reactor Building does not } \\
\text { provide a pressure retention function, and it is } \\
\text { not relied upon to meet the offsite dose } \\
\text { requirements of } 10 \text { CFR } 50.34 \text { (10 CFR 52.79). } \\
\text { Therefore, this criterion regarding piping systems } \\
\text { that may exist between the Reactor Building } \\
\text { atmosphere and the outside environment does } \\
\text { not apply. Requirements regarding the } \\
\text { performance of the modular HTGR Reactor } \\
\text { Building are addressed by new Criterion } 71 \\
\text { (design basis) and Criterion } 72 \text { (provisions for } \\
\text { testing and inspection). }\end{array}$ \\
\hline 55 & $\begin{array}{l}\text { Reactor [coolant pressure] boundary } \\
\text { penetrating containment. } \\
\text { Each line that is part of the reactor [coolant } \\
\text { pressure] boundary and that penetrates the } \\
\text { primary reactor containment structure shall be } \\
\text { provided with containment isolation valves as } \\
\text { follows, unless it can be demonstrated that the } \\
\text { containment isolation provisions for a specific } \\
\text { class of lines, such as instrument lines, are } \\
\text { acceptable on some other defined basis: } \\
\text { (1) One locked closed isolation valve inside and } \\
\text { one locked closed isolation valve outside } \\
\text { containment; or } \\
\text { (2) One automatic isolation valve inside and } \\
\text { one locked closed isolation valve outside } \\
\text { containment; or } \\
\text { (3) One locked closed isolation valve inside and } \\
\text { one automatic isolation valve outside } \\
\text { containment. A simple check valve may not be } \\
\text { used as the automatic isolation valve outside } \\
\text { containment; or } \\
\text { (4) One automatic isolation valve inside and } \\
\text { one automatic isolation valve outside } \\
\text { containment. A simple check valve may not be } \\
\text { used as the automatic isolation valve outside } \\
\text { containment. }\end{array}$ & Not applicable to modular HTGR. & $\begin{array}{l}\text { Lines that form a portion of the reactor Helium } \\
\text { Pressure Boundary do not penetrate the Reactor } \\
\text { Building. Therefore, this criterion does not apply. }\end{array}$ \\
\hline
\end{tabular}




\begin{tabular}{|c|c|c|c|}
\hline \multicolumn{4}{|c|}{ V. Reactor Containment } \\
\hline Criterion & Proposed ARDC Language & Proposed Modular HTGR-DC Language & Rationale for Modification \\
\hline & $\begin{array}{l}\text { Isolation valves outside containment shall be } \\
\text { located as close to containment as practical } \\
\text { and upon loss of actuating power, automatic } \\
\text { isolation valves shall be designed to take the } \\
\text { position that provides greater safety. } \\
\text { Other appropriate requirements to minimize the } \\
\text { probability or consequences of an accidental } \\
\text { rupture of these lines or of lines connected to } \\
\text { them shall be provided as necessary to assure } \\
\text { adequate safety. Determination of the } \\
\text { appropriateness of these requirements, such as } \\
\text { higher quality in design, fabrication, and testing, } \\
\text { additional provisions for inservice inspection, } \\
\text { protection against more severe natural } \\
\text { phenomena, and additional isolation valves and } \\
\text { containment, shall include consideration of the } \\
\text { population density, use characteristics, and } \\
\text { physical characteristics of the site environs. }\end{array}$ & & \\
\hline 56 & $\begin{array}{l}\text { Primary containment isolation. } \\
\text { Each line that connects directly to the } \\
\text { containment atmosphere and penetrates the } \\
\text { primary reactor containment structure shall be } \\
\text { provided with containment isolation valves as } \\
\text { follows, unless it can be demonstrated that the } \\
\text { containment isolation provisions for a specific } \\
\text { class of lines, such as instrument lines, are } \\
\text { acceptable on some other defined basis: } \\
\text { (1) One locked closed isolation valve inside and } \\
\text { one locked closed isolation valve outside } \\
\text { containment; or } \\
\text { (2) One automatic isolation valve inside and } \\
\text { one locked closed isolation valve outside } \\
\text { containment; or } \\
\text { (3) One locked closed isolation valve inside and } \\
\text { one automatic isolation valve outside } \\
\text { containment. A simple check valve may not be } \\
\text { used as the automatic isolation valve outside } \\
\text { containment; or } \\
\text { (4) One automatic isolation valve inside and } \\
\text { one automatic isolation valve outside }\end{array}$ & Not applicable to modular HTGR. & $\begin{array}{l}\text { The modular HTGR Reactor Building does not } \\
\text { provide a pressure retention function, and it is } \\
\text { not relied upon to meet the offsite dose } \\
\text { requirements of } 10 \text { CFR } 50.34 \text {. Therefore, this } \\
\text { criterion regarding isolation valves does not } \\
\text { apply. Requirements regarding the performance } \\
\text { of the modular HTGR Reactor Building are } \\
\text { addressed by new Criterion } 71 \text { (design basis) } \\
\text { and Criterion } 72 \text { (provisions for testing and } \\
\text { inspection). }\end{array}$ \\
\hline
\end{tabular}




\begin{tabular}{|l|l|l|l|}
\hline \multicolumn{2}{|c|}{ V. Reactor Containment } \\
\hline Criterion & Proposed ARDC Language & Proposed Modular HTGR-DC Language & Rationale for Modification \\
\hline $\begin{array}{l}\text { containment. A simple check valve may not be } \\
\text { used as the automatic isolation valve outside } \\
\text { containment. }\end{array}$ & & $\begin{array}{l}\text { Isolation valves outside containment shall be } \\
\text { located as close to the containment as practical } \\
\text { and upon loss of actuating power, automatic } \\
\text { isolation valves shall be designed to take the } \\
\text { position that provides greater safety. }\end{array}$ & $\begin{array}{l}\text { Closed system isolation valves. } \\
\text { Each line that penetrates the primary reactor } \\
\text { containment structure and is neither part of the } \\
\text { reactor [coolant pressure] boundary nor } \\
\text { connected directly to the containment } \\
\text { atmosphere shall have at least one } \\
\text { containment isolation valve which shall be } \\
\text { either automatic, or locked closed, or capable } \\
\text { of remote manual operation. This valve shall be } \\
\text { outside containment and located as close to the } \\
\text { containment as practical. A simple check valve } \\
\text { may not be used as the automatic isolation valve. }\end{array}$ \\
\hline
\end{tabular}

\begin{tabular}{|c|c|c|c|}
\hline \multicolumn{4}{|c|}{ VI. Fuel and Radioactivity Control } \\
\hline Criterion & Proposed ARDC Language & Proposed Modular HTGR-DC Language & Rationale for Modification \\
\hline 60 & $\begin{array}{l}\text { Control of releases of radioactive materials to } \\
\text { the environment. } \\
\text { The nuclear power unit design shall include } \\
\text { means to control suitably the release of } \\
\text { radioactive materials in gaseous and liquid } \\
\text { effluents and to handle radioactive solid wastes } \\
\text { produced during normal reactor operation, } \\
\text { including anticipated operational occurrences. } \\
\text { Sufficient holdup capacity shall be provided for } \\
\text { retention of gaseous and liquid effluents } \\
\text { containing radioactive materials, particularly } \\
\text { where unfavorable site environmental } \\
\text { conditions can be expected to impose unusual } \\
\text { operational limitations upon the release of such } \\
\text { effluents to the environment. }\end{array}$ & $\begin{array}{l}\text { ARDC with no further modular HTGR-specific } \\
\text { clarification provided. }\end{array}$ & \\
\hline
\end{tabular}


Proposed ARDC Language

61 Fuel storage and handling and radioactivity control.

The fuel storage and handling, radioactive waste, and other systems which may contain radioactivity shall be designed to assure adequate safety under normal and postulated accident conditions. These systems shall be designed (1) with a capability to permit appropriate periodic inspection and testing of components important to safety, (2) with suitable shielding for radiation protection, (3) with appropriate containment, confinement, and filtering systems, (4) with a residual heat removal capability having reliability and testability that reflects the importance to safety of decay heat and other residual heat removal, and (5) to prevent significant reduction in fuel storage cooling under accident conditions.

62 Prevention of criticality in fuel storage and handling.

Criticality in the fuel storage and handling system shall be prevented by physical systems or processes, preferably by use of geometrically safe configurations.

63 Monitoring fuel and waste storage. Appropriate systems shall be provided in fuel storage and radioactive waste systems and associated handling areas (1) to detect conditions that may result in loss of residual heat removal capability and excessive radiation levels and (2) to initiate appropriate safety actions.

$64 \quad$ Monitoring radioactivity releases.

Means shall be provided for monitoring the [reactor containment] atmosphere, [spaces containing components for recirculation of loss-of-coolant accident fluids,] effluent discharge paths, and the plant environs for radioactivity that may be released from normal operations, including anticipated operational occurrences, and from postulated accidents.

\section{Proposed Modular HTGR-DC Language}

ARDC with no further modular HTGR-specific clarification provided.

Rationale for Modification

ARDC with no further modular HTGR-specific clarification provided.

\section{ARDC with no further modular HTGR-specific}

clarification provided.

ARDC with additional modular HTGR-specific clarification provided:

Monitoring radioactivity releases.

Means shall be provided for monitoring the [reactor containmentbuilding] atmosphere, [spaces

containing components for recirculation of loss-ofcoolant accident fluids, ] effluent discharge paths, and the plant environs for radioactivity that may be released from normal operations, including anticipated
The underlying concept of monitoring radioactivity releases from the modular HTGR particle fuel to the reactor building, effluent discharge paths, and the plant environs applies. High radioactivity in the reactor building provides input to the plant protection system. In addition, the reactor building atmosphere is monitored for personnel protection. Recirculation of loss-ofcoolant fluids (i.e., water) does not apply to the modular HTGR. 


\begin{tabular}{|l|l|l|l|}
\hline \multicolumn{2}{|c|}{ VI. Fuel and Radioactivity Control } \\
\hline Criterion & Proposed ARDC Language & Proposed Modular HTGR-DC Language & Rationale for Modification \\
\hline & & operational occurrences, and from postulated accidents. & $\begin{array}{l}\text { The descriptions of the associated atmospheres } \\
\text { and spaces that are required to be monitored are } \\
\text { revised to reflect the modular HTGR's different } \\
\text { design configuration and functional containment } \\
\text { arrangement. }\end{array}$ \\
\hline
\end{tabular}

\begin{tabular}{|c|c|c|c|}
\hline \multicolumn{4}{|c|}{ VII. Additional Modular HTGR-DC } \\
\hline Criterion & Proposed ARDC Language & Proposed Modular HTGR-DC Language & Rationale for Modification \\
\hline 70 & N/A & $\begin{array}{l}\text { Reactor vessel and reactor system structural design } \\
\text { basis. } \\
\text { The design of the reactor vessel and reactor system } \\
\text { shall be such that their integrity is maintained during } \\
\text { postulated accidents (1) to ensure the geometry for } \\
\text { passive removal of residual heat from the reactor core } \\
\text { to the ultimate heat sink and (2) to permit sufficient } \\
\text { insertion of the neutron absorbers to provide for reactor } \\
\text { shutdown. }\end{array}$ & $\begin{array}{l}\text { New modular HTGR design-specific GDC is } \\
\text { necessary to assure reactor vessel and reactor } \\
\text { system (reactor internals) integrity is preserved } \\
\text { for passive heat removal and for insertion of } \\
\text { neutron absorbers. }\end{array}$ \\
\hline 71 & $\mathrm{~N} / \mathrm{A}$ & $\begin{array}{l}\text { Reactor building design basis. } \\
\text { The design of the reactor building shall be such that } \\
\text { during postulated accidents it structurally protects the } \\
\text { geometry for passive removal of residual heat from the } \\
\text { reactor core to the ultimate heat sink and provides a } \\
\text { pathway for release of reactor helium from the building } \\
\text { in the event of depressurization accidents. }\end{array}$ & $\begin{array}{l}\text { The reactor building functions are to protect and } \\
\text { maintain passive cooling geometry and to } \\
\text { provide a pathway for the release of helium from } \\
\text { the building in the case of a line break in the } \\
\text { reactor helium pressure boundary. This newly } \\
\text { established criterion assures that these safety } \\
\text { functions are provided. } \\
\text { It is noted that the reactor building is not relied } \\
\text { upon to meet the offsite dose requirements of } 10 \\
\text { CFR } 50.34 \text { (10 CFR 52.79). }\end{array}$ \\
\hline 72 & $\mathrm{~N} / \mathrm{A}$ & $\begin{array}{l}\text { Provisions for periodic reactor building inspection. } \\
\text { The reactor building shall be designed to permit (1) } \\
\text { appropriate periodic inspection of all important structural } \\
\text { areas and the depressurization pathway, and (2) an } \\
\text { appropriate surveillance program. }\end{array}$ & $\begin{array}{l}\text { This newly established criterion regarding } \\
\text { periodic inspection and surveillance provides } \\
\text { assurance that the reactor building will perform } \\
\text { its safety functions of protecting and maintaining } \\
\text { the configuration needed for passive cooling and } \\
\text { providing a discharge pathway for helium } \\
\text { depressurization events. }\end{array}$ \\
\hline
\end{tabular}




\subsection{General Design Criteria - Advanced Reactor Design Criteria - SFR Design Criteria - mHTGR Design Criteria Comparison Table}

The five-column table provided below presents the current GDC language (as it exists in 10 CFR 50, Appendix A) and the proposed language for ARDC, SFR-DC, and modular HTGR-DC in a format that allows for direct comparison of the related design criteria.

The left column contains GDC number and the second column contains the current GDC language. The second column also serves as a reference for comparison with the other columns. The third column from the left contains proposed ARDC language. If the proposed ARDC language for a given criterion is the same as the current GDC language, then the proposed ARDC language column states "Same as GDC." The final two columns contain the proposed SFR-DC and modular HTGR language. If the proposed SFR-DC language is the same as the ARDC, then the proposed SFR-DC language column states "ARDC with no further SFR-specific clarification provided." A similar statement is made in the modular HTGR column, where applicable.

Upon review of the table (from right to left), those design criteria that correspond to the current GDC language with no proposed changes can be quickly identified.

In addition, several ARDC contain brackets around certain phrases that may not apply to all advanced reactor designs. The corresponding design criteria may accept the ARDC bracketed text or propose a design-specific alternative, if appropriate. The bracketed text appears in bold for emphasis. Also, note that newly proposed text is inserted using blue font and deleted text is displayed with a redline/strikeout font style.

\begin{tabular}{|c|c|c|c|c|}
\hline \multicolumn{5}{|c|}{ I. Overall Requirements } \\
\hline Criterion & Current GDC Language & Proposed ARDC Language & Proposed SFR-DC Language & Proposed Modular HTGR-DC Language \\
\hline 1 & $\begin{array}{l}\text { Quality standards and records. } \\
\text { Structures, systems, and components } \\
\text { important to safety shall be designed, } \\
\text { fabricated, erected, and tested to quality } \\
\text { standards commensurate with the importance } \\
\text { of the safety functions to be performed. Where } \\
\text { generally recognized codes and standards are } \\
\text { used, they shall be identified and evaluated to } \\
\text { determine their applicability, adequacy, and } \\
\text { sufficiency and shall be supplemented or } \\
\text { modified as necessary to assure a quality } \\
\text { product in keeping with the required safety } \\
\text { function. A quality assurance program shall be } \\
\text { established and implemented in order to } \\
\text { provide adequate assurance that these } \\
\text { structures, systems, and components will } \\
\text { satisfactorily perform their safety functions. } \\
\text { Appropriate records of the design, fabrication, } \\
\text { erection, and testing of structures, systems, } \\
\text { and components important to safety shall be } \\
\text { maintained by or under the control of the } \\
\text { nuclear power unit licensee throughout the life } \\
\text { of the unit. }\end{array}$ & Same as GDC & $\begin{array}{l}\text { ARDC with no further SFR-specific clarification } \\
\text { provided. }\end{array}$ & $\begin{array}{l}\text { ARDC with no further modular HTGR- } \\
\text { specific clarification provided. }\end{array}$ \\
\hline 2 & $\begin{array}{l}\text { Design bases for protection against natural } \\
\text { phenomena. } \\
\text { Structures, systems, and components }\end{array}$ & Same as GDC & $\begin{array}{l}\text { ARDC with no further SFR-specific clarification } \\
\text { provided. }\end{array}$ & $\begin{array}{l}\text { ARDC with no further modular HTGR- } \\
\text { specific clarification provided. }\end{array}$ \\
\hline
\end{tabular}




\begin{tabular}{|c|c|c|c|c|}
\hline \multicolumn{5}{|c|}{ I. Overall Requirements } \\
\hline Criterion & Current GDC Language & Proposed ARDC Language & Proposed SFR-DC Language & Proposed Modular HTGR-DC Language \\
\hline & $\begin{array}{l}\text { important to safety shall be designed to } \\
\text { withstand the effects of natural phenomena } \\
\text { such as earthquakes, tornadoes, hurricanes, } \\
\text { floods, tsunami, and seiches without loss of } \\
\text { capability to perform their safety functions. } \\
\text { The design bases for these structures, } \\
\text { systems, and components shall reflect: (1) } \\
\text { Appropriate consideration of the most severe } \\
\text { of the natural phenomena that have been } \\
\text { historically reported for the site and } \\
\text { surrounding area, with sufficient margin for the } \\
\text { limited accuracy, quantity, and period of time } \\
\text { in which the historical data have been } \\
\text { accumulated, (2) appropriate combinations of } \\
\text { the effects of normal and accident conditions } \\
\text { with the effects of the natural phenomena and } \\
\text { (3) the importance of the safety functions to be } \\
\text { performed. }\end{array}$ & & & \\
\hline 3 & $\begin{array}{l}\text { Fire protection. } \\
\text { Structures, systems, and components } \\
\text { important to safety shall be designed and } \\
\text { located to minimize, consistent with other } \\
\text { safety requirements, the probability and effect } \\
\text { of fires and explosions. Noncombustible and } \\
\text { heat resistant materials shall be used } \\
\text { wherever practical throughout the unit, } \\
\text { particularly in locations such as the } \\
\text { containment and control room. Fire detection } \\
\text { and fighting systems of appropriate capacity } \\
\text { and capability shall be provided and designed } \\
\text { to minimize the adverse effects of fires on } \\
\text { structures, systems, and components } \\
\text { important to safety. Firefighting systems shall } \\
\text { be designed to assure that their rupture or } \\
\text { inadvertent operation does not significantly } \\
\text { impair the safety capability of these structures, } \\
\text { systems, and components. }\end{array}$ & $\begin{array}{l}\text { Fire protection. } \\
\text { Structures, systems, and components important } \\
\text { to safety shall be designed and located to } \\
\text { minimize, consistent with other safety } \\
\text { requirements, the probability and effect of fires } \\
\text { and explosions. Noncombustible and heat } \\
\text { resistant materials shall be used wherever } \\
\text { practical throughout the unit[, particularly in } \\
\text { locations such as the containment and } \\
\text { control room]. Fire detection and fighting } \\
\text { systems of appropriate capacity and capability } \\
\text { shall be provided and designed to minimize the } \\
\text { adverse effects of fires on structures, systems, } \\
\text { and components important to safety. Firefighting } \\
\text { systems shall be designed to assure that their } \\
\text { rupture or inadvertent operation does not } \\
\text { significantly impair the safety capability of these } \\
\text { structures, systems, and components. }\end{array}$ & $\begin{array}{l}\text { ARDC with no further SFR-specific clarification } \\
\text { provided. }\end{array}$ & $\begin{array}{l}\text { ARDC with additional modular HTGR- } \\
\text { specific clarification provided: } \\
\text { Fire protection. } \\
\text { Structures, systems, and components } \\
\text { important to safety shall be designed and } \\
\text { located to minimize, consistent with other } \\
\text { safety requirements, the probability and } \\
\text { effect of fires and explosions. } \\
\text { Noncombustible and heat resistant materials } \\
\text { shall be used wherever practical throughout } \\
\text { the unit, [particularly in locations such as } \\
\text { the containmentwith safety related } \\
\text { equipment and the control room]. Fire } \\
\text { detection and fighting systems of appropriate } \\
\text { capacity and capability shall be provided and } \\
\text { designed to minimize the adverse effects of } \\
\text { fires on structures, systems, and } \\
\text { components important to safety. Firefighting } \\
\text { systems shall be designed to assure that } \\
\text { their rupture or inadvertent operation does } \\
\text { not significantly impair the safety capability } \\
\text { of these structures, systems, and } \\
\text { components. }\end{array}$ \\
\hline
\end{tabular}




\begin{tabular}{|c|c|c|c|c|}
\hline \multicolumn{5}{|c|}{ I. Overall Requirements } \\
\hline Criterion & Current GDC Language & Proposed ARDC Language & Proposed SFR-DC Language & Proposed Modular HTGR-DC Language \\
\hline & $\begin{array}{l}\text { dynamic effects, including the effects of } \\
\text { missiles, pipe whipping, and discharging } \\
\text { fluids, that may result from equipment failures } \\
\text { and from events and conditions outside the } \\
\text { nuclear power unit. However, dynamic effects } \\
\text { associated with postulated pipe ruptures in } \\
\text { nuclear power units may be excluded from the } \\
\text { design basis when analyses reviewed and } \\
\text { approved by the Commission demonstrate } \\
\text { that the probability of fluid system piping } \\
\text { rupture is extremely low under conditions } \\
\text { consistent with the design basis for the piping. }\end{array}$ & $\begin{array}{l}\text { whipping, and discharging fluids, that may result } \\
\text { from equipment failures and from events and } \\
\text { conditions outside the nuclear power unit. } \\
\text { However, dynamic effects associated with } \\
\text { postulated pipe ruptures in nuclear power units } \\
\text { may be excluded from the design basis when } \\
\text { analyses reviewed and approved by the } \\
\text { Commission demonstrate that the probability of } \\
\text { fluid system piping rupture is extremely low } \\
\text { under conditions consistent with the design } \\
\text { basis for the piping. }\end{array}$ & & \\
\hline 5 & $\begin{array}{l}\text { Sharing of structures, systems, and } \\
\text { components. } \\
\text { Structures, systems, and components } \\
\text { important to safety shall not be shared among } \\
\text { nuclear power units unless it can be shown } \\
\text { that such sharing will not significantly impair } \\
\text { their ability to perform their safety functions, } \\
\text { including, in the event of an accident in one } \\
\text { unit, an orderly shutdown and cooldown of the } \\
\text { remaining units. }\end{array}$ & Same as GDC & $\begin{array}{l}\text { ARDC with no further SFR-specific clarification } \\
\text { provided. }\end{array}$ & $\begin{array}{l}\text { ARDC with additional modular HTGR- } \\
\text { specific clarification provided: } \\
\text { Sharing of structures, systems, and } \\
\text { components. } \\
\text { Structures, systems, and components } \\
\text { important to safety shall not be shared } \\
\text { among reactor modules or reactor module } \\
\text { groups nuclear power units-unless it can be } \\
\text { shown that such sharing will not significantly } \\
\text { impair their ability to perform their safety } \\
\text { functions, including, in the event of an } \\
\text { accident in one reactor module or reactor } \\
\text { module groupunit, an orderly shutdown and } \\
\text { cooldown of the remaining reactor modules } \\
\text { or reactor module groupsunits. }\end{array}$ \\
\hline \multicolumn{5}{|c|}{ II. Multiple Barriers } \\
\hline Criterion & Current GDC Language & Proposed ARDC Language & Proposed SFR-DC Language & Proposed HTGR-DC Language \\
\hline 10 & $\begin{array}{l}\text { Reactor design. } \\
\text { The reactor core and associated coolant, } \\
\text { control, and protection systems shall be } \\
\text { designed with appropriate margin to assure } \\
\text { that specified acceptable fuel design limits are } \\
\text { not exceeded during any condition of normal } \\
\text { operation, including the effects of anticipated } \\
\text { operational occurrences. }\end{array}$ & $\begin{array}{l}\text { Reactor Design. } \\
\text { The reactor core and associated [coolant], } \\
\text { control, and protection systems shall be } \\
\text { designed with appropriate margin to assure that } \\
\text { specified acceptable fuel design limits are not } \\
\text { exceeded during any condition of normal } \\
\text { operation, including the effects of anticipated } \\
\text { operational occurrences. }\end{array}$ & $\begin{array}{l}\text { ARDC with no further SFR-specific clarification } \\
\text { provided. }\end{array}$ & $\begin{array}{l}\text { ARDC with additional modular HTGR- } \\
\text { specific clarification provided: } \\
\text { Reactor design. } \\
\text { The reactor core-system and associated } \\
\text { [coolantheat removal], control, and } \\
\text { protection systems shall be designed with } \\
\text { appropriate margin to assure that specified } \\
\text { acceptable fuel-core radionuclide release } \\
\text { design limits are not exceeded during any } \\
\text { condition of normal operation, including the } \\
\text { effects of anticipated operational } \\
\text { occurrences. }\end{array}$ \\
\hline 11 & $\begin{array}{l}\text { Reactor inherent protection. } \\
\text { The reactor core and associated coolant } \\
\text { systems shall be designed so that in the power } \\
\text { operating range the net effect of the prompt } \\
\text { inherent nuclear feedback characteristics } \\
\text { tends to compensate for a rapid increase in } \\
\text { reactivity. }\end{array}$ & $\begin{array}{l}\text { Reactor inherent protection. } \\
\text { The reactor core and associated coolant } \\
\text { systems that contribute to reactivity feedback } \\
\text { shall be designed so that in the power operating } \\
\text { range the net effect of the prompt inherent } \\
\text { nuclear feedback characteristics tends to } \\
\text { compensate for a rapid increase in reactivity. }\end{array}$ & $\begin{array}{l}\text { ARDC with no further SFR-specific clarification } \\
\text { provided. }\end{array}$ & $\begin{array}{l}\text { ARDC with no further modular HTGR- } \\
\text { specific clarification provided. }\end{array}$ \\
\hline
\end{tabular}




\begin{tabular}{|c|c|c|c|c|}
\hline \multicolumn{5}{|c|}{ II. Multiple Barriers } \\
\hline Criterion & Current GDC Language & Proposed ARDC Language & Proposed SFR-DC Language & Proposed HTGR-DC Language \\
\hline 12 & $\begin{array}{l}\text { Suppression of reactor power oscillations. } \\
\text { The reactor core and associated coolant, } \\
\text { control, and protection systems shall be } \\
\text { designed to assure that power oscillations } \\
\text { which can result in conditions exceeding } \\
\text { specified acceptable fuel design limits are not } \\
\text { possible or can be reliably and readily } \\
\text { detected and suppressed. }\end{array}$ & $\begin{array}{l}\text { Suppression of reactor power oscillations. } \\
\text { The reactor core and associated [coolant], } \\
\text { control, and protection systems shall be } \\
\text { designed to assure that power oscillations which } \\
\text { can result in conditions exceeding specified } \\
\text { acceptable fuel design limits are not possible or } \\
\text { can be reliably and readily detected and } \\
\text { suppressed. }\end{array}$ & $\begin{array}{l}\text { ARDC with no further SFR-specific clarification } \\
\text { provided. }\end{array}$ & $\begin{array}{l}\text { ARDC with additional modular HTGR- } \\
\text { specific clarification provided: } \\
\text { Suppression of reactor power oscillations. } \\
\text { The reactor core and associated [coolant], } \\
\text { control, and protection systems shall be } \\
\text { designed to assure that power oscillations } \\
\text { which can result in conditions exceeding } \\
\text { specified acceptable fuetcore radionuclide } \\
\text { release design limits are not possible or can } \\
\text { be reliably and readily detected and } \\
\text { suppressed. }\end{array}$ \\
\hline 13 & $\begin{array}{l}\text { Instrumentation and control. } \\
\text { Instrumentation shall be provided to monitor } \\
\text { variables and systems over their anticipated } \\
\text { ranges for normal operation, for anticipated } \\
\text { operational occurrences, and for accident } \\
\text { conditions as appropriate to assure adequate } \\
\text { safety, including those variables and systems } \\
\text { that can affect the fission process, the integrity } \\
\text { of the reactor core, the reactor coolant } \\
\text { pressure boundary, and the containment and } \\
\text { its associated systems. Appropriate controls } \\
\text { shall be provided to maintain these variables } \\
\text { and systems within prescribed operating } \\
\text { ranges }\end{array}$ & $\begin{array}{l}\text { Instrumentation and control. } \\
\text { Instrumentation shall be provided to monitor } \\
\text { variables and systems over their anticipated } \\
\text { ranges for normal operation, for anticipated } \\
\text { operational occurrences, and for accident } \\
\text { conditions as appropriate to assure adequate } \\
\text { safety, including those variables and systems } \\
\text { that can affect the fission process, the integrity } \\
\text { of the reactor core, [the reactor coolant } \\
\text { pressure boundary, and the containment and } \\
\text { its associated systems]. Appropriate controls } \\
\text { shall be provided to maintain these variables } \\
\text { and systems within prescribed operating ranges. }\end{array}$ & $\begin{array}{l}\text { ARDC with additional SFR-specific clarification } \\
\text { provided: } \\
\text { Instrumentation and control. } \\
\text { Instrumentation shall be provided to monitor } \\
\text { variables and systems over their anticipated } \\
\text { ranges for normal operation, for anticipated } \\
\text { operational occurrences, and for accident } \\
\text { conditions as appropriate to assure adequate } \\
\text { safety, including those variables and systems } \\
\text { that can affect the fission process, the integrity } \\
\text { of the reactor core, [the reactor primary } \\
\text { coolantpressure boundary, and the } \\
\text { containment and its associated systems]. } \\
\text { Appropriate controls shall be provided to } \\
\text { maintain these variables and systems within } \\
\text { prescribed operating ranges. }\end{array}$ & $\begin{array}{l}\text { ARDC with additional modular HTGR- } \\
\text { specific clarification provided: } \\
\text { Instrumentation and control. } \\
\text { Instrumentation shall be provided to monitor } \\
\text { variables and systems over their anticipated } \\
\text { ranges for normal operation, for anticipated } \\
\text { operational occurrences, and for accident } \\
\text { conditions as appropriate to assure } \\
\text { adequate safety, including those variables } \\
\text { and systems that can affect the fission } \\
\text { process and the integrity of the reactor core, } \\
\text { [the reactor coolant pressure boundary, } \\
\text { and the containment and its associated } \\
\text { systems]functional containment. } \\
\text { Appropriate controls shall be provided to } \\
\text { maintain these variables and systems within } \\
\text { prescribed operating ranges. }\end{array}$ \\
\hline 14 & $\begin{array}{l}\text { Reactor coolant pressure boundary. } \\
\text { The reactor coolant pressure boundary shall } \\
\text { be designed, fabricated, erected, and tested } \\
\text { so as to have an extremely low probability of } \\
\text { abnormal leakage, of rapidly propagating } \\
\text { failure, and of gross rupture. }\end{array}$ & $\begin{array}{l}\text { Reactor [coolant pressure] boundary. } \\
\text { The reactor [coolant pressure] boundary shall } \\
\text { be designed, fabricated, erected, and tested so } \\
\text { as to have an extremely low probability of } \\
\text { abnormal leakage, of rapidly propagating failure, } \\
\text { and of gross rupture. }\end{array}$ & $\begin{array}{l}\text { ARDC with additional SFR-specific clarification } \\
\text { provided: } \\
\text { Reactor [primary coolant-pressure] boundary. } \\
\text { The reactor [primary coolant-pressure] } \\
\text { boundary shall be designed, fabricated, erected, } \\
\text { and tested so as to have an extremely low } \\
\text { probability of abnormal leakage, of rapidly } \\
\text { propagating failure, and of gross rupture. }\end{array}$ & $\begin{array}{l}\text { ARDC with additional modular HTGR- } \\
\text { specific clarification provided: } \\
\text { Reactor [coolanthelium pressure] } \\
\text { boundary. } \\
\text { The reactor [coolant helium pressure] } \\
\text { boundary shall be designed, fabricated, } \\
\text { erected, and tested so as to have an } \\
\text { extremely low probability of abnormal } \\
\text { leakage, of rapidly propagating failure, and } \\
\text { of gross rupture and of unacceptable ingress } \\
\text { of air, secondary coolant, or other fluids.. }\end{array}$ \\
\hline
\end{tabular}




\begin{tabular}{|c|c|c|c|c|}
\hline \multicolumn{5}{|c|}{ II. Multiple Barriers } \\
\hline Criterion & Current GDC Language & Proposed ARDC Language & Proposed SFR-DC Language & Proposed HTGR-DC Language \\
\hline & & & occurrences. & $\begin{array}{l}\text { boundary are not exceeded during any } \\
\text { condition of normal operation, including } \\
\text { anticipated operational occurrences. }\end{array}$ \\
\hline 16 & $\begin{array}{l}\text { Containment design. } \\
\text { Reactor containment and associated systems } \\
\text { shall be provided to establish an essentially } \\
\text { leak-tight barrier against the uncontrolled } \\
\text { release of radioactivity to the environment and } \\
\text { to assure that the containment design } \\
\text { conditions important to safety are not } \\
\text { exceeded for as long as postulated accident } \\
\text { conditions require. }\end{array}$ & $\begin{array}{l}\text { Containment design. } \\
\text { A rReactor functional containment, and } \\
\text { associated systems-consisting of a structure } \\
\text { surrounding the reactor and its cooling system } \\
\text { or multiple barriers internal and/or external to the } \\
\text { reactor and its cooling system, shall be provided } \\
\text { to establish an essentially leak-tight barrier } \\
\text { against the uncontrolled-control the release of } \\
\text { radioactivity to the environment and to assure } \\
\text { that the functional containment design } \\
\text { conditions important to safety are not exceeded } \\
\text { for as long as postulated accident conditions } \\
\text { require. }\end{array}$ & $\begin{array}{l}\text { ARDC with no further SFR-specific clarification } \\
\text { provided. }\end{array}$ & $\begin{array}{l}\text { ARDC with no further modular HTGR- } \\
\text { specific clarification provided. }\end{array}$ \\
\hline 17 & $\begin{array}{l}\text { Electric power systems. } \\
\text { An onsite electric power system and an offsite } \\
\text { electric power system shall be provided to } \\
\text { permit functioning of structures, systems, and } \\
\text { components important to safety. The safety } \\
\text { function for each system (assuming the other } \\
\text { system is not functioning) shall be to provide } \\
\text { sufficient capacity and capability to assure that } \\
\text { (1) specified acceptable fuel design limits and } \\
\text { design conditions of the reactor coolant } \\
\text { pressure boundary are not exceeded as a } \\
\text { result of anticipated operational occurrences } \\
\text { and (2) the core is cooled and containment } \\
\text { integrity and other vital functions are } \\
\text { maintained in the event of postulated } \\
\text { accidents. } \\
\text { The onsite electric power supplies, including } \\
\text { the batteries, and the onsite electric } \\
\text { distribution system, shall have sufficient } \\
\text { independence, redundancy, and testability to } \\
\text { perform their safety functions assuming a } \\
\text { single failure. } \\
\text { Electric power from the transmission network } \\
\text { to the onsite electric distribution system shall } \\
\text { be supplied by two physically independent } \\
\text { circuits (not necessarily on separate rights of } \\
\text { way) designed and located so as to minimize } \\
\text { to the extent practical the likelihood of their } \\
\text { simultaneous failure under operating and } \\
\text { postulated accident and environmental } \\
\text { conditions. A switchyard common to both } \\
\text { circuits is acceptable. Each of these circuits } \\
\text { shall be designed to be available in sufficient } \\
\text { time following a loss of all onsite alternating }\end{array}$ & $\begin{array}{l}\text { Electric power systems. } \\
\text { An onsite eElectric power systems and an offsite } \\
\text { electric power system shall be provided to } \\
\text { permit functioning of structures, systems, and } \\
\text { components important to safety. The safety } \\
\text { function for the each systems (assuming the } \\
\text { other system is not functioning) shall be to } \\
\text { provide sufficient capacity, -and capability, and } \\
\text { reliability to assure that (1) specified acceptable } \\
\text { fuel design limits and design conditions of the } \\
\text { reactor [coolant pressure] boundary are not } \\
\text { exceeded as a result of anticipated operational } \\
\text { occurrences and (2) the core is cooled and the } \\
\text { containment integrity and other-vital functions } \\
\text { that rely on electric power are maintained in the } \\
\text { event of postulated accidents. } \\
\text { The onsite electric power systemssupplies, } \\
\text { including the batteries, and the onsite-electric } \\
\text { distribution system, shall have sufficient } \\
\text { independence, redundancy, and testability to } \\
\text { perform their safety functions, assuming a single } \\
\text { failure. } \\
\text { Electric power from the transmission network to } \\
\text { the onsite electric distribution system shall be } \\
\text { supplied by two physically independent circuits } \\
\text { (not necessarily on separate rights of way) } \\
\text { designed and located so as to minimize to the } \\
\text { extent practical the likelihood of their } \\
\text { simultaneous failure under operating and } \\
\text { postulated accident and environmental } \\
\text { eonditions. A switchyard common to both circuits } \\
\text { is acceptable. Each of these circuits shall be } \\
\text { designed to be available in sufficient time } \\
\text { following a loss of all onsite alternating current } \\
\text { power supplies and the other offsite electric }\end{array}$ & $\begin{array}{l}\text { ARDC with additional SFR-specific clarification } \\
\text { provided: } \\
\text { Electric power systems. } \\
\text { Electric power systems shall be provided to } \\
\text { permit functioning of structures, systems, and } \\
\text { components important to safety. The safety } \\
\text { function for the systems shall be to provide } \\
\text { sufficient capacity, capability, and reliability to } \\
\text { assure that (1) specified acceptable fuel design } \\
\text { limits and design conditions of the reactor } \\
\text { [primary coolant-pressure] boundary are not } \\
\text { exceeded as a result of anticipated operational } \\
\text { occurrences and (2) vital functions that rely on } \\
\text { electric power are maintained in the event of } \\
\text { postulated accidents. } \\
\text { The onsite electric power systems shall have } \\
\text { sufficient independence, redundancy, and } \\
\text { testability to perform their safety functions, } \\
\text { assuming a single failure. }\end{array}$ & $\begin{array}{l}\text { ARDC with additional modular HTGR- } \\
\text { specific clarification provided: } \\
\text { Electric power systems. } \\
\text { Electric-Onsite electric power systems shall } \\
\text { be provided to permit functioning of } \\
\text { structures, systems, and components } \\
\text { important to safety. The safety function for } \\
\text { the systems shall be to provide sufficient } \\
\text { capacity, capability, and reliability to assure } \\
\text { that (1) specified acceptable fuetcore } \\
\text { radionuclide release design limits and design } \\
\text { conditions of the reactor [coolant-helium } \\
\text { pressure] boundary are not exceeded as a } \\
\text { result of anticipated operational occurrences } \\
\text { and (2) vital functions that rely on electric } \\
\text { power are maintained in the event of } \\
\text { postulated accidents. } \\
\text { The onsite electric power systems shall have } \\
\text { sufficient independence, redundancy, and } \\
\text { testability to perform their safety functions, } \\
\text { assuming a single failure as required during } \\
\text { postulated accidents. }\end{array}$ \\
\hline
\end{tabular}




\begin{tabular}{|c|c|c|c|c|}
\hline \multicolumn{5}{|c|}{ II. Multiple Barriers } \\
\hline Criterion & Current GDC Language & Proposed ARDC Language & Proposed SFR-DC Language & Proposed HTGR-DC Language \\
\hline & $\begin{array}{l}\text { current power supplies and the other offsite } \\
\text { electric power circuit, to assure that specified } \\
\text { acceptable fuel design limits and design } \\
\text { conditions of the reactor coolant pressure } \\
\text { boundary are not exceeded. One of these } \\
\text { circuits shall be designed to be available within } \\
\text { a few seconds following a loss-of-coolant } \\
\text { accident to assure that core cooling, } \\
\text { containment integrity, and other vital safety } \\
\text { functions are maintained. } \\
\text { Provisions shall be included to minimize the } \\
\text { probability of losing electric power from any of } \\
\text { the remaining supplies as a result of, or } \\
\text { coincident with, the loss of power generated by } \\
\text { the nuclear power unit, the loss of power from } \\
\text { the transmission network, or the loss of power } \\
\text { from the onsite electric power supplies. }\end{array}$ & $\begin{array}{l}\text { power circuit, to assure that specified acceptable } \\
\text { fuel design limits and design conditions of the } \\
\text { reactor coolant pressure boundary are not } \\
\text { exceeded. One of these circuits shall be } \\
\text { designed to be available within a few seconds } \\
\text { following a loss-of-coolant accident to assure } \\
\text { that core cooling, containment integrity, and } \\
\text { other vital safety functions are maintained. } \\
\text { Provisions shall be included to minimize the } \\
\text { probability of losing electric power from any of } \\
\text { the remaining supplies as a result of, or } \\
\text { coincident with, the loss of power generated by } \\
\text { the nuclear power unit, the loss of power from } \\
\text { the transmission network, or the loss of power } \\
\text { from the onsite electric power supplies. }\end{array}$ & & \\
\hline 18 & $\begin{array}{l}\text { Inspection and testing of electric power } \\
\text { systems. } \\
\text { Electric power systems important to safety } \\
\text { shall be designed to permit appropriate } \\
\text { periodic inspection and testing of important } \\
\text { areas and features, such as wiring, insulation, } \\
\text { connections, and switchboards, to assess the } \\
\text { continuity of the systems and the condition of } \\
\text { their components. The systems shall be } \\
\text { designed with a capability to test periodically } \\
\text { (1) the operability and functional performance } \\
\text { of the components of the systems, such as } \\
\text { onsite power sources, relays, switches, and } \\
\text { buses, and (2) the operability of the systems } \\
\text { as a whole and, under conditions as close to } \\
\text { design as practical, the full operation } \\
\text { sequence that brings the systems into } \\
\text { operation, including operation of applicable } \\
\text { portions of the protection system, and the } \\
\text { transfer of power among the nuclear power } \\
\text { unit, the offsite power system, and the onsite } \\
\text { power system. }\end{array}$ & $\begin{array}{l}\text { Inspection and testing of electric power systems. } \\
\text { Electric power systems important to safety shall } \\
\text { be designed to permit appropriate periodic } \\
\text { inspection and testing of important areas and } \\
\text { features, such as wiring, insulation, connections, } \\
\text { and switchboards, to assess the continuity of the } \\
\text { systems and the condition of their components. } \\
\text { The systems shall be designed with a capability } \\
\text { to test periodically (1) the operability and } \\
\text { functional performance of the components of the } \\
\text { systems, such as [onsite power sources, } \\
\text { relays, switches, and buses] and (2) the } \\
\text { operability of the systems as a whole and, under } \\
\text { conditions as close to design as practical, the } \\
\text { full operation sequence that brings the systems } \\
\text { into operation, including operation of applicable } \\
\text { portions of the protection system, and the } \\
\text { transfer of power among systemsthe nuclear } \\
\text { power unit, the offsite power system, and the } \\
\text { ensite power system }\end{array}$ & $\begin{array}{l}\text { ARDC with no further SFR-specific clarification } \\
\text { provided. }\end{array}$ & $\begin{array}{l}\text { ARDC with no further modular HTGR- } \\
\text { specific clarification provided. }\end{array}$ \\
\hline 19 & $\begin{array}{l}\text { Control room. } \\
\text { A control room shall be provided from which } \\
\text { actions can be taken to operate the nuclear } \\
\text { power unit safely under normal conditions and } \\
\text { to maintain it in a safe condition under } \\
\text { accident conditions, including loss-of-coolant } \\
\text { accidents. Adequate radiation protection shall } \\
\text { be provided to permit access and occupancy } \\
\text { of the control room under accident conditions } \\
\text { without personnel receiving radiation } \\
\text { exposures in excess of } 5 \text { rem whole body, or } \\
\text { its equivalent to any part of the body, for the } \\
\text { duration of the accident. Equipment at }\end{array}$ & $\begin{array}{l}\text { Control room. } \\
\text { A control room shall be provided from which } \\
\text { actions can be taken to operate the nuclear } \\
\text { power unit safely under normal conditions and to } \\
\text { maintain it in a safe condition under accident } \\
\text { conditions, including loss-of-coolant accidents. } \\
\text { Adequate radiation protection shall be provided } \\
\text { to permit access and occupancy of the control } \\
\text { room under accident conditions without } \\
\text { personnel receiving radiation exposures in } \\
\text { excess of } 5 \text { rem total effective dose equivalent } \\
\text { (TEDE)-whole body, or its equivalent to any part } \\
\text { of the body, for the duration of the accident. }\end{array}$ & $\begin{array}{l}\text { ARDC with no further SFR-specific clarification } \\
\text { provided. }\end{array}$ & $\begin{array}{l}\text { ARDC with no further modular HTGR- } \\
\text { specific clarification provided. }\end{array}$ \\
\hline
\end{tabular}




\begin{tabular}{|c|c|c|c|c|}
\hline \multicolumn{5}{|c|}{ II. Multiple Barriers } \\
\hline Criterion & Current GDC Language & Proposed ARDC Language & Proposed SFR-DC Language & Proposed HTGR-DC Language \\
\hline & $\begin{array}{l}\text { appropriate locations outside the control room } \\
\text { shall be provided (1) with a design capability } \\
\text { for prompt hot shutdown of the reactor, } \\
\text { including necessary instrumentation and } \\
\text { controls to maintain the unit in a safe condition } \\
\text { during hot shutdown, and (2) with a potential } \\
\text { capability for subsequent cold shutdown of the } \\
\text { reactor through the use of suitable procedures. } \\
\text { Applicants for and holders of construction } \\
\text { permits and operating licenses under this part } \\
\text { who apply on or after January } 10,1997, \\
\text { applicants for design approvals or certifications } \\
\text { under part } 52 \text { of this chapter who apply on or } \\
\text { after January } 10,1997, \text { applicants for and } \\
\text { holders of combined licenses or manufacturing } \\
\text { licenses under part } 52 \text { of this chapter who do } \\
\text { not reference a standard design approval or } \\
\text { certification, or holders of operating licenses } \\
\text { using an alternative source term under } \S \\
50.67, \text { shall meet the requirements of this } \\
\text { criterion, except that with regard to control } \\
\text { room access and occupancy, adequate } \\
\text { radiation protection shall be provided to ensure } \\
\text { that radiation exposures shall not exceed } 0.05 \\
\text { Sv (5 rem) total effective dose equivalent } \\
\text { (TEDE) as defined in } \S 50.2 \text { for the duration of } \\
\text { the accident. }\end{array}$ & $\begin{array}{l}\text { Adequate habitability measures shall be } \\
\text { provided to permit access and occupancy of the } \\
\text { control room during normal operations and } \\
\text { under accident conditions. } \\
\text { Equipment at appropriate locations outside the } \\
\text { control room shall be provided (1) with a design } \\
\text { capability for prompt hot shutdown of the } \\
\text { reactor, including necessary instrumentation and } \\
\text { controls to maintain the unit in a safe condition } \\
\text { during hot shutdown, and (2) with a potential } \\
\text { capability for subsequent cold shutdown of the } \\
\text { reactor through the use of suitable procedures. } \\
\text { Applicants for and holders of construction } \\
\text { permits and operating licenses under this part } \\
\text { who-apply on or after danuary } 10 \text {, } 1997, \\
\text { applicants for design approvals or certifications } \\
\text { under part } 52 \text { of this chapter who-apply on of } \\
\text { after danuary } 10,1997 \text {, applicants for and } \\
\text { holders of combined licenses or manufacturing } \\
\text { licenses under part } 52 \text { of this chapter who do not } \\
\text { reference a standard design approval or } \\
\text { certification, or holders of operating licenses } \\
\text { using an alternative source term under } \S 50.67 \text {, } \\
\text { shall meet the requirements of this criterion, } \\
\text { except that with regard to control room access } \\
\text { and occupancy, adequate radiation protection } \\
\text { shall be provided to ensure that radiation } \\
\text { exposures shall not exceed } 0.05 \text { Sv ( } 5 \text { rem) total } \\
\text { effective dose equivalent (TEDE) as defined in } \S \\
50.2 \text { for the duration of the accident. }\end{array}$ & & \\
\hline \multicolumn{5}{|c|}{ III. Reactivity Control } \\
\hline Criterion & Current GDC Language & Proposed ARDC Language & Proposed SFR-DC Language & Proposed HTGR-DC Language \\
\hline 20 & $\begin{array}{l}\text { Protection system functions. } \\
\text { The protection system shall be designed (1) to } \\
\text { initiate automatically the operation of } \\
\text { appropriate systems including the reactivity } \\
\text { control systems, to assure that specified } \\
\text { acceptable fuel design limits are not exceeded } \\
\text { as a result of anticipated operational } \\
\text { occurrences and (2) to sense accident } \\
\text { conditions and to initiate the operation of } \\
\text { systems and components important to safety. }\end{array}$ & Same as GDC & $\begin{array}{l}\text { ARDC with no further SFR-specific clarification } \\
\text { provided. }\end{array}$ & $\begin{array}{l}\text { ARDC with additional modular HTGR- } \\
\text { specific clarification provided: } \\
\\
\text { Protection system functions. } \\
\text { The protection system shall be designed (1) } \\
\text { to initiate automatically the operation of } \\
\text { appropriate systems including the reactivity } \\
\text { control systems, to assure that specified } \\
\text { acceptable fuet-core radionuclide release } \\
\text { design limits are not exceeded as a result of } \\
\text { anticipated operational occurrences and (2) } \\
\text { to sense accident conditions and to initiate } \\
\text { the operation of systems and components } \\
\text { important to safety. }\end{array}$ \\
\hline
\end{tabular}




\begin{tabular}{|c|c|c|c|c|}
\hline \multicolumn{5}{|c|}{ III. Reactivity Control } \\
\hline Criterion & Current GDC Language & Proposed ARDC Language & Proposed SFR-DC Language & Proposed HTGR-DC Language \\
\hline 21 & $\begin{array}{l}\text { Protection system reliability and testability. } \\
\text { The protection system shall be designed for } \\
\text { high functional reliability and inservice } \\
\text { testability commensurate with the safety } \\
\text { functions to be performed. Redundancy and } \\
\text { independence designed into the protection } \\
\text { system shall be sufficient to assure that (1) no } \\
\text { single failure results in loss of the protection } \\
\text { function and (2) removal from service of any } \\
\text { component or channel does not result in loss } \\
\text { of the required minimum redundancy unless } \\
\text { the acceptable reliability of operation of the } \\
\text { protection system can be otherwise } \\
\text { demonstrated. The protection system shall be } \\
\text { designed to permit periodic testing of its } \\
\text { functioning when the reactor is in operation, } \\
\text { including a capability to test channels } \\
\text { independently to determine failures and losses } \\
\text { of redundancy that may have occurred. }\end{array}$ & Same as GDC & $\begin{array}{l}\text { ARDC with no further SFR-specific clarification } \\
\text { provided. }\end{array}$ & $\begin{array}{l}\text { ARDC with no further modular HTGR- } \\
\text { specific clarification provided. }\end{array}$ \\
\hline 22 & $\begin{array}{l}\text { Protection system independence. } \\
\text { The protection system shall be designed to } \\
\text { assure that the effects of natural phenomena, } \\
\text { and of normal operating, maintenance, testing, } \\
\text { and postulated accident conditions on } \\
\text { redundant channels do not result in loss of the } \\
\text { protection function, or shall be demonstrated } \\
\text { to be acceptable on some other defined basis. } \\
\text { Design techniques, such as functional diversity } \\
\text { or diversity in component design and principles } \\
\text { of operation, shall be used to the extent } \\
\text { practical to prevent loss of the protection } \\
\text { function. }\end{array}$ & Same as GDC & $\begin{array}{l}\text { ARDC with no further SFR-specific clarification } \\
\text { provided. }\end{array}$ & $\begin{array}{l}\text { ARDC with no further modular HTGR- } \\
\text { specific clarification provided. }\end{array}$ \\
\hline 23 & $\begin{array}{l}\text { Protection system failure modes. } \\
\text { The protection system shall be designed to fail } \\
\text { into a safe state or into a state demonstrated } \\
\text { to be acceptable on some other defined basis } \\
\text { if conditions such as disconnection of the } \\
\text { system, loss of energy (e.g., electric power, } \\
\text { instrument air), or postulated adverse } \\
\text { environments (e.g., extreme heat or cold, fire, } \\
\text { pressure, steam, water, and radiation) are } \\
\text { experienced. }\end{array}$ & $\begin{array}{l}\text { Protection system failure modes. } \\
\text { The protection system shall be designed to fail } \\
\text { into a safe state or into a state demonstrated to } \\
\text { be acceptable on some other defined basis if } \\
\text { conditions such as disconnection of the system, } \\
\text { loss of energy (e.g., [electric power, } \\
\text { instrument air]), or postulated adverse } \\
\text { environments (e.g., [extreme heat or cold, fire, } \\
\text { pressure, steam, water, and radiation]) are } \\
\text { experienced. }\end{array}$ & $\begin{array}{l}\text { ARDC with additional SFR-specific clarification } \\
\text { provided: } \\
\text { Protection system failure modes. } \\
\text { The protection system shall be designed to fail } \\
\text { into a safe state or into a state demonstrated to } \\
\text { be acceptable on some other defined basis if } \\
\text { conditions such as disconnection of the system, } \\
\text { loss of energy (e.g., [electric power, } \\
\text { instrument air]), or postulated adverse } \\
\text { environments (e.g., [extreme heat or cold, fire, } \\
\text { sodium and sodium reaction products, } \\
\text { pressure, steam, water, and radiation]) are } \\
\text { experienced. }\end{array}$ & $\begin{array}{l}\text { ARDC with no further modular HTGR- } \\
\text { specific clarification provided. }\end{array}$ \\
\hline 24 & $\begin{array}{l}\text { Separation of protection and control systems. } \\
\text { The protection system shall be separated from } \\
\text { control systems to the extent that failure of any } \\
\text { single control system component or channel, } \\
\text { or failure or removal from service of any single } \\
\text { protection system component or channel } \\
\text { which is common to the control and protection }\end{array}$ & Same as GDC & $\begin{array}{l}\text { ARDC with no further SFR-specific clarification } \\
\text { provided. }\end{array}$ & $\begin{array}{l}\text { ARDC with no further modular HTGR- } \\
\text { specific clarification provided. }\end{array}$ \\
\hline
\end{tabular}




\begin{tabular}{|c|c|c|c|c|}
\hline \multicolumn{5}{|c|}{ III. Reactivity Control } \\
\hline Criterion & Current GDC Language & Proposed ARDC Language & Proposed SFR-DC Language & Proposed HTGR-DC Language \\
\hline & $\begin{array}{l}\text { systems leaves intact a system satisfying all } \\
\text { reliability, redundancy, and independence } \\
\text { requirements of the protection system. } \\
\text { Interconnection of the protection and control } \\
\text { systems shall be limited so as to assure that } \\
\text { safety is not significantly impaired. }\end{array}$ & & & \\
\hline 25 & $\begin{array}{l}\text { Protection system requirements for reactivity } \\
\text { control malfunctions. } \\
\text { The protection system shall be designed to } \\
\text { assure that specified acceptable fuel design } \\
\text { limits are not exceeded for any single } \\
\text { malfunction of the reactivity control systems, } \\
\text { such as accidental withdrawal (not ejection or } \\
\text { dropout) of control rods. }\end{array}$ & Same as GDC & $\begin{array}{l}\text { ARDC with no further SFR-specific clarification } \\
\text { provided. }\end{array}$ & $\begin{array}{l}\text { ARDC with additional modular HTGR- } \\
\text { specific clarification provided: } \\
\text { Protection system requirements for reactivity } \\
\text { control malfunctions. } \\
\text { The protection system shall be designed to } \\
\text { assure that specified acceptable fuelcore } \\
\text { radionuclide release design limits are not } \\
\text { exceeded for any single malfunction of the } \\
\text { reactivity control systems, such as } \\
\text { accidental withdrawal (not ejection-ør } \\
\text { dropout) of control rods. }\end{array}$ \\
\hline 26 & $\begin{array}{l}\text { Reactivity control system redundancy and } \\
\text { capability. } \\
\text { Two independent reactivity control systems of } \\
\text { different design principles shall be provided. } \\
\text { One of the systems shall use control rods, } \\
\text { preferably including a positive means for } \\
\text { inserting the rods, and shall be capable of } \\
\text { reliably controlling reactivity changes to assure } \\
\text { that under conditions of normal operation, } \\
\text { including anticipated operational occurrences, } \\
\text { and with appropriate margin for malfunctions } \\
\text { such as stuck rods, specified acceptable fuel } \\
\text { design limits are not exceeded. The second } \\
\text { reactivity control system shall be capable of } \\
\text { reliably controlling the rate of reactivity } \\
\text { changes resulting from planned, normal power } \\
\text { changes (including xenon burnout) to assure } \\
\text { acceptable fuel design limits are not exceeded. } \\
\text { One of the systems shall be capable of holding } \\
\text { the reactor core subcritical under cold } \\
\text { conditions. }\end{array}$ & $\begin{array}{l}\text { Reactivity control system redundancy and } \\
\text { capability. } \\
\text { [Two] independent reactivity control systems of } \\
\text { different design principles shall be provided. } \\
\text { One of the systems shall use control rods, } \\
\text { preferably including a positive means for } \\
\text { inserting the rods, and shall be capable of } \\
\text { reliably controlling reactivity changes to assure } \\
\text { that under conditions of normal operation, } \\
\text { including anticipated operational occurrences, } \\
\text { and with appropriate margin for malfunctions } \\
\text { such as stuck rods, specified acceptable fuel } \\
\text { design limits are not exceeded. The A second } \\
\text { reactivity control system shall be capable of } \\
\text { reliably controlling the rate of reactivity changes } \\
\text { resulting from planned, normal power changes } \\
\text { [(including xenon burnout)] to assure } \\
\text { acceptable fuel design limits are not exceeded. } \\
\text { One of the systems shall be capable of holding } \\
\text { the reactor core subcritical under cold } \\
\text { conditions. }\end{array}$ & $\begin{array}{l}\text { ARDC with additional SFR-specific clarification } \\
\text { provided: } \\
\text { Reactivity control system redundancy and } \\
\text { capability. } \\
\text { [Two] independent reactivity control systems of } \\
\text { different design principles shall be provided. } \\
\text { One of the systems shall use control rods, } \\
\text { preferably including a positive means for } \\
\text { inserting the rods, and shall be capable of } \\
\text { reliably controlling reactivity changes to assure } \\
\text { that under conditions of normal operation, } \\
\text { including anticipated operational occurrences, } \\
\text { and with appropriate margin for malfunctions } \\
\text { such as stuck rods, specified acceptable fuel } \\
\text { design limits are not exceeded. A second } \\
\text { reactivity control system shall be capable of } \\
\text { reliably controlling the rate of reactivity changes } \\
\text { resulting from planned, normal power changes } \\
\text { [(including xenon burnout)] to assure } \\
\text { acceptable fuel design limits are not exceeded. } \\
\text { One of the systems shall be capable of holding } \\
\text { the reactor core subcritical under cold } \\
\text { conditions. }\end{array}$ & $\begin{array}{l}\text { ARDC with additional modular HTGR- } \\
\text { specific clarification provided: } \\
\text { Reactivity control system redundancy and } \\
\text { capability. } \\
\text { [Two] independent reactivity control } \\
\text { systems of different design principles shall } \\
\text { be provided. One of the systems shall use } \\
\text { control rods, preferably including a positive } \\
\text { means for inserting the rods, and shall be } \\
\text { capable of reliably controlling reactivity } \\
\text { changes to assure that under conditions of } \\
\text { normal operation, including anticipated } \\
\text { operational occurrences, and with } \\
\text { appropriate margin for malfunctions such as } \\
\text { stuck rods, specified acceptable fuelcore } \\
\text { radionuclide release design limits are not } \\
\text { exceeded. A second reactivity control } \\
\text { system shall be capable of reliably } \\
\text { controlling the rate of reactivity changes } \\
\text { resulting from planned, normal power } \\
\text { changes [(including xenon burnout)] to } \\
\text { assure acceptable fuelcore radionuclide } \\
\text { release design limits are not exceeded. One } \\
\text { of the systems shall be capable of holding } \\
\text { the reactor core subcritical under cold } \\
\text { conditions. }\end{array}$ \\
\hline 27 & $\begin{array}{l}\text { Combined reactivity control systems capability. } \\
\text { The reactivity control systems shall be } \\
\text { designed to have a combined capability, in } \\
\text { conjunction with poison addition by the } \\
\text { emergency core cooling system, of reliably } \\
\text { controlling reactivity changes to assure that } \\
\text { under postulated accident conditions and with } \\
\text { appropriate margin for stuck rods the capability }\end{array}$ & $\begin{array}{l}\text { Combined reactivity control systems capability. } \\
\text { The reactivity control systems shall be designed } \\
\text { to have a combined capability, in conjunction } \\
\text { with poison addition by the emergency core } \\
\text { cooling system, of reliably controlling reactivity } \\
\text { changes to assure that under postulated } \\
\text { accident conditions and with appropriate margin } \\
\text { for stuck rods the capability to cool the core is }\end{array}$ & $\begin{array}{l}\text { ARDC with no further SFR-specific clarification } \\
\text { provided. }\end{array}$ & $\begin{array}{l}\text { ARDC with no further modular HTGR- } \\
\text { specific clarification provided. }\end{array}$ \\
\hline
\end{tabular}




\begin{tabular}{|c|c|c|c|c|}
\hline \multicolumn{5}{|c|}{ III. Reactivity Control } \\
\hline Criterion & Current GDC Language & Proposed ARDC Language & Proposed SFR-DC Language & Proposed HTGR-DC Language \\
\hline & to cool the core is maintained. & maintained. & & \\
\hline 28 & $\begin{array}{l}\text { Reactivity limits. } \\
\text { The reactivity control systems shall be } \\
\text { designed with appropriate limits on the } \\
\text { potential amount and rate of reactivity increase } \\
\text { to assure that the effects of postulated } \\
\text { reactivity accidents can neither (1) result in } \\
\text { damage to the reactor coolant pressure } \\
\text { boundary greater than limited local yielding nor } \\
\text { (2) sufficiently disturb the core, its support } \\
\text { structures or other reactor pressure vessel } \\
\text { internals to impair significantly the capability to } \\
\text { cool the core. These postulated reactivity } \\
\text { accidents shall include consideration of rod } \\
\text { ejection (unless prevented by positive means), } \\
\text { rod dropout, steam line rupture, changes in } \\
\text { reactor coolant temperature and pressure, and } \\
\text { cold water addition. }\end{array}$ & $\begin{array}{l}\text { Reactivity limits. } \\
\text { The reactivity control systems shall be designed } \\
\text { with appropriate limits on the potential amount } \\
\text { and rate of reactivity increase to assure that the } \\
\text { effects of postulated reactivity accidents can } \\
\text { neither (1) result in damage to the reactor } \\
\text { [coolant pressure] boundary greater than } \\
\text { limited local yielding nor (2) sufficiently disturb } \\
\text { the core, its support structures or other reactor } \\
\text { pressure-vessel internals to impair significantly } \\
\text { the capability to cool the core. These postulated } \\
\text { reactivity accidents shall include consideration of } \\
\text { [rod ejection (unless prevented by positive } \\
\text { means), rod dropout, steam line rupture, } \\
\text { changes in reactor coolant temperature and } \\
\text { pressure, and cold water addition]. }\end{array}$ & $\begin{array}{l}\text { ARDC with additional SFR-specific clarification } \\
\text { provided: } \\
\text { Reactivity limits. } \\
\text { The reactivity control systems shall be designed } \\
\text { with appropriate limits on the potential amount } \\
\text { and rate of reactivity increase to assure that the } \\
\text { effects of postulated reactivity accidents can } \\
\text { neither (1) result in damage to the reactor } \\
\text { [primary coolant-pressure] boundary greater } \\
\text { than limited local yielding nor (2) sufficiently } \\
\text { disturb the core, its support structures or other } \\
\text { reactor vessel internals to impair significantly the } \\
\text { capability to cool the core. These postulated } \\
\text { reactivity accidents shall include consideration of } \\
\text { [rod-ejection (unless-prevented bypositive } \\
\text { means), rod-dropout, steam line rupture, } \\
\text { changes in reactor coolant temperature and } \\
\text { pressure, and-cold-water additionchanges in } \\
\text { power/flow rates]. }\end{array}$ & $\begin{array}{l}\text { ARDC with additional modular HTGR- } \\
\text { specific clarification provided: } \\
\text { Reactivity limits. } \\
\text { The reactivity control systems shall be } \\
\text { designed with appropriate limits on the } \\
\text { potential amount and rate of reactivity } \\
\text { increase to assure that the effects of } \\
\text { postulated reactivity accidents can neither } \\
\text { (1) result in damage to the reactor } \\
\text { [coolanthelium pressure] boundary greater } \\
\text { than limited local yielding nor (2) sufficiently } \\
\text { disturb the core, its support structures or } \\
\text { other reactor vessel internals to impair } \\
\text { significantly the capability to cool the core. } \\
\text { These postulated reactivity accidents shall } \\
\text { include consideration of [rod ejection } \\
\text { (unless prevented by positive means), } \\
\text { fod-dropout, steam line-rupture,-changes } \\
\text { in reactor coolant-temperature-and } \\
\text { pressure, and cold water } \\
\text { additionmoisture ingress]. }\end{array}$ \\
\hline 29 & $\begin{array}{l}\text { Protection against anticipated operational } \\
\text { occurrences. } \\
\text { The protection and reactivity control systems } \\
\text { shall be designed to assure an extremely high } \\
\text { probability of accomplishing their safety } \\
\text { functions in the event of anticipated } \\
\text { operational occurrences. }\end{array}$ & Same as GDC & $\begin{array}{l}\text { ARDC with no further SFR-specific clarification } \\
\text { provided. }\end{array}$ & $\begin{array}{l}\text { ARDC with no further modular HTGR- } \\
\text { specific clarification provided. }\end{array}$ \\
\hline
\end{tabular}

\begin{tabular}{|c|c|c|c|c|}
\hline \multicolumn{5}{|c|}{ IV. Fluid Systems } \\
\hline Criterion & Current GDC Language & Proposed ARDC Language & Proposed SFR-DC Language & Proposed HTGR-DC Language \\
\hline 30 & $\begin{array}{l}\text { Quality of reactor coolant pressure boundary. } \\
\text { Components which are part of the reactor } \\
\text { coolant pressure boundary shall be designed, } \\
\text { fabricated, erected, and tested to the highest } \\
\text { quality standards practical. Means shall be } \\
\text { provided for detecting and, to the extent } \\
\text { practical, identifying the location of the source } \\
\text { of reactor coolant leakage. }\end{array}$ & $\begin{array}{l}\text { Quality of reactor [coolant pressure] boundary. } \\
\text { Components which are part of the reactor } \\
\text { [coolant pressure] boundary shall be designed, } \\
\text { fabricated, erected, and tested to the highest } \\
\text { quality standards practical. Means shall be } \\
\text { provided for detecting and, to the extent } \\
\text { practical, identifying the location of the source of } \\
\text { reactor [coolant] leakage. }\end{array}$ & $\begin{array}{l}\text { ARDC with additional SFR-specific clarification } \\
\text { provided: } \\
\text { Quality of reactor [primary coolant-pressure] } \\
\text { boundary. } \\
\text { Components which are part of the reactor } \\
\text { [primary coolant-pressure] boundary shall be } \\
\text { designed, fabricated, erected, and tested to the } \\
\text { highest quality standards practical. Means shall } \\
\text { be provided for detecting and, to the extent } \\
\text { practical, identifying the location of the source of } \\
\text { reactor [coolant] leakage. }\end{array}$ & $\begin{array}{l}\text { ARDC with additional modular HTGR- } \\
\text { specific clarification provided: } \\
\text { Quality of reactor [coolanthelium pressure] } \\
\text { boundary. } \\
\text { Components which are part of the reactor } \\
\text { [coolanthelium pressure] boundary shall } \\
\text { be designed, fabricated, erected, and tested } \\
\text { to the highest quality standards practical. } \\
\text { Means shall be provided for detecting and, } \\
\text { to the extent practical, identifying the } \\
\text { location of the source of reactor } \\
\text { [coolanthelium] leakage. }\end{array}$ \\
\hline 31 & $\begin{array}{l}\text { Fracture prevention of reactor coolant } \\
\text { pressure boundary. } \\
\text { The reactor coolant pressure boundary shall } \\
\text { be designed with sufficient margin to assure } \\
\text { that when stressed under operating, }\end{array}$ & $\begin{array}{l}\text { Fracture prevention of reactor [coolant } \\
\text { pressure] boundary. } \\
\text { The reactor [coolant pressure] boundary shall } \\
\text { be designed with sufficient margin to assure that } \\
\text { when stressed under operating, maintenance, }\end{array}$ & $\begin{array}{l}\text { ARDC with additional SFR-specific clarification } \\
\text { provided: } \\
\text { Fracture prevention of reactor [primary coolant } \\
\text { pressure] boundary. }\end{array}$ & $\begin{array}{l}\text { ARDC with additional modular HTGR- } \\
\text { specific clarification provided: } \\
\text { Fracture prevention of reactor } \\
\text { [Goolanthelium pressure] boundary. }\end{array}$ \\
\hline
\end{tabular}




\begin{tabular}{|c|c|c|c|c|}
\hline \multicolumn{5}{|c|}{ IV. Fluid Systems } \\
\hline Criterion & Current GDC Language & Proposed ARDC Language & Proposed SFR-DC Language & Proposed HTGR-DC Language \\
\hline & $\begin{array}{l}\text { maintenance, testing, and postulated accident } \\
\text { conditions (1) the boundary behaves in a } \\
\text { nonbrittle manner and (2) the probability of } \\
\text { rapidly propagating fracture is minimized. The } \\
\text { design shall reflect consideration of service } \\
\text { temperatures and other conditions of the } \\
\text { boundary material under operating, } \\
\text { maintenance, testing, and postulated accident } \\
\text { conditions and the uncertainties in determining } \\
\text { (1) material properties, (2) the effects of } \\
\text { irradiation on material properties, (3) residual, } \\
\text { steady state and transient stresses, and (4) } \\
\text { size of flaws. }\end{array}$ & $\begin{array}{l}\text { testing, and postulated accident conditions (1) } \\
\text { the boundary behaves in a nonbrittle manner } \\
\text { and (2) the probability of rapidly propagating } \\
\text { fracture is minimized. The design shall reflect } \\
\text { consideration of service temperatures [and } \\
\text { other conditions] of the boundary material } \\
\text { under operating, maintenance, testing, and } \\
\text { postulated accident conditions and the } \\
\text { uncertainties in determining (1) material } \\
\text { properties, (2) the effects of irradiation on } \\
\text { material properties, (3) residual, steady state } \\
\text { and transient stresses, and (4) size of flaws. }\end{array}$ & $\begin{array}{l}\text { The reactor [primary coolant-pressure] } \\
\text { boundary shall be designed with sufficient } \\
\text { margin to assure that when stressed under } \\
\text { operating, maintenance, testing, and postulated } \\
\text { accident conditions (1) the boundary behaves in } \\
\text { a nonbrittle manner and (2) the probability of } \\
\text { rapidly propagating fracture is minimized. The } \\
\text { design shall reflect consideration of service } \\
\text { temperatures [, service degradation of } \\
\text { material properties, creep, fatigue, stress } \\
\text { rupture, and other conditions] of the boundary } \\
\text { material under operating, maintenance, testing, } \\
\text { and postulated accident conditions and the } \\
\text { uncertainties in determining (1) material } \\
\text { properties, (2) the effects of irradiation on } \\
\text { material properties, (3) residual, steady state } \\
\text { and transient stresses, and (4) size of flaws. }\end{array}$ & $\begin{array}{l}\text { The reactor [oolanthelium pressure] } \\
\text { boundary shall be designed with sufficient } \\
\text { margin to assure that when stressed under } \\
\text { operating, maintenance, testing, and } \\
\text { postulated accident conditions (1) the } \\
\text { boundary behaves in a nonbrittle manner } \\
\text { and (2) the probability of rapidly propagating } \\
\text { fracture is minimized. The design shall } \\
\text { reflect consideration of service temperatures } \\
\text { [and other conditions] of the boundary } \\
\text { material under operating, maintenance, } \\
\text { testing, and postulated accident conditions } \\
\text { and the uncertainties in determining (1) } \\
\text { material properties, (2) the effects of } \\
\text { irradiation on material properties, ( } 3 \text { ) } \\
\text { residual, steady state and transient stresses, } \\
\text { and (4) size of flaws. }\end{array}$ \\
\hline 32 & $\begin{array}{l}\text { Inspection of reactor coolant pressure } \\
\text { boundary. } \\
\text { Components which are part of the reactor } \\
\text { coolant pressure boundary shall be designed } \\
\text { to permit (1) periodic inspection and testing of } \\
\text { important areas and features to assess their } \\
\text { structural and leaktight integrity, and (2) an } \\
\text { appropriate material surveillance program for } \\
\text { the reactor pressure vessel. }\end{array}$ & $\begin{array}{l}\text { Inspection of reactor [coolant pressure] } \\
\text { boundary. } \\
\text { Components which are part of the reactor } \\
\text { [coolant pressure] boundary shall be designed } \\
\text { to permit (1) periodic inspection and testing of } \\
\text { important areas and features to assess their } \\
\text { structural and leaktight integrity, and (2) an } \\
\text { appropriate material surveillance program for the } \\
\text { reactor pressure vessel. }\end{array}$ & $\begin{array}{l}\text { ARDC with additional SFR-specific clarification } \\
\text { provided: } \\
\text { Inspection of reactor [primary coolant } \\
\text { pressure] boundary. } \\
\text { Components which are part of the reactor } \\
\text { [primary coolant pressure] boundary shall be } \\
\text { designed to permit (1) periodic inspection and } \\
\text { testing of important areas and features to } \\
\text { assess their structural and leaktight integrity, } \\
\text { and (2) an appropriate material surveillance } \\
\text { program for the reactor vessel. }\end{array}$ & $\begin{array}{l}\text { ARDC with additional modular HTGR- } \\
\text { specific clarification provided: } \\
\text { Inspection of reactor [coolanthelium } \\
\text { pressure] boundary. } \\
\text { Components which are part of the reactor } \\
\text { [coolanthelium pressure] boundary shall } \\
\text { be designed to permit (1) periodic inspection } \\
\text { and testing of important areas and features } \\
\text { to assess their structural and leaktight } \\
\text { integrity, and (2) an appropriate material } \\
\text { surveillance program for the reactor vessel. }\end{array}$ \\
\hline 33 & $\begin{array}{l}\text { Reactor coolant makeup. } \\
\text { A system to supply reactor coolant makeup for } \\
\text { protection against small breaks in the reactor } \\
\text { coolant pressure boundary shall be provided. } \\
\text { The system safety function shall be to assure } \\
\text { that specified acceptable fuel design limits are } \\
\text { not exceeded as a result of reactor coolant } \\
\text { loss due to leakage from the reactor coolant } \\
\text { pressure boundary and rupture of small piping } \\
\text { or other small components which are part of } \\
\text { the boundary. The system shall be designed to } \\
\text { assure that for onsite electric power system } \\
\text { operation (assuming offsite power is not } \\
\text { available) and for offsite electric power system } \\
\text { operation (assuming onsite power is not } \\
\text { available) the system safety function can be } \\
\text { accomplished using the piping, pumps, and } \\
\text { valves used to maintain coolant inventory } \\
\text { during normal reactor operation. }\end{array}$ & $\begin{array}{l}\text { Reactor [coolant] makeupinventory } \\
\text { maintenance. } \\
\text { A system to-supply maintain reactor [coolant] } \\
\text { inventory makoupfor protection against small } \\
\text { breaks in the reactor [coolant pressure] } \\
\text { boundary shall be provided as necessary to - } \\
\text { The system safety function shall be to-assure } \\
\text { that specified acceptable fuel design limits are } \\
\text { not exceeded as a result of reactor [coolant] } \\
\text { inventory loss due to leakage from the reactor } \\
\text { [coolant pressure] boundary and rupture of } \\
\text { small piping or other small components which } \\
\text { are part of the boundary. The system shall be } \\
\text { designed to assure that for onsite electric power } \\
\text { system operation (assuming offsite power is not } \\
\text { available) and for offsite electric power system } \\
\text { operation (assuming onsite power is not } \\
\text { available) the system safety function can be } \\
\text { accomplished using the piping, pumps, and } \\
\text { valves used to maintain coolant inventory during } \\
\text { normal reactor operation. }\end{array}$ & $\begin{array}{l}\text { ARDC with additional SFR-specific clarification } \\
\text { provided: } \\
\text { Reactor [primary coolant] inventory } \\
\text { maintenance. } \\
\text { A system to maintain reactor [coolant] inventory } \\
\text { for protection against small breaks in the reactor } \\
\text { [primary coolant pressure] boundary shall be } \\
\text { provided as necessary to assure that specified } \\
\text { acceptable fuel design limits are not exceeded } \\
\text { as a result of reactor inventory loss due to } \\
\text { leakage from the reactor [primary coolant } \\
\text { pressure] boundary and primary of small piping } \\
\text { or other small components which are part of the } \\
\text { boundary. }\end{array}$ & Not applicable to modular HTGR. \\
\hline 34 & $\begin{array}{l}\text { Residual heat removal. } \\
\text { A system to remove residual heat shall be } \\
\text { provided. The system safety function shall be }\end{array}$ & $\begin{array}{l}\text { Residual heat removal. } \\
\text { A system to remove residual heat shall be } \\
\text { provided. The system safety function shall be to }\end{array}$ & $\begin{array}{l}\text { ARDC with additional SFR-specific clarification } \\
\text { provided: }\end{array}$ & $\begin{array}{l}\text { ARDC with additional modular HTGR- } \\
\text { specific clarification provided: }\end{array}$ \\
\hline
\end{tabular}




\begin{tabular}{|c|c|c|c|c|}
\hline \multicolumn{5}{|c|}{ IV. Fluid Systems } \\
\hline Criterion & Current GDC Language & Proposed ARDC Language & Proposed SFR-DC Language & Proposed HTGR-DC Language \\
\hline & $\begin{array}{l}\text { to transfer fission product decay heat and } \\
\text { other residual heat from the reactor core at a } \\
\text { rate such that specified acceptable fuel design } \\
\text { limits and the design conditions of the reactor } \\
\text { coolant pressure boundary are not exceeded. } \\
\\
\text { Suitable redundancy in components and } \\
\text { features, and suitable interconnections, leak } \\
\text { detection, and isolation capabilities shall be } \\
\text { provided to assure that for onsite electric } \\
\text { power system operation (assuming offsite } \\
\text { power is not available) and for offsite electric } \\
\text { power system operation (assuming onsite } \\
\text { power is not available) the system safety } \\
\text { function can be accomplished, assuming a } \\
\text { single failure. }\end{array}$ & $\begin{array}{l}\text { transfer fission product decay heat and other } \\
\text { residual heat from the reactor core to an ultimate } \\
\text { heat sink at a rate such that specified } \\
\text { acceptable fuel design limits and the design } \\
\text { conditions of the reactor [coolant pressure] } \\
\text { boundary are not exceeded under all plant } \\
\text { shutdown conditions following normal operation, } \\
\text { including anticipated operational occurrences, } \\
\text { and to provide continuous effective core cooling } \\
\text { during postulated accidents. } \\
\text { Suitable redundancy in components and } \\
\text { features, and suitable interconnections, leak } \\
\text { detection, and isolation capabilities shall be } \\
\text { provided to assure that for onsite electric power } \\
\text { system operation (assuming offsite power is not } \\
\text { available) and for offsite electric power system } \\
\text { operation (assuming onsite power is not } \\
\text { avaitable)the system safety function can be } \\
\text { accomplished, assuming a single failure. }\end{array}$ & $\begin{array}{l}\text { Residual heat removal. } \\
\text { A system to remove residual heat shall be } \\
\text { provided. The system safety function shall be to } \\
\text { transfer fission product decay heat and other } \\
\text { residual heat from the reactor core to an ultimate } \\
\text { heat sink at a rate such that specified } \\
\text { acceptable fuel design limits and the design } \\
\text { conditions of the reactor [primary coolant } \\
\text { pressure] boundary are not exceeded under all } \\
\text { plant shutdown conditions following normal } \\
\text { operation, including anticipated operational } \\
\text { occurrences, and to provide continuous effective } \\
\text { core cooling during postulated accidents. } \\
\\
\text { Suitable redundancy in components and } \\
\text { features, and suitable interconnections, leak } \\
\text { detection, and isolation capabilities shall be } \\
\text { provided to assure that the system safety } \\
\text { function can be accomplished, assuming a } \\
\text { single failure. }\end{array}$ & $\begin{array}{l}\text { Residual-Passive residual heat removal. } \\
\text { A passive system to remove residual heat } \\
\text { shall be provided. The system safety } \\
\text { function shall be to transfer fission product } \\
\text { decay heat and other residual heat from the } \\
\text { reactor core to an ultimate heat sink at a rate } \\
\text { such that specified acceptable fuel-core } \\
\text { radionuclide release design limits and the } \\
\text { design conditions of the reactor [coolant } \\
\text { pressure] boundary are not exceeded under } \\
\text { all plant shutdown conditions following } \\
\text { normal operation, including-during } \\
\text { anticipated operational occurrences, and to } \\
\text { provide continuous effective core-cooling } \\
\text { during postulated accidents. } \\
\text { Suitable redundancy in components and } \\
\text { features, and suitable interconnections, leak } \\
\text { detection, and isolation capabilities shall be } \\
\text { provided to assure that the system safety } \\
\text { function can be accomplished,-assuming a } \\
\text { single failure. }\end{array}$ \\
\hline 35 & $\begin{array}{l}\text { Emergency core cooling. } \\
\text { A system to provide abundant emergency core } \\
\text { cooling shall be provided. The system safety } \\
\text { function shall be to transfer heat from the } \\
\text { reactor core following any loss of reactor } \\
\text { coolant at a rate such that (1) fuel and clad } \\
\text { damage that could interfere with continued } \\
\text { effective core cooling is prevented and (2) clad } \\
\text { metal-water reaction is limited to negligible } \\
\text { amounts. } \\
\text { Suitable redundancy in components and } \\
\text { features, and suitable interconnections, leak } \\
\text { detection, isolation, and containment } \\
\text { capabilities shall be provided to assure that for } \\
\text { onsite electric power system operation } \\
\text { (assuming offsite power is not available) and } \\
\text { for offsite electric power system operation } \\
\text { (assuming onsite power is not available) the } \\
\text { system safety function can be accomplished, } \\
\text { assuming a single failure. }\end{array}$ & $\begin{array}{l}\text { Advanced Reactor Design Criterion for core } \\
\text { cooling under accident conditions is contained in } \\
\text { ARDC-34. }\end{array}$ & $\begin{array}{l}\text { ARDC with no further SFR-specific clarification } \\
\text { provided. }\end{array}$ & $\begin{array}{l}\text { ARDC with no further modular HTGR- } \\
\text { specific clarification provided. }\end{array}$ \\
\hline
\end{tabular}




\begin{tabular}{|c|c|c|c|c|}
\hline \multicolumn{5}{|c|}{ IV. Fluid Systems } \\
\hline Criterion & Current GDC Language & Proposed ARDC Language & Proposed SFR-DC Language & Proposed HTGR-DC Language \\
\hline & & & the system. & $\begin{array}{l}\text { and pipingdesign-specific equipment], to } \\
\text { assure the integrity and capability of the } \\
\text { system. }\end{array}$ \\
\hline 37 & $\begin{array}{l}\text { Testing of emergency core cooling system. } \\
\text { The emergency core cooling system shall be } \\
\text { designed to permit appropriate periodic } \\
\text { pressure and functional testing to assure (1) } \\
\text { the structural and leaktight integrity of its } \\
\text { components, (2) the operability and } \\
\text { performance of the active components of the } \\
\text { system, and (3) the operability of the system } \\
\text { as a whole and, under conditions as close to } \\
\text { design as practical, the performance of the full } \\
\text { operational sequence that brings the system } \\
\text { into operation, including operation of } \\
\text { applicable portions of the protection system, } \\
\text { the transfer between normal and emergency } \\
\text { power sources, and the operation of the } \\
\text { associated cooling water system. }\end{array}$ & $\begin{array}{l}\text { Testing of residual heat removalemergency core } \\
\text { cooling system. } \\
\text { The residual heat removal emergency core } \\
\text { cooling-system shall be designed to permit } \\
\text { appropriate periodic pressure and-functional } \\
\text { testing to assure (1) the structural and leaktight } \\
\text { integrity of its components, (2) the operability } \\
\text { and performance of the active-system } \\
\text { components-of the system, and (3) the } \\
\text { operability of the system as a whole and, under } \\
\text { conditions as close to design as practical, the } \\
\text { performance of the full operational sequence } \\
\text { that brings the system into operation, including } \\
\text { operation of associated systems and interfaces } \\
\text { with an ultimate heat sink. including operation of } \\
\text { applicable portions of the protection system, the } \\
\text { transfer between normal and emergency power } \\
\text { sources, and the operation of the associated } \\
\text { cooling water system }\end{array}$ & $\begin{array}{l}\text { ARDC with no further SFR-specific clarification } \\
\text { provided. }\end{array}$ & $\begin{array}{l}\text { ARDC with additional modular HTGR- } \\
\text { specific clarification provided: } \\
\text { Testing of passive residual heat removal } \\
\text { system. } \\
\text { The passive residual heat removal system } \\
\text { shall be designed to permit appropriate } \\
\text { periodic functional testing to assure (1) the } \\
\text { structural integrity of its components, (2) the } \\
\text { operability and performance of the system } \\
\text { components, and (3) the operability of the } \\
\text { system as a whole and, if applicable, under } \\
\text { conditions as close to design as practical, } \\
\text { the performance of the full operational } \\
\text { sequence that brings the system into } \\
\text { operation, including operation of associated } \\
\text { systems and interfaces with an ultimate heat } \\
\text { sink and the transition from the active normal } \\
\text { operation mode to the passive operation } \\
\text { mode relied upon during postulated } \\
\text { accidents. }\end{array}$ \\
\hline 38 & $\begin{array}{l}\text { Containment heat removal. } \\
\text { A system to remove heat from the reactor } \\
\text { containment shall be provided. The system } \\
\text { safety function shall be to reduce rapidly, } \\
\text { consistent with the functioning of other } \\
\text { associated systems, the containment pressure } \\
\text { and temperature following any loss-of-coolant } \\
\text { accident and maintain them at acceptably low } \\
\text { levels. } \\
\text { Suitable redundancy in components and } \\
\text { features, and suitable interconnections, leak } \\
\text { detection, isolation, and containment } \\
\text { capabilities shall be provided to assure that for } \\
\text { onsite electric power system operation } \\
\text { (assuming offsite power is not available) and } \\
\text { for offsite electric power system operation } \\
\text { (assuming onsite power is not available) the } \\
\text { system safety function can be accomplished, } \\
\text { assuming a single failure. }\end{array}$ & $\begin{array}{l}\text { Containment heat removal. } \\
\text { A system to remove heat from the reactor } \\
\text { containment shall be provided as necessary- } \\
\text { The system safety function shall be to maintain } \\
\text { reduce rapidly, consistent with the functioning of } \\
\text { other associated systems, the containment } \\
\text { pressure and temperature within acceptable } \\
\text { limits following following any loss-of-coolant } \\
\text { postulated accidents-and maintain them at } \\
\text { acceptably low levels. } \\
\text { Suitable redundancy in components and } \\
\text { features, and suitable interconnections, leak } \\
\text { detection, isolation, and containment capabilities } \\
\text { shall be provided to assure that for onsite } \\
\text { electric power system operation (assuming } \\
\text { effsite power is not available) and for offsite } \\
\text { electric power system operation (assuming } \\
\text { ensite power is not available)the system safety } \\
\text { function can be accomplished, assuming a } \\
\text { single failure. }\end{array}$ & $\begin{array}{l}\text { ARDC with no further SFR-specific clarification } \\
\text { provided. }\end{array}$ & Not applicable to modular HTGR. \\
\hline 39 & $\begin{array}{l}\text { Inspection of containment heat removal } \\
\text { system. } \\
\text { The containment heat removal system shall be } \\
\text { designed to permit appropriate periodic } \\
\text { inspection of important components, such as } \\
\text { the torus, sumps, spray nozzles, and piping to } \\
\text { assure the integrity and capability of the } \\
\text { system. }\end{array}$ & $\begin{array}{l}\text { Inspection of containment heat removal system. } \\
\text { The containment heat removal system shall be } \\
\text { designed to permit appropriate periodic } \\
\text { inspection of important components, such as } \\
\text { [the torus, sumps, spray nozzles, and piping] } \\
\text { to assure the integrity and capability of the } \\
\text { system. }\end{array}$ & $\begin{array}{l}\text { ARDC with additional SFR-specific clarification } \\
\text { provided: } \\
\text { Inspection of containment heat removal system. } \\
\text { The containment heat removal system shall be } \\
\text { designed to permit appropriate periodic } \\
\text { inspection of important components, such as } \\
\text { [the torus, sumps, spray nozzles, and-piping] }\end{array}$ & Not applicable to modular HTGR. \\
\hline
\end{tabular}




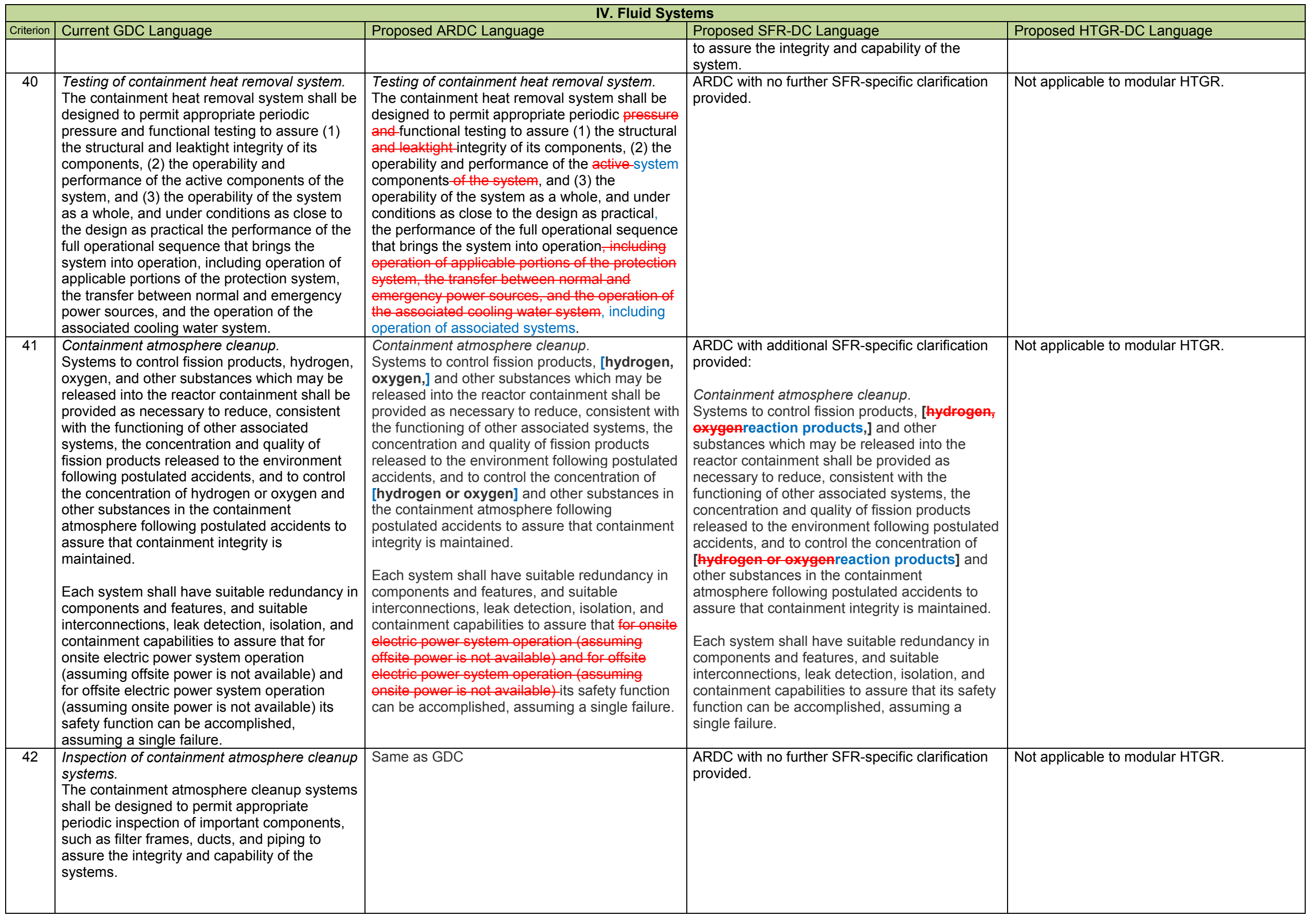




\section{\begin{tabular}{|l|l} 
Criterion & Current GDC Language \\
\hline 43 & Testing of COntainment atm
\end{tabular}}

Testing of containment atmosphere cleanup systems.

The containment atmosphere cleanup systems shall be designed to permit appropriate periodic pressure and functional testing to assure (1) the structural and leaktight integrity of its components, (2) the operability and performance of the active components of the systems such as fans, filters, dampers, pumps and valves and (3) the operability of the

systems as a whole and, under conditions as close to design as practical the performance of the full operational sequence that brings the systems into operation, including operation of applicable portions of the protection system, the transfer between normal and emergency power sources, and the operation of associated systems.

44 Cooling water.

A system to transfer heat from structures,

systems, and components important to safety, to an ultimate heat sink shall be provided. The system safety function shall be to transfer the combined heat load of these structures,

systems, and components under normal

operating and accident conditions.

Suitable redundancy in components and features, and suitable interconnections, leak detection, and isolation capabilities shall be provided to assure that for onsite electric power system operation (assuming offsite power is not available) and for offsite electric power is not avalable and for offic power system operation (assuming onsite power is not available) the system safety function can be accomplished, assuming a single failure.

$45 \quad$ Inspection of cooling water system.

The cooling water system shall be designed to permit appropriate periodic inspection of important components, such as heat exchangers and piping, to assure the integrity and capability of the system.

\section{Testing of cooling water system.}

The cooling water system shall be designed to permit appropriate periodic pressure and functional testing to assure (1) the structura and leaktight integrity of its components, (2) the operability and the performance of the active components of the system, and (3) the

\section{Proposed ARDC Language} Testing of containment atmosphere cleanup systems.

The containment atmosphere cleanup systems shall be designed to permit appropriate periodic pressure and-functional testing to assure (1) the structural and leaktightintegrity of its

components, (2) the operability and performance of the active-system components, of the systems such as fans, filters, dampers, pumps, and

valves-and (3) the operability of the systems as a whole and, under conditions as close to design as practical, the performance of the full

operational sequence that brings the systems into operation, including operation of applicable portions of the protection system, the transfer between normal and emergency power sources, and the operation of associated systems.

Structural and equipment cooling Gooling water. In addition to the heat rejection capability of the residual heat removal system, Asystems to transfer heat from structures, systems, and components important to safety, to an ultimate heat sink shall be provided, as necessary. The system safety function shall be to transfer the combined heat load of these structures, systems, and components under normal operating and accident conditions.

Suitable redundancy in components and features, and suitable interconnections, leak detection, and isolation capabilities shall be provided to assure that for onsite electric power system operation (assuming offsite power is no available) and for offsite electric power system operation (assuming onsite power is not available) the-each system safety function can be accomplished, assuming a single failure.

Inspection of structural and equipment cooling water systems.

The cooling waterstructural and equipment cooling systems shall be designed to permit appropriate periodic inspection of important components, such as heat exchangers and piping, to assure the integrity and capability of the systems.

Testing of structural and equipment cooling
water systems.

The structural and equipment cooling water systems shall be designed to permit appropriate periodic pressure and-functional testing to assure (1) the structural and leaktight integrity of their its-components, (2) the operability and the

\section{Proposed SFR-DC Language}

ARDC with no further SFR-specific clarification provided.

\section{ARDC with no further SFR-specific clarification} provided.

ARDC with no further SFR-specific clarification provided.

ARDC with no further SFR-specific clarification provided.
Proposed HTGR-DC Language

Not applicable to modular HTGR.

Not applicable to modular HTGR.

Not applicable to modular HTGR. 
IV. Fluid Systems

\begin{tabular}{|c|c|c|c|c|}
\hline \multicolumn{5}{|c|}{ IV. Finidu systems } \\
\hline Criterion & Current GDC Language & Proposed ARDC Language & Proposed SFR-DC Language & Proposed HTGR-DC Language \\
\hline & $\begin{array}{l}\text { operability of the system as a whole and, } \\
\text { under conditions as close to design as } \\
\text { practical, the performance of the full } \\
\text { operational sequence that brings the system } \\
\text { into operation for reactor shutdown and for } \\
\text { loss-of-coolant accidents, including operation } \\
\text { of applicable portions of the protection system } \\
\text { and the transfer between normal and } \\
\text { emergency power sources. }\end{array}$ & $\begin{array}{l}\text { performance of the active-system components-of } \\
\text { the system, and (3) the operability of the } \\
\text { systems as a whole and, under conditions as } \\
\text { close to design as practical, the performance of } \\
\text { the full operational sequences that brings the } \\
\text { systems into operation for reactor shutdown and } \\
\text { postulated accidents, including operation of } \\
\text { associated systems-and for loss-of-coolant } \\
\text { accidents, including operation of applicable } \\
\text { portions of the protection system and the } \\
\text { transfer between normal and emergency power } \\
\text { sources. }\end{array}$ & & \\
\hline
\end{tabular}

\begin{tabular}{|c|c|c|c|c|}
\hline \multicolumn{5}{|c|}{ V. Reactor Containment } \\
\hline Criterion & Current GDC Language & Proposed ARDC Language & Proposed SFR-DC Language & Proposed HTGR-DC Language \\
\hline 50 & $\begin{array}{l}\text { Containment design basis. } \\
\text { The reactor containment structure, including } \\
\text { access openings, penetrations, and the } \\
\text { containment heat removal system shall be } \\
\text { designed so that the containment structure } \\
\text { and its internal compartments can } \\
\text { accommodate, without exceeding the design } \\
\text { leakage rate and with sufficient margin, the } \\
\text { calculated pressure and temperature } \\
\text { conditions resulting from any loss-of-coolant } \\
\text { accident. This margin shall reflect } \\
\text { consideration of (1) the effects of potential } \\
\text { energy sources which have not been included } \\
\text { in the determination of the peak conditions, } \\
\text { such as energy in steam generators and as } \\
\text { required by } \S 50.44 \text { energy from metal-water } \\
\text { and other chemical reactions that may result } \\
\text { from degradation but not total failure of } \\
\text { emergency core cooling functioning, (2) the } \\
\text { limited experience and experimental data } \\
\text { available for defining accident phenomena and } \\
\text { containment responses, and (3) the } \\
\text { conservatism of the calculational model and } \\
\text { input parameters. }\end{array}$ & $\begin{array}{l}\text { Containment design basis. } \\
\text { The reactor containment structure, including } \\
\text { access openings, penetrations, and the } \\
\text { containment heat removal system shall be } \\
\text { designed so that the containment structure and } \\
\text { its internal compartments can accommodate, } \\
\text { without exceeding the design leakage rate and } \\
\text { with sufficient margin, the calculated pressure } \\
\text { and temperature conditions resulting from } \\
\text { postulated accidentsany loss-of-coolant } \\
\text { accident. This margin shall reflect consideration } \\
\text { of (1) the effects of potential energy sources } \\
\text { which have not been included in the } \\
\text { determination of the peak conditions, such as } \\
\text { [energy in steam generators and as required } \\
\text { by } \S 50.44 \text { energy from metal-water and other } \\
\text { chemical reactions that may result from } \\
\text { degradation but not total failure of } \\
\text { emergency core cooling functioning], (2) the } \\
\text { limited experience and experimental data } \\
\text { available for defining accident phenomena and } \\
\text { containment responses, and (3) the } \\
\text { conservatism of the calculational model and } \\
\text { input parameters. }\end{array}$ & $\begin{array}{l}\text { ARDC with additional SFR-specific clarification } \\
\text { provided: } \\
\text { Containment design basis. } \\
\text { The reactor containment structure, including } \\
\text { access openings, penetrations, and the } \\
\text { containment heat removal system shall be } \\
\text { designed so that the containment structure and } \\
\text { its internal compartments can accommodate, } \\
\text { without exceeding the design leakage rate and } \\
\text { with sufficient margin, the calculated pressure } \\
\text { and temperature conditions resulting from } \\
\text { postulated accidents. This margin shall reflect } \\
\text { consideration of (1) the effects of potential } \\
\text { energy sources which have not been included in } \\
\text { the determination of the peak conditions, such } \\
\text { as [fission products, potential spray or } \\
\text { aerosol formation, and potential exothermic } \\
\text { chemical reactionenergy in steam generators } \\
\text { and-as required by } \$ 50.44 \text { - energy from } \\
\text { metal-water and-other chemical reactions } \\
\text { that may result from-degradation-but not } \\
\text { total failure of emergency core cooling } \\
\text { functioning], (2) the limited experience and } \\
\text { experimental data available for defining accident } \\
\text { phenomena and containment responses, and (3) } \\
\text { the conservatism of the calculational model and } \\
\text { input parameters. }\end{array}$ & Not applicable to modular HTGR. \\
\hline 51 & $\begin{array}{l}\text { Fracture prevention of containment pressure } \\
\text { boundary. } \\
\text { The reactor containment boundary shall be } \\
\text { designed with sufficient margin to assure that } \\
\text { under operating, maintenance, testing, and } \\
\text { postulated accident conditions (1) its ferritic } \\
\text { materials behave in a nonbrittle manner and } \\
\text { (2) the probability of rapidly propagating }\end{array}$ & $\begin{array}{l}\text { Fracture prevention of containment pressure } \\
\text { boundary. } \\
\text { The reactor containment-boundary of the reactor } \\
\text { containment structure shall be designed with } \\
\text { sufficient margin to assure that under operating, } \\
\text { maintenance, testing, and postulated accident } \\
\text { conditions (1) its ferritic-materials behave in a } \\
\text { nonbrittle manner and (2) the probability of }\end{array}$ & $\begin{array}{l}\text { ARDC with additional SFR-specific clarification } \\
\text { provided: } \\
\text { Fracture prevention of containment prossure } \\
\text { boundary. } \\
\text { The boundary of the reactor containment } \\
\text { structure shall be designed with sufficient margin } \\
\text { to assure that under operating, maintenance, }\end{array}$ & Not applicable to modular HTGR. \\
\hline
\end{tabular}




\begin{tabular}{|c|c|c|c|c|}
\hline \multicolumn{5}{|c|}{ V. Reactor Containment } \\
\hline Criterion & Current GDC Language & Proposed ARDC Language & Proposed SFR-DC Language & Proposed HTGR-DC Language \\
\hline & $\begin{array}{l}\text { fracture is minimized. The design shall reflect } \\
\text { consideration of service temperatures and } \\
\text { other conditions of the containment boundary } \\
\text { material during operation, maintenance, } \\
\text { testing, and postulated accident conditions, } \\
\text { and the uncertainties in determining (1) } \\
\text { material properties, (2) residual, steady state, } \\
\text { and transient stresses, and (3) size of flaws. }\end{array}$ & $\begin{array}{l}\text { rapidly propagating fracture is minimized. The } \\
\text { design shall reflect consideration of service } \\
\text { temperatures and other conditions of the } \\
\text { containment boundary materials during } \\
\text { operation, maintenance, testing, and postulated } \\
\text { accident conditions, and the uncertainties in } \\
\text { determining (1) material properties, (2) residual, } \\
\text { steady state, and transient stresses, and (3) size } \\
\text { of flaws. }\end{array}$ & $\begin{array}{l}\text { testing, and postulated accident conditions (1) } \\
\text { its materials behave in a nonbrittle manner and } \\
(2) \text { the probability of rapidly propagating fracture } \\
\text { is minimized. The design shall reflect } \\
\text { consideration of service temperatures and other } \\
\text { conditions of the containment boundary } \\
\text { materials during operation, maintenance, } \\
\text { testing, and postulated accident conditions, and } \\
\text { the uncertainties in determining (1) material } \\
\text { properties, }(2) \text { residual, steady state, and } \\
\text { transient stresses, and (3) size of flaws. }\end{array}$ & \\
\hline 52 & $\begin{array}{l}\text { Capability for containment leakage rate } \\
\text { testing. } \\
\text { The reactor containment and other equipment } \\
\text { which may be subjected to containment test } \\
\text { conditions shall be designed so that periodic } \\
\text { integrated leakage rate testing can be } \\
\text { conducted at containment design pressure. }\end{array}$ & $\begin{array}{l}\text { Capability for containment leakage rate testing. } \\
\text { The reactor containment structure and other } \\
\text { equipment which may be subjected to } \\
\text { containment test conditions shall be designed so } \\
\text { that periodic integrated leakage rate testing can } \\
\text { be conducted at containment design pressure. }\end{array}$ & $\begin{array}{l}\text { ARDC with no further SFR-specific clarification } \\
\text { provided. }\end{array}$ & Not applicable to modular HTGR. \\
\hline 53 & $\begin{array}{l}\text { Provisions for containment testing and } \\
\text { inspection. } \\
\text { The reactor containment shall be designed to } \\
\text { permit (1) appropriate periodic inspection of all } \\
\text { important areas, such as penetrations, (2) an } \\
\text { appropriate surveillance program, and (3) } \\
\text { periodic testing at containment design } \\
\text { pressure of the leaktightness of penetrations } \\
\text { which have resilient seals and expansion } \\
\text { bellows. }\end{array}$ & $\begin{array}{l}\text { Provisions for containment testing and } \\
\text { inspection. } \\
\text { The reactor containment structure shall be } \\
\text { designed to permit (1) appropriate periodic } \\
\text { inspection of all important areas, such as } \\
\text { penetrations, (2) an appropriate surveillance } \\
\text { program, and (3) periodic testing at containment } \\
\text { design pressure of the leaktightness of } \\
\text { penetrations which have resilient seals and } \\
\text { expansion bellows. }\end{array}$ & $\begin{array}{l}\text { ARDC with no further SFR-specific clarification } \\
\text { provided. }\end{array}$ & Not applicable to modular HTGR. \\
\hline 54 & $\begin{array}{l}\text { Piping systems penetrating containment. } \\
\text { Piping systems penetrating primary reactor } \\
\text { containment shall be provided with leak } \\
\text { detection, isolation, and containment } \\
\text { capabilities having redundancy, reliability, and } \\
\text { performance capabilities which reflect the } \\
\text { importance to safety of isolating these piping } \\
\text { systems. Such piping systems shall be } \\
\text { designed with a capability to test periodically } \\
\text { the operability of the isolation valves and } \\
\text { associated apparatus and to determine if valve } \\
\text { leakage is within acceptable limits. }\end{array}$ & $\begin{array}{l}\text { Piping systems penetrating containment. } \\
\text { Piping systems penetrating the primary reactor } \\
\text { containment structure shall be provided with } \\
\text { leak detection, isolation, and containment } \\
\text { capabilities having redundancy, reliability, and } \\
\text { performance capabilities which reflect the } \\
\text { importance to safety of isolating these piping } \\
\text { systems. Such piping systems shall be designed } \\
\text { with a capability to test periodically the } \\
\text { operability of the isolation valves and associated } \\
\text { apparatus and to determine if valve leakage is } \\
\text { within acceptable limits. }\end{array}$ & $\begin{array}{l}\text { ARDC with additional SFR-specific clarification } \\
\text { provided: } \\
\text { Piping systems penetrating containment. } \\
\text { Piping systems penetrating the primary reactor } \\
\text { containment structure shall be provided with } \\
\text { leak detection, isolation, and containment } \\
\text { capabilities having redundancy, reliability, and } \\
\text { performance capabilities necessary to perform } \\
\text { the containment safety function and which } \\
\text { reflect the importance to safety of preventing } \\
\text { radioactivity releases from containment through } \\
\text { isolating these piping systems. When isolation } \\
\text { valves are required, Such-piping systems shall } \\
\text { be designed with a capability to test periodically } \\
\text { the operability of the isolation valves and } \\
\text { associated apparatus and to determine if valve } \\
\text { leakage is within acceptable limits. }\end{array}$ & Not applicable to modular HTGR. \\
\hline 55 & $\begin{array}{l}\text { Reactor coolant pressure boundary } \\
\text { penetrating containment. } \\
\text { Each line that is part of the reactor coolant } \\
\text { pressure boundary and that penetrates } \\
\text { primary reactor containment shall be provided } \\
\text { with containment isolation valves as follows, } \\
\text { unless it can be demonstrated that the }\end{array}$ & $\begin{array}{l}\text { Reactor [coolant pressure] boundary } \\
\text { penetrating containment. } \\
\text { Each line that is part of the reactor [coolant } \\
\text { pressure] boundary and that penetrates the } \\
\text { primary reactor containment structure shall be } \\
\text { provided with containment isolation valves as } \\
\text { follows, unless it can be demonstrated that the }\end{array}$ & $\begin{array}{l}\text { ARDC with additional SFR-specific clarification } \\
\text { provided: } \\
\text { Reactor [primary coolant-pressure] boundary } \\
\text { penetrating containment. } \\
\text { Each line that is part of the reactor [primary } \\
\text { coolant-pressure] boundary and that }\end{array}$ & Not applicable to modular HTGR. \\
\hline
\end{tabular}




\begin{tabular}{|c|c|c|c|c|}
\hline \multicolumn{5}{|c|}{ V. Reactor Containment } \\
\hline Criterion & Current GDC Language & Proposed ARDC Language & Proposed SFR-DC Language & Proposed HTGR-DC Language \\
\hline & $\begin{array}{l}\text { containment isolation provisions for a specific } \\
\text { class of lines, such as instrument lines, are } \\
\text { acceptable on some other defined basis: } \\
\text { (1) One locked closed isolation valve inside } \\
\text { and one locked closed isolation valve outside } \\
\text { containment; or } \\
\text { (2) One automatic isolation valve inside and } \\
\text { one locked closed isolation valve outside } \\
\text { containment; or } \\
\text { (3) One locked closed isolation valve inside } \\
\text { and one automatic isolation valve outside } \\
\text { containment. A simple check valve may not be } \\
\text { used as the automatic isolation valve outside } \\
\text { containment; or } \\
\text { (4) One automatic isolation valve inside and } \\
\text { one automatic isolation valve outside } \\
\text { containment. A simple check valve may not be } \\
\text { used as the automatic isolation valve outside } \\
\text { containment. } \\
\text { Isolation valves outside containment shall be } \\
\text { located as close to containment as practical } \\
\text { and upon loss of actuating power, automatic } \\
\text { isolation valves shall be designed to take the } \\
\text { position that provides greater safety. } \\
\text { Other appropriate requirements to minimize } \\
\text { the probability or consequences of an } \\
\text { accidental rupture of these lines or of lines } \\
\text { connected to them shall be provided as } \\
\text { necessary to assure adequate safety. } \\
\text { Determination of the appropriateness of these } \\
\text { requirements, such as higher quality in design, } \\
\text { fabrication, and testing, additional provisions } \\
\text { for inservice inspection, protection against } \\
\text { more severe natural phenomena, and } \\
\text { additional isolation valves and containment, } \\
\text { shall include consideration of the population } \\
\text { density, use characteristics, and physical } \\
\text { characteristics of the site environs. }\end{array}$ & $\begin{array}{l}\text { containment isolation provisions for a specific } \\
\text { class of lines, such as instrument lines, are } \\
\text { acceptable on some other defined basis: } \\
\text { (1) One locked closed isolation valve inside and } \\
\text { one locked closed isolation valve outside } \\
\text { containment; or } \\
\text { (2) One automatic isolation valve inside and one } \\
\text { locked closed isolation valve outside } \\
\text { containment; or } \\
\text { (3) One locked closed isolation valve inside and } \\
\text { one automatic isolation valve outside } \\
\text { containment. A simple check valve may not be } \\
\text { used as the automatic isolation valve outside } \\
\text { containment; or } \\
\text { (4) One automatic isolation valve inside and one } \\
\text { automatic isolation valve outside containment. A } \\
\text { simple check valve may not be used as the } \\
\text { automatic isolation valve outside containment. } \\
\text { Isolation valves outside containment shall be } \\
\text { located as close to containment as practical and } \\
\text { upon loss of actuating power, automatic isolation } \\
\text { valves shall be designed to take the position that } \\
\text { provides greater safety. } \\
\text { Other appropriate requirements to minimize the } \\
\text { probability or consequences of an accidental } \\
\text { rupture of these lines or of lines connected to } \\
\text { them shall be provided as necessary to assure } \\
\text { adequate safety. Determination of the } \\
\text { appropriateness of these requirements, such as } \\
\text { higher quality in design, fabrication, and testing, } \\
\text { additional provisions for inservice inspection, } \\
\text { protection against more severe natural } \\
\text { phenomena, and additional isolation valves and } \\
\text { containment, shall include consideration of the } \\
\text { population density, use characteristics, and } \\
\text { physical characteristics of the site environs. }\end{array}$ & $\begin{array}{l}\text { penetrates the primary reactor containment } \\
\text { structure shall be provided with containment } \\
\text { isolation valves as follows, unless it can be } \\
\text { demonstrated that the containment isolation } \\
\text { provisions for a specific class of lines, such as } \\
\text { instrument lines, are acceptable on some other } \\
\text { defined basis: } \\
\text { (1) One locked closed isolation valve inside and } \\
\text { one locked closed isolation valve outside } \\
\text { containment; or } \\
\text { (2) One automatic isolation valve inside and one } \\
\text { locked closed isolation valve outside } \\
\text { containment; or } \\
\text { (3) One locked closed isolation valve inside and } \\
\text { one automatic isolation valve outside } \\
\text { containment. A simple check valve may not be } \\
\text { used as the automatic isolation valve outside } \\
\text { containment; or } \\
\text { (4) One automatic isolation valve inside and one } \\
\text { automatic isolation valve outside containment. A } \\
\text { simple check valve may not be used as the } \\
\text { automatic isolation valve outside containment. } \\
\\
\text { Isolation valves outside containment shall be } \\
\text { located as close to containment as practical and } \\
\text { upon loss of actuating power, automatic isolation } \\
\text { valves shall be designed to take the position that } \\
\text { provides greater safety. } \\
\text { Other appropriate requirements to minimize the } \\
\text { probability or consequences of an accidental } \\
\text { rupture of these lines or of lines connected to } \\
\text { them shall be provided as necessary to assure } \\
\text { adequate safety. Determination of the } \\
\text { appropriateness of these requirements, such as } \\
\text { higher quality in design, fabrication, and testing, } \\
\text { additional provisions for inservice inspection, } \\
\text { protection against more severe natural } \\
\text { phenomena, and additional isolation valves and } \\
\text { containment, shall include consideration of the } \\
\text { population density, use characteristics, and } \\
\text { physical characteristics of the site environs. }\end{array}$ & \\
\hline 56 & $\begin{array}{l}\text { Primary containment isolation. } \\
\text { Each line that connects directly to the } \\
\text { containment atmosphere and penetrates } \\
\text { primary reactor containment shall be provided } \\
\text { with containment isolation valves as follows, } \\
\text { unless it can be demonstrated that the } \\
\text { containment isolation provisions for a specific } \\
\text { class of lines, such as instrument lines, are } \\
\text { acceptable on some other defined basis: } \\
\text { (1) One locked closed isolation valve inside } \\
\text { and one locked closed isolation valve outside }\end{array}$ & $\begin{array}{l}\text { Primary containment isolation. } \\
\text { Each line that connects directly to the } \\
\text { containment atmosphere and penetrates the } \\
\text { primary reactor containment structure shall be } \\
\text { provided with containment isolation valves as } \\
\text { follows, unless it can be demonstrated that the } \\
\text { containment isolation provisions for a specific } \\
\text { class of lines, such as instrument lines, are } \\
\text { acceptable on some other defined basis: } \\
\text { (1) One locked closed isolation valve inside and } \\
\text { one locked closed isolation valve outside }\end{array}$ & $\begin{array}{l}\text { ARDC with no further SFR-specific clarification } \\
\text { provided. }\end{array}$ & Not applicable to modular HTGR. \\
\hline
\end{tabular}




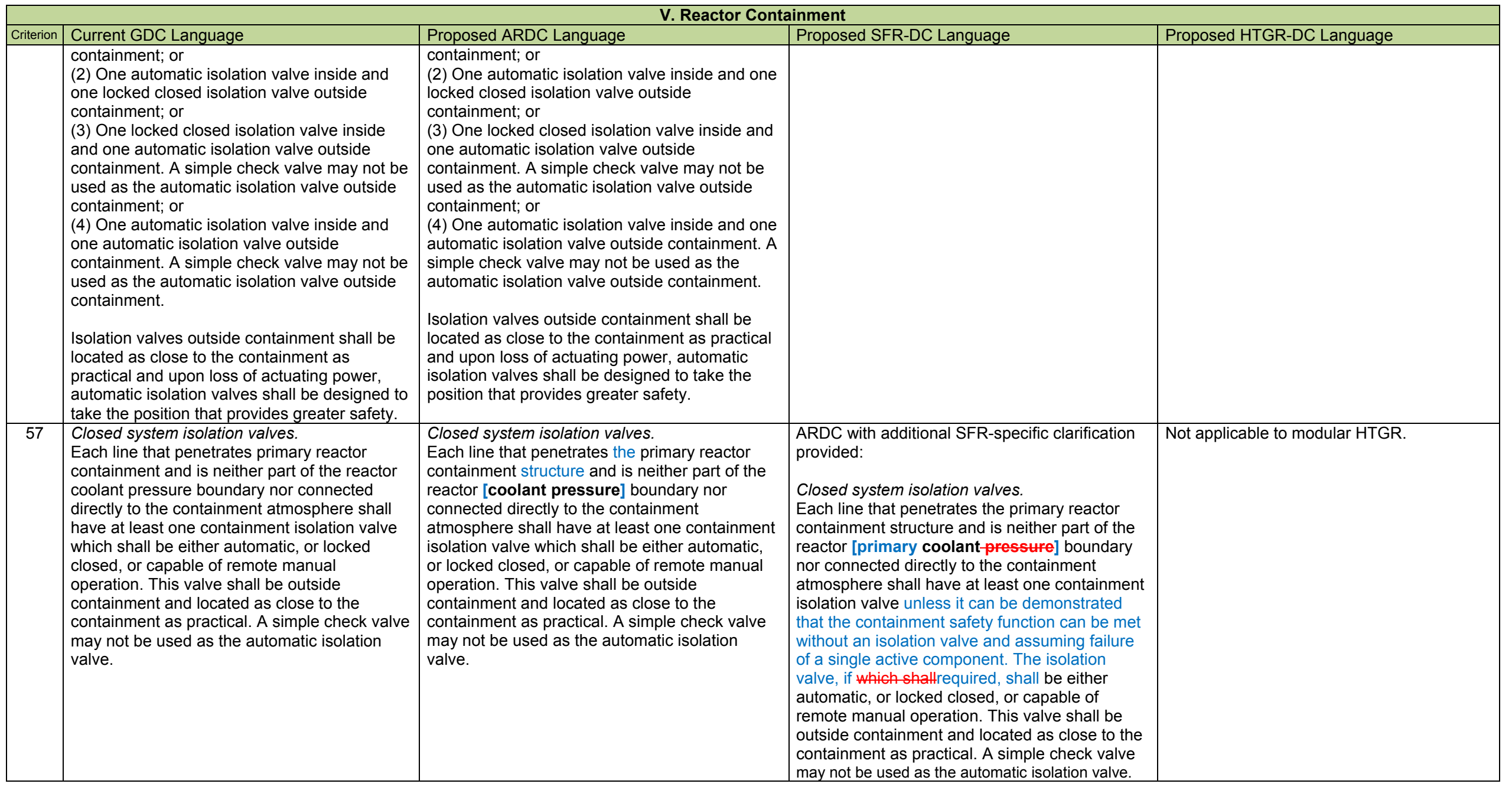


Criterion Current GDC Language

Control of releases of radioactive materials to the environment.

The nuclear power unit design shall include means to control suitably the release of

radioactive materials in gaseous and liquid

effluents and to handle radioactive solid

wastes produced during normal reactor

operation, including anticipated operational

occurrences. Sufficient holdup capacity shall

be provided for retention of gaseous and liquid

effluents containing radioactive materials,

particularly where unfavorable site

environmental conditions can be expected to

impose unusual operational limitations upon

the release of such effluents to the

environment.

$61 \quad$ Fuel storage and handling and radioactivity control.

The fuel storage and handling, radioactive waste, and other systems which may contain radioactivity shall be designed to assure adequate safety under normal and postulated accident conditions. These systems shall be designed (1) with a capability to permit

appropriate periodic inspection and testing of components important to safety, (2) with suitable shielding for radiation protection, (3) with appropriate containment, confinement, and filtering systems, (4) with a residual heat removal capability having reliability and

testability that reflects the importance to safety of decay heat and other residual heat removal, and (5) to prevent significant reduction in fuel storage coolant inventory under accident conditions.

62 Prevention of criticality in fuel storage and handling.

Criticality in the fuel storage and handling system shall be prevented by physical systems or processes, preferably by use of geometrically safe configurations.

63 Monitoring fuel and waste storage. Appropriate systems shall be provided in fuel storage and radioactive waste systems and associated handling areas (1) to detect conditions that may result in loss of residual heat removal capability and excessive radiation levels and (2) to initiate appropriate safety actions.

$64 \quad$ Monitoring radioactivity releases. Means shall be provided for monitoring the reactor containment atmosphere, spaces containing components for recirculation of

\section{Proposed ARDC Languag} Same as GDC

V.

and Radioactivi

Proposed SFR-DC Language

provided.

Proposed HTGR-DC Language
ARDC with no further modular HTGR-

specific clarification provided.

Fuel storage and handling and radioactivity control.

The fuel storage and handling, radioactive waste, and other systems which may contain radioactivity shall be designed to assure adequate safety under normal and postulated accident conditions. These systems shall be designed (1) with a capability to permit

appropriate periodic inspection and testing of

components important to safety, (2) with suitable shielding for radiation protection, (3) with appropriate containment, confinement, and filtering systems, (4) with a residual heat removal capability having reliability and

testability that reflects the importance to safety of decay heat and other residual heat removal, and (5) to prevent significant reduction in fuel storage coolant inventory-cooling under accident conditions.

Same as GDC

\section{ARDC with}

provided.

provided.

ARDC with no further modular HTGR-

specific clarification provided.

\begin{tabular}{|l|l|}
\hline Same as GDC & $\begin{array}{l}\text { ARDC with no further SFR-specific clarification } \\
\text { provided. }\end{array}$ \\
\hline $\begin{array}{l}\text { Monitoring radioactivity releases. } \\
\text { Means shall be provided for monitoring the } \\
\text { [reactor containment] atmosphere, [spaces } \\
\text { containing components for recirculation of }\end{array}$ & $\begin{array}{l}\text { ARDC with additional SFR-specific clarification } \\
\text { provided: } \\
\text { Monitoring radioactivity releases. }\end{array}$ \\
\hline
\end{tabular}

[reactor containment] atmosphere, [spaces
ARDC with no further modular HTGRspecific clarification provided.

ARDC with no further modular HTGRspecific clarification provided. specific clarification provided:

Monitoring radioactivity releases.
ARDC with additional modular HTGR- 


\section{Criterion Current GDC Language}

loss-of-coolant accident fluids, effluent

discharge paths, and the plant environs for

radioactivity that may be released from normal

operations, including anticipated operational

occurrences, and from postulated accidents.

\section{Proposed ARDC Language}

loss-of-coolant accident fluids,] effluent discharge paths, and the plant environs for

radioactivity that may be released from normal

operations, including anticipated operational

occurrences, and from postulated accidents.

\section{Proposed SFR.}

Proposed SFR-DC Language

[reactor containment] atmosphere, [spaces

containing components for-recirculation of

loss-of-coolant accident fluids primary

system sodium and cover gas cleanup and processing,] effluent discharge paths, and the plant environs for radioactivity that may be released from normal operations, including

anticipated operational occurrences, and from postulated accidents.
Proposed HTGR-DC Language

Means shall be provided for monitoring the

[reactor containmentbuilding]

atmosphere, [spaces-containing

components for recirculation-ofloss-of-

coolant accident fluids ] effluent discharge

paths, and the plant environs for radioactivity

that may be released from normal

operations, including anticipated operational

occurrences, and from postulated accidents. 